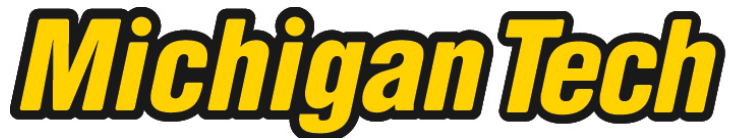 \\ Michigan Technological University Create the Future Digital Commons @ Michigan Tech
}

\section{The effect of long-term water table manipulations on vegetation, pore water, substrate quality, and carbon cycling in a Northern poor fen peatland}

John A. Hribljan

Michigan Technological University

Follow this and additional works at: https://digitalcommons.mtu.edu/etds

Part of the Forest Sciences Commons

Copyright 2012 John A. Hribljan

Recommended Citation

Hribljan, John A., "The effect of long-term water table manipulations on vegetation, pore water, substrate quality, and carbon cycling in a Northern poor fen peatland", Dissertation, Michigan Technological University, 2012.

https://doi.org/10.37099/mtu.dc.etds/132

Follow this and additional works at: https://digitalcommons.mtu.edu/etds

8 Part of the Forest Sciences Commons 
THE EFFECT OF LONG-TERM WATER TABLE MANIPULATIONS ON VEGETATION, PORE WATER, SUBSTRATE QUALITY, AND CARBON CYCLING IN A NORTHERN POOR FEN PEATLAND

By

John A. Hribljan

\begin{abstract}
A DISSERTATION
Submitted in partial fulfillment of the requirements for the degree of DOCTOR OF PHILOSOPHY

In Forest Science
\end{abstract}

MICHIGAN TECHNOLOGICAL UNIVERSITY

2012

(C) 2012 John A. Hribljan 
This dissertation has been approved in partial fulfillment of the requirements for the Degree of DOCTOR OF PHILOSOPHY in Forest Science.

\section{School of Forest Resources and Environmental Science}

Dissertation Advisor: Dr. Rodney A. Chimner

Committee Member: Dr. Molly A. Cavaleri

Committee Member: Dr. Thomas G. Pypker

Committee Member: $\quad$ Dr. Merritt R. Turetsky

School Dean: $\quad$ Dr. Terry L. Sharik 


\section{Table of Contents}

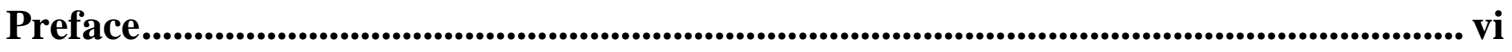

Acknowledgements ............................................................................................... vii

Dissertation Abstract ...............................................................................................iii

Chapter 1. Introduction ..................................................................................................... 1

1.1 Climate Change effects on Northern Peatland Carbon Stocks.............................. 1

1.2 Northern Peatland Carbon Cycling ………………............................................ 4

1.3 Project overview.......................................................................................... 6

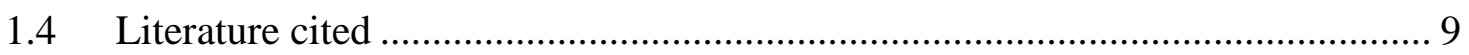

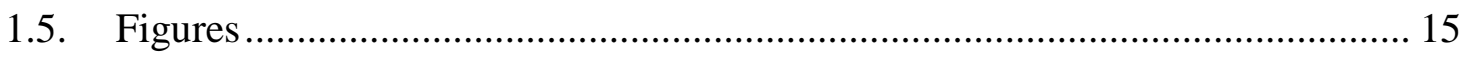

Chapter 2. Vegetation Structure, Biomass, and Productivity across a Long-term Water Table Gradient in a Poor Fen Peatland ............................................................... 17

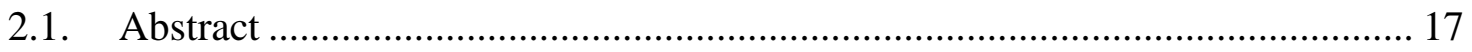

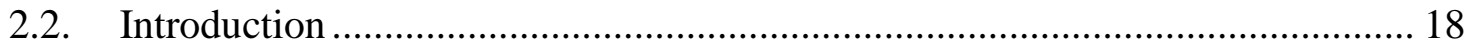

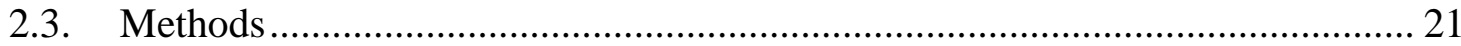

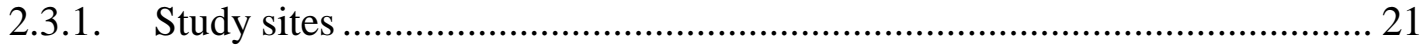

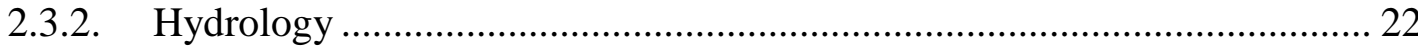

2.3.3. Understory vegetation survey ………………......................................... 22

2.3.4. Overstory biomass and primary productivity ............................................. 23

2.3.5. Understory aboveground biomass and primary productivity....................... 24

2.3.6. Understory belowground biomass and primary productivity ...................... 26

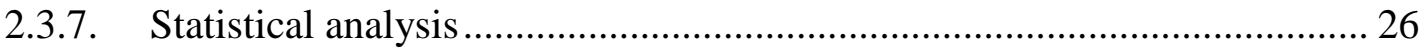

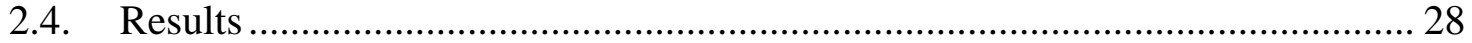

2.4.1 Hydrology and microtopography ………............................................. 28

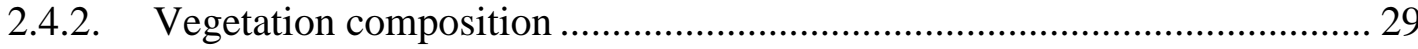

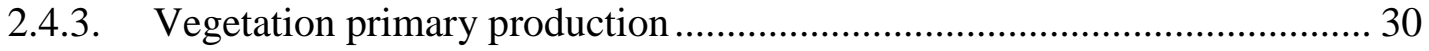

2.4.3. Vegetation biomass ................................................................................ 30

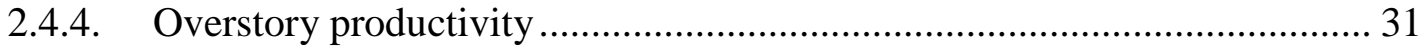

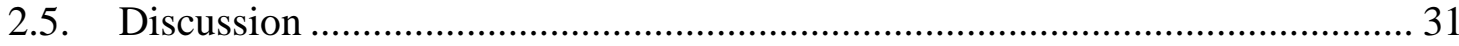

2.5.1. Understory vegetation community structure.............................................. 32

2.5.2. Understory vegetation biomass and NPP................................................... 34 
2.5.3. Shifts in overstory primary production ....................................................... 36

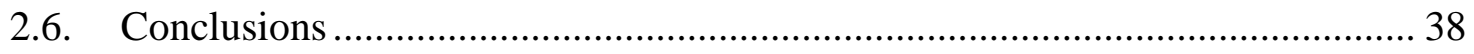

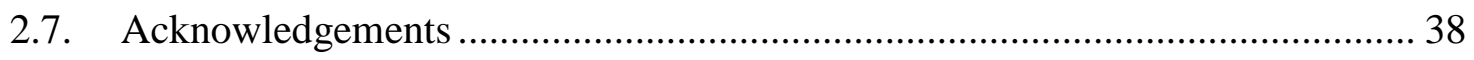

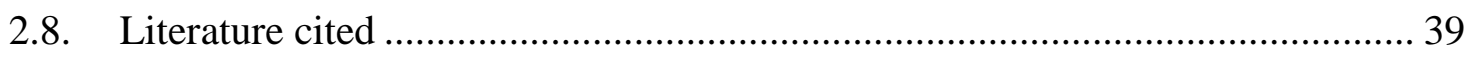

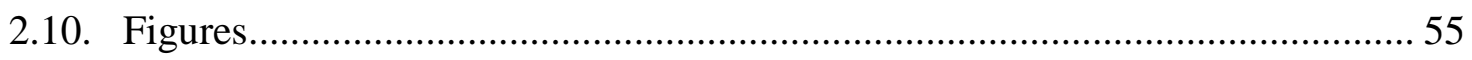

Chapter 3. The Effect of Long-term Water Table Manipulations on Dissolved Organic Carbon Production and Quality in a Poor Fen Peatland................................ 64

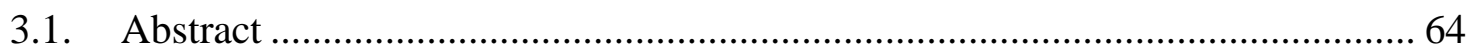

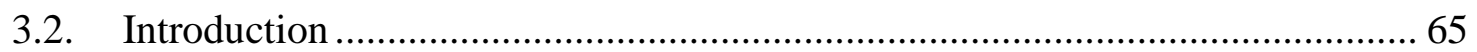

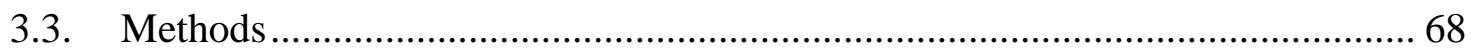

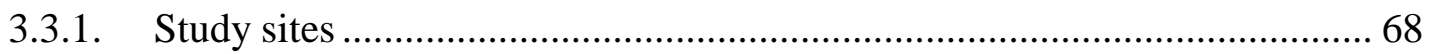

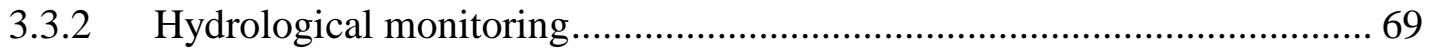

3.3.3 Field sampling methods ....................................................................... 70

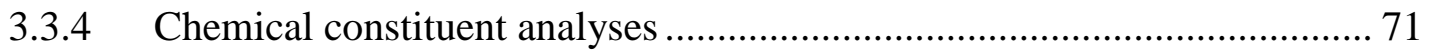

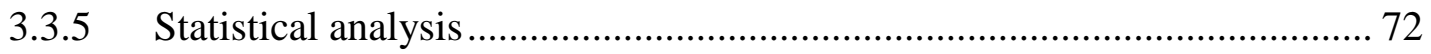

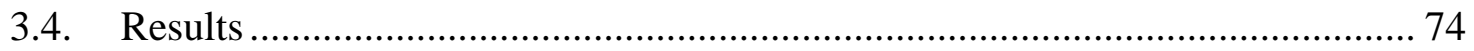

3.4.1. Site Topography and Hydrology............................................................ 74

3.4.2. Site electrochemistry and pore water chemical constituents ....................... 75

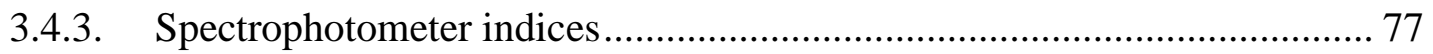

3.4.4. DOC incubation experiment …………………....................................... 77

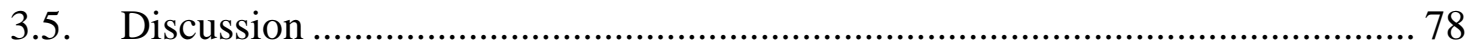

3.5.1. Water table effects on DOC dynamics....................................................... 78

3.5.2. Pore water residence time ...................................................................... 79

3.5.3. Pore water DOC chemical characteristics and lability ................................. 81

3.5.4. Potential algae influence on DOC dynamics ............................................. 84

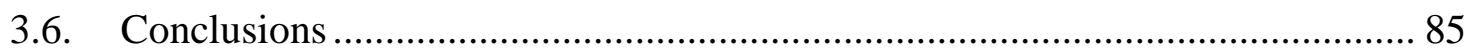

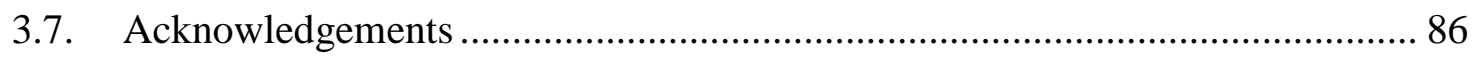

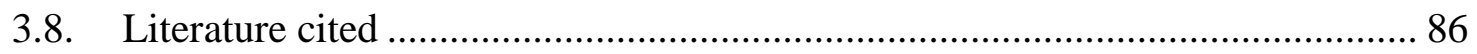

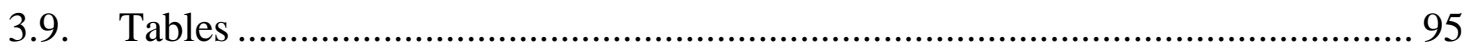

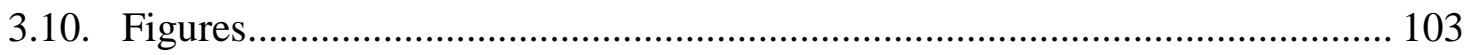

Chapter 4. The Effect of Long-term Hydrology Changes on Peat Substrate Quality in a Northern Peatland ................................................................................................... 114

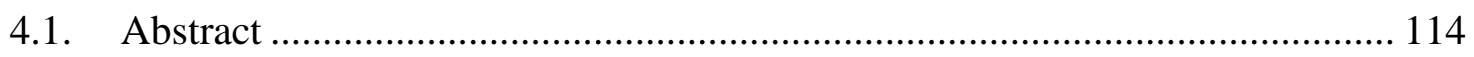




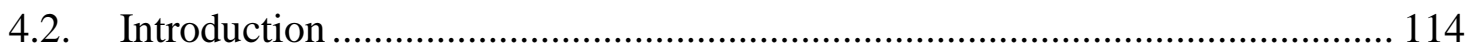

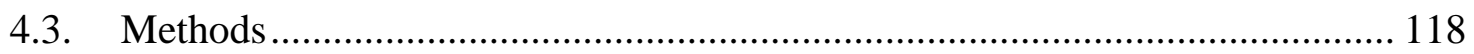

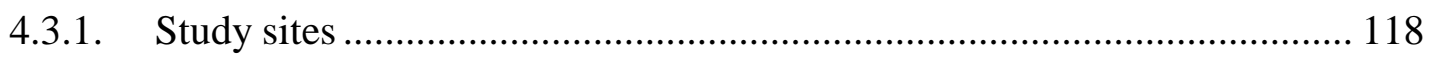

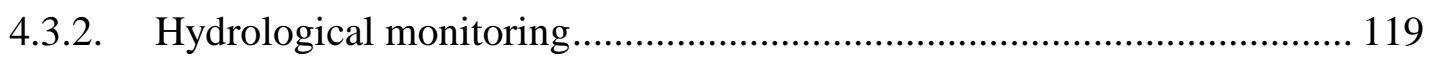

4.3.3. Peat physical and chemical analysis ........................................................ 119

4.3.4. Mineralization experiment .................................................................. 120

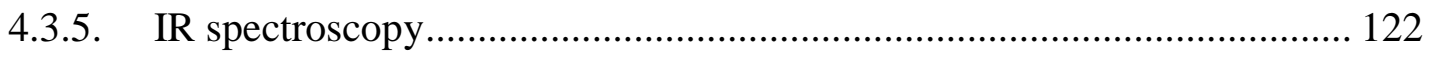

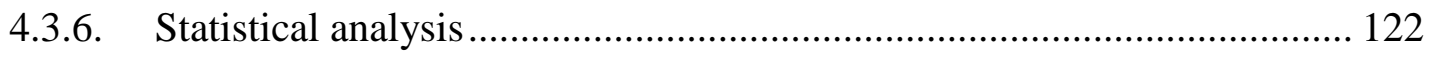

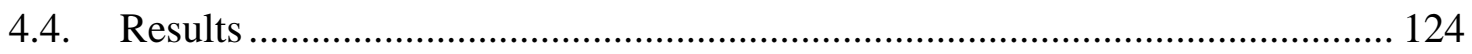

4.4.1. Hydrology and surface topography....................................................... 124

4.4.2. Soil core physical and chemical parameters ............................................. 124

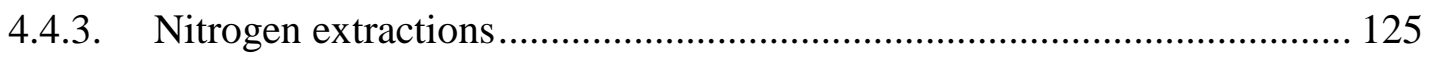

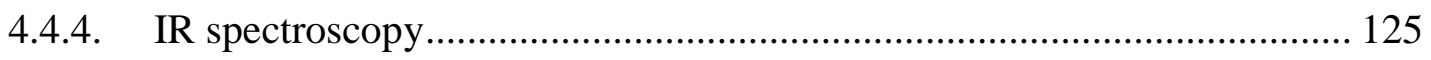

4.4.5. Mineralization experiment .................................................................. 128

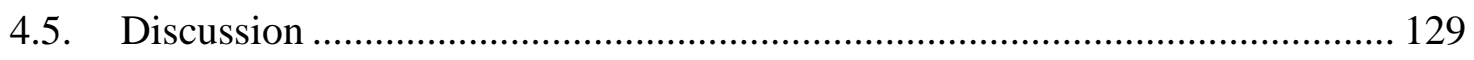

4.5.1. Long-term water table manipulation effects on peat quality .................... 129

4.5.2. Water table effects on potential aerobic CO2 production.......................... 131

4.5.3. Water table effects on anaerobic carbon mineralization............................. 133

4.5.4. Microtopography peat quality and lability.............................................. 134

4.5.5. Nitrogen stabilization........................................................................ 137

4.6. Conclusion........................................................................................ 138

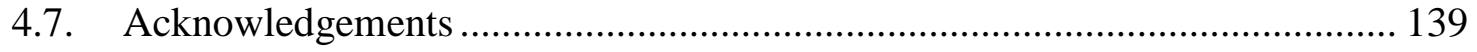

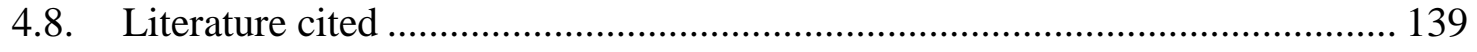

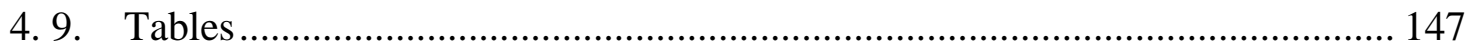

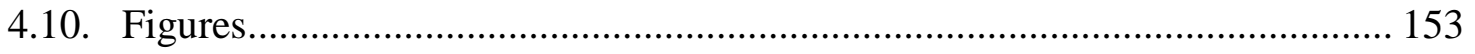




\section{Preface}

This dissertation is based on the following papers as referred by their chapter number, which are in preparation for submission into ecological journals. Text throughout the document is written in first person plural to recognize the contribution of multiple authors.

Chapter 2. Hribljan, J.A., Pypker, T.G. \& Chimner, R.A. Vegetation Structure, Biomass, and Productivity across a Long-term Water Table Gradient in a Poor Fen Peatland. Manuscript.

Chapter 3. Hribljan, J.A., Kane E.S., Turetsky, M.R., \& Chimner, R.A. The Effect of Long-term Water Table Manipulations on Dissolved Organic Carbon Production and Quality in a Poor Fen Peatland. Manuscript.

Chapter 4. Hribljan, J.A., Kane E.S., Pypker, T.G., \& Chimner, R.A. The Effect of Long-term Hydrology Changes on Peat Substrate Quality in a Northern Peatland. Manuscript. 


\section{Acknowledgements}

The completion of this dissertation was successful because of the support, financial backing, and encouragement of multiple individuals. I am deeply indebted to my advisor Dr. Rodney Chimner for his patient guidance throughout this endeavor. I am also extremely appreciative of the freedom he gave me to explore and contemplate the fascinating realm of peatland ecology. I would also like to thank my committee members Dr. Molly Cavaleri, Dr. Thomas Pypker, and Dr. Merritt Turetsky who gave me valuable insights and direction when I was faced with uncertainty. Dr. Evan Kane provided incredibly valuable mentorship, especially concerning the chapters on peatland dissolved organic carbon and peat substrate quality. Dr. Andy Burton provided generous use of his laboratory facilities. I received assistance from many students with field and laboratory work including: Drew Ballantyne, Jim Bess, Elizabeth Boisvert, Shawna Bork, Jamie Bourgo, Ellen Brenna, Robin Conklin, Aleta Daniels, Arielle Garrett, Laura Kangas, Chris Johnson, Laura Matkala, and Cassandra Ott.

This research was supported by the U.S. Department of Energy's Office of Science (BER) through the Midwestern Regional Center of the National Institute for Climatic Change Research at Michigan Technological University. Additional support was provided by the Ecosystem Science Center at Michigan Technological University and the USDA Forest Service Northern Research Station. This project would not have been possible without the generous cooperation and support of the Seney National Wildlife Refuge, in particular Dr. Greg Corace and Dave Olson, providing research support and access to the study site.

I would like to give special recognition to my wife Christa Luokkala for her endless support and encouragement. Without her help this dissertation would not have been possible. Thank you. 


\section{Dissertation Abstract}

Northern peatlands are large reservoirs of soil organic carbon (C). Historically peatlands have served as a sink for $\mathrm{C}$ since decomposition is slowed primarily because of a raised water table (WT) that creates anoxic conditions. Climate models are predicting dramatic changes in temperature and precipitation patterns for the northern hemisphere that contain more than $90 \%$ of the world's peatlands. It is uncertain whether climate change will shift northern peatlands from $\mathrm{C}$ sequestering systems to a major global $\mathrm{C}$ source within the next century because of alterations to peatland hydrology. This research investigated the effects of 80 years of hydrological manipulations on peatland $\mathrm{C}$ cycling in a poor fen peatland in northern Michigan. The construction of an earthen levee within the Seney National Wildlife Refuge in the 1930’s resulted in areas of raised and lowered WT position relative to an intermediate WT site that was unaltered by the levee. We established sites across the gradient of long-term WT manipulations to examine how decadal changes in WT position alter peatland C cycling. We quantified vegetation dynamics, peat substrate quality, and pore water chemistry in relation to trace gas $\mathrm{C}$ cycling in these manipulated areas as well as the intermediate site. Vegetation in both the raised and lowered WT treatments has different community structure, biomass, and productivity dynamics compared to the intermediate site. Peat substrate quality exhibited differences in chemical composition and lability across the WT treatments. Pore water dissolved organic carbon (DOC) concentrations increased with impoundment and WT drawdown. The raised WT treatment DOC has a low aromaticity and is a highly labile C source, whereas WT drawdown has increased DOC aromaticity. This study has demonstrated a subtle change of the long-term WT position in a northern peatland will induce a significant influence on ecosystem $\mathrm{C}$ cycling with implications for the fate of peatland C stocks. 


\section{Chapter 1. Introduction}

\subsection{Climate Change effects on Northern Peatland Carbon Stocks}

Peatlands are classified as carbon (C) accumulating systems in which net primary production occurs in excess of organic matter decomposition resulting in the formation of peat (Rydin and Jeglum 2006). This delicate C balance is largely influenced and regulated by the rate of heterotrophic consumption of peat and to a lesser extent the loss of $\mathrm{C}$ through the leaching of dissolved and suspended particulate matter into the surrounding catchment (Moore and Basiliko 2006). Historically peatlands have served as a sink for $\mathrm{C}$ since decomposition is slowed primarily because of a raised water table (WT) creating anoxic conditions and at times a lowered peat temperature that inhibits microbial processing of peat (Vitt 2006). The lack of oxygen in water logged peat limits microbial access to oxidized electron acceptors that are favored for peat decomposition (Rydin and Jeglum 2006). In addition, cool peat temperatures created from the insulating properties of the thick organic horizon and the close proximity of the WT can slow enzymatic processing of peat (Davidson and Janssens 2006; Fenner et al. 2005).

Currently northern peatlands cover approximately 3\% of the global land area and the organic matter stored in peatlands represents 12 - 30\% of the global soil C pool (Gorham 1991) that is equivalent to approximately $60 \%$ of the current carbon dioxide $\left(\mathrm{CO}_{2}\right)$ concentration in the atmosphere (Oechel 1993). Peatland $\mathrm{C}$ stocks are threatened by multiple disturbances that include forestry, agriculture, and peat extraction (Chapman et al. 2003). However, climate change has become an increasingly important concern because of the multiple and complicated responses of peatlands to climate induced changes in peat temperature and moisture. Furthermore, climate change will not only cause cumulative effects on current peatland disturbances but will also influence regions that are currently unaffected by direct anthropogenic disturbances (Seigal 1988; Turetsky and St Louis 2006). Therefore, climate change is a predominant and growing concern to global peatland C stocks. 
It is estimated high-latitude regions in the northern hemisphere contain more than 90\% of the world's peatlands (Yu et al. 2010). Climate models are predicting warmer, drier conditions for the next century with the greatest temperatures increases of $4-8{ }^{\circ} \mathrm{C}$ (IPCC 2001) occurring in locations resided by northern peatlands. In addition, dramatic changes in precipitation are predicted for the northern hemisphere (Stocks et al. 1998; Tarnocai 2006; Thomas and Rowntree 2006). Future increases in global temperature with concurrent shifts in precipitation will influence both thermal and moisture regimes in northern ecosystems with implications for peatland primary production and decomposition dynamics (Ise et al. 2008). It is uncertain whether climate change will shift northern peatlands from $\mathrm{C}$ sequestering systems to a major global C source within the next century (Kim et al. 2007). Therefore, it is imperative to understand the potential effects of climate change on peatland $\mathrm{C}$ stocks and fluxes, since peatlands have the potential to become a significant source of atmospheric C (Freeman et al. 2001) from emissions of $\mathrm{CO}_{2}$ and methane $\left(\mathrm{CH}_{4}\right)$, which are both potent greenhouse gases (Laine et al. 1996). Furthermore, increased emissions of $\mathrm{CO}_{2}$ and $\mathrm{CH}_{4}$ could create a positive feedback loop to climate change by increasing the greenhouse effect, leading to higher global temperatures and resulting in amplified climate induced disturbances to northern peatland C stocks (Friedlingstein et al. 2006) (Figure 1.1).

Alterations to peatland hydrology, especially a change in WT position, is a principal threat to peatland C cycling because of the tight coupling between WT and reduction/oxidation (redox) reactions that regulate oxygen availability for heterotrophic processing of peat (Reddy and DeLaune 2008; Grant et al. 2012). Therefore, a subtle shift in WT position has the potential to alter peatland C sequestering capacity (Bubier et al. 2003). However, uncertainty exists concerning the $C$ cycling trajectory of peatlands (McGuire et al. 2009) affected by climate induced hydrological alterations since the changes can be multidimensional (Belyea and Malmer 2004; Whittington and Price 2006; Ise et al. 2008). For example, an increased oxic zone created by WT drawdown can contribute to accelerated microbial decomposition of peat. However, increased oxygen availability can reduced $\mathrm{CH}_{4}$ production due to aerobic conditions inhibiting methanogens and enhanced methane oxidation by methanotrophs (Strack et al. 2004). In 
contrast, a raised WT will typically decrease $\mathrm{CO}_{2}$ production and increase $\mathrm{CH}_{4}$ emissions because of the elevated anoxic environment in the peat profile (Moore and Dalva 2006).

In addition to emissions of trace $\mathrm{C}$ gases, dissolved and particulate organic $\mathrm{C}$ export and import is a potentially important component of the $\mathrm{C}$ balance in northern peatlands (Frasir et al. 2001; Billett et al. 2004). Pore water C transport is directly affected by WT changes. Pore water has a reduced mobility when confined to the lower peat horizons from WT drawdown because of increased peat density and decreased saturated hydraulic conductivity ( $\left.\mathrm{K}_{\mathrm{sat}}\right)$. However, an elevated WT can contribute to increased pore water export because of high water mobility from increased $\mathrm{K}_{\text {sat }}$ in the porous surface peat (Jager et al. 2009). Thus, shifting WT's in northern peatlands have the potential to significantly affect dissolved and particulate organic $\mathrm{C}$ residence time.

Climate change models are predicting wetter and drier soil conditions for regions that contain northern peatlands depending on changes to global temperatures and precipitation patterns. Therefore, it is important to investigate both WT drawdown and impoundment on peatland C cycling. Moreover, investigations into peatland WT manipulations effects over a decadal or century time frame on vegetation, peat, and pore water dynamics will provide more realistic simulations of the possible changes that we can expect to influence peatland $\mathrm{C}$ cycling from climate change.

Peatland studies examining the effects of long-term WT manipulations on peatland C cycling are scarce (Kluge et al. 2008; Talbot et al. 2010). To the best of our knowledge only one long-term WT manipulation study has been conducted in a North American peatland (Talbot et al. 2010). Multiple studies have investigated peatland responses to short-term WT manipulations (1-10 years) in situ (Prévost et al. 1999; Strack et al. 2004; Turetsky et al. 2008) and with laboratory incubations (Moore and Dalva 1993; Keller et al. 2004; Updegraff et al. 1995). However, it is unknown whether peatlands will display similar trajectories in C cycling between long-term and short-term WT alterations (Chapin et al. 2002). Therefore, there is a need for additional long-term studies in northern peatlands to enable scientists to improve current $\mathrm{C}$ cycling models to allow better predictions of the fate of peatland C stocks. In particular, studies investigating long-term WT manipulations in northern peatlands are a primary research 
priority to determine peatland resiliency and C cycling trajectories influenced by climate change.

\subsection{Northern Peatland Carbon Cycling}

The cycling of $\mathrm{C}$ through a peatland is dependent on many tightly coupled biotic and abiotic interactions between vegetation, the peat matrix, and pore water (Figure 1.1). The predominant pathway for peatland C cycling starts with autotrophic (primarily plant but can also include algal and cyanobacteria) photosynthetic uptake of $\mathrm{CO}_{2}$ that is incorporated into above- and belowground biomass. The majority of biomass introduced into the peat column is from plant litter. Thus, peat is operationally defined as a complex mixture of organic matter primarily composed of the partially decayed remains of plants (Weltzin et al. 2003). Furthermore, the substrate quality of peat is principally determined by the chemical composition of the plant litter introduced into the peatland (Turetsky 2004) that strongly influences heterotrophic decomposition of peat (Moore et al. 2007).

Vegetation chemistry is most distinct across plant functional groups and species; however, intraspecies plant chemistry can also display significant differences created by environmental disturbances including changes in temperature and moisture (Dorrepaal et al. 2005). Additionally, climate induced changes to peatland hydrology has the potential to initiate and accelerate vegetation successional trajectories and how plants assemble into communities (Pellerin et al. 2009). Therefore, alterations to peatland WT position can have dramatic and significant implications for vegetation dynamics that can strongly influence $\mathrm{C}$ cycling through controls on peat formation and substrate quality (Weltzin et al. 2000; Laiho et al.2003; Belyea and Malmer 2004; Strack et al. 2006).

As noted earlier, $\mathrm{C}$ that has been sequestered into the peatland is released back into the atmosphere during heterotrophic respiration (Figure 1.1). Microbial communities utilize peat as a $\mathrm{C}$ and energy source for growth and reproduction (Reddy and DeLaune 2008). The end product of microbial processing of organic matter is the release of $\mathrm{CO}_{2}$ and $\mathrm{CH}_{4}$ that is highly dependent on the redox conditions within the peatland (Blodau et al. 2004) and the substrate quality of the peat (DeBusk and Reddy 1998). Surprisingly, we currently do not fully understand peat substrate quality controls on the emissions of 
$\mathrm{CO}_{2}$ and $\mathrm{CH}_{4}$ from northern peatlands (Reiche et al 2010). However, it has been demonstrated that small perturbations in hydrology can transform peatlands to new states of soil chemistry (Turetsky 2004). Since WT position creates the boundary between the anaerobic and aerobic zones in the peat column, it is critically important in establishing and controlling peatland thermodynamics that drive microbial decomposition of peat. Therefore, peat chemistry is related not only to peatland type and litter inputs but is also strongly influenced by alterations to the WT position in a peatland.

The balance between peatland autotrophic and heterotrophic processes is the primary determinate of the ability of a peatland to serve as a long-term $\mathrm{C}$ sink. However, pore water containing high concentrations of dissolved organic carbon (DOC) can represent an important component of the annual peatland C budget (Frasir et al. 2001; Billett et al. 2004). Moreover, peatland pore water export of C, although minor compared to heterotrophic respiration, can determine if a peatland has a net positive or negative $\mathrm{C}$ accumulation rate (Roulet et al. 2007), especially if autotrophic and heterotrophic processes are closely balanced.

DOC is produced from the leaching and decomposition of plant, microbial and soil organic matter (Reddy and DeLaune 2008). Peatland DOC production, consumption, quality, and transport are tightly coupled to WT position (Moore et al. 2001; Freeman et al. 1993). Figure 1.2 depicts the opposing effects that changes in WT can have on DOC cycling in a peatland. A lowering of the WT increases the upper oxic zone in the peatland that can produce high peat decay rates and the production of DOC. In contrast, an elevated WT can reduce microbial production of DOC due to the anoxic environment; however, the increased photic zone created from standing water on the peat surface has the potential to drive algal derived DOC inputs and increased leaching of recently deposited plant litter. Algae derived DOC is highly labile and has the potential to not only increase peatland DOC concentrations, but more importantly could create a powerful priming effect on microbial communities promoting an increase in peat decomposition (Wyatt et al. 2011).

Additionally WT drawdown and impoundment can influence DOC residence time through changes in peat porosity, bulk density, and $\mathrm{K}_{\text {sat. }}$ Pore water velocity has been 
shown to affect DOC absorption and desorption properties in the peat matrix, thus regulating the fraction of DOC that can be transport through the peatland. Additionally, pore water residence time changes can influence biotic processing of DOC by altering contact time with microbial communities (Neff and Asner, 2001). Therefore, WT position can exert a strong control on DOC production, decomposition, and transport within a peatland. Despite the importance of DOC dynamics in peatland C budgets, research is limited and inconclusive concerning the influence of long-term WT alterations on DOC cycling in northern peatlands.

Improving our understanding of the effects of long-term WT alterations in northern peatlands on vegetation, peat substrate quality, and DOC dynamics is imperative to accurately forecast the $\mathrm{C}$ cycling trajectories for northern peatland ecosystems under a changing global climate. As we have shown, peatlands are very sensitive to hydrological alterations (Aerts and Ludwig 1997; Blodau et al. 2004; Moore et al. in review) and even subtle shifts in WT position can destabilize a peatlands C sequestering capability (Bubier et al. 2003) by inducing changes in vegetation, peat quality, and pore water dynamics. Surprisingly, data is lacking on the effects of long-term WT alterations in northern peatlands.

\subsection{Project overview}

Advances in peatland research, especially within the last twenty years, has brought to our attention the tremendous potential for peatlands to influence the global climate. A small shift in the earth's climate has the potential to produce significant alterations of temperature and moisture regimes in northern peatland ecosystems with concurrent shifts in peatland $\mathrm{C}$ cycling processes. However, there is uncertainty how climate change will ultimately affect peatland greenhouse gas cycling.

My overall objective for this dissertation was to investigate the impact of longterm WT changes on northern peatland C cycling. Specifically, the long-term effects of raising and lowering the WT on peatland vegetation structure and productivity, pore water DOC dynamics, and peat substrate quality and how changes in these parameters, if present, will influence peatland C cycling. Our sites located in the Seney National 
Wildlife Refuge were altered in the 1930's by the construction of an extensive diking system that was constructed to provide open water impoundments for migratory waterfowl (Kowalski and Wilcox 2003). The diking operation created both WT drawdown and impoundment across large peatland expanses within the refuge. The direct effects of diking on hydrology in the refuges' peatlands provided a unique opportunity to examine the effects of long-term ( $~ 80$ years) WT manipulations on peatland C cycling processes.

Furthermore, most long-term WT investigations are from peatlands drained for forestry by ditching that typically display a dramatic drawdown of the WT (Wells and Williams 1996; Sundström et al. 2000; Laiho et al. 2006). Moreover, forestry drainage typically requires a network of drainage ditches to lower the WT that results in a very nonuniform WT drawdown across the peatland (Roulet et al. 2002). In contrast, the WT alterations across our sites are comparable to the predicted $\sim \pm 10 \mathrm{~cm}$ shift in peatland WT's under future climate change scenarios (Gorham 1991; Roulet et al. 2002). Thus, our treatments provided an unparalleled and realistic long-term in situ representation of climate induced WT changes on peatland vegetation, pore water, peat substrate quality, and ultimately $\mathrm{C}$ cycling dynamics in a northern peatland that could be expected within the next century. Our overall research hypothesis is that: Long-term WT alterations in a northern poor fen peatland will change $C$ cycling dynamics by controlling rates of heterotrophic respiration and vegetation structure and productivity.

Chapter two of this dissertation focuses specifically on peatland vegetation responses to long-term WT manipulations. Investigating peatlands that have experienced long-term WT manipulations is essential to determine plant responses to climate change since vegetation can display strong biological inertia to environment disturbances (Gorham 1957; Summerfield 1972; Keuper et al. 2011). Therefore, short-term studies may not fully capture shifts in plant dynamics that become evident only after sustained long-term disturbances.

Because plant communities influence peatland C cycling through controls on soil organic matter formation and quality it is imperative to have an understanding of potential climate induced changes to peatland vegetation dynamics. We measured plant 
metrics including community structure, biomass, and productivity across our WT manipulations. My objectives were to 1) determine if vegetation composition, primary production, and biomass has been influenced by the long-term WT alterations, 2) investigate if the partitioning between above- and belowground vegetation biomass and productivity is influenced by long-term WT manipulations, and 3) examine if peatland vegetation responds differently to long-term WT depending on the microtopical position (hummock and lawns) of the plant communities. Furthermore, we not only investigated vegetation metrics across plant functional groups but also examined species specific responses to the WT changes in an attempt to identify particular peatland plant species that might display sensitivity to the WT position.

My overall objective for chapter three was to examine the influence of long-term WT alterations in a northern peatland on pore water DOC production/consumption, substrate quality, and transport parameters. As previously reviewed, DOC consumption/production and export dynamics are primary factors determining if a peatland has a net positive or negative $\mathrm{C}$ accumulation rate and are tightly regulated by WT position. Therefore, we investigated peatland pore water dynamics to determine if 1) peatland DOC concentrations are dependent on long-term WT position, 2) there are changes in pore water residence time and the effect on DOC cycling, and 3) peatland DOC substrate quality is correlated to the long-term WT position and residence time of pore water.

My primary goal of chapter four was to determine if long-term WT alterations in a northern peatland will have an influence on peat substrate quality. We utilized Fourier transformed infrared (FTIR) spectroscopy, nutrient extractions of peat, and laboratory peat incubations to tease apart the long-term effects of altered WT's on peat substrate quality and commented on the resulting implications for peatland C cycling. My objectives were to investigate the effects of long-term WT manipulations in a northern peatland on 1) the chemical composition of the peat, 2) the potential $\mathrm{C}$ mineralization of the peat to determine whether differences exist in microbial available $\mathrm{C}$ substrates, and 3) peat nitrogen $(\mathrm{N})$ cycling and stabilization because peatland substrate quality is strongly regulated by $\mathrm{N}$ availability (Rydin and Jeglum 2006). 


\section{$1.4 \quad$ Literature cited}

Aerts, R. and F. Ludwig. 1997. Water-table changes and nutritional status affect trace gas emissions from laboratory columns of peatland soils. Soil Biology and Biochemistry 29:1691-1698.

Belyea, L. R. and N. Malmer. 2008. Carbon sequestration in peatland: patterns and mechanisms of response to climate change. Global Change Biology 10:10431052.

Billett, M., S. Palmer, D. Hope, C. Deacon, R. Storeton-West, K. Hargreaves, C. Flechard, and D. Fowler. 2004. Linking land-atmosphere-stream carbon fluxes in a lowland peatland system. Global Biogeochemical Cycles 18:GB1024.

Blodau, C., N. Basiliko, and T. R. Moore. 2004. Carbon turnover in peatland mesocosms exposed to different water table levels. Biogeochemistry 67:331-351.

Bubier, J. L., G. Bhatia, T. R. Moore, N. T. Roulet, and P. M. Lafleur. 2003. Spatial and temporal variability in growing-season net ecosystem carbon dioxide exchange at a large peatland in Ontario, Canada. Ecosystems 6:353-367.

Chapin, F., A. McGuire, J. Randerson, R. Pielke, D. Baldocchi, S. Hobbie, N. Roulet, W. Eugster, E. Kasischke, and E. Rastetter. 2002. Arctic and boreal ecosystems of western North America as components of the climate system. Global Change Biology 6:211-223.

Chapman, S., A. Buttler, A. J. Francez, F. Laggoun-Défarge, H. Vasander, M. Schloter, J. Combe, P. Grosvernier, H. Harms, and D. Epron. 2003. Exploitation of northern peatlands and biodiversity maintenance: a conflict between economy and ecology. Frontiers in Ecology and the Environment 1:525-532.

Davidson, E. A. and I. A. Janssens. 2006. Temperature sensitivity of soil carbon decomposition and feedbacks to climate change. Nature 440:165-173.

DeBusk, W. and K. Reddy. 1998. Turnover of detrital organic carbon in a nutrientimpacted Everglades marsh. Soil Science Society of America Journal 62:14601468.

Dorrepaal, E., J. H. C. Cornelissen, R. Aerts, B. Wallén, and R. S. P. Van Logtestijn. 2005. Are growth forms consistent predictors of leaf litter quality and decomposability across peatlands along a latitudinal gradient? Journal of Ecology 93:817-828. 
Fenner, N., C. Freeman, and B. Reynolds. 2005. Hydrological effects on the diversity of phenolic degrading bacteria in a peatland: implications for carbon cycling. Soil Biology and Biochemistry 37:1277-1287.

Fraser, C., N. Roulet, and T. Moore. 2001. Hydrology and dissolved organic carbon biogeochemistry in an ombrotrophic bog. Hydrological Processes 15:3151-3166.

Freeman, C., M. Lock, and B. Reynolds. 1993. Climatic change and the release of immobilized nutrients from Welsh riparian wetland soils. Ecological Engineering 2:367-373.

Freeman, C., N. Ostle, and H. Kang. 2001. An enzymic 'latch’on a global carbon store. Nature 409:149.

Friedlingstein, P., P. Cox, R. Betts, L. Bopp, W. Von Bloh, V. Brovkin, P. Cadule, S. Doney, M. Eby, and I. Fung. 2006. Climate-carbon cycle feedback analysis: Results from the C4MIP model intercomparison. Journal of Climate 19:33373353.

Gorham, E. 1957. The development of peat lands. Quarterly Review of Biology:145-166.

Gorham, E. 1991. Northern peatlands: role in the carbon cycle and probable responses to climatic warming. Ecological applications 1:182-195.

Grant, R., A. Desai, and B. Sulman. 2012. Modelling contrasting responses of wetland productivity to changes in water table depth. Biogeosciences Discuss 9:55795623.

Ise, T., A. L. Dunn, S. C. Wofsy, and P. R. Moorcroft. 2008. High sensitivity of peat decomposition to climate change through water-table feedback. Nature Geoscience 1:763-766.

Jager, D. F., M. Wilmking, and J. V. K. Kukkonen. 2009. The influence of summer seasonal extremes on dissolved organic carbon export from a boreal peatland catchment: Evidence from one dry and one wet growing season. Science of the Total Environment 407:1373-1382.

Keller, J. K., J. R. White, S. D. Bridgham, and J. Pastor. 2004. Climate change effects on carbon and nitrogen mineralization in peatlands through changes in soil quality. Global Change Biology 10:1053-1064.

Keuper, F., E. Dorrepaal, P. M. Van Bodegom, R. Aerts, R. S. P. Van Logtestijn, T. V. Callaghan, and J. H. C. Cornelissen. 2011. A Race for Space? How Sphagnum fuscum stabilizes vegetation composition during long-term climate manipulations. Global Change Biology 17:2162-2171. 
Kim, Y., M. Ueyama, F. Nakagawa, U. Tsunogai, Y. Harazono, and N. Tanaka. 2007. Assessment of winter fluxes of $\mathrm{CO} 2$ and $\mathrm{CH} 4$ in boreal forest soils of central Alaska estimated by the profile method and the chamber method: a diagnosis of methane emission and implications for the regional carbon budget. Tellus B 59:223-233.

Kluge, B., G. Wessolek, M. Facklam, M. Lorenz, and K. Schwärzel. 2008. Long-term carbon loss and $\mathrm{CO} 2-\mathrm{C}$ release of drained peatland soils in northeast Germany. European Journal of Soil Science 59:1076-1086.

Kowalski, K. P. and D. A. Wilcox. 2003. Differences in sedge fen vegetation upstream and downstream from a managed impoundment. The American midland naturalist 150:199-220.

Laiho, R. 2006. Decomposition in peatlands: reconciling seemingly contrasting results on the impacts of lowered water levels. Soil Biology and Biochemistry 38:20112024.

Laiho, R., H. Vasander, T. Penttilä, and J. Laine. 2003. Dynamics of plant-mediated organic matter and nutrient cycling following water-level drawdown in boreal peatlands. Global Biogeochemical Cycles 17:1053.

Laine, J., J. Silvola, K. Tolonen, J. Alm, H. Nykänen, H. Vasander, T. Sallantaus, I. Savolainen, J. Sinisalo, and P. J. Martikainen. 1996. Effect of water-level drawdown on global climatic warming: Northern peatlands. Ambio:179-184.

McGuire, A. D., L. G. Anderson, T. R. Christensen, S. Dallimore, L. Guo, D. J. Hayes, M. Heimann, T. D. Lorenson, R. W. Macdonald, and N. Roulet. 2009. Sensitivity of the carbon cycle in the Arctic to climate change. Ecological Monographs 79:523-555.

Moore, T. and N. Basiliko. 2006. Decomposition in boreal peatlands. Boreal peatland ecosystems:125-143.

Moore, T. and M. Dalva. 2001. Some controls on the release of dissolved organic carbon by plant tissues and soils. Soil Science 166:38-47.

Moore, T. and M. Dalva. 2006. The influence of temperature and water table position on carbon dioxide and methane emissions from laboratory columns of peatland soils. Journal of Soil Science 44:651-664.

Moore, T. R., J. L. Bubier, and L. Bledzki. 2007. Litter decomposition in temperate peatland ecosystems: the effect of substrate and site. Ecosystems 10:949-963. 
Neff, C. N.and G. P. Asner. 2001. Dissolved organic carbon in terrestrial ecosystems: synthesis and a model. Ecosystems 4:29-48.

Oechel, W. C., S. J. Hastings, G. Vourlitis, M. Jenkins, G. Riechers, and N. Grulke. 1993. Recent change of Arctic tundra ecosystems from a net carbon dioxide sink to a source.

Pellerin, S., M. Mercure, A. Desaulniers, and C. Lavoie. 2009. Changes in plant communities over three decades on two disturbed bogs in southeastern Québec. Applied Vegetation Science 12:107-118.

Prévost, M., A. P. Plamondon, and P. Belleau. 1999. Effects of drainage of a forested peatland on water quality and quantity. Journal of Hydrology 214:130-143.

Reddy, K. R. and R. D. DeLaune. 2008. Biogeochemistry of wetlands: science and applications. CRC.

Reiche, M., G. Gleixner, and K. Küsel. 2010. Effect of peat quality on microbial greenhouse gas formation in an acidic fen. Biogeosciences 7:187-198.

Roulet, N., T. Moore, J. Bubier, and P. Lafleur. 2002. Northern fens: methane flux and climatic change. Tellus B 44:100-105.

Roulet, N. T., P. M. Lafleur, P. J. H. Richard, T. R. Moore, E. R. Humphreys, and J. Bubier. 2006. Contemporary carbon balance and late Holocene carbon accumulation in a northern peatland. Global Change Biology 13:397-411.

Rydin, H., J. Jeglum, and J. Jeglum. 2006. The biology of peatlands. Oxford university press.

Siegel, D. I. 1988. Evaluating cumulative effects of disturbance on the hydrologic function of bogs, fens, and mires. Environmental Management 12:621-626.

Stocks, B. J., M. Fosberg, T. Lynham, L. Mearns, B. Wotton, Q. Yang, J. Jin, K. Lawrence, G. Hartley, and J. Mason. 1998. Climate change and forest fire potential in Russian and Canadian boreal forests. Climatic Change 38:1-13.

Strack, M., J. Waddington, L. Rochefort, and E. S. Tuittila. 2006. Response of vegetation and net ecosystem carbon dioxide exchange at different peatland microforms following water table drawdown. Journal of Geophysical Research 111:G02006.

Strack, M., J. Waddington, and E. S. Tuittila. 2004. Effect of water table drawdown on northern peatland methane dynamics: Implications for climate change. Global Biogeochemical Cycles 18:GB4003.

Summerfield, R. 1972. Biological Inertia--An Example. The Journal of Ecology:793-798. 
Sundström, E., T. Magnusson, and B. Hånell. 2000. Nutrient conditions in drained peatlands along a north-south climatic gradient in Sweden. Forest ecology and management 126:149-161.

Talbot, J., P. Richard, N. Roulet, and R. Booth. 2009. Assessing long-term hydrological and ecological responses to drainage in a raised bog using paleoecology and a hydrosequence. Journal of Vegetation Science 21:143-156.

Tarnocai, C. 2006. The effect of climate change on carbon in Canadian peatlands. Global and planetary Change 53:222-232.

Thomas, G. and P. Rowntree. 2006. The boreal forests and climate. Quarterly Journal of the Royal Meteorological Society 118:469-497.

Turetsky, M., W. Donahue, and B. Benscoter. 2011. Experimental drying intensifies burning and carbon losses in a northern peatland. Nature Communications 2:514.

Turetsky, M. and V. St. Louis. 2006. Disturbance in boreal peatlands. Boreal peatland ecosystems:359-379.

Turetsky, M., C. Treat, M. Waldrop, J. Waddington, J. Harden, and A. McGuire. 2008. Short-term response of methane fluxes and methanogen activity to water table and soil warming manipulations in an Alaskan peatland. Journal of Geophysical Research 113:G00A10.

Turetsky, M. R. 2004. Decomposition and Organic Matter Quality in Continental peatlands: The ghost of permafrost past. Ecosystems 7:740-750.

Updegraff, K., J. Pastor, S. D. Bridgham, and C. A. Johnston. 1995. Environmental and substrate controls over carbon and nitrogen mineralization in northern wetlands. Ecological applications 5:151-163.

Vitt, D. H. 2006. Functional characteristics and indicators of boreal peatlands. Boreal peatland ecosystems:9-24.

Wells, E. and B. Williams. 1996. Effects of drainage, tilling and PK-fertilization on bulk density, total N, P, K, Ca and Fe and net N-mineralization in two peatland forestry sites in Newfoundland, Canada. Forest ecology and management 84:97-108.

Weltzin, J. F., S. D. Bridgham, J. Pastor, J. Chen, and C. Harth. 2003. Potential effects of warming and drying on peatland plant community composition. Global Change Biology 9:141-151. 
Weltzin, J. F., J. Pastor, C. Harth, S. D. Bridgham, K. Updegraff, and C. T. Chapin. 2000. Response of bog and fen plant communities to warming and water-table manipulations. Ecology 81:3464-3478.

Wyatt, K. H., M. R. Turetsky, A. R. Rober, D. Giroldo, E. S. Kane, and R. J. Stevenson. 2011. Contributions of algae to GPP and DOC production in an Alaskan fen: effects of historical water table manipulations on ecosystem responses to a natural flood. Oecologia:1-12.

Whittington, P. N. and J. S. Price. 2006. The effects of water table draw-down (as a surrogate for climate change) on the hydrology of a fen peatland, Canada. Hydrological Processes 20:3589-3600. 


\subsection{Figures}

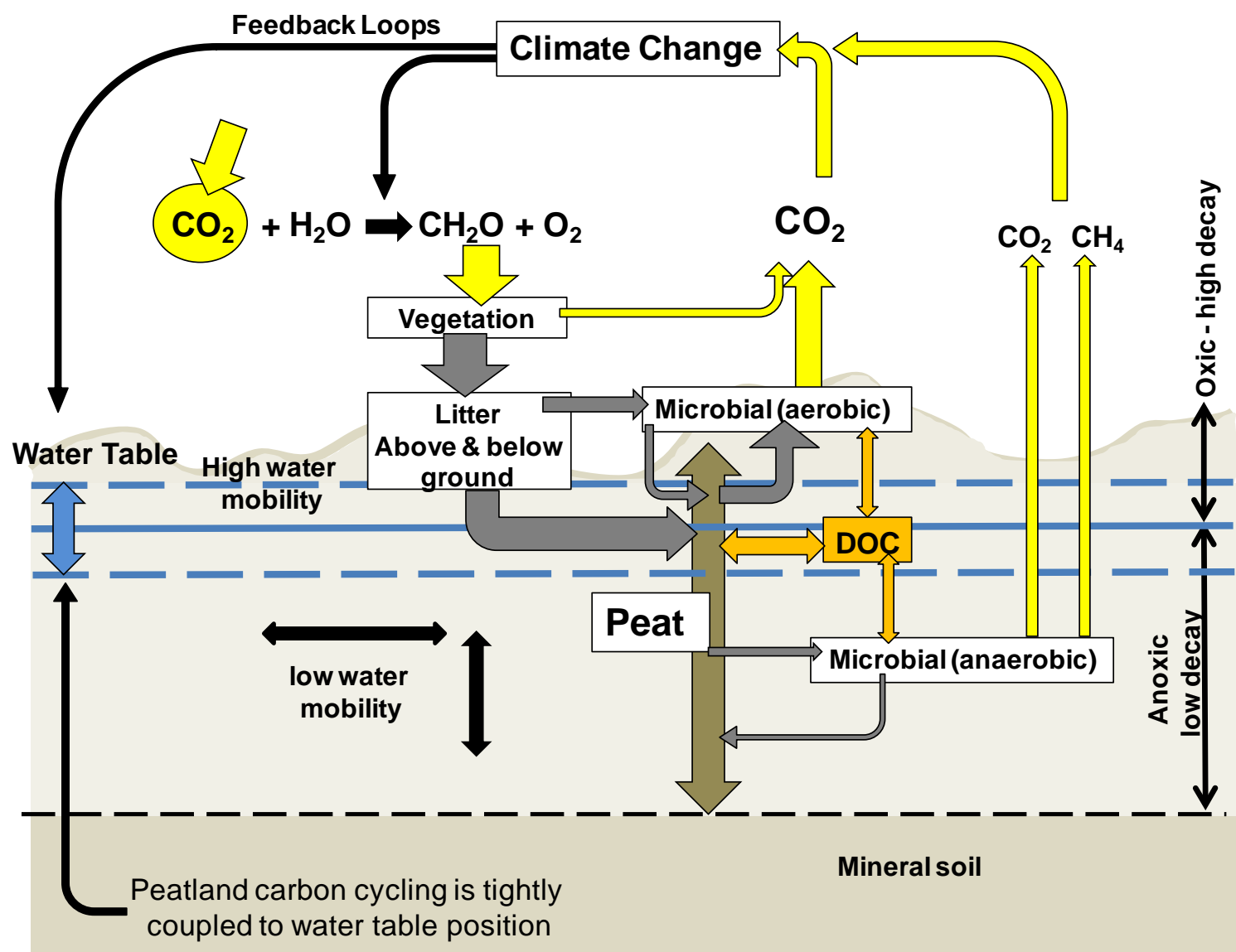

Figure 1.1 Peatland C cycling is controlled by tightly coupled interactions between autotrophic and microbial processes that are strongly influenced by the WT position that establishes the oxic and anoxic zones within the peat column. Increases in $\mathrm{C}$ emission could accentuate climate change resulting in feedback loops to peatland processes that could cause further destabilization of $\mathrm{C}$ stores. 


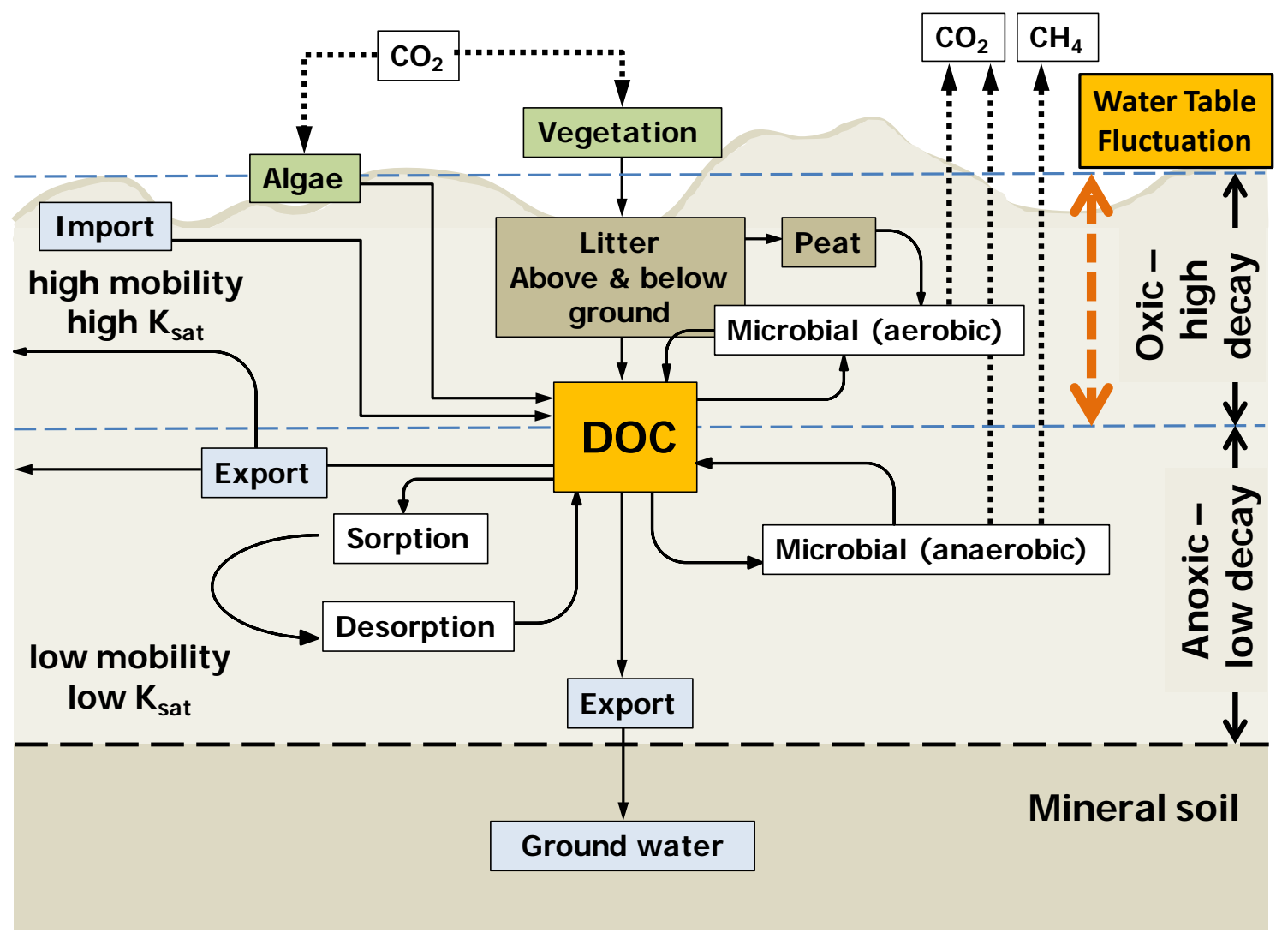

Figure 1.2 Cycling of peatland dissolved organic carbon (DOC) is regulated by multiple processes that influence production, consumption, quality, and transport throughout the peat column. The position of the WT controlling the oxic and anoxic zones is the strongest regulator of DOC transformations and transport. 


\section{Chapter 2. Vegetation Structure, Biomass, and Productivity across a Long-term Water Table Gradient in a Poor Fen Peatland ${ }^{1}$}

\subsection{Abstract}

Northern peatlands are large reservoirs of soil organic carbon (C). Historically peatlands have served as a sink for $\mathrm{C}$ since decomposition is slowed primarily because of a raised water table (WT) creating anoxic conditions. Climate models are predicting dramatic changes in temperature and precipitation patterns for the northern hemisphere that contain more than $90 \%$ of the world's peatlands. It is uncertain whether climate change will shift northern peatlands from $\mathrm{C}$ sequestering systems to a major global C source within the next century because of alterations to peatland hydrology. Our research investigated the effects of long-term hydrological manipulations on peatland vegetation dynamics in a poor fen peatland in northern Michigan. The construction of an earthen levee within the Seney National Wildlife Refuge in the 1930's resulted in areas of raised and lowered WT position relative to an intermediate WT site that was unaltered by the levee. We established sites across the gradient of long-term WT manipulations to examine how decadal changes in WT alter vegetation processes that influence peatland C cycling. We quantified vegetation structure, biomass, primary production, and plant resource partitioning between vegetative structures in relation to ecosystem C cycling characteristics in these manipulated areas as well as the intermediate site. The raised and lowered long-term WT treatments in comparison to the unaltered site are displaying divergent vegetation successional pathways, changes in moss and vascular plant productivity, and differences in biomass accumulation. Our study has demonstrated that a subtle change of the long-term WT position in a northern peatland will induce a significant influence on vegetation successional trajectories and growth dynamics with implications for the fate of peatland C stocks.

\footnotetext{
${ }^{1}$ The material contained in this chapter is planned for submission in the near future to the journal Plant Ecology by Hribljan, J.A., Pypker, T.G. and Chimner R.A.
} 


\subsection{Introduction}

Historically peatlands have served as a sink for carbon (C) since organic matter production is greater than decomposition primarily due to a raised water table (WT) creating anoxic conditions (Vitt 2006). The organic matter "peat” stored in peatlands represents 12 - $30 \%$ of the global soil C pool (Gorham 1991) that is equivalent to approximately $60 \%$ of the current carbon dioxide $\left(\mathrm{CO}_{2}\right)$ concentration in the atmosphere (Oechel 1993). Climate models predict warmer, drier conditions and northern peatlands are located primarily in high latitudes expected to experience dramatic warming (Limpens et al. 2008). Increasing global temperatures and changes in precipitation patterns have the potential to affect thermal and moisture regimes in peatlands (Ise et al. 2008). However, uncertainty exists on how predicted changes in climate will influence peatland ecosystems that capture and store C (McGuire et al. 2009). Additionally, the large C stocks contained in peatlands have the potential to create a strong positive feedback loop to climate change from enhanced emissions of carbon dioxide $\left(\mathrm{CO}_{2}\right)$ and methane $\left(\mathrm{CH}_{4}\right)$ into the upper atmosphere from northern peat soils (Dorrepaal et al. 2009).

Vegetation is the main driver of peat formation (Vitt 2006) and is the determining factor in the classification of peat type - Sphagnum, sedge and woody (Rydin and Jeglum 2006). Therefore, vegetation has a direct and multidimensional influence on peatland $C$

cycling. For example, heterotrophic decomposition of peat is largely regulated by the substrate quality of plant organic matter inputs derived from litter and root exudates (Crow and Wieder 2005; Bardgett et al. 2008). In addition, vegetation can act as conduits for gas exchange. In particular, sedges contain aerenchyma tissue that provide an effective pathway for $\mathrm{CH}_{4}$ release (Kelker and Chanton 1997) and can also transport oxygen into anoxic zones enhancing microbial decomposition of peat (Strack et al. 2006). Furthermore, peat accumulation rate is plant specific (Frolking et al. 2001). For example, Sphagnum dominated peatlands produce some of the highest rates of $\mathrm{C}$ sequestration (Rydin and Jeglum 2006).

Within northern peatlands WT position is a predominant controller on plant primary production, litter chemistry, and successional trajectories (Limpens et al. 2008). 
Thus, alterations of peatland WT position has the potential to create significant shifts in the quantity and quality of vegetation litter inputs into the peat column that will have direct affects on peatland C cycling (Laiho et al. 2003).

Surprisingly, despite the urgency to gain an improved understanding of long-term peatland response to climate change, research is limited on the effects of decadal hydrological alterations on peatland vegetation dynamics (Miller 2011). Furthermore, most long-term WT investigations are from Fennoscandinavian peatlands drained for forestry by ditching that typically depicts a dramatic WT drawdown greater than $30 \mathrm{~cm}$ (Wells and Williams 1996; Sundström et al. 2000; Laiho et al. 2008) that is not comparable to the predicted $14 \mathrm{~cm}$ WT drawdown for northern peatlands under a $2 \times \mathrm{CO}_{2}$ future climate change scenario (Roulet et al. 1992). Moreover, forest drainage practices typically utilize a network of drainage ditches to lower the WT that results in a very nonuniform drawdown across the peatland (Roulet et al. 2002). Research is lacking, especially in North American peatlands, on subtle $(\sim \pm 10 \mathrm{~cm})$ long-term ( $>70$ years) WT alteration effects on vegetation composition and dynamics that closely mimics the conditions predicted for northern regions in the next century.

Peatland paleoecology can provide valuable insight into long-term vegetation successional dynamics in relation to climate induced alterations to hydrology (Talbot et al. 2009). However, the complex interactions between vegetation, hydrology, chemistry, groundwater flows, production/consumption dynamics, and unique microtopographical development of peat can be difficult to tease apart from paleoecological assessments (Kuhry and Turunen 2006). Therefore, in situ long-term WT experiments can provide an important analog to paleoecological reconstructions of climate induced vegetation changes in peatlands.

Considerable research has investigated peatland responses to short-term (1-10 years) WT manipulations that demonstrates the sensitivity of vegetation to even small changes in peatland WT position (Weltzin et al. 2003; Strack et al. 2006; Breeuwer et al. 2009; Churchill 2011; Laine et al. 2011). However, it is uncertain if observed vegetation trends from short-term WT manipulation studies will follow a similar trajectory when viewed on a multi-decadal time scale (Churchill 2011). Therefore, investigating northern 
peatlands that have experienced long-term WT manipulations is essential to determine vegetation resilience to climate change. Especially since peatland vegetation can display strong biological inertia to environment change (Gorham 1957; Summerfield 1972; Keuper et al. 2011). Thus, short-term hydrological studies might not fully capture shifts in vegetation dynamics that would only become evident after sustained long-term WT disturbances.

Furthermore, peatland climate change research needs to thoroughly investigate fine scale vegetation patterns (Bubier et al. 2006) because peatlands are typically composed of a heterogeneous surface topography of microforms with unique plant structure. Subtle shifts in plant community structure, productivity, and litter quality are potentially hidden when considering the peatland as a homogenous surface. Teasing apart processes associated with individual plant species related to topographic position will allow improved insight into vegetation species that are most responsive and susceptible to hydrological alterations (Strack et al. 2006). Seemingly imperceptible shifts in vegetation structure resulting from small changes in WT position may be more indicative of future climate change scenarios predicted for northern peatlands. Moreover, investigating and quantifying small scale vegetation processes that operate over different time scales (short and long-term) will provide improvements to models that predict climate change effects on peatland C cycling (Yu 2006).

We investigated vegetation dynamics along a long-term gradient of WT manipulations in a northern poor fen peatland in the Seney National Wildlife Refuge. Peatland hydrology was altered by a series of levees constructed in the early 1930's to improve habitat for migratory birds resulting in the drying and inundation of wetlands throughout the refuge. The WT manipulations across our sites provided a unique research opportunity to examine the long-term effect of raising and lowering peatland WT position by only $\sim \pm 10 \mathrm{~cm}$ on vegetation dynamics. Our objectives were to 1 ) determine if peatland vegetation structure, primary production, and biomass is different across long-term WT manipulations, 2) investigate if the partitioning between above and below ground vegetation productivity and biomass is influenced by long-term WT 
manipulations, and 3) examine if peatland vegetation responds differently to long-term WT alterations depending on microtopical location (hummock and lawns).

We hypothesized: Vegetation structure will change in response to long-term WT alterations. In particular, hydric species will become more prevalent in the raised WT treatment and xeric species will become more dominant in the lowered WT treatment. Because soil moisture controls peatland plant productivity we also predicted that: $a$. Long-term WT drawdown will increase woody biomass and productivity from increased shrub and tree growth because of an increased aerobic rooting zone stimulating plant growth. In contrast, inundation will decrease woody biomass production because of anoxic conditions. b. Moss productivity will decline with long-term WT drawdown because of moisture stress and competition from increased vascular plant growth; however, long-term inundation will increase moss productivity because of saturated conditions improving moss growth and reducing vascular plant competition.

\subsection{Methods}

\subsubsection{Study sites}

Our research sites are in the Seney National Wildlife Refuge (SNWF) located in the central portion of the Upper Peninsula of Michigan (Schoolcraft County), USA. The greater landscape comprising SNWR is composed of a large sand plain (Heinselman 1965) consisting of well sorted sands, 0-60 m thick, deposited during the retreat of the Lake Michigan lobe of the Laurentide ice sheet (Krist and Lusch 2004). The sand plain covers a parent material of Ordovician sandstone, limestone, and dolomite (Wilcox et al. 2006). Two-thirds of the refuge is composed of a mosaic of marshes and peatlands (Nagel et al. 2008) interspersed with eskers formed from the underlining glacial sand. The sand plain has a gradual southeast slope of $1.89 \mathrm{~m} / \mathrm{km}$ (USFWS 2009). The climate of the refuge is greatly influenced by Lakes Michigan to the south and Lake Superior to the north. The average annual precipitation is $81 \mathrm{~cm}$ with an average annual snowfall of $312 \mathrm{~cm}$ (USFWS 2009). Annual average temperature is $5.1^{\circ} \mathrm{C}$ (Wilcox et al. 2006).

Six sites were established east of the Marsh Creek flooding $\left(46^{\circ} 11^{\prime} \mathrm{W}, 86^{\circ} 01^{\prime} \mathrm{N}\right)$ on a poor fen peatland complex. The original hydrology was altered in the 1930's when 
the U.S. Fish and Wildlife Service constructed a series of earthen levees utilizing the existing eskers to create open water impoundments for migratory waterfowl habitat (Kowalski and Wilcox 2003) resulting in both the inundation and drying of peatlands within the refuge. Our sites have been positioned to take advantage of the hydrological alterations resulting from the levees intercepting south-eastern sheetflow traveling across the refuge. Figure 2.1 depicts our six sites split equally between three different WT regimes; an intermediate ( $A$ and $B$ ), raised (C and D), and lowered ( $E$ and $F$ ). The levee has restricted the surface flow to sites $\mathrm{E}$ and $\mathrm{F}$ hydrologically separating the area from sites $\mathrm{C}$ and $\mathrm{D}$ that are currently inundated. Sites A and B were relatively unaffected by the construction of the levees.

\subsubsection{Hydrology}

Depth to WT at each site was monitored (April - October, 2010 and 2011) with non-vented pressure transducers (Levellogger Junior Model 3001; Solinst, Canada) set at a recording interval of one hour in slotted wells inserted to the mineral soil. A Barologger (Baralogger Gold Model 3001; Solinst, Canada) provided barometric compensation for all Leveloggers. Daily mean WT levels were used in the WT calculations. Water table elevations are in relation to the mean microtopography of each site. Microtopography was measured with a transit level at $0.5 \mathrm{~m}$ increments along a 50 $\mathrm{m}$ transect centered at the monitoring well of each site. All well elevations across the study sites were surveyed relative to each other and referenced to a common datum.

\subsubsection{Understory vegetation survey}

To characterize understory vegetation at each of the six sites a $400 \mathrm{~m}^{2}$ plot was established and stratified into four $100 \mathrm{~m}^{2}$ subplots. Within each subplot we randomly selected two $1 \mathrm{~m}^{2}$ quadrats split between a hummock and lawn microform for a total of 8 quadrats for each site and a total of 48 plots across the three WT treatments. Plant community structure to the species level was determined by a point intercept sampling method (Mitchell et al. 2001; Lang et al. 2009). An aluminum frame consisting of a movable cross bar was equipped with a bullseye bubble to level the frame above each 
quadrat. Grid point intercepts were recorded at 100 points uniformly distributed across the $1 \mathrm{~m}^{2}$ quadrat. Hits were recorded with a laser moved across the frame for all vascular plants and bryophytes from the top of the canopy to the peat surface with heights recorded for each vascular plant species. Sphagnum species $S$. capillifolium and $S$. rubellum were grouped as $S$. capillifolium because of the difficulty distinguishing between the two species in the field. The two Sphagnum species can hybridize and display phenotypic plasticity due to environmental conditions (Shaw et al. 2005). Foliar cover for each species was calculated from the total number of laser hit divided by the total number of grid points. Vegetation surveys were conducted at the peak of the growing season between August 14 and Sept 1, 2009. Vegetation nomenclature followed Laine et al. (2009) for Sphagna; Crum and Anderson (1981) for mosses; and Voss (1985) for vascular plants.

\subsubsection{Overstory biomass and primary productivity}

To characterize overstory vegetation we established a $400 \mathrm{~m}^{2}$ plot within each WT treatment and extracted increment cores from all trees with a DBH greater than $3 \mathrm{~cm}$. The cores were taken directly above the root collar (Pellerin and Lavoie 2003), located below the surface of the peat. Cores were dried, mounted on wood blocks, sanded, and then measured on a binocular microscope and stage micrometer to the nearest $0.01 \mathrm{~mm}$. Additionally, tree heights were measured with a clinometer and diameter at breast height $(\mathrm{DBH})$ at $1.37 \mathrm{~m}$ above the peat surface was obtained for all trees within the plot.

Tree total above ground biomass consisting of stems, branches (new and old), and foliage (old and new) were calculated with allometric equations derived by BondLamberty et al. (2002):

$$
\begin{array}{lc}
\log _{10} \operatorname{mass}_{P . \text { mariana }}(\mathrm{g}) & \begin{array}{c}
\text { Equation } 1 \\
= \\
=
\end{array} .011+1.202\left(\log _{10} \mathrm{DBH}\right)-0.010(\text { age })+0.011\left(\log _{10} \mathrm{DBH}^{*} \text { age }\right) \\
\log _{10} \text { mass }_{\text {L. laricina }}(\mathrm{g}) & \text { Equation } 2 \\
=2.648+0.715\left(\log _{10} \mathrm{DBH}\right) &
\end{array}
$$




$$
\begin{array}{rc}
\log _{10} \operatorname{mass}_{P . ~ b a n k s i a n a}(\mathrm{~g}) & \text { Equation } 3 \\
= & 2.889+0.789\left(\log _{10} \mathrm{DBH}\right)-0.014(\mathrm{age})+0.025\left(\log _{10} \mathrm{DBH}^{*} \text { age }\right)
\end{array}
$$

Tree above ground net primary production (ANPP) was calculated for each year from 1988 to 2008 for each species to capture current tree growth dynamics across the three WT treatments. Productivity was calculated from the yearly increase in biomass estimated from the listed allometric equations based on the increment core measurements.

\subsubsection{Understory aboveground biomass and primary productivity}

We established six biomass plots in 2010 and eight plots in 2011 split between hummock and lawn microforms equally spaced along two $20 \mathrm{~m}$ transects at each of the six sites. All aboveground vascular vegetation within a $0.25 \mathrm{~m}^{2}$ quadrat was clipped to the surface of the peat and sort to species. Sphagnum moss was collected from a $625 \mathrm{~cm}^{2}$ subplot within the vegetation quadrat and biomass was estimated from the upper $1 \mathrm{~cm}$ of the plant (Moore et al. 2002). Vegetation was dried at $75^{\circ} \mathrm{C}$ until a constant mass was obtained ( 48 hours). Above ground net primary productivity measurements were conducted on the 2011 biomass clippings. Current year growth was clipped from the shrubs, which included leaves, fruits, and stems (Fahey and Knapp 2007). Seasonal growth for shrubs was determined by marking a subset of shrubs in the spring with water proof paint when new growth was appearing on the stems. We did not measure stem radial growth, so shrub ANPP is underestimated. Graminoid ANPP was calculated as the total live biomass harvested (Fahey and Knapp 2006). We used allometric equations developed from the relationship between the 2011vegetation biomass and ANPP data to estimate ANPP from the 2010 biomass harvest quadrates (Table 2.1 and Figure 2.2). Biomass and ANPP plots from 2010 and 2011 were grouped together (14 hummock and 14 lawn quadrats for each parameter from each WT treatment) since we were interested in differences across the WT treatments and not interannual variability.

Sphagnum ANPP was measured in 2010 and 2011utilizing the cranked wire method (Clymo 1970; Fahey and Knapp 2007). In each site we established two plots each consisting of a $5 \mathrm{~m}$ transect of 50 cranked wires spaced $10 \mathrm{~cm}$ apart randomly 
placed over the peatland surface to capture hummock and lawn microforms. Thus, we had 4 plots of 50 wires for each WT treatment per year for a total of 400 wire measurements in each WT treatment when combining 2010 and 2011. The horizontal "crank" in the wire was positioned approximately $1 \mathrm{~cm}$ below the Sphagnum surface, which served to anchor the wire in place and allow for vertical plant growth up the wire. Sphagnum growth was measured between May and October, thus representing seasonal and not yearly growth so ANPP is underestimated. Wires that showed signs of disturbance were not measured. Sphagnum bulk density cores $(10 \mathrm{~cm}$ diameter x $10 \mathrm{~cm}$ deep) were extracted from hummocks and lawns in the six sites for each species $(\mathrm{n}=\sim 5)$ to scale production to the site level. Bulk density was determined from a two $\mathrm{cm}$ section of stem directly below the capitulum. Calculation of production at each plot for individual Sphagnum species was performed by multiplying the mean stem bulk density $\left(\mathrm{g} \mathrm{cm}^{-1}\right.$ ) by the seasonal mean stem growth $(\mathrm{mm})$ from each WT treatment measured with the cranked wires (Fahey and Knapp 2007) and then scaled to the site $\left(\mathrm{g} \mathrm{m}^{-2} \mathrm{yr}^{-1}\right)$ using the point intercept percent cover data. Sphagnum production plots form 2010 and 2011 were pooled $(n=8)$ since we were interested in differences across the WT treatments and not interannual variability. Sphagnum fuscum was present in only two point intercept quadrats that was not captured by the cranked wire transects so ANPP was estimated from a bulk density of $21 \mathrm{mg} \mathrm{cm}^{-3}$ (Wieder et al. 2010) and scaled to percent cover measurements. Corrections were not applied for temporal differences in cranked wire measurements since wire placement and measurements were within several days between years and applying a growth rate per day could result in a greater error (Dorrepaal et al. 2004; Lang et al. 2009).

Aulacomnium palustre ANPP was calculated using a patch density of $50.7 \mathrm{~g} \mathrm{~m}^{-2}$ $\mathrm{yr}^{-1}$ (Harden et al. 2009) and scaled to each site with our point intercept cover measurements. Polytrichum strictum productivity was estimated from the linear growth of Sphagnum since this moss typical grows at a similar rate of the companion Sphagnum moss (Vitt 2007). We used mass/shoot length ratios derived by Weltzin et al. (2001) to calculate estimates of $P$. strictum ANPP and then scaled to the site with our point intercept cover measurements. 


\subsubsection{Understory belowground biomass and primary productivity}

Shrub and graminoid belowground biomass was calculated with allometric equations. Murphy (2009) found that the best predictor of below ground biomass for vascular plants was their species specific above ground biomass and the above:belowground biomass ratio was not significantly influenced by WT position.

Log below ground biomass C. calyculata $=1.01 \times$ Log $_{\text {above ground biomass }}+0.12 \quad$ Equation 4

$\log _{\text {below ground biomass K. polifolia }}=0.72 \times$ Log $_{\text {above ground biomass }}+0.59 \quad$ Equation 5

$\log _{\text {below ground biomass L. groenlandicum }}=1.10 \times$ Log $_{\text {above ground biomass }}-0.08 \quad$ Equation 6

$\log _{\text {below ground biomass V. myrtilloides }}=0.99 \times \log _{\text {above ground biomass }}-0.32 \quad$ Equation 7

$\log _{\text {below ground biomass V. oxycoccus }}=1.1 \times \log _{\text {above ground biomass }}-0.13 \quad$ Equation 8

An allometric equation developed for Eriophorum vaginatum (Murphy 2009) was applied to the total above ground graminoid biomass for each WT treatment since species specific equations were not available.

$\log _{\text {below ground biomass E. vaginatum }}=1.07 \log _{\text {above ground biomass }}+0.66 \quad$ Equation 9

Shrub and sedge fine root belowground net primary production (BNPP) was calculated with allometric equations relating aboveground biomass to root production (Murphy 2009). We did not separate $V$. oxycoccus stems from leaves so a relationship between aboveground biomass and fine root production was utilized (Murphy 2009).

$\mathrm{BNPP}_{\text {shrub }}=0.75 \mathrm{x}$ shrub stem biomass +0.02

$\mathrm{BNPP}_{V \text {. oxycoccus }}=0.4 \mathrm{x}$ aboveground biomass +0.72

$\mathrm{BNPP}_{\text {sedge root }}=0.69 \mathrm{x}$ sedge aboveground biomass +0.18
Equation 10

Equation 11

Equation 12

\subsubsection{Statistical analysis}

To characterize vegetation community structure across the WT treatments a Nonmetric multidimensional scaling (NMS) ordination was performed on each microform 
(hummock and lawn) of the point intercept data in PC-ORD (McCune and Grace 2002). The NMS technique was chosen because of the nonnormal distribution of the data lacking linear relationships among variables. A general revitalization was applied to species data to help equalize heterogeneity between abundant and less abundant species since we were interested in subtle changes of plant structure from the small changes in WT position. Logarithmic transformations were applied to correct the highly skewed nature of the data by using the FORM = LOG, GENERALIZED option in PC-ORD that helps to preserve order-of-magnitude for small samples. The ordination solution was obtained with Sørensen distances and dimensionality was determined by choosing the solution with a final stress less than 20, a Monte Carlo test p-value $<0.05$, and a minimum reduction of five points of stress with the addition of an axis. We used a starting configuration determined by the best solution from 250 runs of random data applied to 250 runs of real data. Only solutions with an instability $<10^{-4}$ were accepted. Pearson correlation scores from the NMS ordination were examined to determine vegetation species and environmental parameters that strongly influenced ordination solutions. Vegetation species richness (S), evenness (E), and the Simpson diversity index (D) in each WT treatment were calculated with PC-ORD.

A nonparametric multivariate multi-response permutation procedure (MRPP) was applied to the point intercept surveys to test for vegetation structure group differences across the WT treatments microforms (hummocks and lawns). The MRPP test, which is robust to high heterogeneity was run on non-transformed data with a Sørensen distance measure. A small MRPP p-value is an indication of greater within than between group similarity. The agreement statistic (A) measures the within group similarity with an increasing A-value indicative of increased group similarity and the T-value is a metric of between group similarity with a highly negative T-value representing a strong separation.

Biomass and productivity measurements were converted to a $\mathrm{C}$ biomass based on the assumption of a 50\% C content in plant mass (Fahey et al 2005). Comparisons of vegetation biomass and productivity across the WT treatments for each microform (hummock and lawn) separately were conducted with analysis of variance (ANOVA) to detect differences in spatial variation between the WT treatments since individual WT 
treatments were not replicated to the landscape scale (Oksanen 2001). We applied log transformations to nonnormal data. If normality was not corrected with the applied transformation then the treatment groups were analyzed with a nonparametric KruskalWallis test. Analysis of covariance (ANCOVA) was used to explore the relationships between biomass and ANPP across the WT treatments by comparing slopes and intercepts (Minitab 2011). The tree ANPP data from 1988 - 2008 were fitted with trend analysis to determine growth trajectories. Because of autocorrelation between tree ANPP and year of sampling, comparisons between WT treatments for tree ANPP was analyzed with a GLM repeated measures model for within subject effects of year and WT treatment on ANPP. Descriptive statistics were determined with Sigmastat and comparisons between all treatments were conducted using Tukey's post-hoc test with differences at $\mathrm{p}<0.05$ considered significant.

\subsection{Results}

\subsubsection{Hydrology and microtopography}

Combining the sites within each WT treatment resulted in a similar microtopographical relief for the intermediate and lowered WT treatment sites (mean \pm 1 SD; $22.6 \pm 10.0 \mathrm{~cm}$ and $22.4 \pm 12.5 \mathrm{~cm}$ respectively) with a slightly lower relief in the raised treatment (17.0 \pm 9.3). The expected differences in seasonal (April - October) WT levels across the WT treatments were confirmed for 2010 and 2011 relative to mean microtopography of each site. The lowered WT sites south of the impoundment experienced the greatest WT draw-down with two year seasonal mean WT of $36.6 \pm 5.7$ $\mathrm{cm}$ (mean \pm 1 SD below mean topography). The raised WT treatment had the highest WT $(14.4 \pm 6.9 \mathrm{~cm})$ while the intermediate treatment $(26.2 \pm 7.1 \mathrm{~cm})$ was staged between the raised and lowered WT treatments. The wettest site in the raised WT treatment (site C) had standing water above the lawn microforms for 97\% (2010) and 81\% (2011) of the time period recorded for the seasonal WT levels (Figure 2.3). 


\subsubsection{Vegetation composition}

Of the total species recorded across the WT treatments the intermediate site contained $89 \%$, the raised $78 \%$, and the lowered $78 \%$ of the eighteen species. All dominant vegetation species were present across three WT treatments. Only five vegetation species Carex canadensis, , Pleurozium schreberi, Sphagnum fuscum, Warnstorfia fluitans, and Vaccinium angustifolium were not present in all three WT treatments. Carex Canadensis ( $<3 \%)$ and Warnstorfia fluitans $(<1 \%)$ were only present in the raised treatment. Pleurozium schreberi $(<1 \%)$ and Sphagnum fuscum $(<5 \%)$ were unique to the intermediate treatment. The most dominate hummock shrub, graminoid, and moss was Chamaedaphne calyculata, Carex oligosperma, and Sphagnum capillifolium respectively. The lawns were also dominated by Chamaedaphne calyculata and Carex oligosperma; however, Sphagnum angustifolium was the predominate moss.

Differences in vegetation structure across WT treatments were detected with NMS ordination dividing the treatments into distinct groupings based on percent cover (Figure 2.4). There is a consistent trend of separation between the raised and lowered WT treatments when examining the hummocks and lawns separately, and also when combining the microforms (MRPP; $\mathrm{A}=0.06, \mathrm{p}=0.018 ; \mathrm{A}=0.07, \mathrm{p}=0.012$; and $\mathrm{A}=$ 0.07, $\mathrm{p}<0.001$ respectively) (Table 2.2). The gradient along axis 1 was strongly correlated with WT for the hummock and lawn microforms $(r=0.76$ and 0.83 respectively). Pearson correlation scores indicate the separation of the hummocks between the raised and lowered WT treatments are an increased cover of, Polytrichum strictum, and V. angustifolium in the lowered WT treatment hummocks with the raised treatment hummocks containing greater Sphagnum magellanicum and C. oligosperma cover. For the lawns, Ledum greonlandicum and $V$. angustifolium with axis 1 in the lowered WT treatment and greater abundance of Vaccinium oxycoccus and Carex oligasperma in the raised WT treatment. The intermediate WT treatment only displayed a significant separation relative to the lowered treatment for the lawn microforms $(\mathrm{A}=$ 0.09, $\mathrm{p}=0.003)$ and when microforms were combined together $(\mathrm{A}=0.04, \mathrm{p}=0.009)$ (Table 2.2). The lower WT treatment lawns contained greater cover of L. greonladicum, S capillifolium, and S. magellanicum compared to the intermediate (Table 2.3). 


\subsubsection{Vegetation primary production}

Vegetation total net primary production (TNPP) (combining above and belowground NPP) (Table 2.4) was not different between the WT treatments ( $F=0.67, p$ $=0.52$ ); however, there was an $11 \%$ reduction of TNPP in the raised treatment compared to the intermediate treatment. When we examined TNPP separately for the hummocks and lawn microforms (Figure 2.5, Tables 2.5 and 2.6), then it is apparent that the reduction in the raised treatment TNPP is primary driven by the $37 \%$ and $38 \%$ significantly lower mean TNPP of the raised WT hummocks compared to the intermediate and lowered treatments respectively $(F=7.19, \mathrm{p}=0.002)$. Even though Kalmia polifolia has a significantly greater productivity in the raised hummock treatments, this is heavily countered by the reduction in Chamaedaphne calyculata TNPP compared to the intermediate and lowered treatments (65\% and $74 \%$ respectively). Since the moss ground layer is the largest contributor to TNPP it is important to note the decline in mean moss productivity in the raised (33\%) and lowered (30 \%) treatments in relation to the intermediate treatment despite the nonsignificance $(\mathrm{F}=1.34, \mathrm{p}=0.31)$.

The hydrological alterations are also significantly influencing plant productivity in the lawn microforms. Surprisingly, the lawns in the raised WT treatment had a slightly greater TNPP than the lowered treatment $(\mathrm{F}=2.55, \mathrm{p}=0.09)$. TNPP is primarily elevated in the raised treatment lawns by the significant increase in C. calyculata over the intermediate and lowered treatments (60\% and $64 \%$ respectively).

\subsubsection{Vegetation biomass}

Total vegetation biomass (combining above and belowground shrub and graminoid biomass) was not significantly different between the WT treatments ( $F=1.56$, $\mathrm{p}=0.21$ ) and in contrast to the NPP measurements, the lowered treatment biomass was elevated in relation to the intermediate treatment. The high total biomass in the lowered treatment is the result of a $12 \%$ higher mean belowground biomass. Partitioning the hummock and lawn biomass data (Figure 2.6, Tables 2.7 and 2.8) revealed significant hydrological disturbance to lawn microform vegetation biomass accumulation. Total above and belowground biomass from hummock microforms was 39 \% lower in the 
raised WT treatment $(\mathrm{p}=0.002)$, but only $15 \%$ greater $(\mathrm{p}=0.21)$ in the lower treatment than the intermediate treatment. The raised WT treatment lawns have a $30 \%$ greater above and belowground biomass $(\mathrm{p}=0.05)$ over the intermediate treatment. Biomass differences across the WT treatments were primarily driven by Chamaedaphne calyculata.

We also detected very different $\mathrm{C}$ allocation patterns into biomass for the shrubs. Shrub leaf:stem quotients for C. calyculata , Kalmia polifolia, and Ledum groenlandicum showed that shrubs in the raised and lowered WT treatments are placing a greater concentration of $\mathrm{C}$ into stem biomass than leaf production (Table 2.8). In addition, mean plant heights differed across the WT treatments. Chamaedaphne calculata was taller on the hummocks in the lowered WT treatment than the intermediate and raised hummock treatments. Kalmia polifolia was significantly shorter in the lawns of the raised WT treatment compared to the intermediate and lowered WT treatment lawns (Table 2.9).

\subsubsection{Overstory productivity}

Increment tree core measurements along with historical aerial photographs confirmed that tree establishment was initiated in the lowered WT treatment post- levee construction (Figure 2.7). The raised WT treatment site was initially unpopulated before the WT manipulation and currently only supports a few individuals in the drier sections of site D close to the levee where there is a slight increase in peatland elevation (Hribljan unpublished data). Figure 2.8 illustrates tree ring growth data of the three WT treatments and in particular shows the current decline in growth rates for black spruce, tamarack, and jack pine for lowered treatment that is further confirmed by the declining ANPP since 1990 (Figure 2.9).

\subsection{Discussion}

Our sites provided a unique opportunity to investigate vegetation responses to long-term WT impoundment and draw-down in a northern poor fen peatland. A network of levees constructed in the early 1930's has altered the WT levels by $\pm \sim 10 \mathrm{~cm}$ across the WT treatments that is similar to the predicted climate induced hydrological changes 
for northern peatlands within the next century (Roulet et al. 2002). Thus, our sites are a realistic in situ simulation of potential climate change effects on northern peatland vegetation dynamics from altered hydrology. Arial photographs pre-levee construction clearly illustrate how predominant surface water flow paths across the greater peatland landscape were altered by the installation of the levees (Figure 2.1a). Furthermore, we believe the original peatland complex that contained our sites was partitioned into three different WT manipulations containing similar poor fen vegetation communities when the levees were installed. Preliminary macrofossil analysis of peat cores from across the WT treatments revealed similar vegetation successional processes (Hribljan and Chimner; unpublished data). All three WT treatment sites transitioned from sedge dominated peatlands to the current Sphagnum dominated poor fens at similar depths in the peat column ( $70 \mathrm{~cm}$ below the surface)

\subsubsection{Understory vegetation community structure}

The understory vegetation community composition was surprisingly similar across the WT treatments despite the long-term WT manipulations; however, perceptible differences in plant structure are apparent from the vegetation survey. Hummock microforms across the WT treatments have a similar species richness and diversity index. Conversely, the lawns in the WT drawdown treatment have a higher diversity index than the lawns in the intermediate and raised treatments. This trend is also seen when combining the microforms within each WT treatment and making comparisons across the WT treatments. The high diversity in the lowered WT treatment lawns appears to be driven by a greater evenness of the vegetation community. Thus, the lowered WT treatment lawns are creating an environment that can continue to sustain lawn species, in addition to plant species that typically prefer drier hummocks. Typically, a reduction in plant diversity is observed with a lowered WT; however, this is usually associated with a WT drawdown greater than 30 cm (Jukaine et al. 1995; Miller 2011).

We detected differences in understory vegetation community structure with NMS ordination across the WT treatments. The raised and the lowered WT treatment vegetation communities are diverging in opposite successional trajectories from the 
intermediate treatment for both the hummock and lawn microforms (Figure 2.4). The main drivers for this trend in the raised WT treatment hummocks are an increase of species more tolerant of elevated moisture conditions when compared to the intermediate treatment. This included an increase abundance of Sphagnum magellanicum that tolerates the wetter conditions in the lawns (Crum 1992) and the shrub Vaccinium oxycoccos that is highly tolerant of elevated WT's (Jacquemart 1997). However, total moss cover on the raised treatment hummocks was less than the intermediate and lowered treatment hummocks, mainly because of the lower abundance of Sphagnum capillifolium that is sensitive to an elevated WT (Andrus et al. 1983). Vegetation abundance was similar for most plant species between the intermediate and lowered WT treatment hummocks. However, we measured slightly lower total shrub abundance on the lowered treatment hummocks, which is surprising, since multiple studies have reported increased shrub growth with WT drawdown (Laiho et al. 2004; Murphy et al. 2009). This can be explained by the disproportionate allocation of biomass production between leaves and stems in the lowered WT treatment (Table 2.8). The shrubs are allocating more energy into stem production than aerial leaf production that is creating a sparser understory canopy cover in response to the WT drawdown (Murphy et al. 2009).

The lawn microform NMS ordination shows the raised WT treatment plots are most distinct in plant structure from the intermediate and lowered treatments. We attribute this to the reduction in moss cover from the seasonally elevated WT. The most pronounced vegetation changes in the lowered WT treatment lawns when compared to the intermediate treatment was the shift to a drier moss community with greater Sphagnum capillifolium and a reduction in Sphagnum angustifolium.

Furthermore, the relative distances between the microforms within each WT treatment are different across the WT treatments and appear to be influencing vegetation community structure. In particular, the raised WT treatment is losing microtopographic distinction between the hummock and lawn microforms. MRPP results show the raised WT treatment microforms have the greatest within-group homogeneity, indicating the microforms are converging together (Table 2.2). This is attributed to the elevated WT influencing vegetation composition by reducing the abundance of the dominant hummock 
plant species. In particular, Sphagnum capillifolium, Polytrichum strictum, and Chamnedaphnia calyculata on the raised WT hummocks have a lower abundance than the intermediate and lowered treatments hummocks. Thus, the vegetation changes in the raised WT treatment are causing community structure to become more homogenous between hummock and lawn microforms. For example, the dominant shrub C. calyculata is displaying only a $12 \%$ difference in cover between the hummocks and lawns in the raised WT treatment compared to $21 \%$ and $27 \%$ respectively in the intermediate and lowered treatments.

\subsubsection{Understory vegetation biomass and NPP}

Peatland WT drawdown has been shown to reduce moss growth (Mulligan and Gignac 2001; Robroek et al. 2008) with a concurrent increase in shrub productivity and biomass (Laiho et al. 2003). An increased aerobic zone can stimulate shrub root production; however, a drastic reduction in the WT limits availability and upward conductance of water to vascular plant roots and moss respectively (Lafleur et al. 2005). Excessively dry conditions can inhibit moss growth and promote species shifts as the moss communities adjust to the altered hydrological conditions. Research on peatland vegetation NPP responses to an elevated WT is scarce. A subtle increase in WT ( 1-2 cm) can promote moss and shrub production (Rydin and Jeglum 2006). However, drastic inundation will create loss of moss cover and reduced woody plant productivity from the highly anoxic conditions (Thormann and Bayley 1997). Furthermore, the relationship between plant NPP and WT position is complicated, because plant growth response can be unimodal and can vary between short and long-term hydrological alterations due to nutrient availability. Lastly, microtopographical niche is an important determinant how the plant with respond to changing WT position. Plant species that prefer lawn microforms, especially mosses, display a greater sensitivity to WT changes than hummock species (Andrus et al. 1983).

We measured significant differences in vegetation primary production across the WT treatments with concurrent changes in biomass accumulation in the plant communities. It is interesting to note that many of the significant differences in 
productivity and biomass were only apparent after analyzing hummock and lawn microforms separately. Thus, treating the peatland as a homogenous ecosystem can conceal potentially important shifts in vegetation structure and dynamics.

The hummock plant communities in the lowered WT treatment responded to the increased aeration in the upper peat horizon by increasing shrub TNPP and accumulating higher shrub biomass. However, despite the elevated shrub growth, the lowered WT treatment hummocks did not have a higher understory TNPP in comparison to the intermediate treatment hummocks. This contradiction is caused by the reduced ANPP in moss lowering TNPP in the lowered WT treatment hummocks. The hummock moss in the lowered WT treatment likely experienced reduced ANPP because WT drawdown created drought-like conditions that lead to moss desiccation and reduced photosynthesis (Lafleur et al. 2005).

Surprisingly, the lawns in the raised WT treatment had a $49 \%$ greater shrub TNPP than the intermediate treatment. This was unexpected because an elevated WT is known to reduce shrub abundance. However, the high shrub productivity could be explained by reduced moss cover. In the wettest site (site C) of the raised WT treatment moss cover was only $30 \%$ compared to $94 \%$ and $104 \%$ in the intermediate and lowered treatments respectively. Sphagnum is extremely efficient at capturing and sequestering nutrients, thus limiting availability to competing plants (Heijmans 2002). Therefore, nutrient restraints could be lifted in the raised WT by the smaller moss community in the lawns facilitating increase shrub growth.

To determine if our understory vegetation productivity measurements scaled up to the ecosystem level, we compared vegetation NPP results with ecosystem gross primary production (GPP) chamber based measurements across the WT treatments (Ballantyne 2010). Carbon flux data showed the lowered WT treatment GPP was 15\% greater and $7 \%$ less in the raised treatment than the intermediate treatment. The GPP results from the raised WT treatment was in accordance with the plant NPP data; however, the greater GPP in the lowered treatment was not fully represented by our NPP measurements (Table 2.4). GPP can be partitioned into several sources, including plant, algae, and microbial, but it is unlikely that the greater GPP in the lowered treatment was a result of algae and 
microbial productivity because of the drier conditions from WT drawdown. We believe that the discrepancy can be accounted for by a greater shrub radial growth (indicated by the decreased leaf:stem quotient) and height for the prominent shrub Chamaedaphne calyculata that was not captured by our NPP plant measurements (Table 2.8 and 2.9).

The WT manipulations negatively affected moss productivity in both the lowered and raised WT treatment hummock and lawn microforms. The moss communities also changed community structure and composition in response to the long-term changes in hydrology. Shrub growth responded favorably to WT drawdown and allocated a greater percentage of $\mathrm{C}$ into stem growth. Furthermore, shrub productivity responded favorably to elevated WT conditions when accompanied with a decrease in moss cover that possibly alleviated competition for nutrients. Since moss productivity can contribute the majority of the carbon sequestering ability in a Sphagnum dominated peatland, the changes we have measured in understory vegetation dynamics should raise concern in light of climate change prediction for northern latitudes. Additionally, plant responses are multidimensional to changes in their environment, and as we have demonstrated do not follow linear responses to disturbances. Additional long-term studies are needed to better understand understory vegetation responses to sustained long-term WT alterations.

\subsubsection{Shifts in overstory primary production}

Tree NPP can comprise a significant portion of peatland $C$ sequestering ability (Bond -Lamberty et al. 2004). Peatland tree encroachment typically occurs after WT drawdown because of increased oxic conditions and availability of nutrients in the upper peat profile that are favorable for tree establishment (Laiho et al. 2004; Talbot et al. 2009). Increased shrub and tree NPP after WT drawdown has been proposed as an offset to the increased loss of $\mathrm{C}$ from accelerated aerobic peat decomposition, thus tempering or preventing peatlands from become a $\mathrm{C}$ source under climate induced drought conditions (Minkkinen et al. 2002). However, uncertainty exists if woody plant productivity will provide a long-term stabilization of $\mathrm{C}$ cycling in drained peatlands.

Aerial photography of the peatland revealed the lowered WT treatment sites were devoid of tree cover prior to the construction of the levee. The tree coring data verified a 
post-levee encroachment of trees in the early 1950's initiated by jack pine that rapidly expanded to create the current dense tree cover that is predominant throughout site $\mathrm{F}$ and is starting to invade the peatland around site $\mathrm{E}$ in the lowered WT treatment. In contrast, aerial photographs from 1930 confirm that site A in the intermediate WT treatment has historically supported tree cover. Interestingly, tree growth in the lowered WT treatment displayed a lower ANPP, most predominantly for black spruce, when examined over the past 20 years compared to the intermediate treatment (Figure 2.9) that has sustained a consistent linear growth pattern over the past 100 years (Figure 2.8).

Tree ANPP measurements of all three tree species present across the WT treatments were comparable to the low range measured in other peatlands (Miller 2011; Bond -Lamberty et al. 2004), and thus might be operating at nutrient thresholds restraining tree ANPP growth rates. The lowered WT treatment lower tree ANPP than the intermediate treatment could be attributed to WT changes influencing nutrient accessibility. Turetsky et al. (2011) measured a large increase in tree production after WT drawdown in a Canadian peatland. However, tree productivity displayed a possible decline 20 years post-drainage that was suggested to be attributed to nutrient availability. Interestingly, the raised and lowered sites have elevated concentrations of phenolics in the peat and pore water compared to the intermediate treatment (Hribljan et al. in preparation) that are known to complex with nitrogen $(\mathrm{N})$ and limit availability for plant growth (Knicker 2004).

Diminishing $\mathrm{C}$ sequestration rates in tree communities associated with WT drawdown questions the ability for increased woody production to be a long-term offset to increased decomposition. Shrub productivity in the lowered WT treatment exhibited a $20 \%$ elevated rate of TNPP compared to the intermediate treatment, along with the tree encroachment, this area of the peatland is still operating at a net carbon loss due to high ecosystem respiration. The lower WT treatment had the lowest seasonal NEE (net ecosystem exchange) of the three WT treatments as measured with eddy covariance (Pypker; unpublished data). Therefore, the initial large sequestration of $\mathrm{C}$ in woody biomass associated with WT drawdown might not provide a long-term C offset to increased heterotrophic respiration and accelerated peat decomposition. Furthermore, 
peatlands that have a lowered WT are more susceptible to fires that can quickly release the additional C temporally stored into woody biomass (Flanagan et al. 2009).

\subsection{Conclusions}

We were able to utilize hydrological alterations in a northern poor fen peatland to explore the response of vegetation to long-term WT alterations. Our data illustrates the importance of investigating vegetation dynamics on a decadal timeframe and beyond functional group classifications. We believe that an important conclusion from our study is that significant changes in vegetation dynamics are possible with only a $\pm \sim 10 \mathrm{~cm}$ alteration in the long-term WT position of a northern peatland. The raised and lowered long-term WT treatments in comparison to an unaltered site are displaying divergent vegetation successional pathways, changes in moss and vascular plant productivity, and differences in biomass accumulation.

All three WT treatments have retained the same plant communities after 70 years of WT alterations, illustrating the strong biological inertia and resiliency peatlands can display in response to environmental disturbances. However, subtle shifts in plant organization have the potential to create significant changes to peatland $\mathrm{C}$ cycling. Additionally, it is unknown if the current conditions will eventually create a tipping point in the peatland that will promote accelerated ecological changes through the loss or introduction of vegetation species.

\subsection{Acknowledgements}

The authors gratefully acknowledge Tamara Baker, Arielle Garrett, Chris Johnson, and Laura Kangus for help with field and lab work. This research was supported by the U.S. Department of Energy's Office of Science (BER) through the Midwestern Regional Center of the National Institute for Climatic Change Research at Michigan Technological University. Additional support was provided by the Ecosystem Science Center at Michigan Technological University. The project would not have been possible without the cooperation of the SNWR providing access to the site. 


\section{8. $\quad$ Literature cited}

Andrus, R. E., D. J. Wagner, and J. E. Titus. 1983. Vertical zonation of Sphagnum mosses along hummock-hollow gradients. Canadian Journal of Botany 61:31283139.

Ballantyne, D. M. 2010. The Effects of Long-term Water Table Manipulations on Carbon Cycling in a Great Lakes Peatland. Michigan Technological University.

Bardgett, R. D., C. Freeman, and N. J. Ostle. 2008. Microbial contributions to climate change through carbon cycle feedbacks. The ISME Journal 2:805-814.

Bond-Lamberty, B., C. Wang, and S. Gower. 2002. Aboveground and belowground biomass and sapwood area allometric equations for six boreal tree species of northern Manitoba. Canadian Journal of Forest Research 32:1441-1450.

Bond-Lamberty, B., C. Wang, and S. T. Gower. 2004. A global relationship between the heterotrophic and autotrophic components of soil respiration? Global Change Biology 10:1756-1766.

Breeuwer, A., B. J. M. Robroek, J. Limpens, M. M. P. D. Heijmans, M. G. C. Schouten, and F. Berendse. 2009. Decreased summer water table depth affects peatland vegetation. Basic and Applied Ecology 10:330-339.

Bubier, J. L. B. J. L., T. R. M. T. R. Moore, and G. C. G. Crosby. 2006. Fine-scale vegetation distribution in a cool temperate peatland. Botany 84:910-923.

Churchill, A. 2011. Presented to the Faculty Of the University of Alaska Fairbanks.

Clymo, R. 1970. The growth of Sphagnum: methods of measurement. The Journal of Ecology:13-49.

Crow, S. E. and R. K. Wieder. 2005. Sources of CO2 emission from a northern peatland: root respiration, exudation, and decomposition. Ecology 86:1825-1834.

Crum, H. 1992. A focus on peatlands and peat mosses. University of Michigan Press/Regional.

Crum, H. A. and L. E. Anderson. 1981. Mosses of Eastern North America. New York: Columbia University Press.

Dorrepaal, E., R. Aerts, J. H. C. Cornelissen, T. V. Callaghan, and R. S. P. Van Logtestijn. 2003. Summer warming and increased winter snow cover affect Sphagnum fuscum growth, structure and production in a sub-arctic bog. Global Change Biology 10:93-104. 
Dorrepaal, E., S. Toet, R. S. P. Van Logtestijn, E. Swart, M. J. Van De Weg, T. V. Callaghan, and R. Aerts. 2009. Carbon respiration from subsurface peat accelerated by climate warming in the subarctic. Nature 460:616-619.

Fahey, T., G. Tierney, R. Fitzhugh, G. Wilson, and T. Siccama. 2005. Soil respiration and soil carbon balance in a northern hardwood forest ecosystem. Canadian Journal of Forest Research 35:244-253.

Fahey, T. J. and A. K. Knapp. 2007. Principles and standards for measuring primary production. Oxford University Press, USA.

Flannigan, M., B. Stocks, M. Turetsky, and M. Wotton. 2008. Impacts of climate change on fire activity and fire management in the circumboreal forest. Global Change Biology 15:549-560.

Frolking, S., N. Roulet, E. Tuittila, J. Bubier, A. Quillet, J. Talbot, and P. Richard. 2010. A new model of Holocene peatland net primary production, decomposition, water balance, and peat accumulation. Earth System Dynamics 1:1-21.

Gerdol, R., A. Petraglia, L. Bragazza, P. Iacumin, and L. Brancaleoni. 2007. Nitrogen deposition interacts with climate in affecting production and decomposition rates in Sphagnum mosses. Global Change Biology 13:1810-1821.

Gorham, E. 1957. The development of peatlands. Quarterly Review of Biology:145-166.

Gorham, E. 1991. Northern peatlands: role in the carbon cycle and probable responses to climatic warming. Ecological applications 1:182-195.

Harden, J., J. Munster, K. Manies, M. Mack, and J. Bubier. 2009. Changes in species, areal cover, and production of moss across a fire chronosequence in Interior Alaska.

Heijmans, M. M. P. D., H. Klees, and F. Berendse. 2002. Competition between Sphagnum magellanicum and Eriophorum angustifolium as affected by raised CO2 and increased N deposition. Oikos 97:415-425.

Heinselman, M. 1965. String bogs and other patterned organic terrain near Seney, Upper Michigan. Ecology:185-188.

Ise, T., A. L. Dunn, S. C. Wofsy, and P. R. Moorcroft. 2008. High sensitivity of peat decomposition to climate change through water-table feedback. Nature Geoscience 1:763-766. 
Jacquemart, A. L. 1997. Vaccinium oxycoccos L.(Oxycoccus palustris Pers.) and Vaccinium microcarpum (Turcz. ex Rupr.) Schmalh.(Oxycoccus microcarpus Turcz. ex Rupr.). Journal of Ecology:381-396.

Jukaine, J. Laine, H. Vasander, and R. Laiho. 1995. Long-term effects of water level drawdown on the vegetation of drained pine mires in southern Finland. Journal of Applied Ecology:785-802.

Kelker, D. and J. Chanton. 1997. The effect of clipping on methane emissions from Carex. Biogeochemistry 39:37-44.

Keuper, F., E. Dorrepaal, P. M. Van Bodegom, R. Aerts, R. S. P. Van Logtestijn, T. V. Callaghan, and J. H. C. Cornelissen. 2011. A Race for Space? How Sphagnum fuscum stabilizes vegetation composition during long-term climate manipulations. Global Change Biology 17:2162-2171.

Knicker, H. 2004. Stabilization of N-compounds in soil and organic-matter-rich sediments—what is the difference? Marine Chemistry 92:167-195.

Kowalski, K. P. and D. A. Wilcox. 2003. Differences in sedge fen vegetation upstream and downstream from a managed impoundment. The American midland naturalist 150:199-220.

Krist, F. J. and D. P. Lusch. 2004. Glacial history of Michigan, USA: A regional perspective. Developments in Quaternary Sciences 2:111-117.

Kuhry, P. and J. Turunen. 2006. The postglacial development of boreal and subarctic peatlands. Boreal Peatland Ecosystems:25-46.

Lafleur, P. M., R. A. Hember, S. W. Admiral, and N. T. Roulet. 2005. Annual and seasonal variability in evapotranspiration and water table at a shrub-covered bog in southern Ontario, Canada. Hydrological Processes 19:3533-3550.

Laiho, R., J. Laine, C. C. Trettin, and L. Finér. 2004. Scots pine litter decomposition along drainage succession and soil nutrient gradients in peatland forests, and the effects of inter-annual weather variation. Soil Biology and Biochemistry 36:10951109.

Laiho, R., K. Minkkinen, J. Anttila, P. Vávřová, and T. Penttilä. 2008. Dynamics of litterfall and decomposition in peatland forests: Towards reliable carbon balance estimation? Wastewater treatment, plant dynamics and management in constructed and natural wetlands:53-64. 
Laiho, R., H. Vasander, T. Penttilä, and J. Laine. 2003. Dynamics of plant-mediated organic matter and nutrient cycling following water-level drawdown in boreal peatlands. Global Biogeochemical Cycles 17:1053.

Laine, A. M., J. Bubier, T. Riutta, M. B. Nilsson, T. R. Moore, H. Vasander, and E. S. Tuittila. 2011. Abundance and composition of plant biomass as potential controls for mire net ecosytem CO2 exchange. Botany 90:63-74.

Laine, J. 2009. The intricate beauty of Sphagnum mosses: a Finnish guide to identification.

Limpens, J., F. Berendse, C. Blodau, J. Canadell, C. Freeman, J. Holden, N. Roulet, H. Rydin, and G. Schaepman-Strub. 2008. Peatlands and the carbon cycle: from local processes to global implications? a synthesis. Biogeosciences Discussions 5:13791419.

McCune, B., J. B. Grace, and D. L. Urban. 2002. Analysis of ecological communities. MjM Software Design Gleneden Beach, Oregon.

McGuire, A. D., L. G. Anderson, T. R. Christensen, S. Dallimore, L. Guo, D. J. Hayes, M. Heimann, T. D. Lorenson, R. W. Macdonald, and N. Roulet. 2009. Sensitivity of the carbon cycle in the Arctic to climate change. Ecological Monographs 79:523-555.

Miller, C. A. 2011. The Effect of Long-Term Drainage on Plant Community Composition, Biomass, and Productivity in Boreal Continental Peatlands.

Minkkinen, K., R. Korhonen, I. Savolainen, and J. Laine. 2002. Carbon balance and radiative forcing of Finnish peatlands 1900-2100-the impact of forestry drainage. Global Change Biology 8:785-799.

Mitchell, E. A. D., A. Buttler, P. Grosvernier, H. Rydin, C. Albinsson, A. Greenup, M. Heijmans, M. Hoosbeek, and T. Saarinen. 2001. Relationships among testate amoebae (Protozoa), vegetation and water chemistry in five Sphagnum-dominated peatlands in Europe. New Phytologist 145:95-106.

Moore, T. R., J. L. Bubier, S. E. Frolking, P. M. Lafleur, and N. T. Roulet. 2002. Plant biomass and production and $\mathrm{CO} 2$ exchange in an ombrotrophic bog. Journal of Ecology 90:25-36.

Mulligan, R. C. and L. D. Gignac. 2001. Bryophyte community structure in a boreal poor fen: reciprocal transplants. Canadian Journal of Botany 79:404-411.

Murphy, M., R. Laiho, and T. R. Moore. 2009. Effects of water table drawdown on root production and aboveground biomass in a boreal bog. Ecosystems 12:1268-1282. 
Murphy, M. T. 2009. Getting to the root of the matter: Variations in vascular root biomass and production in peatlands and responses to global change.

Nagel, L. M., R. G. Corace, and A. J. Storer. 2008. An Experimental Approach to Testing the Efficacy of Management Treatments for Glossy Buckthorn at Seney National Wildlife Refuge, Upper Michigan. Ecological Restoration 26:136-142.

Oechel, W. C., S. J. Hastings, G. Vourlitis, M. Jenkins, G. Riechers, and N. Grulke. 1993. Recent change of Arctic tundra ecosystems from a net carbon dioxide sink to a source.

Oksanen, L. 2003. Logic of experiments in ecology: is pseudoreplication a pseudoissue? Oikos 94:27-38.

Pellerin, S. and C. Lavoie. 2003. Recent expansion of jack pine in peatlands of southeastern Québec: a paleoecological study. Ecoscience 10:247-257.

Robroek, B. J. M., M. G. C. Schouten, J. Limpens, F. Berendse, and H. Poorter. 2008. Interactive effects of water table and precipitation on net $\mathrm{CO} 2$ assimilation of three co-occurring Sphagnum mosses differing in distribution above the water table. Global Change Biology 15:680-691.

Roulet, N., T. Moore, J. Bubier, and P. Lafleur. 2002. Northern fens: methane flux and climatic change. Tellus B 44:100-105.

Roulet, N. T., R. Ash, W. L. Quinton, and T. Moore. 1993. Methane flux from drained northern peatlands: effect of a persistent water table lowering on flux.

Rydin, H., J. Jeglum, and J. Jeglum. 2006. The biology of peatlands. Oxford university press.

Shaw, A. J., C. J. Cox, S. B. Boles, and S. B. Hoot. 2005. Phylogeny, species delimitation, and recombination in Sphagnum section Acutifolia. Systematic Botany 30:16-33.

Strack, M., J. Waddington, L. Rochefort, and E. S. Tuittila. 2006. Response of vegetation and net ecosystem carbon dioxide exchange at different peatland microforms following water table drawdown. Journal of Geophysical Research 111:G02006.

Summerfield, R. 1972. Biological Inertia--An Example. The Journal of Ecology:793-798.

Sundström, E., T. Magnusson, and B. Hånell. 2000. Nutrient conditions in drained peatlands along a north-south climatic gradient in Sweden. Forest ecology and management 126:149-161. 
Talbot, J., P. Richard, N. Roulet, and R. Booth. 2009. Assessing long-term hydrological and ecological responses to drainage in a raised bog using paleoecology and a hydrosequence. Journal of Vegetation Science 21:143-156.

Thormann, M. N. and S. E. Bayley. 1997. Aboveground plant production and nutrient content of the vegetation in six peatlands in Alberta, Canada. Plant Ecology 131:1-16.

Turetsky, M., W. Donahue, and B. Benscoter. 2011. Experimental drying intensifies burning and carbon losses in a northern peatland. Nature Communications 2:514.

Vitt, D. H. 2006. Functional characteristics and indicators of boreal peatlands. Boreal Peatland Ecosystems:9-24.

Voss, E. 1996. Michigan Flora Parts I-III. Cranbrook Institute of Science. Ann Arbor, Michigan, USA.

Wells, E. and B. Williams. 1996. Effects of drainage, tilling and PK-fertilization on bulk density, total N, P, K, Ca and Fe and net N-mineralization in two peatland forestry sites in Newfoundland, Canada. Forest ecology and management 84:97-108.

Weltzin, J. F., S. D. Bridgham, J. Pastor, J. Chen, and C. Harth. 2003. Potential effects of warming and drying on peatland plant community composition. Global Change Biology 9:141-151.

Weltzin, J. F., C. Harth, S. D. Bridgham, J. Pastor, and M. Vonderharr. 2001. Production and microtopography of bog bryophytes: response to warming and water-table manipulations. Oecologia 128:557-565.

Wieder, K. R., D. H. Vitt, M. Burke-ScolL, K. D. Scott, M. House, and M. A. Vile. 2010. Nitrogen and sulphur deposition and the growth of Sphagnum fuscum in bogs of the Athabasca Oil Sands Region, Alberta. Journal of Limnology 69:161-170.

Wilcox, D. A., M. J. Sweat, M. L. Carlson, and K. P. Kowalski. 2006. A water-budget approach to restoring a sedge fen affected by diking and ditching. Journal of Hydrology 320:501-517.

Yu, Z. 2006. Holocene carbon accumulation of fen peatlands in boreal western Canada: A complex ecosystem response to climate variation and disturbance. Ecosystems 9:1278-1288. 


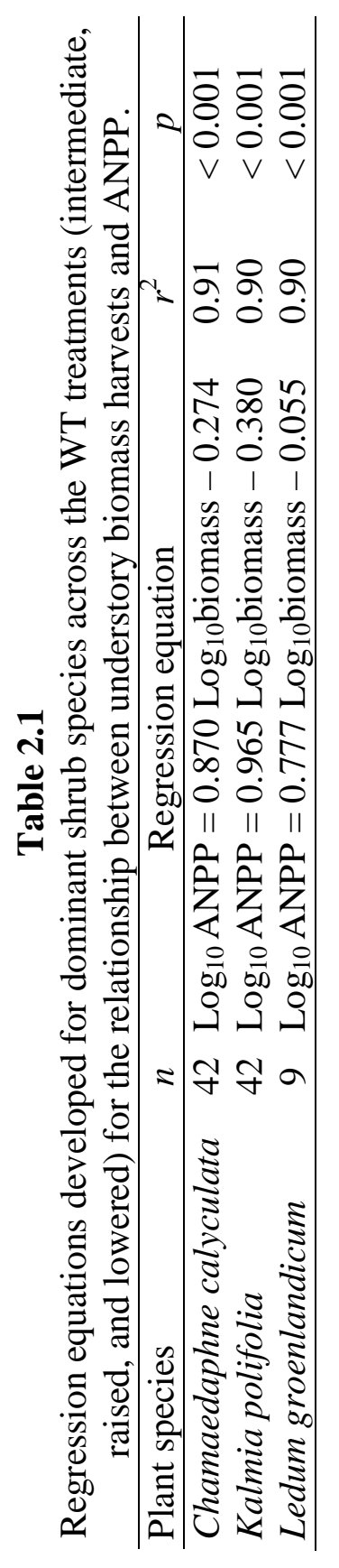




\section{Table 2.2}

Multi-response permutation procedure (MRPP) results testing differences in understory vegetation distribution on microforms (hummocks and lawns) across the WT treatments (intermediate, raised, and lowered). The p-value tests for group differences, the A-value describes within-group homogeneity, and T-value describes the separation between groups.

\section{Microforms combined}

Intermediate vs. Raised

\begin{tabular}{ccc}
$\mathrm{T}$ & $\mathrm{A}$ & $\mathrm{p}$ \\
\hline & & \\
-1.41 & 0.02 & 0.092 \\
-3.48 & 0.04 & 0.009 \\
-5.98 & 0.07 & $<0.001$
\end{tabular}

\section{Hummock}

Intermediate vs. Raised

$-0.60$

0.01

0.231

Intermediate vs. Lowered

$-1.32$

0.03

0.102

Raised vs. Lowered

$-2.69$

0.06

0.018

\section{Lawn}

Intermediate vs. Raised $\quad-0.71 \quad 0.02 \quad 0.207$

$\begin{array}{llll}\text { Intermediate vs. Lowered } & -3.85 & 0.09 & 0.003\end{array}$

$\begin{array}{llll}\text { Raised vs. Lowered } & -2.97 & 0.07 & 0.012\end{array}$

\section{Hummock vs. Lawn}

Intermediate

$\begin{array}{lll}-3.21 & 0.09 & 0.011\end{array}$

Raised

$-0.07$

0.002

0.366

Lowered

$-2.81$

0.09

0.019

Note: A more negative $\mathrm{T}$ the stronger the separation between groups. The greater the A-value the greater the similarity of sample units within groups. 


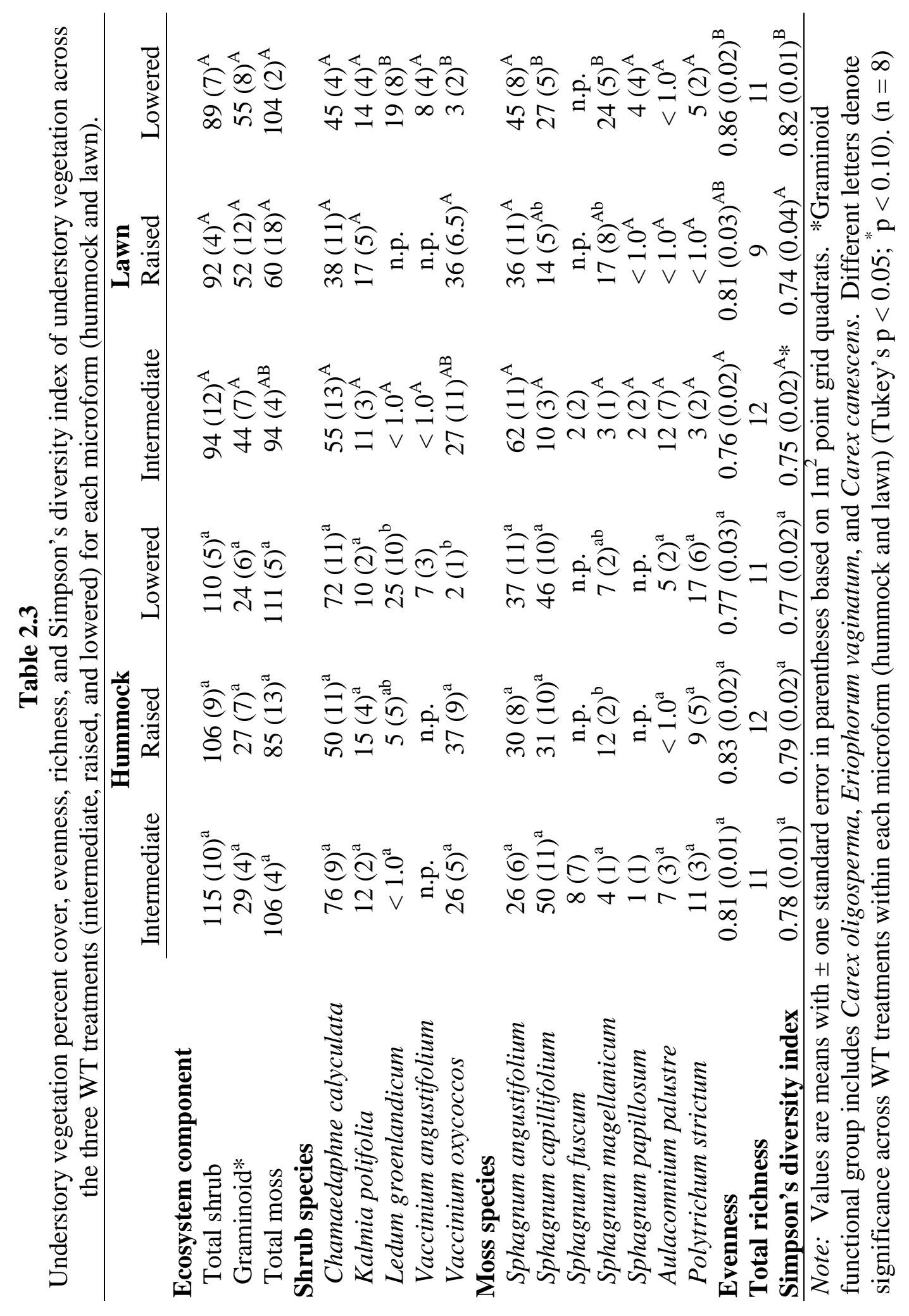


Table 2.4

Understory vegetation NPP ( $\mathrm{g} \mathrm{C} \mathrm{m}^{-2} \mathrm{yr}^{-1}$ ) and biomass $\left(\mathrm{g} \mathrm{C} \mathrm{m}^{-2}\right)$ data combining microforms (hummocks and lawns) across the WT treatments (intermediate, raised, and lowered).

\begin{tabular}{lccc}
\hline & Intermediate $^{\mathrm{a}}$ & Raised & Lowered \\
\cline { 2 - 4 } TNPP & $255(22)^{\mathrm{a}}$ & $227(17)^{\mathrm{a}}$ & $253(18)^{\mathrm{a}}$ \\
ANPP & $159(15)^{\mathrm{a}}$ & $134(12)^{\mathrm{a}}$ & $138(14)^{\mathrm{a}}$ \\
BNPP & $97(14)^{\mathrm{a}}$ & $93(12)^{\mathrm{a}}$ & $116(14)^{\mathrm{a}}$ \\
Total biomass & $565(46)^{\mathrm{a}}$ & $539(47)^{\mathrm{a}}$ & $647(42)^{\mathrm{a}}$ \\
Aboveground vegetation biomass & $186(37)^{\mathrm{a}}$ & $173(40)^{\mathrm{a}}$ & $216(31)^{\mathrm{a}}$ \\
Belowground vascular plant biomass & $379(23)^{\mathrm{ab}}$ & $366(20)^{\mathrm{a}}$ & $432(23)^{\mathrm{b}^{*}}$ \\
\hline
\end{tabular}

Note: Values are means with \pm one standard error in parentheses. Different letters represent significant differences across WT treatments (Tukey’s $\mathrm{p}<0.05$; ${ }^{*} \mathrm{p}<0.10$ ). $(\mathrm{n}=28)$ 


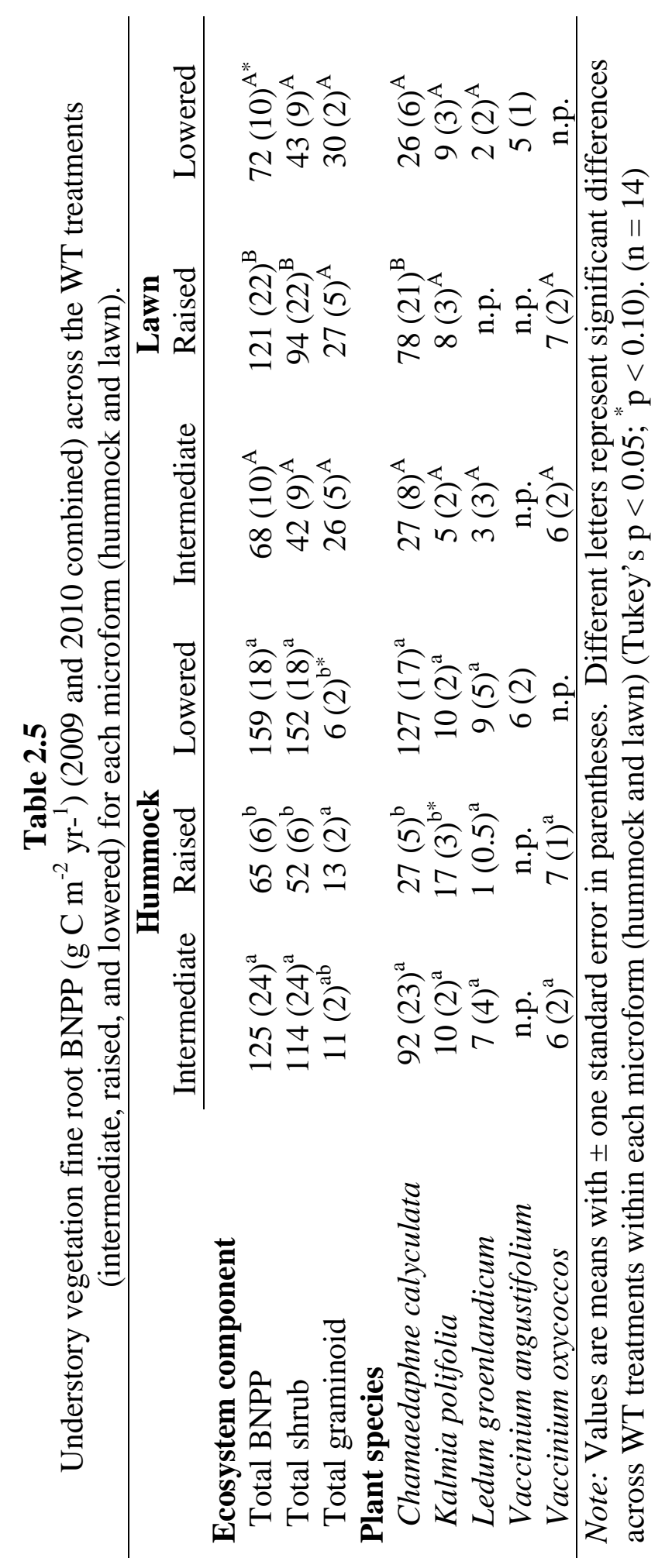




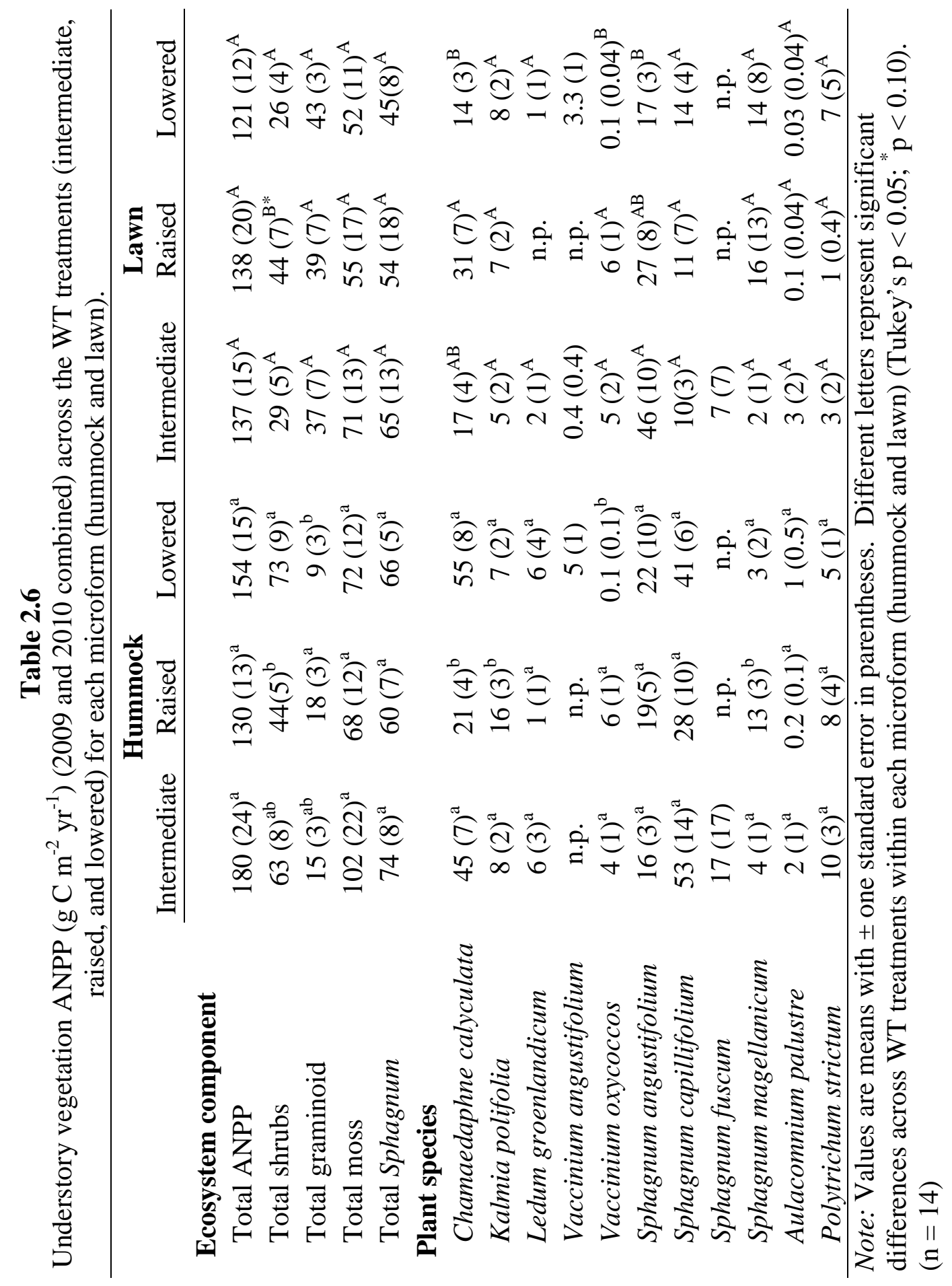




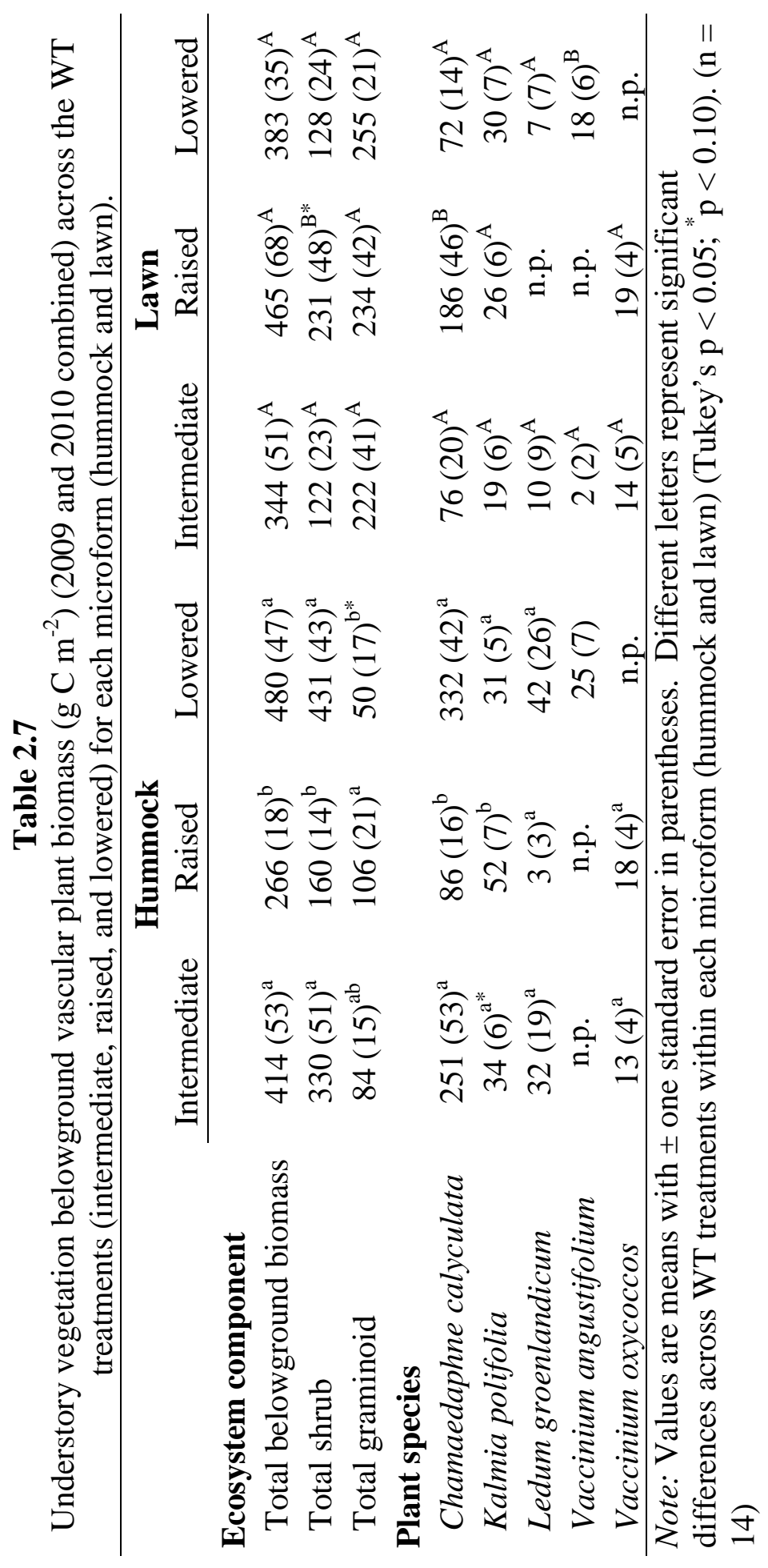




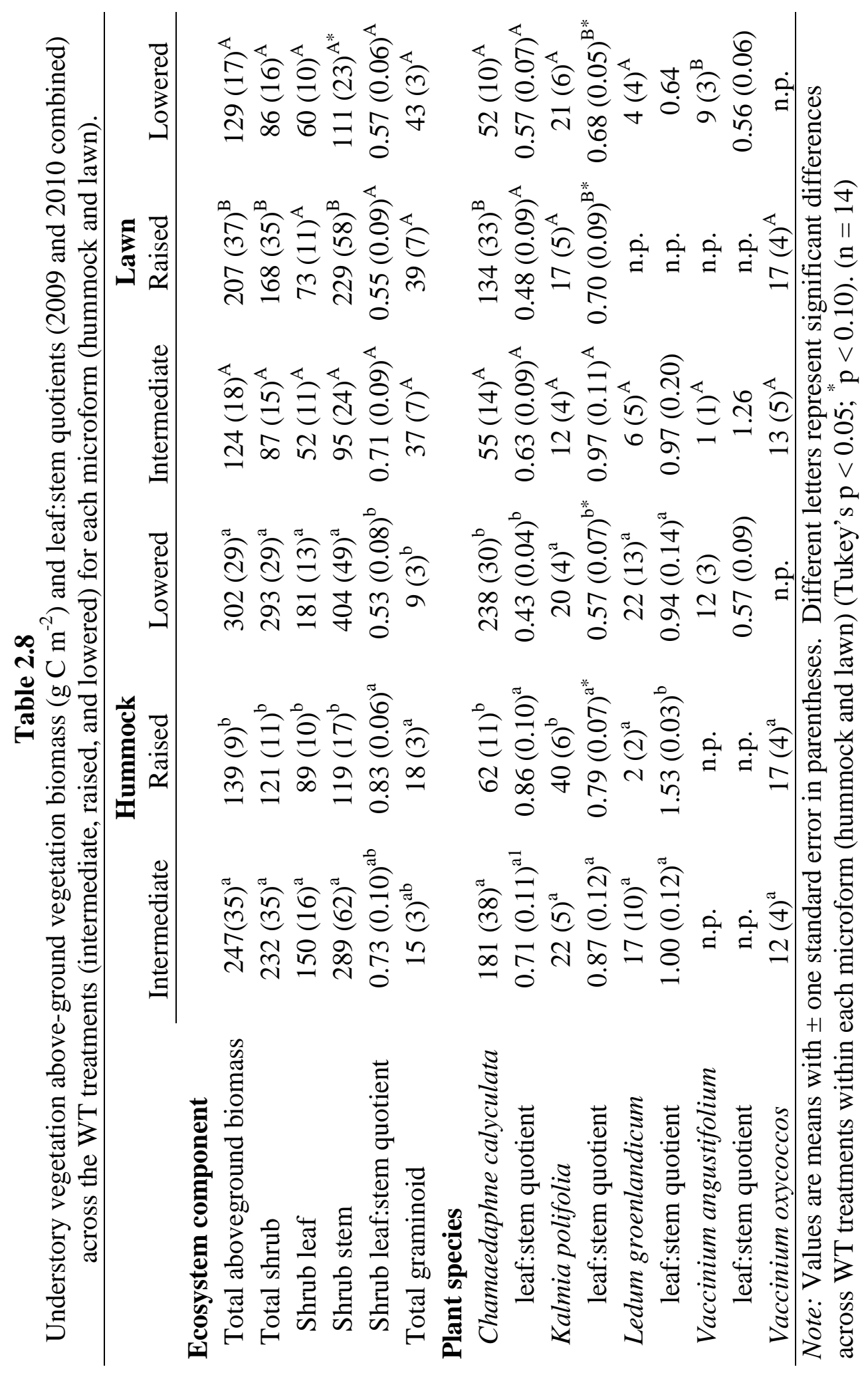




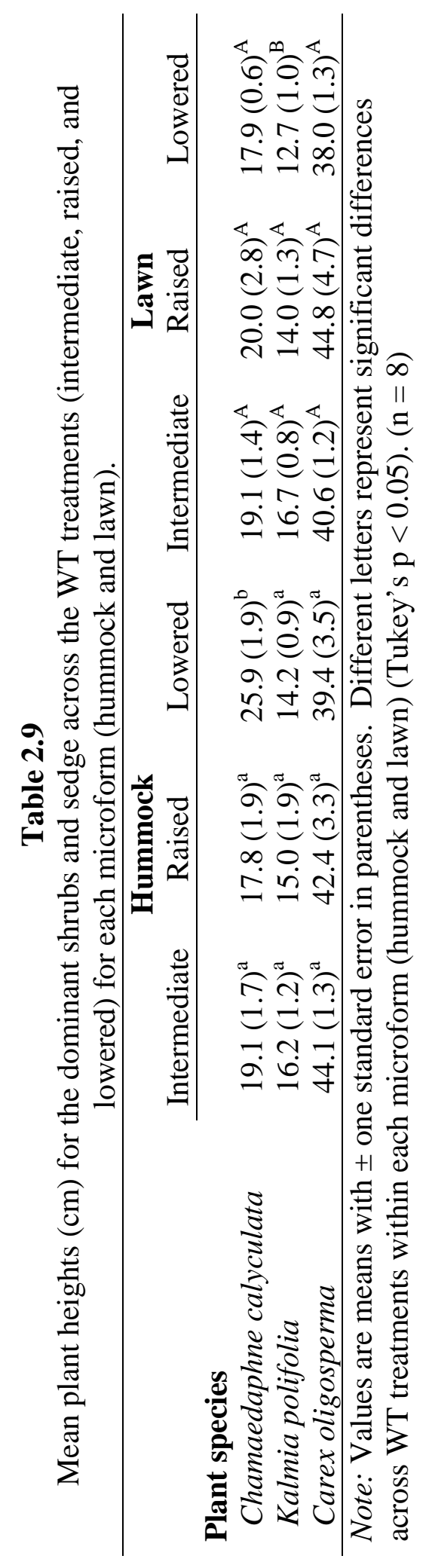


Table 2.10

Tree metrics across the WT treatments (intermediate, raised, and lowered).

\begin{tabular}{lcccccc}
\hline & $\mathrm{n}$ & Age (year) & $\mathrm{DBH}^{\mathrm{a}}(\mathrm{cm})$ & Height $(\mathrm{m})$ & $\mathrm{SBA}^{\mathrm{b}}\left(\mathrm{m}^{2}\right)$ & $\mathrm{g} \mathrm{C} \mathrm{m}^{-2}$ \\
\cline { 2 - 7 } Black spruce & & & & & & \\
$\quad$ Intermediate & 74 & $41.1(2.0)$ & $13.5(0.6)$ & $5.8(0.3)$ & 1.22 & 3061 \\
$\quad$ Raised & 4 & $29.8(3.9)$ & $14.0(0.6)$ & $6.9(0.4)$ & 0.06 & 148 \\
$\quad$ Lowered & 54 & $28.7(0.7)$ & $13.3(0.6)$ & $6.3(0.3)$ & 0.86 & 1925 \\
Tamarack & & & & & & \\
$\quad$ Intermediate & 17 & $50.4(4.7)$ & $17.3(1.0)$ & $6.1(0.5)$ & 0.40 & 68 \\
$\quad$ Raised & 5 & $29.8(1.4)$ & $17.8(1.2)$ & $6.8(0.4)$ & 0.13 & 22 \\
$\quad$ Lowered & 9 & $32.7(1.6)$ & $13.0(1.3)$ & $5.4(0.5)$ & 0.13 & 31 \\
Jack pine & & & & & & \\
$\quad$ Lowered & 8 & $36.3(4.9)$ & $16.1(2.3)$ & $5.4(0.6)$ & 0.21 & 541 \\
\hline
\end{tabular}

Note: Values are means with \pm one standard error in parentheses. ${ }^{\mathrm{a}} \mathrm{DBH}=$ diameter at breast height. ${ }^{\mathrm{b}} \mathrm{SBA}=$ stem basal area. 


\subsection{Figures}

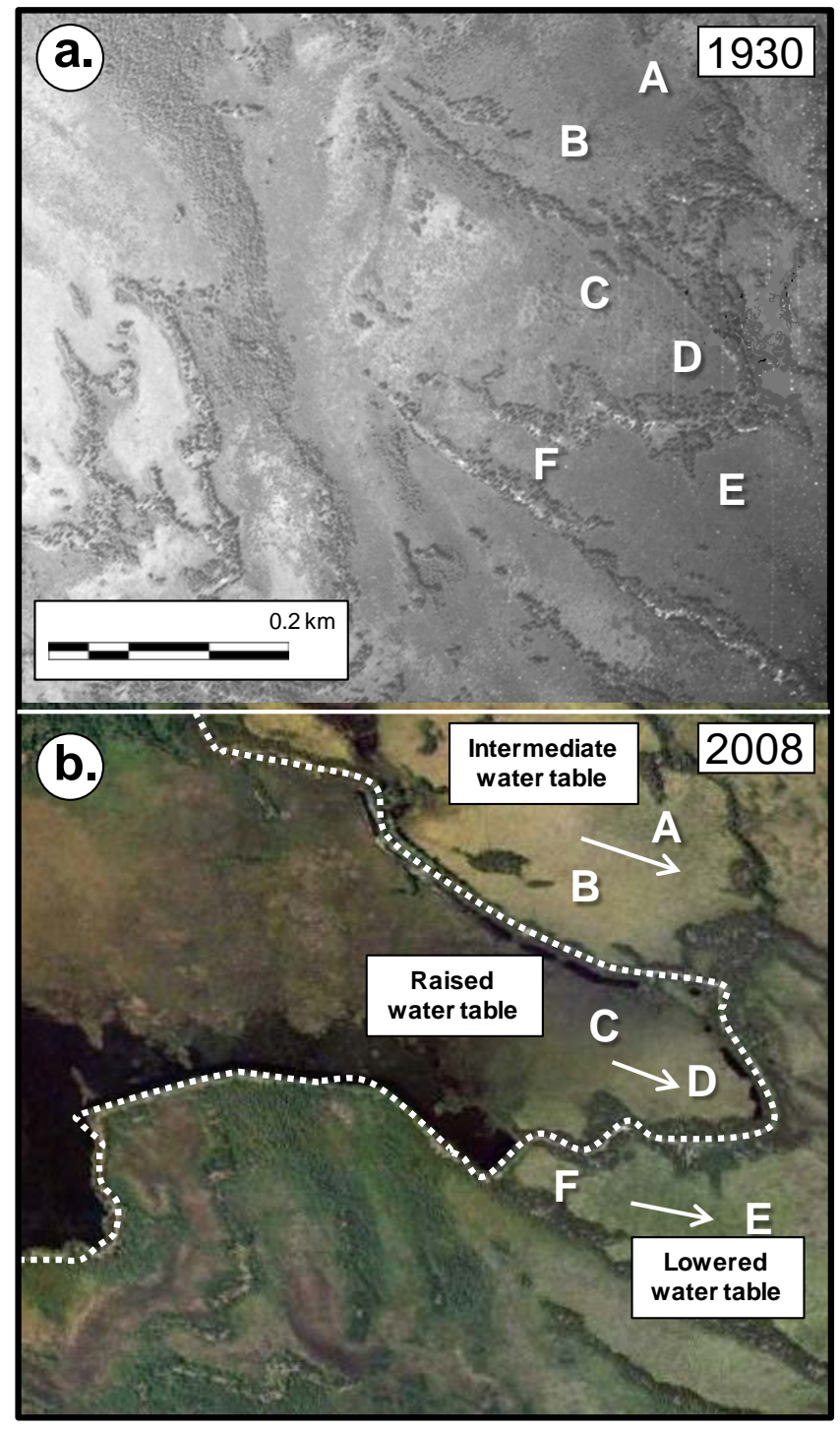

Figure 2.1 (a). Arial photograph from 1930 before the earthen levee was constructed. (b). Arial photograph from 2008 illustrating location of the six research sites positioned across the three water table treatments. Surface water impounding behind the levee has elevated the water table at sites $\mathrm{C}$ and $\mathrm{D}$ and lowered the water table at sites $\mathrm{E}$ and $\mathrm{F}$. Arrows indicate approximate water flow paths within each treatment based on horizontal hydraulic gradients between sites. Image in panel (b): Google Earth 2012. Seney, Michigan, 46¹1'15.22" N 8600'54.93" W, elevation 683ft., Accessed 8 October 2012. 

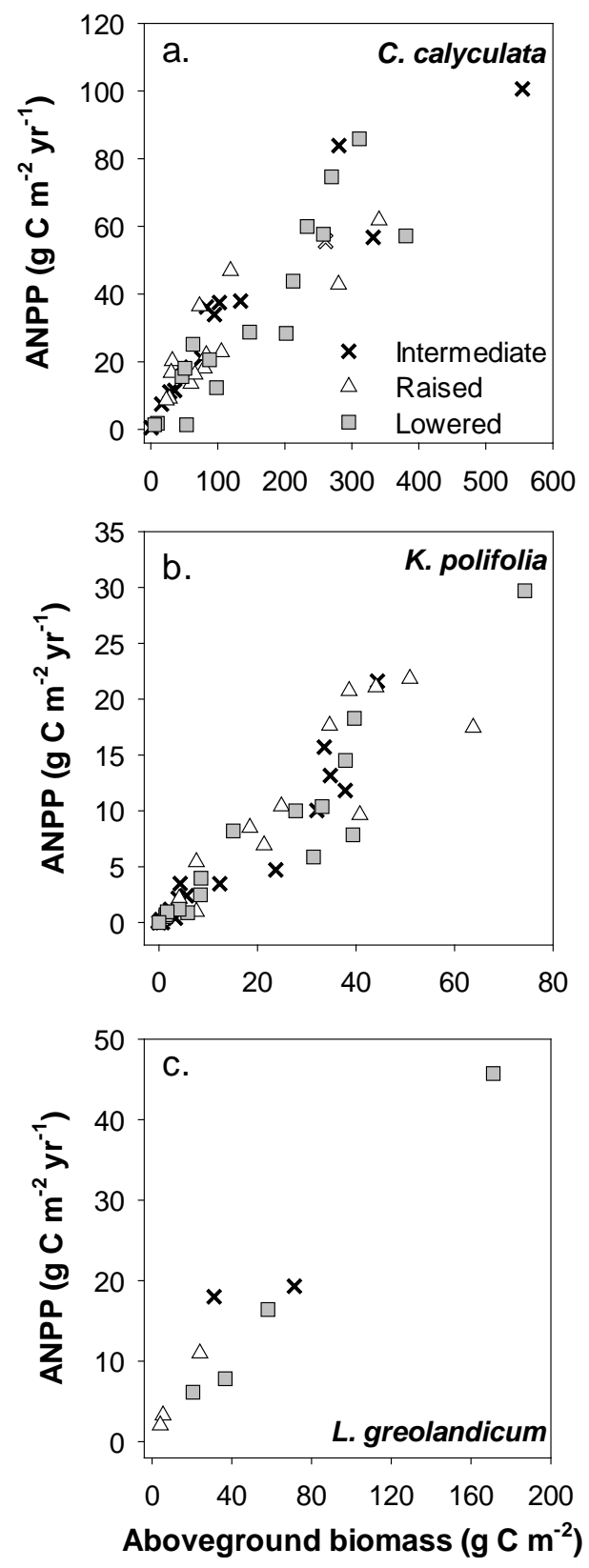

Figure 2.2 Relationships between aboveground understory vegetation biomass and ANPP for the dominant shrubs (a). Chamaedaphne calyculata, (b). Kalmia polifolia, and (c). Ledum groenlandicum. There was no significant difference of ANPP versus biomass as a function of WT treatment for $C$. calyculata (ANCOVA; $F=0.36, \mathrm{p}=0.70$ ) and $K$. polifolia, (ANCOVA; $\mathrm{F}=1.64, \mathrm{p}=0.21$ ). 


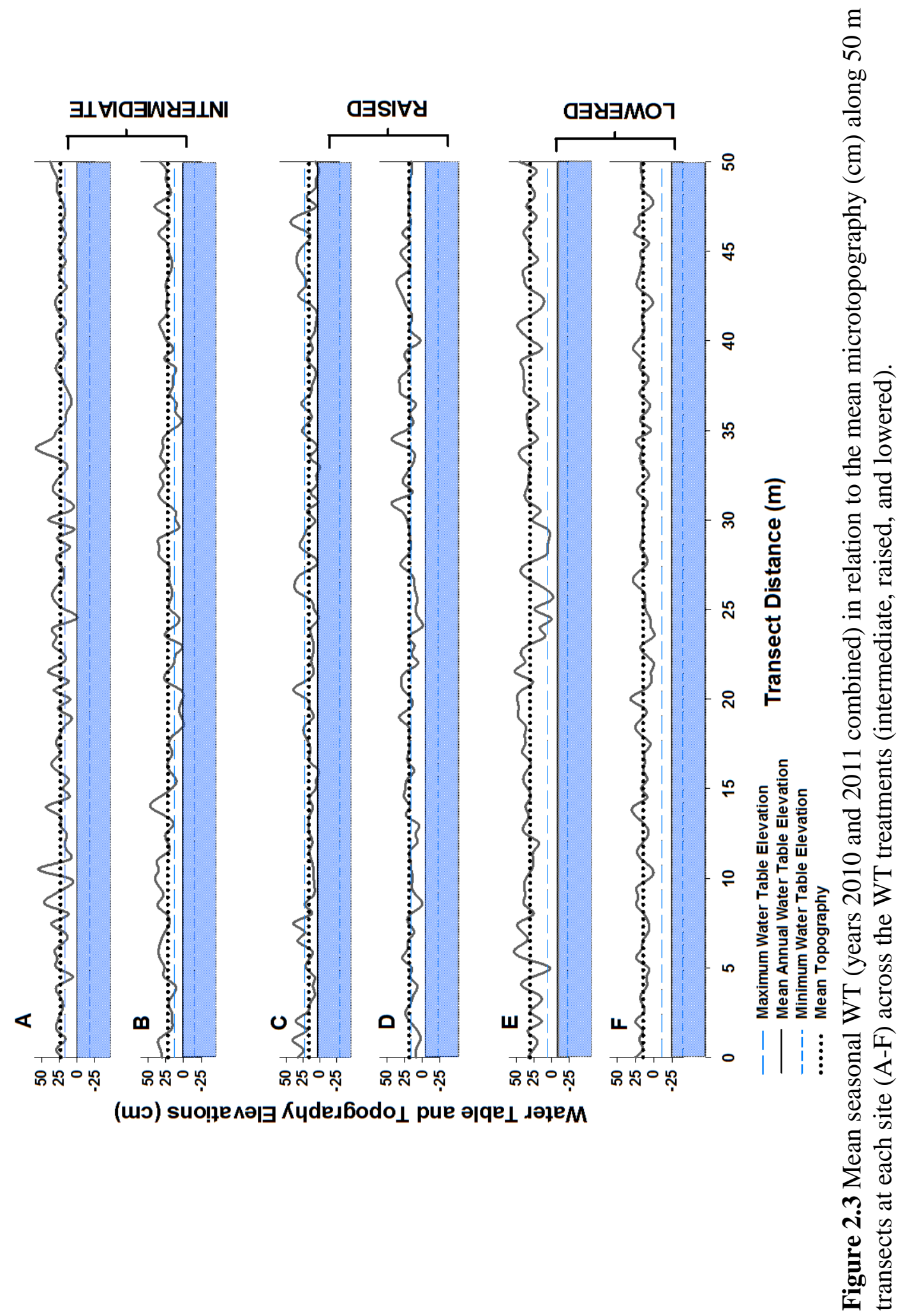




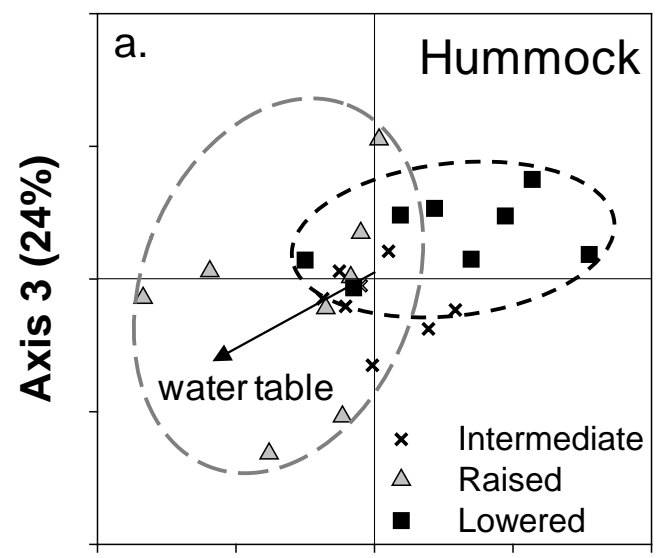

Axis 1 (48\%)

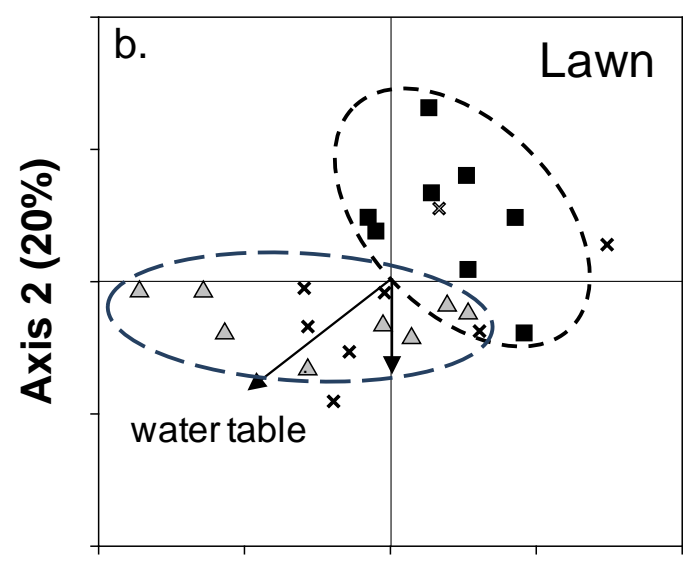

Axis $1(53 \%)$

Figure 2.4 NMS ordination of understory vegetation community structure based on percent cover across the WT treatments (intermediate, raised, and lowered) for the (a). hummock and (b). lawn microforms. Overlaid joint plot shows WT correlated to ordination axes where line length is proportional to correlation strength. The percent variation explained by each axis is shown in parentheses. 


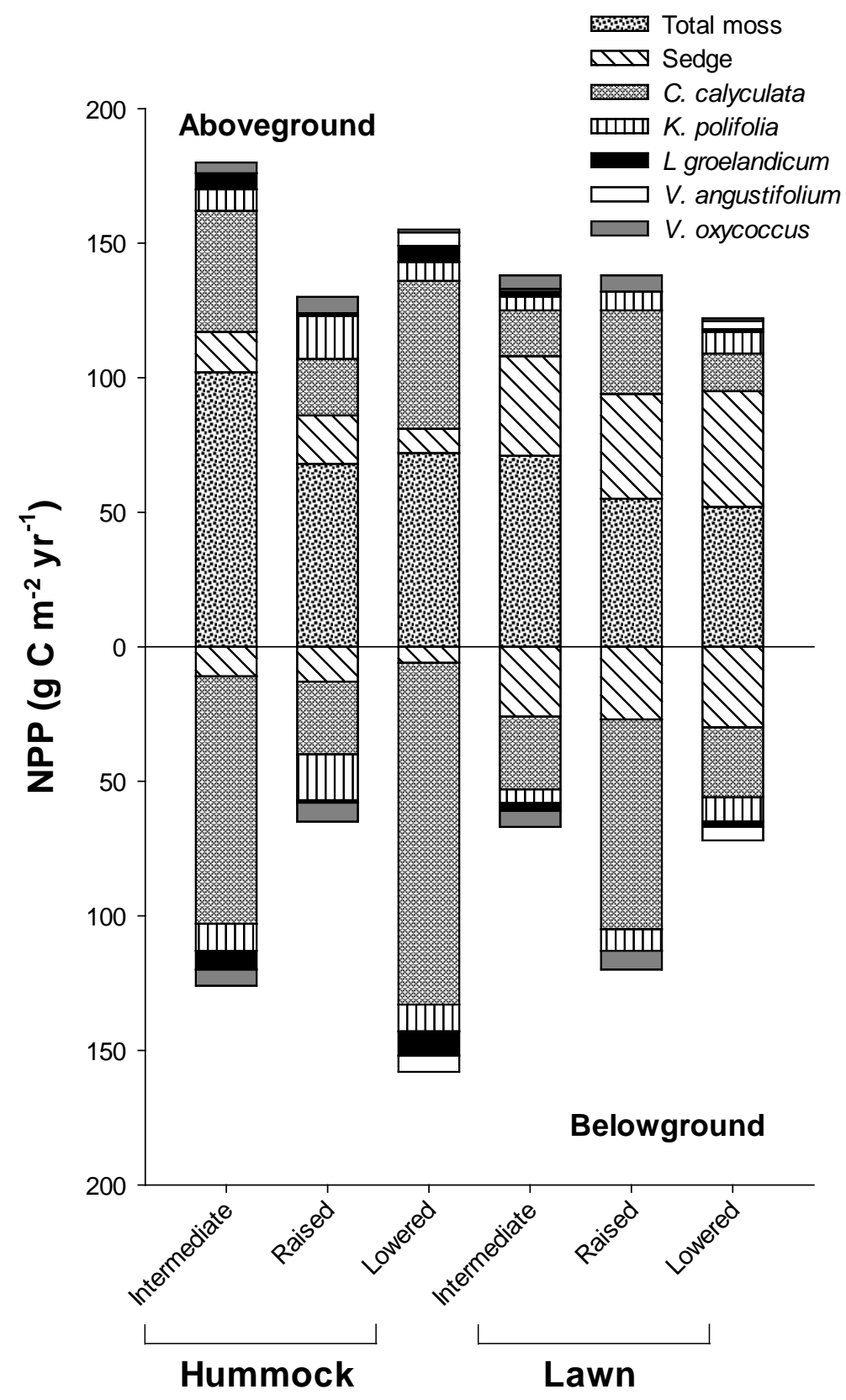

Figure 2.5 Understory vegetation above-and belowground NPP across the WT treatments (intermediate, raised, and lowered) split between microforms (hummocks and lawns) combining sample years 2010 and 2011. $(\mathrm{n}=14)$ 


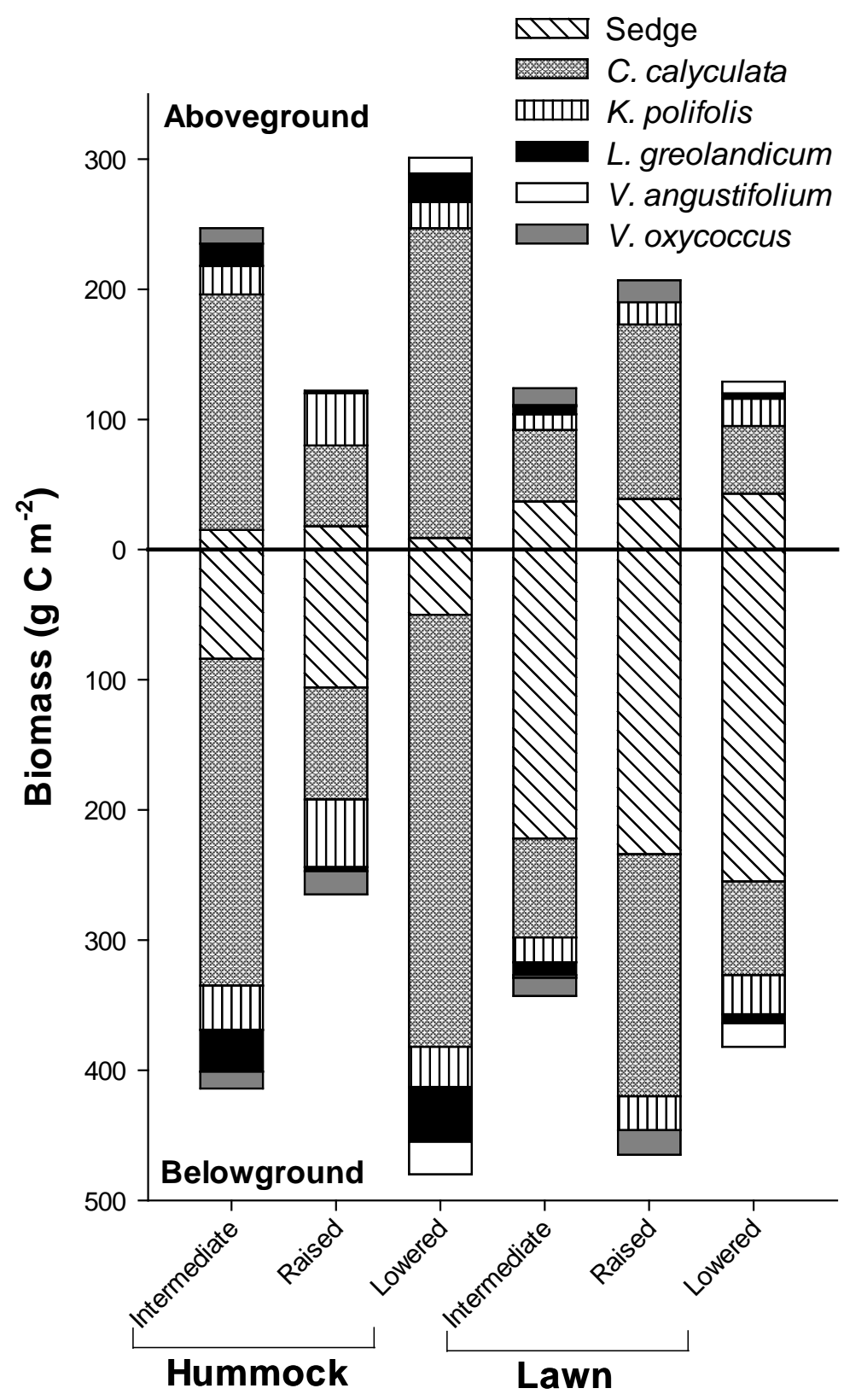

Figure 2.6 Understory vegetation above-and belowground biomass across the WT treatments (intermediate, raised, and lowered) split between microforms (hummocks and lawns) combining sample years 2010 and 2011. $(n=14)$ 


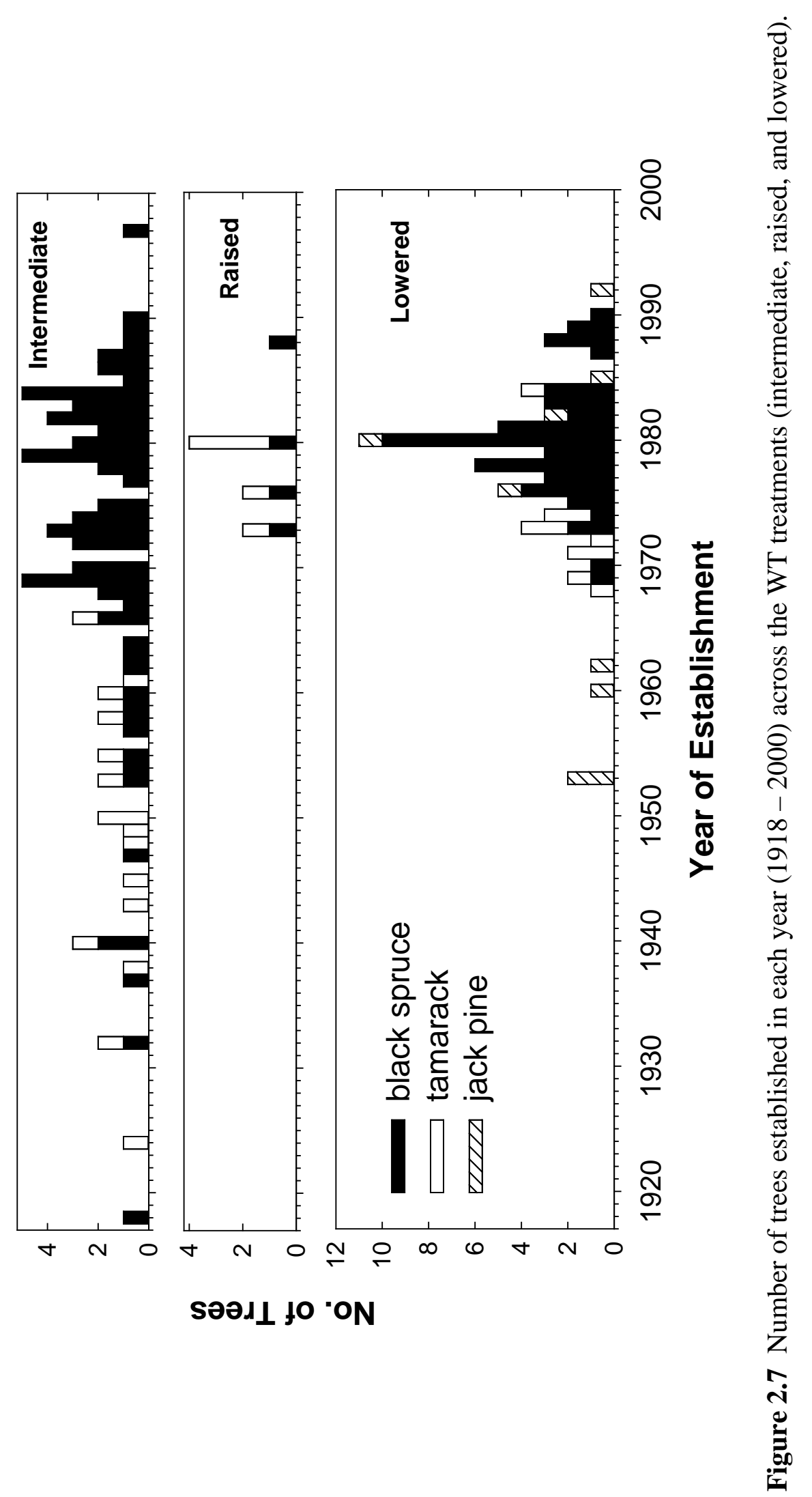




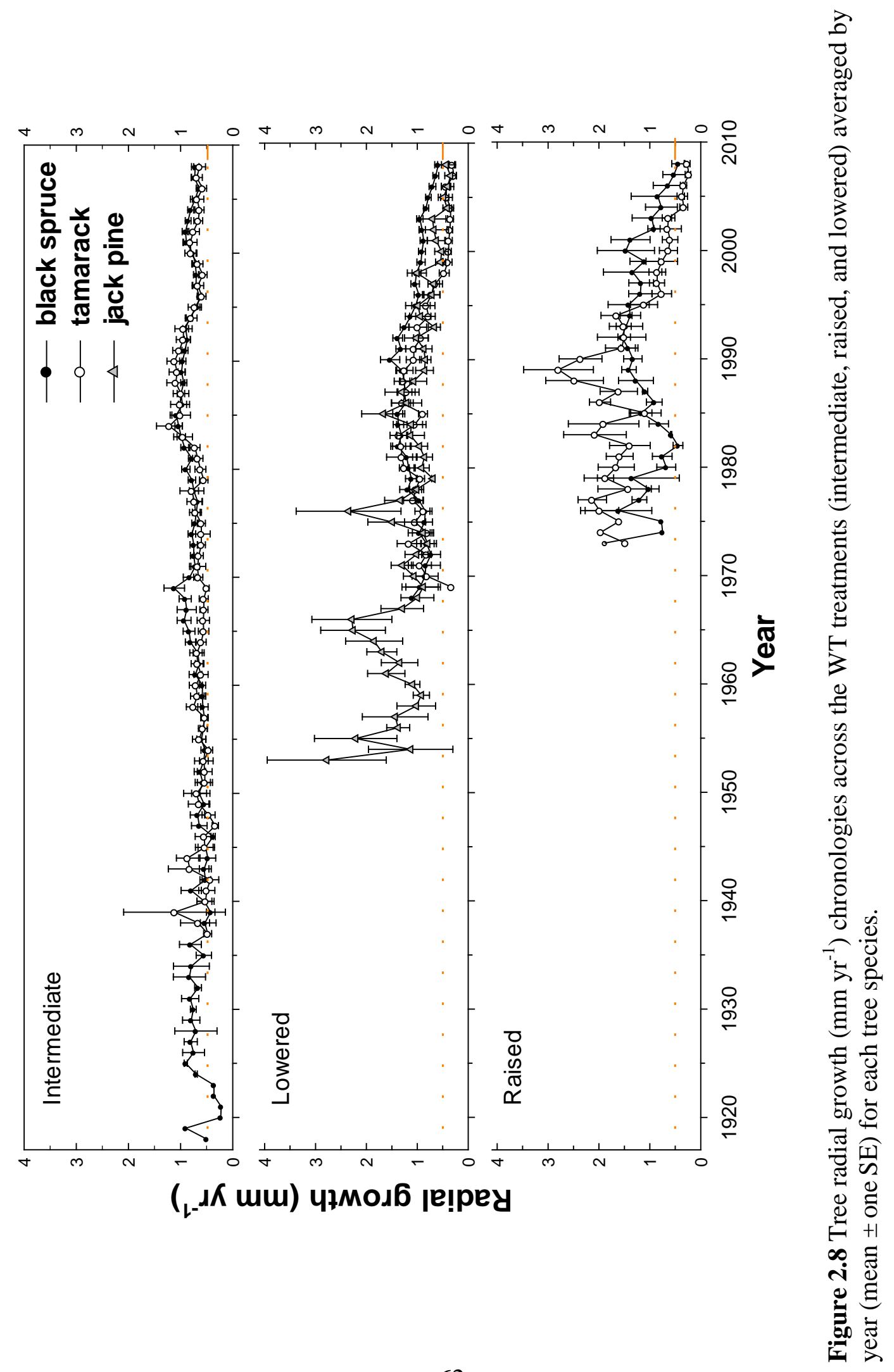



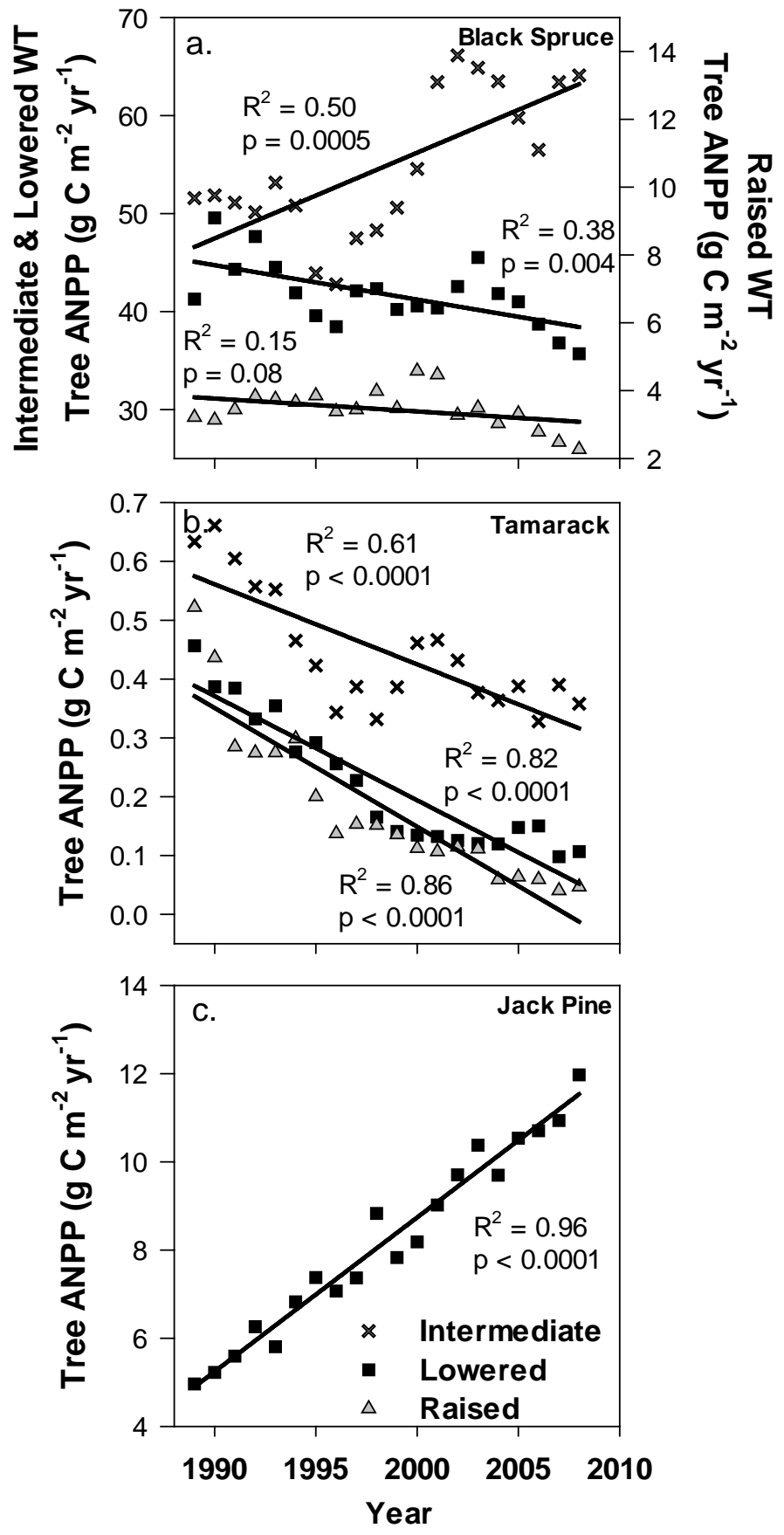

Figure 2.9 Tree annual ANPP ( $\mathrm{g} \mathrm{C} \mathrm{m}^{-2} \mathrm{yr}^{-1}$ ) for (a). black spruce, (b). tamarack, and (c). jack pine across the WT treatments (intermediate, raised, and lowered) over the time period $1990-2010$. 


\section{Chapter 3. The Effect of Long-term Water Table Manipulations on Dissolved Organic Carbon Production and Quality in a Poor Fen}

\section{Peatland $^{1}$}

\subsection{Abstract}

Dissolved organic carbon (DOC) production, consumption, quality, and transport were effected by 80 years of hydrological alterations in a poor fen peatland in northern Michigan. The construction of an earthen levee resulted in areas of raised and lowered water table (WT) position relative to an intermediate WT site. We quantified pore water chemical and physical characteristics in these manipulated areas as well as an intermediate site in which hydrology was unaltered by diking. After 80 years of altered hydrology, the lowered WT treatment had increased peat aeration and larger seasonal WT vertical fluctuations resulting in elevated decomposition and subsidence with subsequent increases in bulk density, vertical hydraulic gradient (VHG), and a decreased hydraulic conductivity $\left(\mathrm{K}_{\mathrm{sat}}\right)$ resulting in a greater pore water residence time relative to the intermediate site. The raised WT treatment also had a decreased $\mathrm{K}_{\text {sat }}$ relative to the intermediate site combined with numerous seasonal upwelling events that contributed to a longer residence time. These changes are likely associated with the elevated DOC concentrations measured at both the lowered and raised WT treatments. Moreover, the lowered WT treatment DOC was more aromatic, had a lower molecular weight, and contained elevated concentrations of phenolics compared to the intermediate site. The raised WT treatment DOC was less aromatic, more humified, and also had a greater phenolic content than the intermediate site. Furthermore, DOC in the raised WT treatment had the most labile carbon source. Based on our findings, long-term changes in peatland WT levels can have significant effects on pore water DOC concentrations and quality; however, WT position alone was not a good predictor of DOC concentrations, though impoundment is likely to result in more labile DOC whereas drainage increases DOC aromaticity.

\footnotetext{
${ }^{1}$ The material contained in this chapter is planned for submission in the near future to the journal Ecohydrology by Hribljan, J.A., Kane E.S., Turetsky, M.R., and Chimner R.A.
} 


\subsection{Introduction}

Climate change is predicted to influence dissolved organic carbon (DOC) cycling in northern peatlands (Pastor et al. 2003; Freeman et al. 2004) and elevated DOC concentrations are currently observed in many peatland catchments (Freeman et al. 2001; Worrall et al. 2003; Evans et al. 2005; Frey and Smith 2005; Billett et al. 2010; Yallop et al. 2010). Peatland DOC export (5-40 $\mathrm{g} \mathrm{m}^{-2}$ year $^{-1}$; Moore 1998) represents an important component of the annual carbon (C) balance of a peatland (Frasir et al. 2001; Billett et al. 2004) and is a primary factor determining if a peatland has a net positive or negative $C$ accumulation rate (Roulet 2007). Globally, peatlands contribute 20\% of terrestrial derived DOC to the oceans (Fenner et al. 2007) and Gorham (1991) estimated that the long-term $\mathrm{C}$ accumulation rate of a northern peatland is comparable to the annual export of DOC. Since northern peatlands store up to $25 \%$ of the global soil C stocks (Roulet et al. 2007) and are expected to experience changes in hydrology during the next century (Schiff et al. 1998; Roulet 2000; Pastor et al. 2003; Clark et al. 2009), it is imperative to understand the long-term effects of climate change on peatland hydrology and DOC dynamics.

DOC is produced from the leaching and decomposition of plant, microbial and soil organic matter (Reddy and DeLaune 2008). Pore water DOC is operationally defined as organic matter smaller than a diameter of $0.45 \mu \mathrm{m}$ (Kalbitz et al. 2000) and composed of a diverse mixture of recalcitrant humic substances and labile compounds including carbohydrates, peptides, amino acids, carboxylic acids and alcohols (Sachse et al. 2005). Temperature (Koehler et al. 2009; Preston et al. 2011), moisture (Kane et al. 2010), peat substrate quality (Laiho et al. 2003; Wickland et al. 2007), and redox status (Moore et al. 2001; Freeman et al. 1993) influence DOC production/consumption and are tightly coupled to water table (WT) position. Evaporative concentration, dilution by increased precipitation, and ground water upwelling are additional hydrological factors influencing

DOC cycling in peatlands (Siegel et al. 1995; Waddington and Roulet 1997; Whitfield et al. 2010). 
Furthermore, DOC concentrations are regulated by water movement through the peat matrix. Peat hydraulic conductivity $\left(\mathrm{K}_{\text {sat }}\right)$ and pore structure are susceptible to changes in WT position (Chow et al. 1992). Peatlands experiencing WT draw-down have enhanced oxidation that accelerates decomposition resulting in primary compression (Price 2003). Peat compaction reduces pore volume and $\mathrm{K}_{\text {sat }}$ that can increase pore water residence time (Beer et al. 2008). Additionally, biogenetic gas bubbles can impede pore water transport by blocking advective water movement in deep anaerobic and surface peat experiencing an elevated WT (Kellner and Waddington 2005). Thus, translocation of DOC through the peat matrix can be impeded because of slow diffusion rates (Cornel et al. 1986) or reduced advective movement of water from hydrological influenced pore deformations and entrapped bubbles (Price 2003). Increased pore water residence time can create recalcitrant DOC that is resistant to microbial decomposition (Wickland et al. 2007). Since DOC is an important substrate for microbial growth and mineralization (Chanton et al. 1995) and a carbon source for plant productivity (Kielland 1994), small changes in DOC residence time can have significant implications for peatland C cycling (Olefeldt and Roulet 2012).

When conditions favor pore water export, regional redistribution of DOC from a peatland can provide a substantial and labile source of $\mathrm{C}$ to streams and lakes with the potential to be readily mineralized into $\mathrm{CO}_{2}$ (Kling et al. 1991; Harrison et al. 2008). Consequently, hydrological alterations in peatlands can have dramatic impacts on DOC cycling not only within the peatland, but also significantly impact the greater peatland catchment.

Despite the importance of DOC dynamics in northern peatland C budgets, research is limited and inconclusive concerning the influence of WT alterations on DOC cycling in northern peatlands. Changes in DOC export and production have been noted form long-term drainage experiments (Turunen 2008; Höll et al. 2009; Blodau and Siems 2012). However, these studies represent peatlands drained for forestry and/or peat extraction that typically display a dramatic WT drawdown that is not comparable to the predicted $14 \mathrm{~cm}$ WT drawdown for northern peatlands under a $2 \mathrm{x} \mathrm{CO}_{2}$ future climate change scenario (Roulet et al. 1992). Thus, it is unknown how subtle long-term changes 
in the WT of a peatland will affect biogeochemical processes and contribute to changes in C cycling.

Short-term WT studies have provided a better representation of climate induced hydrological changes in northern peatlands (Strack et al. 2008; Kane et al. 2010). However, it is unknown if peatlands will display similar trajectories in DOC dynamics between long-term and short-term WT alterations. Mesocosm investigations utilizing peat cores have demonstrated WT manipulations can display contradicting trends in DOC cycling (Freeman et al. 1993; Clark et al. 2009; Preston et al. 2011). Additionally, mesocosm manipulations have reported WT position is not a primary predictor in DOC production/consumption (Pastor et al. 2003; Blodau and Moore 2004). Lastly, long periods of drought can provide a way to examine lowered WT effects on DOC cycling in peatlands that could most closely resemble future climate-induced changes in hydrology, however results are contradictory. Freeman et al. (2004) artificially created seasonal drought conditions in a peatland and found no increase in DOC export during or following the manipulations; whereas Worrall et al. (2006) measured increases in DOC export from peatlands coinciding with time periods of hydrological drought temporarily lower the WT position.

To further our understanding of climate-induced effects on northern peatland DOC dynamics, it is essential to not only investigate variables that influence DOC production/consumption and transport dynamics, but also examine decadal changes in hydrology that parallel the expected time frame of climate change. Our sites represent approximately 80 years of subtle WT alterations $( \pm \sim 10 \mathrm{~cm})$ in a northern poor fen peatland. Hydrological manipulations in the Seney National Wildlife Refuge in the 1930's to improve wildlife habitat created a unique opportunity to explore long-term WT draw-down and inundation effects on peatland DOC production and cycling. We established sites to represent a gradient of WT positions (intermediate, lowered, and raised) in a large peatland complex. Because of limited long-term WT manipulation research on DOC dynamics in peatlands, particularly in North America, this study will advance our understanding of DOC responses to future climate change. 
Objectives of our study were to examine how long-term WT alterations in a northern peatland influence DOC production/consumption, and quality. We hypothesized peatland DOC concentrations will increase after long-term WT draw-down because of accelerated decomposition due to oxidation of the peat and increased accumulation of water-soluble products of decomposition from an increased pore water residence time. We also hypothesized peatland DOC concentrations will decrease from a long-term raised WT because of suppressed decomposition and increased flushing of pore water from the peat. Because WT position influences plant productivity, mineralization and redox conditions that control DOC quality our final hypothesis was peatland DOC quality is dependent on WT position and residence time of pore water. In particular, a long-term lowered WT position will result in the increase of DOC components that have a reduced lability because of increased aerobic decomposition resulting in an accumulation of refractory compounds. In contrast, a long-term raised WT will accumulate labile DOC components because of suppressed decomposition from anaerobic conditions.

\subsection{Methods}

\subsubsection{Study sites}

Our research sites are within the Seney National Wildlife Refuge (SNWF) in the central portion of the Upper Peninsula of Michigan (Schoolcraft County), USA. The greater landscape comprising SNWR is composed of a large sand plain (Heinselman 1965) consisting of well sorted sands, 0-60 m thick, deposited during the retreat of the Lake Michigan lobe of the Laurentide ice sheet (Krist and Lusch 2004). The sand plain has a gradual southeast slope of $1.89 \mathrm{~m} / \mathrm{km}$ (USFWS 2009). The climate of the refuge is greatly influenced by Lakes Michigan to the south and Lake Superior to the north. The average annual precipitation is $81 \mathrm{~cm}$ with an average annual snowfall of $312 \mathrm{~cm}$ (USFWS 2009). Annual average temperature is $5.1^{\circ} \mathrm{C}$ (Wilcox et al. 2006).

Six sites were established east of the Marsh Creek flooding $\left(46^{\circ} 11^{\prime} 18^{\prime \prime} \mathrm{W}\right.$, $86^{\circ} 01^{\prime} 03^{\prime \prime} \mathrm{N}$ ) on a poor fen peatland complex. Hydrology was altered in the 1930's when the U.S. Fish and Wildlife Service constructed a series of earthen levees utilizing existing 
eskers to create open water impoundments for migratory waterfowl habitat (Kowalski and Wilcox 2003) resulting in both the inundation and drying of peatlands within the refuge. Six sites were split equally across three different peatland WT treatments: an intermediate (A and B), raised (C and D), and lowered (E and F) (Figure 3.1). The levee has restricted surface flow to sites $\mathrm{E}$ and $\mathrm{F}$ hydrologically separating the area from sites $\mathrm{C}$ and $\mathrm{D}$ that are currently inundated. Sites A and B were comparatively unaffected by the levee construction. Boardwalks were constructed at each site to prevent peat compaction around pore water sampling wells and piezometers.

\subsubsection{Hydrological monitoring}

Depth to WT at each site was monitored (April - October, 2010 and 2011) with non-vented pressure transducers (Levellogger Junior Model 3001; Solinst, Canada) set at an hourly recording interval in slotted wells inserted to the mineral soil. A barologger (Baralogger Gold Model 3001; Solinst, Canada) provided barometric compensation for all pressure transducers. Water table elevations are in relation to the mean microtopography of each site. Microtopography was measured with a transit level at 0.5 $\mathrm{m}$ increments along a $50 \mathrm{~m}$ transect centered at the monitoring well of each site. Well elevations were surveyed relative to each other and referenced to a common datum. Vertical hydraulic gradients (VHG) and peat $\mathrm{K}_{\text {sat }}$ were measured in nests of three piezometers at each site installed in a lawn microform. Piezometers were constructed with a $10 \mathrm{~cm}$ slotted intake wrapped with nylon mesh centered at a depth of 25, 50, and $75 \mathrm{~cm}$ below the peat lawn surface. The piezometers were carefully inserted into an augured hole with a slightly smaller diameter than the piezometer pipe. Stage heights were measured monthly from June through October 2010 and May through October 2011 before pore water collection. Peat $\mathrm{K}_{\text {sat }}$ measurements were conducted in late summer 2011 utilizing bail tests recorded with pressure transducers (Levellogger Junior Model 3001; Solinst, Canada) set at a recording interval of $0.5 \mathrm{sec}$ for $25 \mathrm{~cm}$ piezometers because of the rapid recharge and $60 \mathrm{sec}$ for $50 \mathrm{~cm}$ piezometers to accommodate the low $\mathrm{K}_{\text {sat }}$ of peat at this depth. Peat $\mathrm{K}_{\text {sat }}$ was calculated following Hvorslev (1951). Pore water velocity and VHG was estimated by (Fretter 1994): 
$\mathrm{V}=\left(\mathrm{K}_{\mathrm{sat}} / \mathrm{n}\right)(\mathrm{dh} / \mathrm{dl})$

where $\mathrm{V}$ is pore water velocity, $\mathrm{K}_{\text {sat }}$ is the saturated pore water hydraulic conductivity $\left(\mathrm{cm} \mathrm{s}^{-1}\right), \mathrm{n}$ is the peat porosity, dh is the difference in head between piezometers $(\mathrm{cm})$, and $\mathrm{dl}$ is the distance between piezometers $(\mathrm{cm})$. Pore water VHG was calculated by: $\mathrm{VHG}=\mathrm{dh} / \mathrm{dl}$.

\subsubsection{Field sampling methods}

Pore water was collected monthly from May to November 2010 and May to September 2011 from piezometer nests. Preceding water sampling, 25 cm piezometers were pumped dry and allowed to recharge. Because of the extremely long recharge in the $50 \mathrm{~cm}$ and $75 \mathrm{~cm}$ piezometers flushing was only possible two weeks before collection. Pore water $\mathrm{pH}$, conductivity, and temp were measured from the $25 \mathrm{~cm}$ piezometers immediately after water collection then transported on ice in a cooler to Michigan Technological University Wetland Laboratory and placed in a refrigerator at $4^{\circ} \mathrm{C}$. Pore water was filtered within 24 hours through $0.45 \mu$ m nylon membrane filters. Water samples were then split into three aliquots: (1) $50 \mathrm{ml}$ was acidified to $\mathrm{pH} 2$ with $\mathrm{HCl}$ and refrigerated at $4{ }^{\circ} \mathrm{C}$ prior to DOC and TDN analysis, (2) $50 \mathrm{ml}$ was frozen at $-20{ }^{\circ} \mathrm{C}$ prior to anion, cation, organic acid, and phenolic analysis, (3) $20 \mathrm{ml}$ was refrigerated at $4{ }^{\circ} \mathrm{C}$ for spectrophotometer analyses. Additional pore water samples $(n=4)$ were collected (November 2010; May and August 2011) from 25 cm below the lawn microforms at each site equally spaced within a $400 \mathrm{~m}^{2}$ plot around the piezometer nest with a stainless steel sipper that confirmed DOC WT treatment effects were representative of the greater WT treatments $(\mathrm{F}=18.25, \mathrm{p}<0.001)$.

Peat depth was measured at each site $(n=8)$ with a tile probe. To conduct peat physical analysis, three $10 \mathrm{~cm}$ diameter x $50 \mathrm{~cm}$ deep soil cores were extracted at each site from lawn microforms equally spaced along a $20 \mathrm{~m}$ transect. PVC pipes were carefully inserted into the peat by cutting around the perimeter of the pipe with a bread knife as the pipe was lowered into the peat. After extracting the peat core, the bottom and top of the PVC pipe were immediately capped to eliminate water loss. Cores were transported to Michigan Technological University Wetland Laboratory, frozen, and 
sectioned into $10 \mathrm{~cm}$ horizons with a bandsaw. Bulk density and porosity was determined for each core horizon. Porosity was based on a standard particle density of $1.5 \mathrm{~g} \mathrm{~cm}^{-3}$ (Redding and DeVito 2006).

\subsubsection{Chemical constituent analyses}

Dissolved organic carbon and total dissolved nitrogen (TDN) were measured on a Shimadzu TOC-V Combustion Analyzer with a TNM-1 Total Nitrogen module (Shimadzu Scientific Instruments, Columbia, MD, USA). Pore water cations $(25 \mathrm{~cm}$ depth), anions (25, 50 and $75 \mathrm{~cm}$ ), and metals $(25 \mathrm{~cm}$ ) were measured in 2010. Bromide $\left(\mathrm{Br}^{-}\right)$, chloride $\left(\mathrm{Cl}^{-}\right)$, fluoride $\left(\mathrm{F}^{-}\right)$, nitrate $\left(\mathrm{NO}_{3}{ }^{-}\right)$, nitrite $\left(\mathrm{NO}_{2}{ }^{-}\right)$, phosphate $\left(\mathrm{PO}_{4}^{-3}\right)$, sulfate $\left(\mathrm{SO}_{4}{ }^{-2}\right)$, acetate, propionate, formate, and oxalate were determined with an ICS2000 ion chromatograph (Dionex Corporation, Bannockburn, IL, USA). Dissolved organic $\mathrm{N}$ was determined as the difference between TDN and inorganic $\mathrm{N}\left(\mathrm{NH}_{4}{ }^{+}, \mathrm{NO}_{3}{ }^{-}\right.$, and $\left.\mathrm{NO}_{2}^{-}\right)$. Cations calcium $\left(\mathrm{Ca}^{+2}\right)$, magnesium $\left(\mathrm{Mg}^{+2}\right)$, sodium $\left(\mathrm{Na}^{+}\right)$total iron $(\mathrm{Fe})$, and potassium $\left(\mathrm{K}^{+}\right)$and metals copper $(\mathrm{Cu})$, aluminum $(\mathrm{Al})$, Zinc $(\mathrm{Zn})$ were determined with an inductively-coupled plasma optical emission spectrometer (ICP-OES) (PerkinElmer Corporation, Waltham, Ma, USA).

Pore water ultraviolet absorbance (ABS) was measured at $\lambda=254,365,465$, and 665 to characterize composition of DOC with a SpectraMax M2 multimode microplate reader (Molecular Devices Corporation, Sunnyvale, Ca, USA) using a $1 \mathrm{~cm}$ quartz cuvette and reverse osmosis (RO) water for the blank. The ratio of absorption spectra at $\lambda=254$ to $\lambda=365$ (E2:E3) is used as an index for the molecular size of the dissolved organic matter (DOM) molecules (Lou and Xie 2006). Specific ultraviolet absorbance (SUVA 254 ) is calculated from the absorption spectra at $\lambda=254$ divided by sample DOC concentration and increases linearly with measured DOC aromaticity (Weishaar et al. 2003). The ratio of absorption spectra at $\lambda=465$ to $\lambda=665$ (E4:E6) is an indicator of DOC humification, with a larger ratio generally considered relatively more aromatic (Worrall et al. 2002).

Ammonium $\left(\mathrm{NH}_{4}{ }^{+}\right)$and total phenolics were determined by reagent packets from Hach (Loveland, CO, USA) scaled down to a microplate technique. Total phenolics were 
quantified by adding $250 \mu \mathrm{l}$ of sample to each microplate well and then adding $10 \mu \mathrm{l}$ of TanniVer reagent (catalog no. 256032) to each well. Next, sodium pyrophosphate $\left(\mathrm{NaP}_{2} \mathrm{O}_{7}\right)$ dissolved in $\mathrm{RO}$ water $(0.2 \mathrm{~g}$ per $2 \mathrm{~mL})$ was added to each well to eliminate possible ferrous iron interference followed by $50 \mu \mathrm{l}$ of sodium carbonate solution (catalog no. 67549). The plate was shaken, incubated covered for 25 min and ABS measured at $700 \mathrm{~nm}$. A total phenolic standard curve was produced from tannic acid diluted to 1.5, 3, 6, and 9 ppm. The Hach tannin and lignin method determines all hydroxylated aromatic compounds, so it is a test for total phenolics present in the assayed pore water. Ammonium was determined by methods outlined in Sinsabaugh et al. (2000) with a standard curve produced from ammonium acetate diluted to $0.01,0.05,1,2$, and 5 ppm.

An incubation experiment to test DOC potential mineralization was conducted August 2011 with pore water from sites B, C, and E to represent the three WT treatments. Bulk pore water was collected at $25 \mathrm{~cm}$ below the peat surface with a stainless steel sipper from four locations equally spaced along a $20 \mathrm{~m}$ transect that included the $25 \mathrm{~cm}$ piezometer as one of the collection points. Water was placed on ice, transport back to Michigan Technological University Wetland Laboratory, and processed for initial DOC, TDN, ABS indexes, and total phenolics within 24 hours. Additional filtered water samples were placed in acid washed bottles to provide four replicates for four harvest dates ( $3,7,14$, and 28 days) and inoculated with a $1 \mathrm{~mL}$ common innoculum prepared by mixing equal proportions of bulk pore water from each site then sequentially diluting to $10^{-3}$ (Wickland et al. 2007). Samples were incubated in the dark at a constant temperature of $20^{\circ} \mathrm{C}$. Samples were filtered upon harvesting and analyzed for DOC, TDN, ABS indexes, and phenolic compounds.

\subsubsection{Statistical analysis}

We treated the different WT levels created by hydrologic alterations as a natural experiment, with WT level differences used as treatments. A two-way, repeated measures analysis of variance was conducted using PROC MIXED to test for WT differences in ecosystem DOC and TDN concentrations (SAS Institute Inc., Cary, NC, 
USA, version 8). Each site was an experimental unit, so replicate measurements were averaged by site for each year of analysis. Individual sites within each WT treatment were used as replications, WT treatments were treated as whole plots, and depth was treated as subplots. Water table treatment and depth interactions were treated as fixed effects, sites were treated as random effects, and sample years were treated as repeated measures. We used complex symmetry covariance structure for repeated measures analysis as determined by looking at the fit statistics and the Kenward and Roger's correction for degrees of freedom (Littell et al. 2006). Pore water constituents and spectrophotometer indices were analyzed with a general linear model (Minitab 2011) with WT and depth as fixed effects, site as a random factor, and date as repeated measure. The relationship between DOC and chloride, TDN and DOC, and DOC and $\mathrm{K}_{\mathrm{sat}}$ were explored with analysis of covariance (ANCOVA). A multivariate principle component analysis (PCA) was applied to the entire 2011 pore water chemistry data set from the $25 \mathrm{~cm}$ piezometers to determine the best predictor variables for WT treatments. A PCA was additionally utilized to examine cation and organic acid relationships to WT treatments using PC-ORD 6 (MjM Software, Gleneden Beach, OR, USA). Between WT treatment comparisons for the PCA derived groups were explored with multi-response permutation procedures (MRPP) using PC-ORD. One-way analysis of variance (ANOVA) was used to analyze the mineralization experiment and the most significant predictors (utilizing WT treatment, beginning DOC concentration, SUVA $254, \mathrm{E} 2: \mathrm{E} 3$, E4:E6, phenolics, and TDN) of DOC mineralization were explored with a best subset regression analysis. The fit of the model was evaluated with Mallow's Cp, which should be smaller or equal to the number of degrees of freedom in the regression model (Minitab 2011). Descriptive statistics were determined with Sigmastat and comparisons between all treatments were conducted using Tukey's post-hoc test with differences at $\mathrm{p}<0.05$ considered significant. 


\subsection{Results}

\subsubsection{Site Topography and Hydrology}

Direction of water flow across the sites as determined from hydraulic well head elevations matches the general northwest to southeast surface water flow across the greater Seney landscape (Figure 3.1b). The mean microtopography of sites A ( $0.23 \pm$ $0.10 \mathrm{~m}( \pm 1 \mathrm{SD}))$ and $\mathrm{B}(0.22 \pm 0.10 \mathrm{~m})$ were similar with a slight slope of the peat surface from B to A of $0.20 \mathrm{~m} / \mathrm{km}$. Site $C$ is inclined toward $D$ at $0.53 \mathrm{~m} / \mathrm{km}$ with a mean microtopography of $0.16 \pm 0.10 \mathrm{~m}$ and $0.18 \pm 0.83 \mathrm{~m}$ respectively. To the south of the impoundment site $\mathrm{F}$ slopes to $\mathrm{E}$ at $0.66 \mathrm{~m} / \mathrm{km}$ and the surface microtopography is $0.15 \pm$ $0.07 \mathrm{~m}$ and $0.30 \pm 0.12 \mathrm{~m}$ respectively.

The expected WT treatment effects were confirmed for (2010 and 2011) relative to mean microtopography of each site. The lowered WT sites south of the impoundment experienced the greatest draw-down with two year seasonal mean (April - October) WT of $36.6 \pm 5.7 \mathrm{~cm}$ (mean $\pm 1 \mathrm{SD}$ below mean topography). The raised treatment had the highest WT $(14.4 \pm 6.9 \mathrm{~cm})$ while the intermediate treatment $(26.2 \pm 7.1 \mathrm{~cm})$ was staged between the raised and lowered WT treatments (Figure 3.2).

The two year mean VHG between the 50 and $75 \mathrm{~cm}$ piezometers displayed a general trend of downwelling across the WT treatments with the lowered treatment displaying a significantly greater VHG $(\mathrm{p}<0.001)$. The raised WT treatment VHG between the 50 and $75 \mathrm{~cm}$ piezometers exhibited seven upwelling episodes in 2010 and 2011, whereas the only other reversal to downwelling was in site B (May 2011; VHG 0.04). In contrast, the two year mean VHG between the 25 and $50 \mathrm{~cm}$ piezometers showed a slight upwelling across the three WT treatments. The raised water treatment had the smallest upward mean VHG ( $<$ 0.001). The VHG between the 25 and $50 \mathrm{~cm}$ piezometers did reverse to downwelling in the intermediate WT in 2011 for September (sites A and B) and October (site B) and the raised WT treatment displayed several upwelling episodes in 2010 and 2011(Table 3.1).

Hydraulic conductivity was lower in the raised and lowered WT treatments in the $25 \mathrm{~cm}$ (69\% and 54\% respectively) and $50 \mathrm{~cm}$ (two and three orders of magnitude respectively) piezometers compared to the intermediate treatment (Table 3.2). Seasonal 
mean DOC concentrations at $50 \mathrm{~cm}$ were inversely correlated to $\mathrm{K}_{\mathrm{sat}}\left(\mathrm{R}^{2}=0.91, \mathrm{p}=\right.$ 0.001) (Figure 3.3) and there was a significant WT treatment by DOC interaction confirming the raised and lowered WT treatments were different than the intermediate treatment $(\mathrm{F}=7.58, \mathrm{p}<0.001)$. Bulk density displayed a significant nonlinear inverse relationship to hydraulic conductivity $\left(\mathrm{R}^{2}=0.67, \mathrm{p}=0.001\right)$. Bulk density was higher in the lower WT treatment $(10-50 \mathrm{~cm})$ and raised treatment $(30-50 \mathrm{~cm})$ peat horizons than the intermediate treatment (Table 3.2).

\subsubsection{Site electrochemistry and pore water chemical constituents}

The raised WT treatment pore water $\mathrm{pH}$ (two year seasonal mean; $3.84 \pm 0.20 \pm 1$ SD) was greater than the intermediate and lowered treatment $\mathrm{pH}(3.61 \pm 0.27$, and $3.56 \pm$ 0.23 respectively; $\mathrm{F}=6.89, \mathrm{p}=0.002$ ). The lowered $\mathrm{WT}$ treatment electrical conductivity (two year seasonal mean; $71.6 \pm 8.5 \mu \mathrm{S} \mathrm{cm}^{-1}$ ) was greater than the intermediate $\left(60.2 \pm 7.8 \mu \mathrm{S} \mathrm{cm}^{-1}\right)$ and raised $\left(56.9 \pm 5.8 \mu \mathrm{S} \mathrm{cm}^{-1}\right)$ treatments $(\mathrm{F}=18.2 \mathrm{p}$ $<0.001$ ). Pore water temperature (25 cm depth, two year seasonal means) was similar across the intermediate, raised, and lowered, WT treatments than the lowered and intermediate $\left(14.8 \pm 0.73^{\circ} \mathrm{C}, 14.4 \pm 0.79,16.0 \pm 0.83\right.$ respectively; $\left.\mathrm{F}=0.47, \mathrm{p}=0.63\right)$.

Base cations $\mathrm{Ca}^{+2}, \mathrm{Fe}, \mathrm{K}^{+}, \mathrm{Mg}^{+2}$, and $\mathrm{Na}^{+}$(25 cm piezometers) were elevated in the raised WT treatment (Table 3.3). PCA ordination illustrated the strong positive relationship between cations and the raised WT treatment (Figure 3.4 and Table 3.4). Aluminum concentrations were different across WT treatments with the lowered treatment exhibiting the highest concentrations $\left(0.36 \pm 0.03 \mathrm{mg} \mathrm{L}^{-1}\right)$ followed by the raised and intermediate $\left(0.29 \pm 0.04 \mathrm{mg} \mathrm{L}^{-1}, 0.16 \pm 0.03\right.$ respectively). The anion $\mathrm{SO}_{4}{ }^{-2}$ was greater in the raised and lowered compared to the intermediate treatment in the 50 cm piezometers. Across the WT treatments seasonal mean $\mathrm{DOC}: \mathrm{Cl}^{-}$ratios were not significantly different (Kruskal-Wallis; $\mathrm{H}=2.56, \mathrm{p}=0.28$ ) and the relationship of DOC

versus $\mathrm{Cl}^{-}$displayed similar trends in slope $(\mathrm{F}=0.54, \mathrm{p}=0.59)$ suggesting that increased DOC was the result of additional factors and not solely evaporative concentration (Figure 3.5). 
Concentrations of organic acids were not significantly different across the WT treatments for each piezometer depth due to a large seasonal variation in species concentrations (Table 3.5). The highest concentrations of organic acids were recorded in the $75 \mathrm{~cm}$ piezometers in the early season samples (Data not shown for individual sample days). Furthermore, early season (May) samples combining all treatments were elevated in acetate and propionate compared to late season samples (September - November) (MRPP; $\mathrm{T}=-20.98, \mathrm{~A}=0.28, \mathrm{p}<0.001$ ).

Dissolved organic carbon concentrations were significantly different across the three WT treatments and three piezometers depths $\left(\mathrm{F}_{2,3}=10.20, \mathrm{p}=0.04\right.$ and $\mathrm{F}_{2,24}=$ 12.50, $\mathrm{p}<0.001$ respectively) (Figure 3.6). The raised and lowered WT treatments two year mean DOC concentrations were significantly greater than the intermediate treatment in the $25 \mathrm{~cm}$ piezometers (33.5\% and 29.6\% respectively) and $50 \mathrm{~cm}$ piezometers (31.1\% and $29.0 \%$ respectively). Only the lowered WT treatment was different than the intermediate at the $75 \mathrm{~cm}$ depth (22.3\%). Within each WT treatment there was a consistent trend for DOC concentrations to decrease with depth. The raised and lowered WT treatment DOC concentrations decreased $18.2 \%$ and $25.0 \%$ respectively between the $25 \mathrm{~cm}$ and $75 \mathrm{~cm}$ piezometers, whereas the intermediate treatment declined only 4.3\% (Table 3.5). Pore water phenolic concentrations decreased with depth in the raised and lowered WT treatments ( $\mathrm{F}=15.87, \mathrm{p}<0.001)$. The raised and lowered WT treatment displayed elevated phenolic concentrations compared to the intermediate treatment $(\mathrm{F}=$ 29.21, $\mathrm{p}<0.001$ ) (Figure 3.7).

Pore water TDN concentrations displayed a positive relationship with DOC for both sample years and all three piezometer depths across the WT treatments. However, we did not detect any influence of DOC on TDN concentrations (Figure 3.8). Ammonium was present in very low concentrations across the WT treatments with the raised $\left(0.07 \pm \mathrm{mg} \mathrm{L}^{-1}\right)$ and lowered $\left(0.08 \pm \mathrm{mg} \mathrm{L}^{-1}\right)$ WT treatments not significantly different than the intermediate treatment $\left(0.05 \pm \mathrm{mg} \mathrm{L}^{-1}\right)$. Dissolved concentrations of $\mathrm{NO}_{3}{ }^{-}$and $\mathrm{NO}_{2}{ }^{-}$were below instruments detection limits. 


\subsubsection{Spectrophotometer indices}

The SUVA 254 ratio displayed differences with depth $\left(\mathrm{F}_{2,41}=4.92, \mathrm{p}=0.015\right)$ and across WT treatments $\left(\mathrm{F}_{2,41}=4.13, \mathrm{p}=0.027\right)$ (Figure 3.9a). A strong interaction $\left(\mathrm{F}_{4,41}=\right.$ 6.63, $\mathrm{p}=0.001$ ) was present between decreasing SUVA 254 values with depth in the intermediate and lowered WT treatments (8\% and 13\% respectively between $25 \mathrm{~cm}$ and $75 \mathrm{~cm}$ ) and the increase measured in the raised treatment (3\%). The E2:E3 ratios were greatest for the intermediate WT treatment $\left(\mathrm{F}_{2,41}=115.19\right.$, $\left.\mathrm{p}<0.001\right)$ and $75 \mathrm{~cm}$ depth $\left(\mathrm{F}_{2,41}=172.93, \mathrm{p}<0.001\right)$ across all three WT treatments. An interaction was present between WT and depth $\left(\mathrm{F}_{4,41}=58.31, \mathrm{p}<0.001\right)$ that was predominantly the result of the large increase in the E2:E3 ratio (18\%) form the $75 \mathrm{~cm}$ to the $25 \mathrm{~cm}$ piezometer (Figure 3.9b). The E4:E6 ratio displayed differences across WT treatments $\left(\mathrm{F}_{2,41}=10.76, \mathrm{p}<\right.$ $0.001)$,but not for depth with each treatment $\left(\mathrm{F}_{2,41}=1.38, \mathrm{p}<0.268\right)$. Interaction between WT and depth was not present $\left(\mathrm{F}_{4,41}=0.95, \mathrm{p}<0.452\right)$ (Figure 3.9c). The E2:E3 and E4:E6 ratios were normalized to DOC concentrations to determine if ratios were indicative of inherent properties of each treatment (Zaccone et al. 2009). The ratios displayed similar trends so unnormalized values are reported. Multivariate analysis combing DOC, phenolics, spectrophotometer indices, and $\mathrm{K}_{\mathrm{sat}}$ showed a distinct separation of the WT treatments (Figure 3.10) and MNPP analysis found significant differences between the WT treatments (Table 3.7).

\subsubsection{DOC incubation experiment}

Initial DOC concentrations of the intermediate (36.65 \pm 2.03$)$, raised (76.78 \pm 2.91), and lowered WT treatments (56.29 \pm 1.63) displayed a similar significant difference $\left(\mathrm{F}_{2,14}=778.06, \mathrm{p}<0.001\right)$ as the two year DOC means. The raised WT treatment mineralized a greater concentration of DOC $(7.98 \pm 0.85 \mathrm{mg})$ than the intermediate treatment $(4.74 \pm 0.28)$ and both were not significantly different from the lowered treatment (5.57 \pm 0.79 ) over the 28 day incubation experiment (Figure 3.11a). Spectrophotometer indices and phenolic concentrations displayed the same trends as seasonal mean values. The variables WT treatment and SUVA 254 were the best predictors of DOC mineralization (Table 3.8). 


\subsection{Discussion}

\subsubsection{Water table effects on DOC dynamics}

We measured significantly elevated DOC concentrations for two consecutive years in the lowered and raised WT treatments compared to the intermediate treatment (Figure 3.6). The WT alterations across our sites are comparable to the predicted \pm 10 cm shift in peatland WT's under future climate change scenarios (Gorham 1991; Roulet et al. 1992). Thus, our treatments provided a realistic in situ representation of climate induced changes of DOC concentrations in a northern peatland.

The lowered WT treatment had the greatest WT draw-down and is displaying a high seasonal WT fluctuation during dry years (20\% greater seasonal WT STD than the intermediate treatment in 2011). The highly variable and deeper WT of the lowered treatment is potentially creating oxygen enrichment in the peat column and stimulating microbial decomposition of peat that can enhance DOC production (Fenner and Freeman 2011). Furthermore, rewetting of peat with the rise of the WT can abiotically flush newly produced DOC from oxic peat into the ascending pore waters (Chow et al. 2006; Clark et al. 2009). This process is especially effective in the upper peat surface that is rich with recently senescent plant litter experiencing aerobic microbial processing (Fenner et al. 2011). Additionally, the production of DOC can continue under reestablished anaerobic conditions due to a legacy effect of oxygen activated phenolic oxidases reducing phenolic inhibition on microbial and enzymatic processes responsible for peat degradation (Worrall and Burt, 2004; Fenner and Freeman 2011). Furthermore, a lowered WT can increase the availability of recharged electron acceptors for microbial activity (Knorr and Bladou 2009).

The measured differences in DOC concentrations in our WT drawdown treatments are comparable to other experimental WT manipulations that simulated a lowering of the WT. Kane et al. (2010) reported a $21.8 \%$ increase in DOC when the WT was lowered in an Alaskan fen over the course of four years. The enhanced DOC production was attributed to elevated peat temperatures and a greater seasonal thaw depth. After eleven years of WT draw-down, Strack et al. (2008) also documented an increase in DOC pore water concentrations in a poor fen with a lowered WT compared to 
a control site that was attributed to shifts in plant biomass and a greater seasonal fluctuation in WT position. The previous studies are from short-term WT manipulations, thus our study provides a valuable prediction that peatlands under subtle long-term WT drawdown ( $\sim 80$ years) will experience sustained elevated concentrations of DOC production.

In contrast to the lowered WT treatment, the elevated WT in the raised treatment has inundated the peatland increasing the anoxic environment of the peat. Despite the anaerobic conditions, the raised WT treatment DOC concentrations were significantly greater at all three piezometer depths compared to the intermediate treatment (Figure 3.6). The increased DOC concentrations measured in the raised treatment was unexpected and opposite to the $12 \%$ reduction in DOC Kane et al. (2010) measured in raised WT plots relative to control plots. Höll et al. (2009) demonstrated that rewetting a peatland after long-term WT drawdown can increase DOC concentrations; however, to the best of our knowledge, our study is the first report of a peatland experiencing a longterm elevated WT position similar to climate change predictions $( \pm \sim 10 \mathrm{~cm})$ with persistently elevated DOC concentrations. Our WT treatments are suggesting that WT alone is not a strong predictor of DOC concentrations in northern peatlands and the mechanisms are multidimensional. For example, increased decomposition in the lowered treatment is potentially enriching the DOC pool; however, in the raised treatment the increased photic zone created from the elevated WT could provide an ideal environment for peatland algae that could be a potent driver of DOC production and quality (Wyatt et al. 2011) (see algae discussion below).

\subsubsection{Pore water residence time}

Changes in pore water residence time can influence DOC concentrations from reduced vertical flushing of DOC enriched water into the substratum (Fraser et al. 2001). Reeve et al. (2000) proposed that vertical flow can be enhanced when the WT drops to the base of the acrotelm (the upper peat horizon) reducing the influence of lateral discharge. Despite the lowered WT treatment displaying the largest VHG, residence time was significantly longer than the intermediate treatment because of a lower $\mathrm{K}_{\text {sat }}$ and peat 
porosity that resulted in a significantly reduced downward pore water velocity $\left(7.95 \mathrm{x} 10^{-}\right.$ ${ }^{4} \mathrm{~cm} \mathrm{sec}^{-1}$ and $0.27 \mathrm{~cm} \mathrm{sec}^{-1}$ respectively). In the raised WT treatment we also measured a low $\mathrm{K}_{\text {sat }}$ in the deep piezometers; however, the VHG was the lowest of all three treatments. The reduced vertical advective flow, especially with an elevated WT position, can occur from anaerobic gas production creating bubbles blocking pores in the peat matrix (Romanowicz et al. 1995; Beckwith and Baird 2001; Kellner et al. 2005). Increased methane production was measured in the raised sites (Ballantyne et al. submitted). Additionally, numerous upward flow reversals in the raised treatment were measured in the deep piezometers over the two year sampling period that can contribute to a reduced pore water residence time by countering downward flows (Reeve et al. 2000). The flow reversals were substantiated by the elevated base cations $\left(\mathrm{Ca}^{+2}\right.$ and $\mathrm{Mg}^{+2}$ ) concentrations in the raised site that are known to commonly enter the peatland from upwelling ground water rich in minerals (Siegel et al. 1995). Thus, the combination of a low VHG, $\mathrm{K}_{\mathrm{sat}}$, and porosity with numerous upwelling events are all contributing to a pore water velocity of $0.02 \mathrm{~cm} \mathrm{sec}^{-1}$ that has created a high residence time in the raised treatment. We propose that the greater residence time in our raised and lowered WT treatments is having significant effects on DOC production/consumption dynamics. Water residence time can significantly alter DOC concentrations by controlling flushing and retention of pore water (Wickland et al. 2007) and DOC quality is strongly controlled by microbial contact time with DOC substrates (Beer et al. 2008). The strong relationship we found between DOC and $\mathrm{K}_{\text {sat }}$ suggests that DOC concentrations are significantly affected by pore water residence time (Figure 3.3).

Lastly, we explored if evaporative concentration of pore water was increasing DOC concentrations across our treatments (Whitfield et al. 2010), especially when combined with a greater pore water residence time limiting DOC export from the peatland (Waiser 2006). Evapotranspiration (ET) determined by eddy covariance techniques (Pypker unpublished data, two year means, $\mathrm{n}=55$ days) was not significantly greater in the intermediate WT treatment $\left(63.2 \pm 3.10 \mathrm{~W} \mathrm{~m}^{-2}\right)$ compared to the raised $(73.3 \pm 3.8 \mathrm{SE})$ or lowered treatment $(61.7 \pm 2.9)$. Furthermore, $\mathrm{Cl}^{-}$examined as a conservative tracer (Waiser 2006; Anderson and Stedmon 2007) did not display a 
significant increase relative to DOC concentrations in the near surface pore waters and the DOC: $\mathrm{Cl}^{-}$was not a significant predictor across the WT treatments confirming the small influence of evaporative concentration on solute concentrations (Figure 3.5).

\subsubsection{Pore water DOC chemical characteristics and lability}

Pore water DOC quality displayed significant differences in aromaticity, molecular weight, and composition of humic compounds across the WT treatments. A PCA ordination showed a strong separation for pore water quality parameters $\mathrm{SUVA}_{254}$, E2:E3, E4:E6, and phenolic compounds across the three WT treatments (Figure 3.10). Our characterization of pore water quality indicates that significant differences in the chemical composition of DOC are present across the three WT treatments.

The lower $\mathrm{SUVA}_{254}$ value measured in the upper peat profile of the raised treatment is indicative of DOC influenced primarily by an autochthonous (microbial and/or algal) source in contrast to an allochthonous (terrestrial) carbon pool (Barber et al. 2001; Mash et al. 2004) (Figure 3.9a). As previously stated the seasonally elevated WT in the raised treatment is creating an increased surface water photic zone that can support algae growth and influence pore water aromaticity (Casamatta et al. 2001). Additionally, suppressed microbial activity in the raised WT treatment from anoxic conditions could slow down decomposition of surface litter that is a rich source of aromatic carbon compounds (Freeman et al. 1996). Thus, the WT treatments are displaying different trends in DOC quality with the lowered treatment more aromatic and the raised treatment a more labile carbon source. When examining $\mathrm{SUVA}_{254}$ in relation to depth, the intermediate and lowered treatments are responding very differently than the raised treatment with a noticeable reduction from shallow $(25 \mathrm{~cm})$ to deep pore water $(75 \mathrm{~cm})$ (decreasing 9\% and 14\% respectively). Kane et al. (2008) reported increasing SUVA with depth across a short-term WT manipulation that was explained as an accumulation of recalcitrant DOC in deeper peat profiles. Our results contradict these findings; however, decreasing $\mathrm{SUVA}_{254}$ has been report in forest and grassland systems and is attributed to selective absorption of dissolved aromatic compounds onto the peat matrix (Sanderman et al. 2008; Fröberg et al 2011). Furthermore microbial phenolic degradation 
can occur in anaerobic environments (Elder and Kelly 1994). The long-term WT treatments are displaying distinct and complex differences in DOC aromaticity across treatments and peat depth.

The intermediate and lowered treatments are both displaying a greater E4:E6 ratio (index of humification) than the raised site that is most pronounced in the upper peat profile ( 25 and $50 \mathrm{~cm}$ piezometers) and is potentially the effect of the greater oxic conditions contributing to accelerated breakdown of surface plant litter (Figure 3.9c). A reduced E4:E6 ratio is attributed to anaerobic conditions with depressed microbial activity that results in the accumulation of humic acids. In contrast, an elevated E4:E6 ratio is indicative of DOC with a high fulvic acid (FA) content (Wallage et al. 2006; Blodau and Siems 2012). Pore water FA can be readily produced from microbial decomposition of plant litter in an aerobic environment (Knight et al. 2001). Additionally, an elevated E4:E6 ratio is suggestive of DOC with higher concentrations of condensed aromatic compounds (Chen et al. 1977) that is supported by the elevated $\mathrm{SUVA}_{254}$ values in the intermediate and lowered treatment in the upper peat that is indicative of recent aromatic plant litter decomposition products entering the water column (Figure 3.9a). Typical values for E4:E6 ratios for DOC containing predominantly FA are 8 - 9 (DOC with predominately humic acid is 5-6) that are slightly lower than our ratios in the intermediate and lowered treatments; however, Chen et al. (2010) states that the E4:E6 ratio increases with additional oxygenated bonds thus making our values very realistic because of the aerated peat surface at these treatments. With sufficient oxygen, pore water compounds are formed containing high concentrations of carboxylic and ketonic bonds $(\mathrm{C}=\mathrm{O}$ ) (Uyguner et al. 2005) in addition to aromatic bonds linked and substituted primary by oxygen (Chen et al. 2010) that readily absorb light at $465 \mathrm{~nm}$ (E4) thus elevating the E4:E6 ratio. Our E4:E6 ratios are demonstrating that the WT treatments have different chemical properties driven by the subtle WT changes affecting redox and decomposition dynamics.

Lastly, the E2:E3 ratio that is inversely related to the average molecular weight of DOC (Lou and Xie, 2006) was significantly reduced in lowered WT treatment compared to the raised and intermediate treatments indicating DOC with a greater percentage of 
HMW molecules. Increased oxic conditions from WT drawdown can activate phenol oxidases (McLatchey and Reddy 1998; Freeman et al. 2004; Fenner et al. 2011) and recharge microbial electron acceptors creating a favorable environment for the enhanced breakdown of plant litter plentiful in HMW phenolic compounds, e.g., lignin and tannin (Limpens et al. 2008) that is shown by the elevated concentrations of phenolics in the 25 $\mathrm{cm}$ deep pore water at the lowered WT treatment. Furthermore, the greater $\mathrm{SO}_{4}{ }^{2-}$ concentrations in the lowered treatment than the intermediate treatments can stimulate phenolic release from peat (Fenner et al. 2011). Quantification of phenolic oxidase enzymatic activities across our treatments could help to further elucidate this process (Kang et al. 2009). We propose that WT draw-down stimulates phenol oxidase resulting in increased phenolic compounds whereas phenolic accumulation in inundated peatlands is related to residence time and increased leaching of plant material.

The raised WT treatment also has a higher percentage of HMW compounds as indicated by the lower DOC E2:E3 ratio compared to the intermediate treatment. Interestingly, algae are known to release HMW compounds upon senescence (Reddy and Delaune 2008) and leachates from algae have a lower E2:E3 value ( 3) corresponding to a higher molecular size (Cuassolo et al. 2011). Additionally, complex HMW compounds leached from vegetation litter in a reduced environment can accumulate in pore water (Reddy and Delaune 2008).

Decomposition of DOC has been suggested to follow a size reactivity model based on four classes of molecules: labile, semilabile, recalcitrant, and refractory (Sinsabaugh and Forman 2003). The refractory class of this model is composed predominately of LMW compounds termed stable diagenetic products (SDP), which are no longer energetically favorably to microbial utilization and can accumulate in highly humified systems. Additionally, Amon and Benner (1998) suggested that age of DOM material is a better indicator of bioreactivity and liability than molecular weight. Appling the size reactivity model to the E2:E3 ratio values explains the significant increase observed for all three WT treatments in the $75 \mathrm{~cm}$ piezometers compared to the $25 \mathrm{~cm}$ piezometers indicating an accumulation of refractory LMW compounds with depth in the pore water (Figure 3.9b). 
Incubation results supported indices of pore water DOC quality with total mineralized DOC greatest from the raised WT treatment compared to the intermediate and lowered treatments (percent increase, 68\% and 43\% respectively) (Figure 3.11a). Percent DOC mineralized was not different across the three treatments and was probably due to the significantly different DOC concentrations in the pore water that mirrored the seasonal [DOC] means. The strongest predictors of DOC mineralized were WT treatment and SUVA 254 . Pore water aromaticity $\left(\mathrm{SUVA}_{254}\right)$ is a strong controller of DOC mineralization (Kalbitz et al. 2003). The SUVA 254 index was lowest in the raised treatments and is attributed to algal contribution to pore water DOC (see below). The lowered WT treatment high SUVA 254 is likely caused by increased decomposition in the upper peat profile and accumulation of dissolved aromatic compounds lowering DOC lability (Wickland et al. 2007) substantiated by the high E4:E6 ratio. An additional variable influencing the high lability of the raised WT treatment pore water is photoproduction of highly labile compounds. As we previously noted, the raised treatment has an elevated WT above the lawn microforms creating a larger photic zone than the other WT treatments and contains a significantly higher fraction of humic acids in the pore water. Bano et al. (1998) reported that humic acids exposed to sunlight increased bacterial degradation by $300 \%$.

\subsubsection{Potential algae influence on DOC dynamics}

We proposed algae activity could be a strong factor driving the elevated DOC concentrations in the raised WT treatment. Standing WT's present throughout most of the growing season and elevated nutrients recorded at the raised treatment (Hribljan et al. in preparation) provide a potentially favorable environment for algal productivity, which can excrete approximately $19 \%$ of photosynthetically fixed carbon into the water column (Wyatt et al. 2011). The wettest site in the raised WT treatment (site C) had standing water above the lawn microforms for 97\% (2010) and 81\% (2011) of the time period recorded for the seasonal WT levels (April - October). Surprisingly published research is limited on the effects of altered hydrology on algal community dynamics in northern peatlands. 
Additionally, algae can influence peat and pore water chemistry in a peatland. Knight et al. (1994) stated the overall FA proportion of DOC is reduced when algae are the main source of DOC production. Algae can absorb FA to outer cell surfaces as a means to possibly facilitate the uptake of carbon and potentially could sequester up to $31 \%$ of the DOC FA fraction during large blooms especially in low pH environments with high DOC concentrations (Knauer and Buffle 2001). Knauer and Buffle (2001) reported FA adsorption by the algae Chlamydomonas reihadrii, Scenedesmus spp., and Chlorella spp., which are all found in northern peatlands (Quinn et al. 2001; Klemencic et al. 2010). The significantly lower E4:E6 spectrophotometer ratio measured at the raised treatment in the upper $50 \mathrm{~cm}$ of the peatland is suggestive of a reduction of FA in the DOC pool (Wallace 2007) (Figure 3.9c).

Moreover, the increased mineralization of DOC measured from the raised WT treatment pore water incubation is potentially related to algal derived inputs into the water column. Algae excreted DOC is readily assimilated by heterotrophic bacteria (Wiebe et al. 1977, Brock and Clyne 1984; Wyatt et al. 2006) and in select environments can comprise approximately half of the bacterial carbon requirement (MalinskyRushansky and Legrand 1996). In addition, algal excretion of DOC is generally more labile than plant derived DOC (Klug 2005) that is supported by the low SUVA 254 values we measured throughout the growing season at the raised WT treatment.

\subsection{Conclusions}

Pore water DOC concentrations increased with impoundment and WT drawdown following 80 years of hydrological alterations in a poor fen peatland compared to an unaltered portion of the peatland complex. The greater DOC concentrations in the lowered site are apparently driven by increased oxic conditions accelerating the decomposition and flushing of $\mathrm{C}$ compounds into the pore water. Additionally, a longer residence time at the lowered treatment is reducing pore water flushing from the peatland and promoting DOC accumulation. The raised WT treatment also displayed an increased residence time with greater DOC concentrations. However, the elevated WT has dramatically increased the photic zone that is potentially supporting increased algae 
photosynthate production with subsequent DOC release into the peatland water column. Impoundment of the raised WT treatment has created DOC that has low aromaticity and is a highly labile C source. In contrast, WT drawdown has increased DOC aromaticity. Based on our findings, long-term WT manipulations can have a significant effect on peatland pore water DOC concentrations and chemical characteristics. Furthermore, these data suggest that WT position alone is not a reliable predictor of DOC

production/consumption dynamics. Removing impediments to surface flows could help to restore the original hydrology and possibly alleviate increased DOC concentrations. However, it is uncertain to what extent irreversible changes have been caused to the peat structure and carbon cycling dynamics.

\subsection{Acknowledgements}

The authors gratefully acknowledge Arielle Garrett and Jim Bess for help with site construction, as well as field and lab work. This research was supported by the U.S. Department of Energy's Office of Science (BER) through the Midwestern Regional Center of the National Institute for Climatic Change Research at Michigan Technological University. Additional support was provided by the Ecosystem Science Center at Michigan Technological University. The project would not have been possible without the cooperation of the Seney National Wildlife Refuge providing access to the site.

\subsection{Literature cited}

Amon, R. M. W. and R. Benner. 1996. Bacterial utilization of different size classes of dissolved organic matter. Limnology and Oceanography:41-51.

Anderson, N. and C. A. Stedmon. 2007. The effect of evapoconcentration on dissolved organic carbon concentration and quality in lakes of SW Greenland. Freshwater Biology 52:280-289.

Bano, N., M. A. Moran, and R. E. Hodson. 1998. Photochemical formation of labile organic matter from two components of dissolved organic carbon in a freshwater wetland. Aquatic microbial ecology 16:95-102. 
Barber, L. B., J. A. Leenheer, T. I. Noyes, and E. A. Stiles. 2001. Nature and transformation of dissolved organic matter in treatment wetlands. Environmental science \& technology 35:4805-4816.

Beckwith, C. W. and A. J. Baird. 2001. Effect of biogenic gas bubbles on water flow through poorly decomposed blanket peat. Water Resources Research 37:551-558.

Beer, J., K. Lee, M. Whiticar, and C. Blodau. 2008. Geochemical controls on anaerobic organic matter decomposition in a northern peatland. Limnology and Oceanography 53:1393-1407.

Bengtsson, G. and N. Törneman. 2004. Dissolved organic carbon dynamics in the peatstreamwater interface. Biogeochemistry 70:93-116.

Billett, M., D. Charman, J. Clark, C. Evans, M. Evans, N. Ostle, F. Worrall, A. Burden, K. Dinsmore, and T. Jones. 2010. Carbon balance of UK peatlands: current state of knowledge and future research challenges. Clim. Res 45:13-29.

Billett, M., S. Palmer, D. Hope, C. Deacon, R. Storeton-West, K. Hargreaves, C. Flechard, and D. Fowler. 2004. Linking land-atmosphere-stream carbon fluxes in a lowland peatland system. Global Biogeochemical Cycles 18:GB1024.

Blodau, C., N. Basiliko, and T. R. Moore. 2004. Carbon turnover in peatland mesocosms exposed to different water table levels. Biogeochemistry 67:331-351.

Blodau, C. and T. R. Moore. 2003. Experimental response of peatland carbon dynamics to a water table fluctuation. Aquatic Sciences-Research Across Boundaries 65:4762.

Blodau, C. and M. Siems. Drainage-induced forest growth alters belowground carbon biogeochemistry in the Mer Bleue bog, Canada. Biogeochemistry:1-17.

Chanton, J. P., J. E. Bauer, P. A. Glaser, D. I. Siegel, C. A. Kelley, S. C. Tyler, E. H. Romanowicz, and A. Lazrus. 1995. Radiocarbon evidence for the substrates supporting methane formation within northern Minnesota peatlands. Geochimica et Cosmochimica Acta 59:3663-3668.

Chasar, L., J. Chanton, P. Glaser, and D. Siegel. 2000. Methane concentration and stable isotope distribution as evidence of rhizospheric processes: comparison of a fen and bog in the Glacial Lake Agassiz peatland complex. Annals of Botany 86:655663.

Chen, M. Y., Y. Z. Chang, F. J. Lu, and J. L. Chen. 2010. Capillary Electrophoretic Determination of Selected Phenolic Compounds in Humic Substances of Well Waters and Fertilizers. Analytical Sciences 26:561-567. 
Chin, Y.; G. Alken; E. O’Loughlin. 1994. Molecular weight, polydispersity, and spectroscopic properties of aquatic humic substances. Environmental Science and Technology 28:1853-1858.

Chow, A. T., K. K. Tanji, S. Gao, and R. A. Dahlgren. 2006. Temperature, water content and wet-dry cycle effects on DOC production and carbon mineralization in agricultural peat soils. Soil Biology and Biochemistry 38:477-488.

Chow, T., H. Rees, I. Ghanem, and R. Cormier. 1992. Compactibility of cultivated Sphagnum peat material and its influence on hydrologic characteristics. Soil Science 153:300.

Clark, J., S. Bottrell, C. Evans, D. Monteith, R. Bartlett, R. Rose, R. Newton, and P. Chapman. 2010. The importance of the relationship between scale and process in understanding long-term DOC dynamics. Science of the Total Environment 408:2768-2775.

Clark, J. M., D. Ashley, M. Wagner, P. Chapman, S. Lane, C. Evans, and A. L. Heathwaite. 2009. Increased temperature sensitivity of net DOC production from ombrotrophic peat due to water table draw-down. Global Change Biology 15:794807.

Cornel, P. K., R. S. Summers, and P. V. Roberts. 1986. Diffusion of humic acid in dilute aqueous solution. Journal of colloid and interface science 110:149-164.

Davidson, E. A. and I. A. Janssens. 2006. Temperature sensitivity of soil carbon decomposition and feedbacks to climate change. Nature 440:165-173.

Evans, C., D. Monteith, and D. Cooper. 2005. Long-term increases in surface water dissolved organic carbon: observations, possible causes and environmental impacts. Environmental Pollution 137:55-71.

Fenner, N. and C. Freeman. 2011. Drought-induced carbon loss in peatlands. Nature Geoscience.

Fenner, N., C. Freeman, A. Maurice, H. Harmens, B. Reynolds, and T. Sparks. 2007. Interactions between elevated CO2 and warming could amplify DOC exports from peatland catchments. Environmental science \& technology 41:3146-3152.

Fetter, C. W. and C. Fetter. 1994. Applied hydrogeology. Prentice Hall Nueva Jersey.

Fraser, C., N. Roulet, and T. Moore. 2001. Hydrology and dissolved organic carbon biogeochemistry in an ombrotrophic bog. Hydrological Processes 15:3151-3166. 
Freeman, C., C. Evans, D. Monteith, B. Reynolds, and N. Fenner. 2001. Export of organic carbon from peat soils. Nature 412:785.

Freeman, C., N. Fenner, N. Ostle, H. Kang, D. Dowrick, B. Reynolds, M. Lock, D. Sleep, S. Hughes, and J. Hudson. 2004. Export of dissolved organic carbon from peatlands under elevated carbon dioxide levels. Nature 430:195-198.

Freeman, C., M. Lock, and B. Reynolds. 1993. Climatic change and the release of immobilized nutrients from Welsh riparian wetland soils. Ecological Engineering 2:367-373.

Freeman, C., G. Liska, N. Ostle, M. Lock, B. Reynolds, and J. Hudson. 1996. Microbial activity and enzymic decomposition processes following peatland water table drawdown. Plant and Soil 180:121-127.

Frey, K. E. and L. C. Smith. 2005. Amplified carbon release from vast West Siberian peatlands by 2100. Geophys. Res. Lett 32:L09401.

Gorham, E. 1991. Northern peatlands: role in the carbon cycle and probable responses to climatic warming. Ecological applications 1:182-195.

Harrison, A. F., K. Taylor, A. Scott, J. Poskitt, D. Benham, J. Grace, J. Chaplow, and P. Rowland. 2008. Potential effects of climate change on DOC release from three different soil types on the Northern Pennines UK: examination using field manipulation experiments. Global Change Biology 14:687-702.

Heinselman, M. 1965. String bogs and other patterned organic terrain near Seney, Upper Michigan. Ecology:185-188.

Holl, B. S., S. Fiedler, H. F. Jungkunst, K. Kalbitz, A. Freibauer, M. Drosler, and K. Stahr. 2009. Characteristics of dissolved organic matter following 20 years of peatland restoration. Science of the Total Environment 408:78-83.

Horner, J. D., J. R. Gosz, and R. G. Cates. 1988. The role of carbon-based plant secondary metabolites in decomposition in terrestrial ecosystems. American Naturalist:869-883.

Hvorslev, M. J. 1951. Time lag and soil permeability in ground-water observations. DTIC Document.

Kalbitz, K., S. Solinger, J. H. Park, B. Michalzik, and E. Matzner. 2000. Controls on the dynamics of dissolved organic matter in soils: a review. Soil Science 165:277.

Kane, E. S., M. R. Turetsky, J. W. Harden, A. D. McGuire, and J. M. Waddington. 2010. Seasonal ice and hydrologic controls on dissolved organic carbon and nitrogen concentrations in a boreal-rich fen. J. Geophys. Res 115:G04012. 
Kang, H., S. H. Lee, S. M. Lee, and S. Jung. 2009. Positive relationships between phenol oxidase activity and extractable phenolics in estuarine soils. Chemistry and Ecology 25:99-106.

Kellner, E., J. Waddington, and J. Price. 2005. Dynamics of biogenic gas bubbles in peat: Potential effects on water storage and peat deformation. Water Resources Research 41:W08417.

Kielland, K. 1994. Amino acid absorption by arctic plants: implications for plant nutrition and nitrogen cycling. Ecology 75:2373-2383.

Klemenčič, A. K., N. Smolar-Žvanut, D. Istenič, and T. Griessler-Bulc. 2010. Algal community patterns in Slovenian bogs along environmental gradients. Biologia 65:422-437.

Kling, G. W., G. W. Kipphut, and M. C. Miller. 1991. Arctic lakes and streams as gas conduits to the atmosphere: Implications for tundra carbon budgets. Science 251:298.

Knauer, K. and J. Buffle. 2001. Adsorption of fulvic acid on algal surfaces and its effect on carbon uptake. Journal of Phycology 37:47-51.

Knorr, K. H. and C. Blodau. 2009. Impact of experimental drought and rewetting on redox transformations and methanogenesis in mesocosms of a northern fen soil. Soil Biology and Biochemistry 41:1187-1198.

Koehler, A. K., K. Murphy, G. Kiely, and M. Sottocornola. 2009. Seasonal variation of DOC concentration and annual loss of DOC from an Atlantic blanket bog in South Western Ireland. Biogeochemistry 95:231-242.

Kowalski, K. P. and D. A. Wilcox. 2003. Differences in sedge fen vegetation upstream and downstream from a managed impoundment. The American midland naturalist 150:199-220.

Krist, F. J. and D. P. Lusch. 2004. Glacial history of Michigan, USA: A regional perspective. Developments in Quaternary Sciences 2:111-117.

Kuhry, P. and D. H. Vitt. 1996. Fossil carbon/nitrogen ratios as a measure of peat decomposition. Ecology:271-275.

Laiho, R. 2006. Decomposition in peatlands: reconciling seemingly contrasting results on the impacts of lowered water levels. Soil Biology and Biochemistry 38:20112024. 
Laiho, R., H. Vasander, T. Penttilä, and J. Laine. 2003. Dynamics of plant-mediated organic matter and nutrient cycling following water-level drawdown in boreal peatlands. Global Biogeochemical Cycles 17:1053.

Lou, T. and H. Xie. 2006. Photochemical alteration of the molecular weight of dissolved organic matter. Chemosphere 65:2333-2342.

Mash, H., P. K. Westerhoff, L. A. Baker, R. A. Nieman, and M. L. Nguyen. 2004. Dissolved organic matter in Arizona reservoirs: Assessment of carbonaceous sources. Organic geochemistry 35:831-843.

McCune, B. and J. B. Grace. 2002. Analysis of ecological communities. MjM Software Design.

McKnight, D. M., E. W. Boyer, P. K. Westerhoff, P. T. Doran, T. Kulbe, and D. T. Andersen. 2001. Spectrofluorometric characterization of dissolved organic matter for indication of precursor organic material and aromaticity. Limnology and Oceanography:38-48.

McLatchey, G. P. and K. Reddy. 1998. Regulation of organic matter decomposition and nutrient release in a wetland soil. Journal of Environmental Quality 27:12681274.

Minkkinen, K., R. Korhonen, I. Savolainen, and J. Laine. 2002. Carbon balance and radiative forcing of Finnish peatlands 1900-2100-the impact of forestry drainage. Global Change Biology 8:785-799.

Moore, T. and M. Dalva. 2001. Some controls on the release of dissolved organic carbon by plant tissues and soils. Soil Science 166:38.

Moore, T., N. Roulet, and J. Waddington. 1998. Uncertainty in predicting the effect of climatic change on the carbon cycling of Canadian peatlands. Climatic Change 40:229-245.

Nagel, L. M., R. G. Corace III, and A. J. Storer. 2008. An Experimental Approach to Testing the Efficacy of Management Treatments for Glossy Buckthorn at Seney National Wildlife Refuge, Upper Michigan. Ecological Restoration 26:136-142.

Neff, J. C. and G. P. Asner. 2001. Dissolved organic carbon in terrestrial ecosystems: synthesis and a model. Ecosystems 4:29-48.

Pastor, J., J. Solin, S. D. Bridgham, K. Updegraff, C. Harth, P. Weishampel, and B. Dewey. 2003. Global warming and the export of dissolved organic carbon from boreal peatlands. Oikos 100:380-386. 
Preston, M. D., M. C. Eimers, and S. A. Watmough. 2011. Effect of moisture and temperature variation on DOC release from a peatland: Conflicting results from laboratory, field and historical data analysis. Science of the Total Environment.

Preston, M. D., M. C. Eimers, and S. A. Watmough. 2011. Effect of moisture and temperature variation on DOC release from a peatland: Conflicting results from laboratory, field and historical data analysis. Science of the Total Environment.

Price, J. S. 2003. Role and character of seasonal peat soil deformation on the hydrology of undisturbed and cutover peatlands. Water Resources Research 39:1241.

Quinn, J. M., M. Eriksson, J. L. Moseley, and S. Merchant. 2002. Oxygen Deficiency Responsive Gene Expression inChlamydomonas reinhardtii through a CopperSensing Signal Transduction Pathway. Plant physiology 128:463-471.

Reddy, K. R. and R. D. DeLaune. 2008. Biogeochemistry of wetlands: science and applications. CRC.

Reeve, A., D. Siegel, and P. Glaser. 2000. Simulating vertical flow in large peatlands. Journal of Hydrology 227:207-217.

Romanowicz, E. A., D. I. Siegel, J. P. Chanton, and P. H. Glaser. 1995. Temporal variations in dissolved methane deep in the Lake Agassiz peatlands, Minnesota. Global Biogeochemical Cycles 9:197-212.

Roulet, N. T. 2000. Peatlands, carbon storage, greenhouse gases, and the Kyoto Protocol: Prospects and significance for Canada. Wetlands 20:605-615.

Roulet, N. T., P. M. Lafleur, P. J. H. Richard, T. R. Moore, E. R. Humphreys, and J. Bubier. 2007. Contemporary carbon balance and late Holocene carbon accumulation in a northern peatland. Global Change Biology 13:397-411.

Rydin, H., J. K. Jeglum, and A. Hooijer. 2006. The biology of peatlands. Oxford University Press, USA.

Sachse, A., R. Henrion, J. Gelbrecht, and C. Steinberg. 2005. Classification of dissolved organic carbon (DOC) in river systems: influence of catchment characteristics and autochthonous processes. Organic geochemistry 36:923-935.

Schiff, S., R. Aravena, E. Mewhinney, R. Elgood, B. Warner, P. Dillon, and S. Trumbore. 1998. Precambrian shield wetlands: hydrologic control of the sources and export of dissolved organic matter. Climatic Change 40:167-188. 
Schuur, E. A. G., J. Bockheim, J. G. Canadell, E. Euskirchen, C. B. Field, S. V. Goryachkin, S. Hagemann, P. Kuhry, P. M. Lafleur, and H. Lee. 2008. Vulnerability of permafrost carbon to climate change: Implications for the global carbon cycle. BioScience 58:701-714.

Siegel, D., A. Reeve, P. Glaser, and E. Romanowicz. 1995. Climate-driven flushing of pore water in peatlands. Nature 374:531-533.

Sinsabaugh, R., H. Reynolds, and T. Long. 2000. Rapid assay for amidohydrolase (urease) activity in environmental samples. Soil Biology and Biochemistry 32:2095-2097.

Strack, M., E. Kellner, and J. Waddington. 2005. Dynamics of biogenic gas bubbles in peat and their effects on peatland biogeochemistry. Global Biogeochemical Cycles 19:GB1003.

Strack, M., J. Waddington, R. Bourbonniere, E. Buckton, K. Shaw, P. Whittington, and J. Price. 2008. Effect of water table drawdown on peatland dissolved organic carbon export and dynamics. Hydrological Processes 22:3373-3385.

Turunen, J. 2008. Development of Finnish peatland area and carbon storage 1950-2000. Boreal environment research 13:319-334.

Uyguner, C. S. and M. Bekbolet. 2005. Evaluation of humic acid photocatalytic degradation by UV-vis and fluorescence spectroscopy. Catalysis Today 101:267274.

Waddington, J. and N. Roulet. 1997. Groundwater flow and dissolved carbon movement in a boreal peatland. Journal of Hydrology 191:122-138.

Waiser, M. J. 2006. Relationship between hydrological characteristics and dissolved organic carbon concentration and mass in northern prairie wetlands using a conservative tracer approach. Journal of geophysical research 111:G02024.

Wallage, Z. E., J. Holden, and A. T. McDonald. 2006. Drain blocking: an effective treatment for reducing dissolved organic carbon loss and water discolouration in a drained peatland. Science of the Total Environment 367:811-821.

Weishaar, J. L., G. R. Aiken, B. A. Bergamaschi, M. S. Fram, R. Fujii, and K. Mopper. 2003. Evaluation of specific ultraviolet absorbance as an indicator of the chemical composition and reactivity of dissolved organic carbon. Environmental science \& technology 37:4702-4708. 
Whitfield, C. J., J. Aherne, J. J. Gibson, T. A. Seabert, and S. A. Watmough. 2010. The controls on boreal peatland surface water chemistry in Northern Alberta, Canada. Hydrological Processes 24:2143-2155.

Wickland, K. P., J. C. Neff, and G. R. Aiken. 2007. Dissolved organic carbon in Alaskan boreal forest: Sources, chemical characteristics, and biodegradability. Ecosystems 10:1323-1340.

Wieder, R. K. and D. H. Vitt. 2006. Boreal peatland ecosystems. Springer Verlag.

Wilcox, D. A., M. J. Sweat, M. L. Carlson, and K. P. Kowalski. 2006. A water-budget approach to restoring a sedge fen affected by diking and ditching. Journal of Hydrology 320:501-517.

Worrall, F. and T. Burt. 2004. Time series analysis of long-term river dissolved organic carbon records. Hydrological Processes 18:893-911.

Worrall, F., T. Burt, and J. Adamson. 2006. Trends in drought frequency-the fate of DOC export from British peatlands. Climatic Change 76:339-359.

Worrall, F., T. Burt, R. Jaeban, J. Warburton, and R. Shedden. 2002. Release of dissolved organic carbon from upland peat. Hydrological Processes 16:3487-3504.

Worrall, F., M. Reed, J. Warburton, and T. Burt. 2003. Carbon budget for a British upland peat catchment. The Science of the Total Environment 312:133-146.

Wyatt, K. H. and R. J. Stevenson. 2010. Effects of acidification and alkalinization on a periphytic algal community in an Alaskan wetland. Wetlands:1-10.

Wyatt, K. H., M. R. Turetsky, A. R. Rober, D. Giroldo, E. S. Kane, and R. J. Stevenson. 2011. Contributions of algae to GPP and DOC production in an Alaskan fen: effects of historical water table manipulations on ecosystem responses to a natural flood. Oecologia:1-12.

Yallop, A. R., B. Clutterbuck, and J. Thacker. 2010. Increases in humic dissolved organic carbon export from upland peat catchments: the role of temperature, declining sulphur deposition and changes in land management. Clim Res 45:43-56. 


\subsection{Tables}

\section{Table 3.1}

Vertical hydraulic gradients (VHG) (2010 and 2011) determined from head differences in piezometers nests across the WT treatments (intermediate, raised, and lowered). Negative values represent upwelling and positive values downwelling.

\begin{tabular}{lcccc}
\hline & \multicolumn{2}{c}{2010} & \multicolumn{2}{c}{2011} \\
Treatment & $25 \mathrm{~cm}-50 \mathrm{~cm}$ & $50 \mathrm{~cm}-75 \mathrm{~cm}$ & $25 \mathrm{~cm}-50 \mathrm{~cm}$ & $50 \mathrm{~cm}-75 \mathrm{~cm}$ \\
\hline Intermediate & $-0.13(0.02)^{\mathrm{a}}$ & $0.44(0.08)^{\mathrm{a}}$ & $-0.08(0.03)^{\mathrm{ab}}$ & $0.24(0.08)^{\mathrm{a}}$ \\
Raised & $0.02(0.03)^{\mathrm{b}}$ & $0.32(0.09)^{\mathrm{a}}$ & $-0.03(0.01)^{\mathrm{a}}$ & $0.19(0.11)^{\mathrm{a}}$ \\
Lowered & $-0.15(0.01)^{\mathrm{a}}$ & $0.87(0.13)^{\mathrm{b}}$ & $-0.11(0.02)^{\mathrm{b}}$ & $0.61(0.12)^{\mathrm{b}}$ \\
\hline
\end{tabular}

Note: Values are seasonal means with \pm one standard error in parentheses. Different letters represent significant differences across WT treatments for each depth profile (Tukey's $\mathrm{p}<0.05$ ). 
Table 3.2

Bulk density $\left(\mathrm{g} \mathrm{cm}^{-3}\right)$ for in upper $50 \mathrm{~cm}$ peat horizon below the lawn microforms across the WT treatments (intermediate, raised, and lowered). Hydraulic conductivity $\left(\mathrm{K}_{\mathrm{sat}} ; \mathrm{cm} \mathrm{s}^{-1}\right)$ in the 25 and $50 \mathrm{~cm}$ piezometers across the three water table treatments.

\begin{tabular}{|c|c|c|c|c|}
\hline \multirow{6}{*}{ 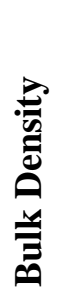 } & Depth $(\mathrm{cm})$ & Intermediate & Raised & Lowered \\
\hline & $0-10$ & $0.01(0.002)^{\mathrm{a}}$ & $0.02(0.003)^{\mathrm{a}}$ & $0.02(0.003)^{\mathrm{a}}$ \\
\hline & $10-20$ & $0.04(0.003)^{a}$ & $0.05(0.005)^{\mathrm{ab}}$ & $0.06(0.003)^{b}$ \\
\hline & $20-30$ & $0.04(0.003)^{\mathrm{a}}$ & $0.05(0.003)^{a b}$ & $0.06(0.004)^{b}$ \\
\hline & $30-40$ & $0.05(0.003)^{a}$ & $0.07(0.004)^{\mathrm{b}}$ & $0.09(0.008)^{\mathrm{C}}$ \\
\hline & $40-50$ & $0.07(0.007)^{\mathrm{a}}$ & $0.10(0.011)^{\mathrm{b}}$ & $0.12(0.008)^{b}$ \\
\hline \multirow{3}{*}{ 苞 } & Depth $(\mathrm{cm})$ & Intermediate & Raised & Lowered \\
\hline & 25 & $1.68(0.03)^{\mathrm{a}}$ & $0.52(0.05)^{b}$ & $0.77(0.14)^{b}$ \\
\hline & 50 & $0.51(0.06)^{a}$ & $0.03(0.02)^{b}$ & $3.6 \times 10^{-4}\left(1.2 \times 10^{-4}\right)^{b}$ \\
\hline
\end{tabular}

Note: Values are means with \pm one standard error in parentheses. Different letters represent significant differences across WT treatments for each depth (Tukey's p < $0.05)$. 


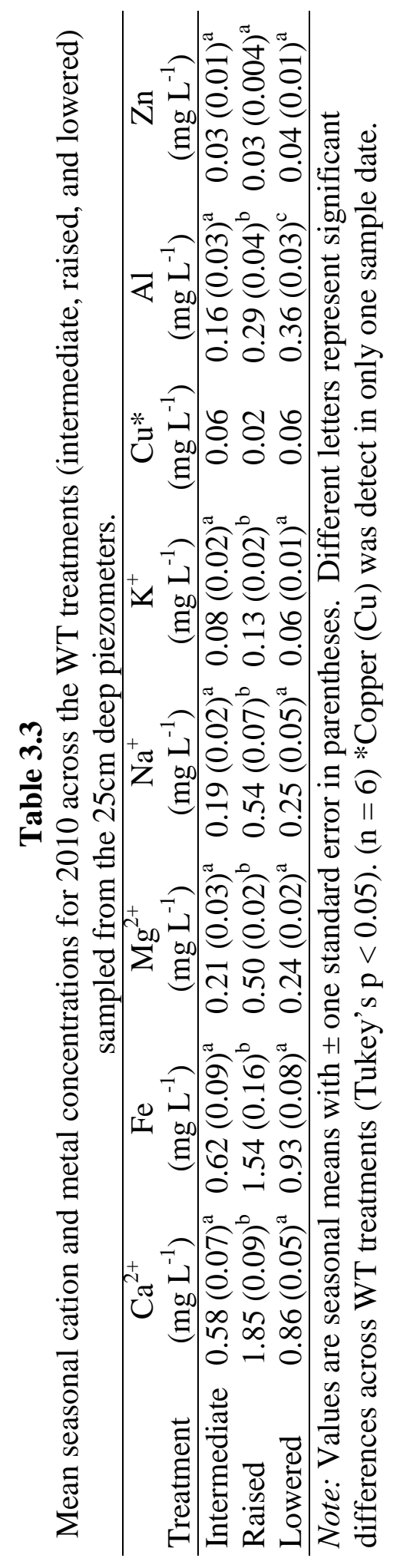


Table 3.4

Pearson $\left(\mathrm{r}^{2}\right)$ and Kendall ranked (tau) correlations of cation and environmental variables with ordination axis and a multi-response permutation procedure (MRPP) between the WT treatments (intermediate, raised, and lowered). The MRPP p-value tests for group differences, the A-value describes within-group homogeneity, and T-value describes the separation between groups.

\begin{tabular}{lcccc}
\hline & \multicolumn{2}{c}{ axis 1 } & \multicolumn{2}{c}{ axis 2 } \\
\cline { 3 - 5 } calcium & $\mathrm{r}^{2}$ & tau & $\mathrm{r}^{2}$ & tau \\
iron & 0.97 & 0.80 & 0.00 & 0.26 \\
magnesium & 0.92 & 0.71 & 0.01 & 0.21 \\
sodium & 0.87 & 0.65 & 0.01 & 0.12 \\
potassium & 0.79 & 0.71 & 0.04 & 0.15 \\
DOC & 0.22 & 0.36 & 0.24 & 0.39 \\
$\mathrm{~K}_{\text {sat }}$ & 0.33 & 0.47 & 0.45 & 0.49 \\
pH & 0.24 & -0.35 & 0.20 & -0.32 \\
conductivity & 0.11 & -0.09 & 0.50 & -0.60 \\
WT & 0.16 & 0.07 & 0.71 & 0.66 \\
& 0.53 & -0.31 & 0.22 & 0.35 \\
\cline { 2 - 5 } & & \multicolumn{3}{c}{ MRPP } \\
\cline { 2 - 5 } & & $\mathrm{T}$ & $\mathrm{A}$ & $\mathrm{P}$ \\
\hline Intermediate vs. Raised & -6.348 & 0.156 & $<0.001$ \\
Intermediate vs. Lowered & -10.087 & 0.280 & $<0.001$ \\
Raised vs. Lowered & -7.741 & 0.198 & $<0.001$ \\
\hline
\end{tabular}

Note: A more negative $\mathrm{T}$ the stronger the separation between groups. The greater the A-value the greater the similarity of sample units within groups. 


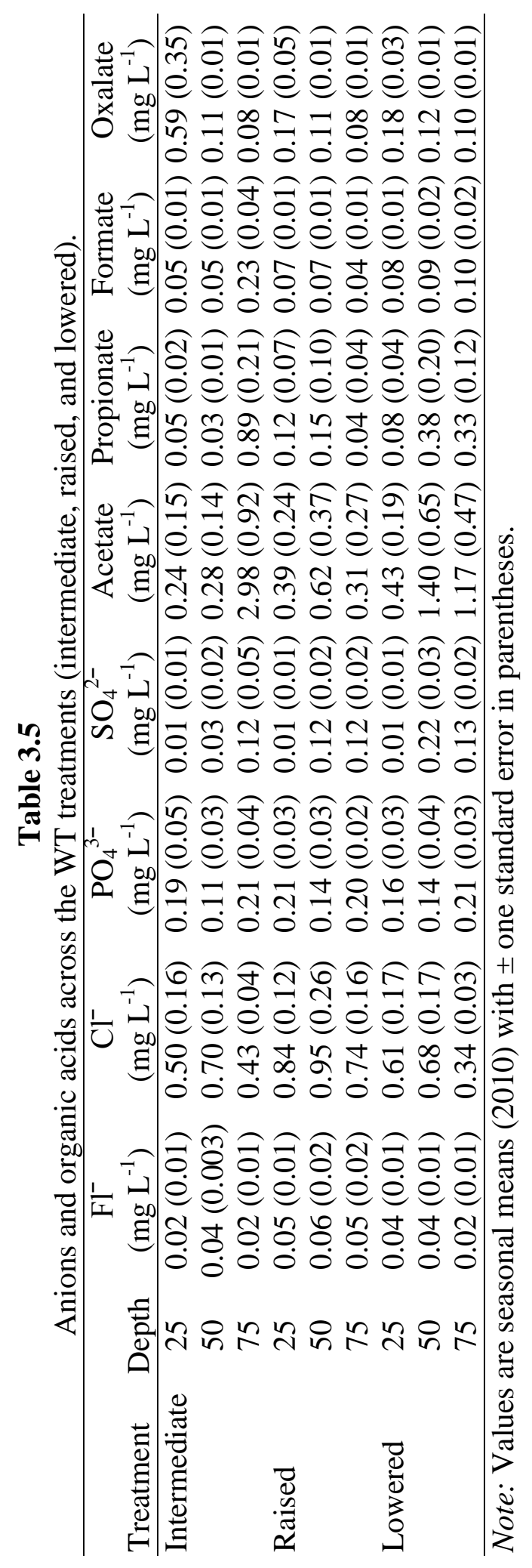




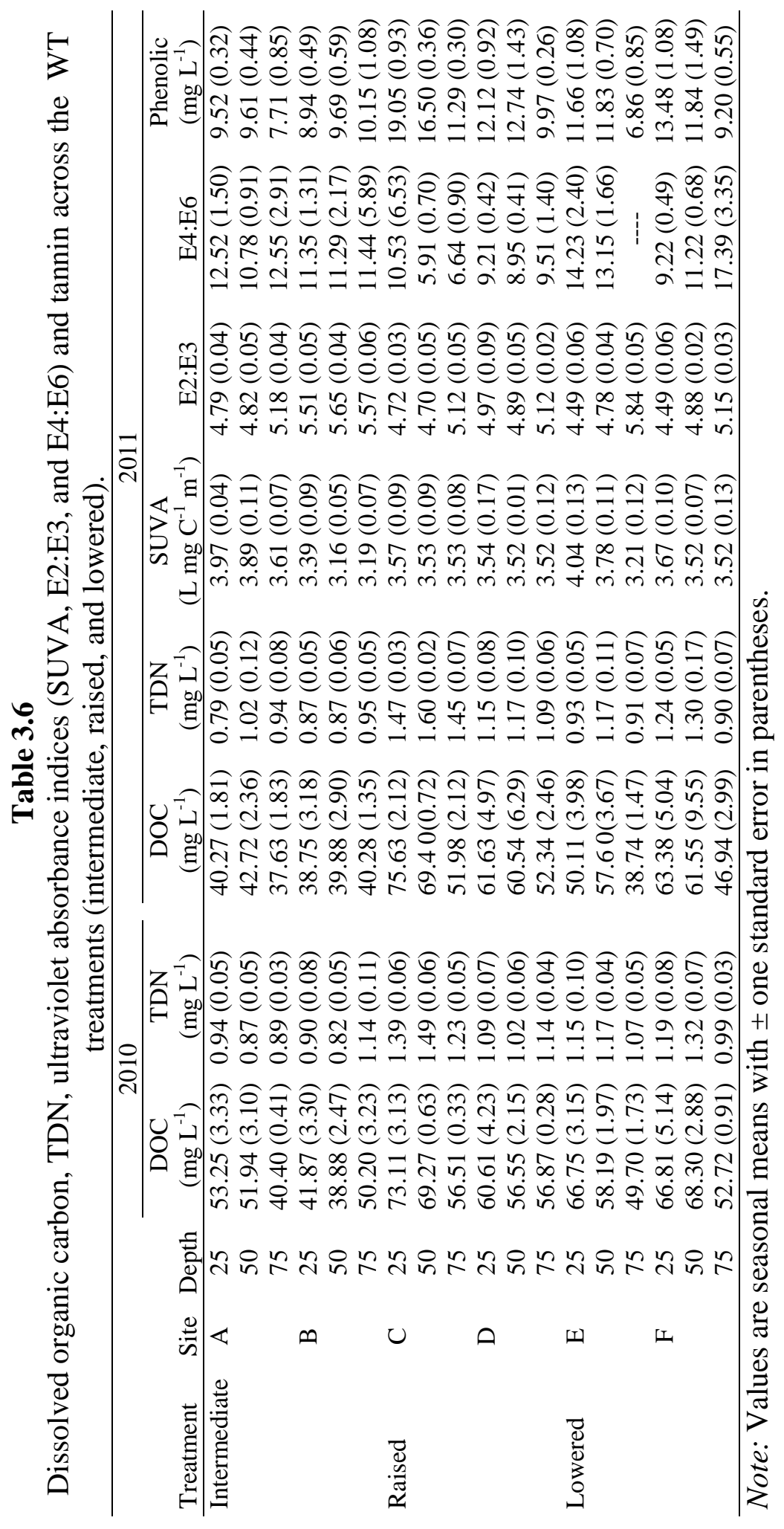




\section{Table 3.7}

Pearson $\left(\mathrm{r}^{2}\right)$ and Kendall ranked (tau) correlations of DOC physical and chemical characteristics with ordination axis and a multi-response permutation procedure (MRPP) between the WT treatments (intermediate, raised, and lowered). The MRPP p-value tests for group differences, the A-value describes within-group homogeneity, and T-value describes the separation between groups.

\begin{tabular}{lcccc}
\hline & \multicolumn{2}{c}{ axis 1 } & \multicolumn{2}{c}{ axis 2 } \\
& $\mathrm{r}^{2}$ & tau & $\mathrm{r}^{2}$ & tau \\
\hline DOC & 0.91 & -0.81 & 0.00 & 0.00 \\
E2:E3 & 0.27 & 0.25 & 0.66 & -0.60 \\
E4:E6 & 0.55 & 0.62 & 0.14 & 0.27 \\
phenolics & 0.47 & -0.48 & 0.06 & -0.14 \\
SUVA $_{254}$ & 0.00 & 0.06 & 0.88 & 0.74 \\
TDN $_{\text {Kat }}$ & 0.90 & -0.84 & 0.02 & -0.11 \\
K $_{\text {sat }}$ & 0.47 & 0.37 & 0.05 & -0.05 \\
\hline
\end{tabular}

\begin{tabular}{lrcr} 
& \multicolumn{3}{c}{ MRPP } \\
\cline { 2 - 4 } & $\mathrm{T}$ & $\mathrm{A}$ & \multicolumn{1}{c}{$\mathrm{P}$} \\
\hline Intermediate vs. Raised & -9.810 & 0.422 & $<0.001$ \\
Intermediate vs. Lowered & -6.765 & 0.202 & $<0.001$ \\
Raised vs. Lowered & -2.681 & 0.086 & 0.025 \\
\hline
\end{tabular}

Note: A more negative $\mathrm{T}$ the stronger the separation between groups. The greater the A-value the greater the similarity of sample units within groups. 
Table 3.8

Results from 'best subset regression' analysis to determine the best predictors of potential DOC mineralization.

\begin{tabular}{ccccc}
\hline Variable & Coef. & Std. & $\mathrm{t}$ & $\mathrm{p}$ \\
\hline Constant & 35.49 & 6.45 & 5.5 & $<0.001$ \\
Water table & 4.08 & 0.87 & 4.7 & 0.001 \\
SUVA $_{254}$ & -10.63 & 2.25 & -4.73 & 0.001 \\
Overall R $^{2}=0.72$ & & & & \\
\hline
\end{tabular}




\subsection{Figures}

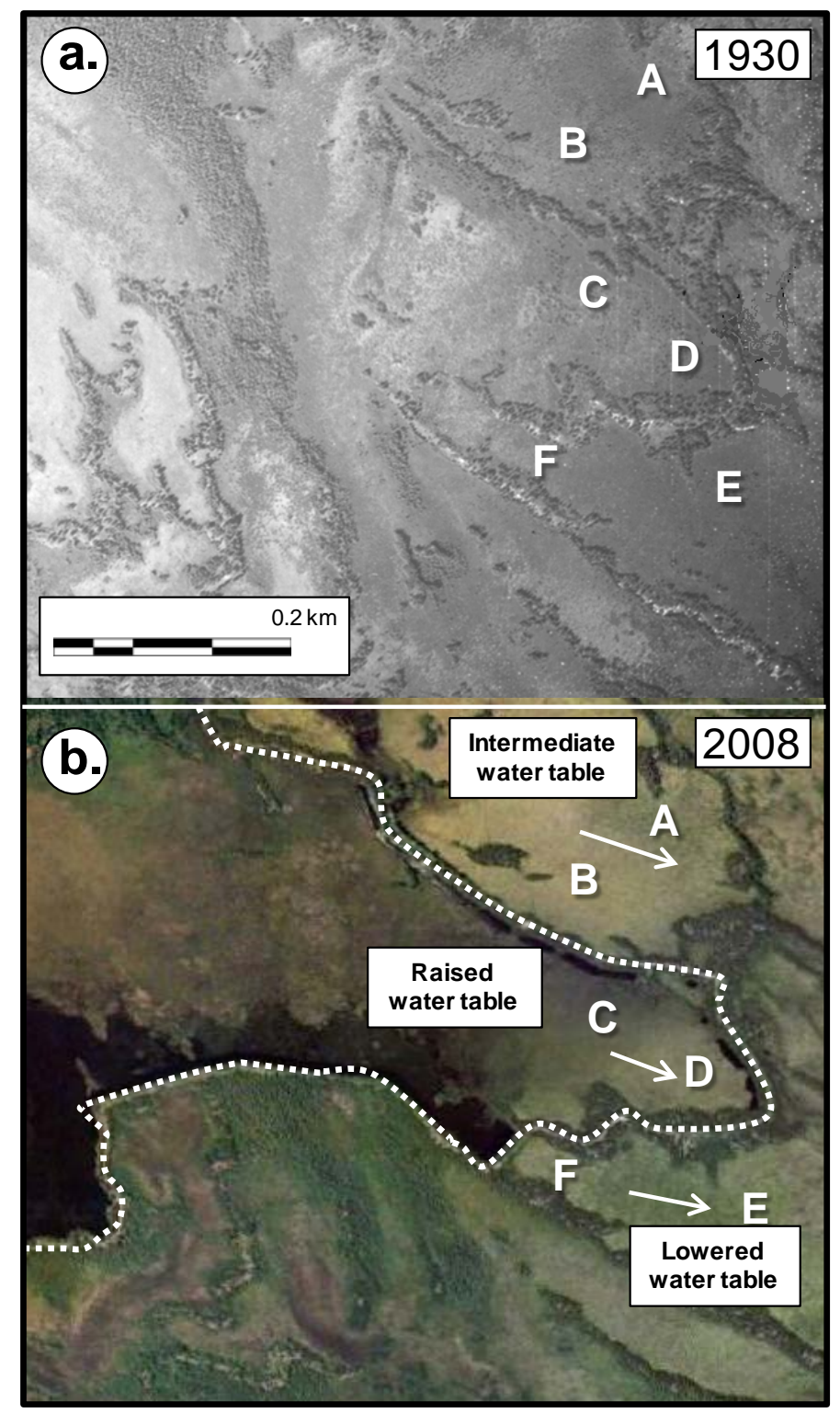

Figure 3.1 (a). Arial photograph from 1930 before the earthen levee was constructed. (b). Arial photograph from 2008 illustrating location of the six research sites positioned across the three water table treatments. Surface water impounding behind the levee has elevated the water table at sites $\mathrm{C}$ and $\mathrm{D}$ and lowered the water table at sites $\mathrm{E}$ and $\mathrm{F}$. Arrows indicate approximate water flow paths within each treatment based on horizontal hydraulic gradients between sites. Image in panel (b): Google Earth 2012. Seney, Michigan, 46²11'15.22" N 8600'54.93" W, elevation 683ft., Accessed 8 October 2012. 


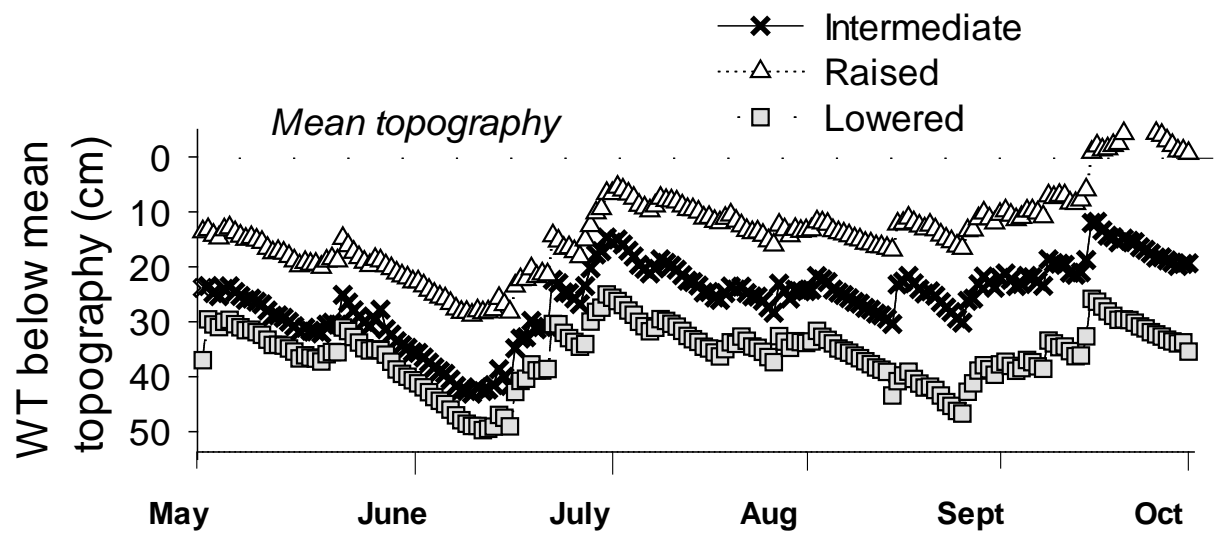

Figure 3.2 Position of seasonal two year mean (2010 and 2011) WT's in relation to the mean topography across the WT treatments (intermediate, raised, and lowered). Elevations are referenced to an arbitrary common datum set at zero. 


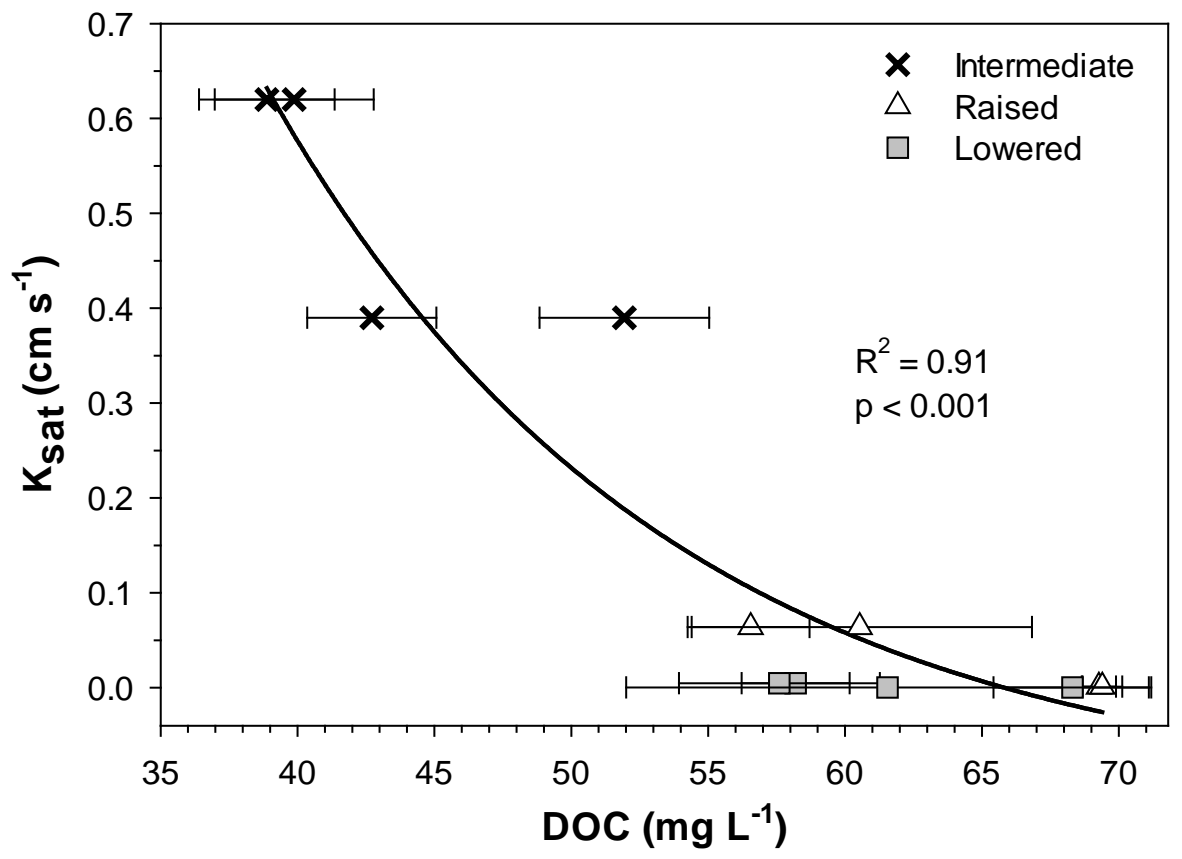

Figure 3.3 Relationship between hydraulic conductivity $\left(\mathrm{K}_{\mathrm{sat}}\right)$ and mean seasonal DOC concentrations (mean \pm one SE) at $50 \mathrm{~cm}$ below the peat surface across the WT treatments (intermediate, raised, and lowered). There was an effect of $\mathrm{K}_{\text {sat }}$ on DOC across the WT treatments (ANCOVA; $\mathrm{F}=35.57, \mathrm{p}<0.001$ ) and WT treatment by DOC interaction was significant (ANCOVA; $F=7.58$, $\mathrm{p}<0.001$ ). 


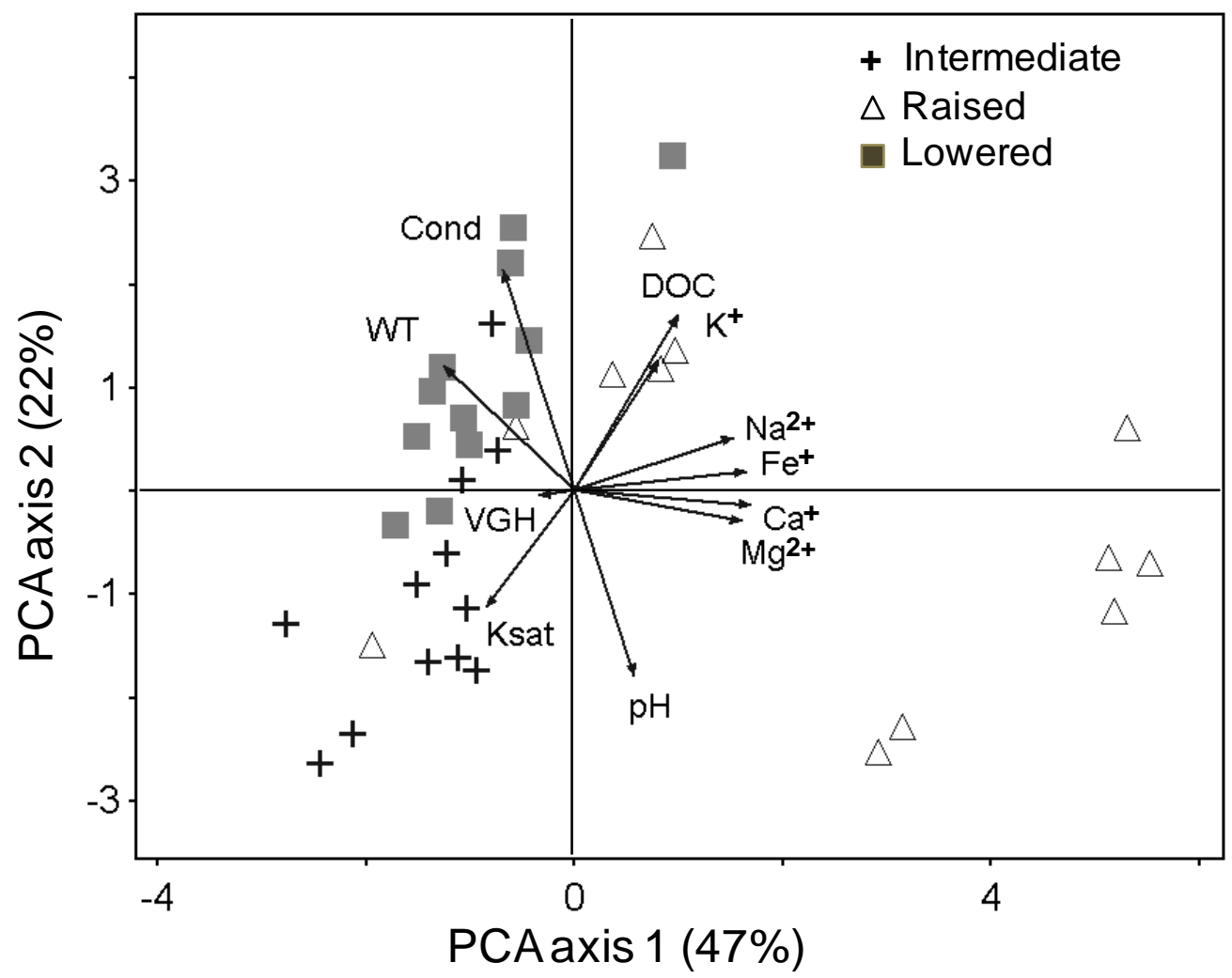

Figure 3.4 Principle component analysis (PCA) of pore water cations and environmental variables from the $25 \mathrm{~cm}$ piezometers across the WT treatments (intermediate, raised, and lowered). Each point represents an individual water sample collected throughout the 2011 field season. The first and second axis explains 47\% and $22 \%$ respectively of the variation in the ordination. 


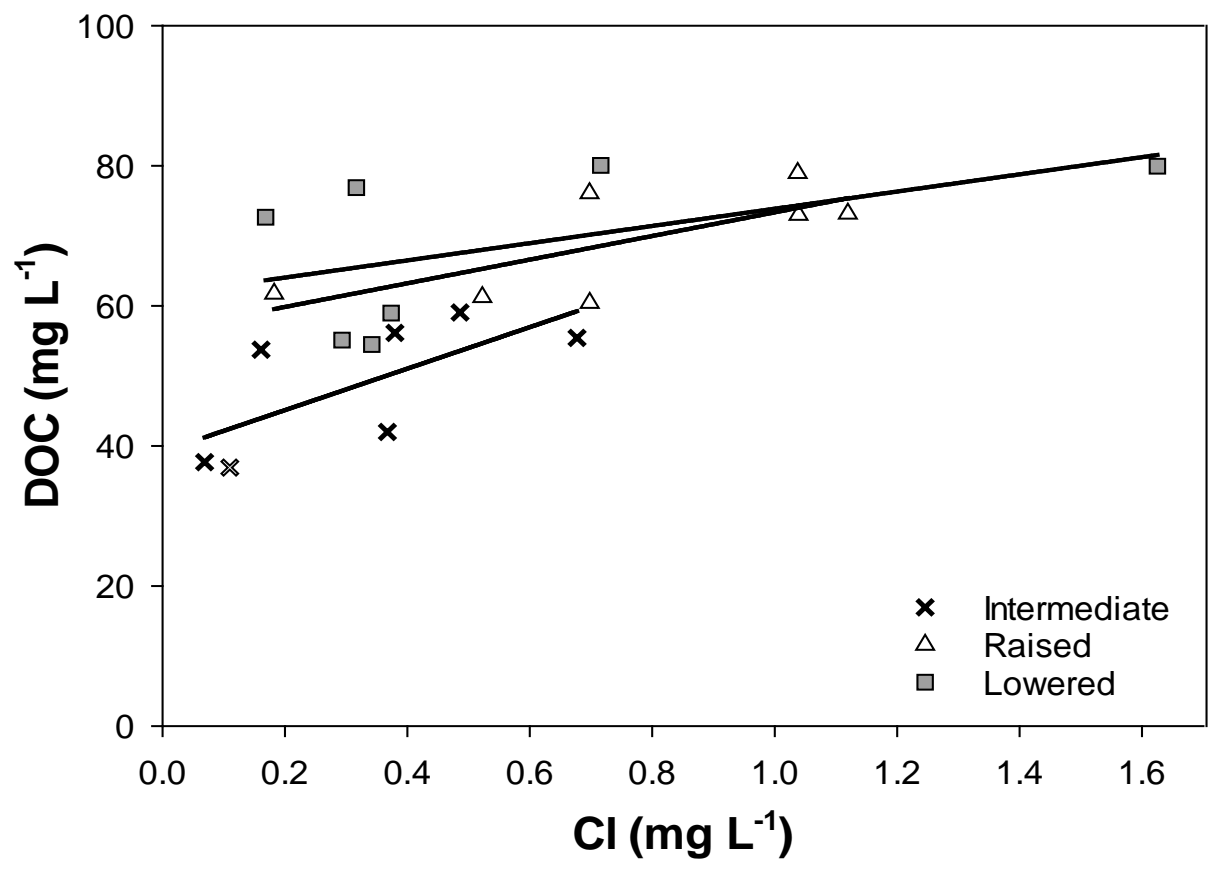

Figure 3.5 Relationship between DOC and Cl across the WT treatments (intermediate, raised, and lowered) from the $25 \mathrm{~cm}$ deep piezometers. There was no significant difference of DOC versus $\mathrm{Cl}$ as a function of WT treatments (ANCOVA; F $=0.54, \mathrm{p}=$ 0.59). 


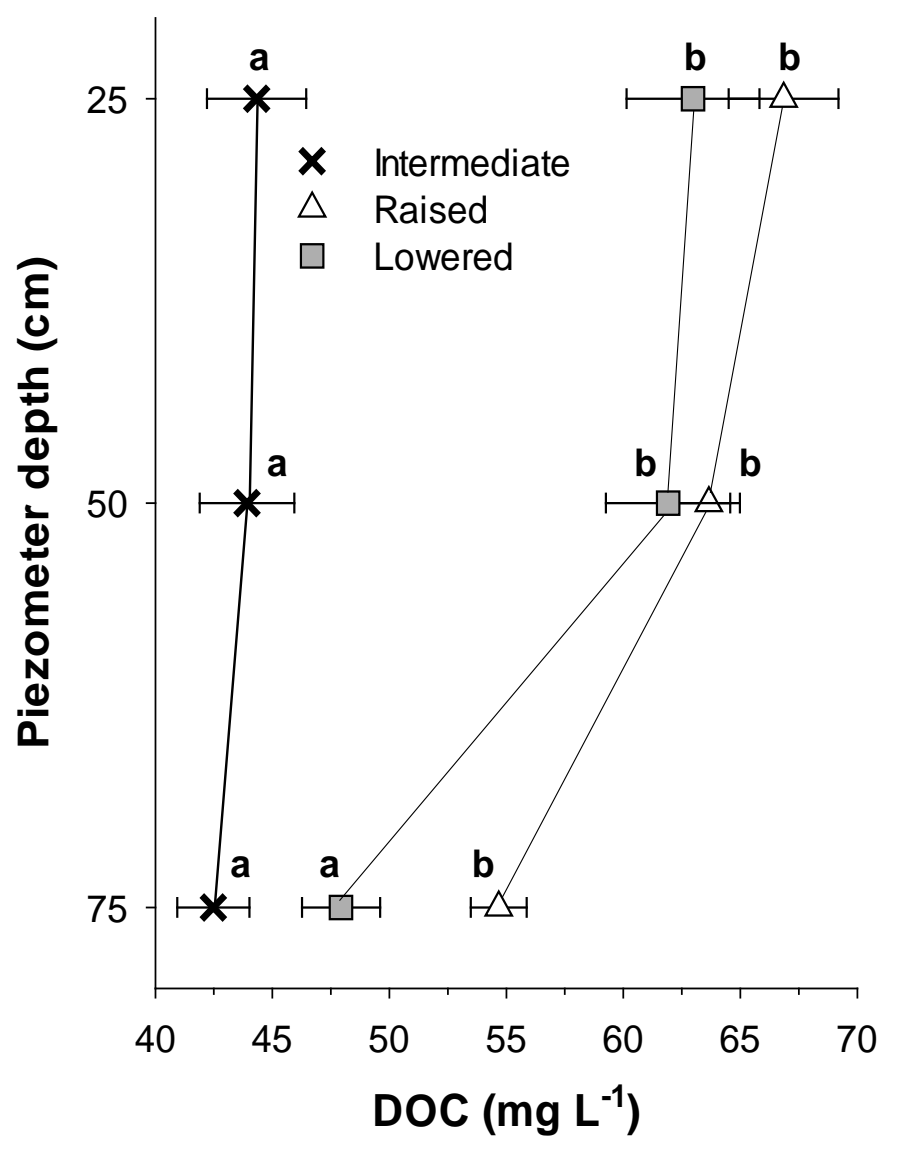

Figure 3.6 Two year (2010 and 2011) DOC concentrations (mean \pm one SE) across the water table treatments (intermediate, raised, and lowered) by depth of piezometer $(25,50$, and $75 \mathrm{~cm}$ ). Different letters above bars represent significant differences across WT treatments for each piezometer depth (Tukey's $\mathrm{p}<0.05$ ). 


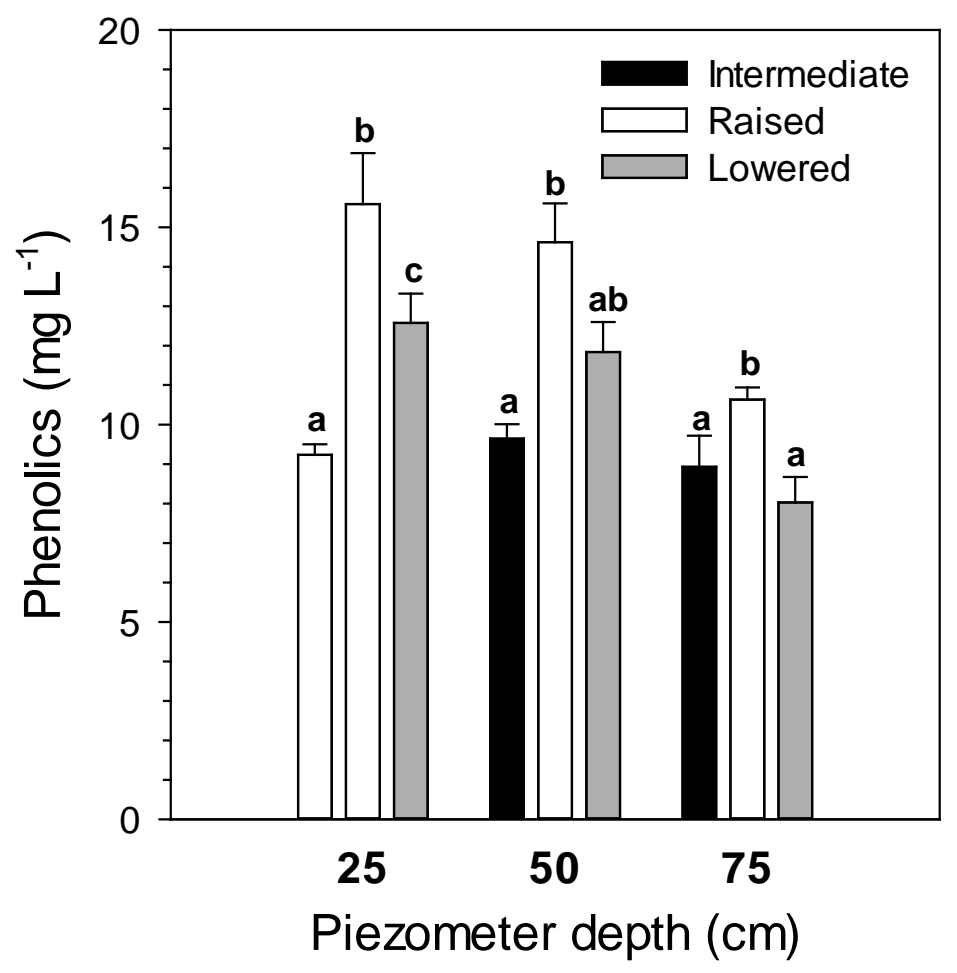

Figure 3.7 Phenolic concentrations (mean + one SE) across the WT treatments (intermediate, raised, and lowered) from piezometer pore water sampled at 25, 50,and 75 cm below the peat lawns. Different letters above bars represent significant differences across WT treatments for each depth (Tukey's $\mathrm{p}<0.05$; ${ }^{1} \mathrm{p}<0.10$ ). 


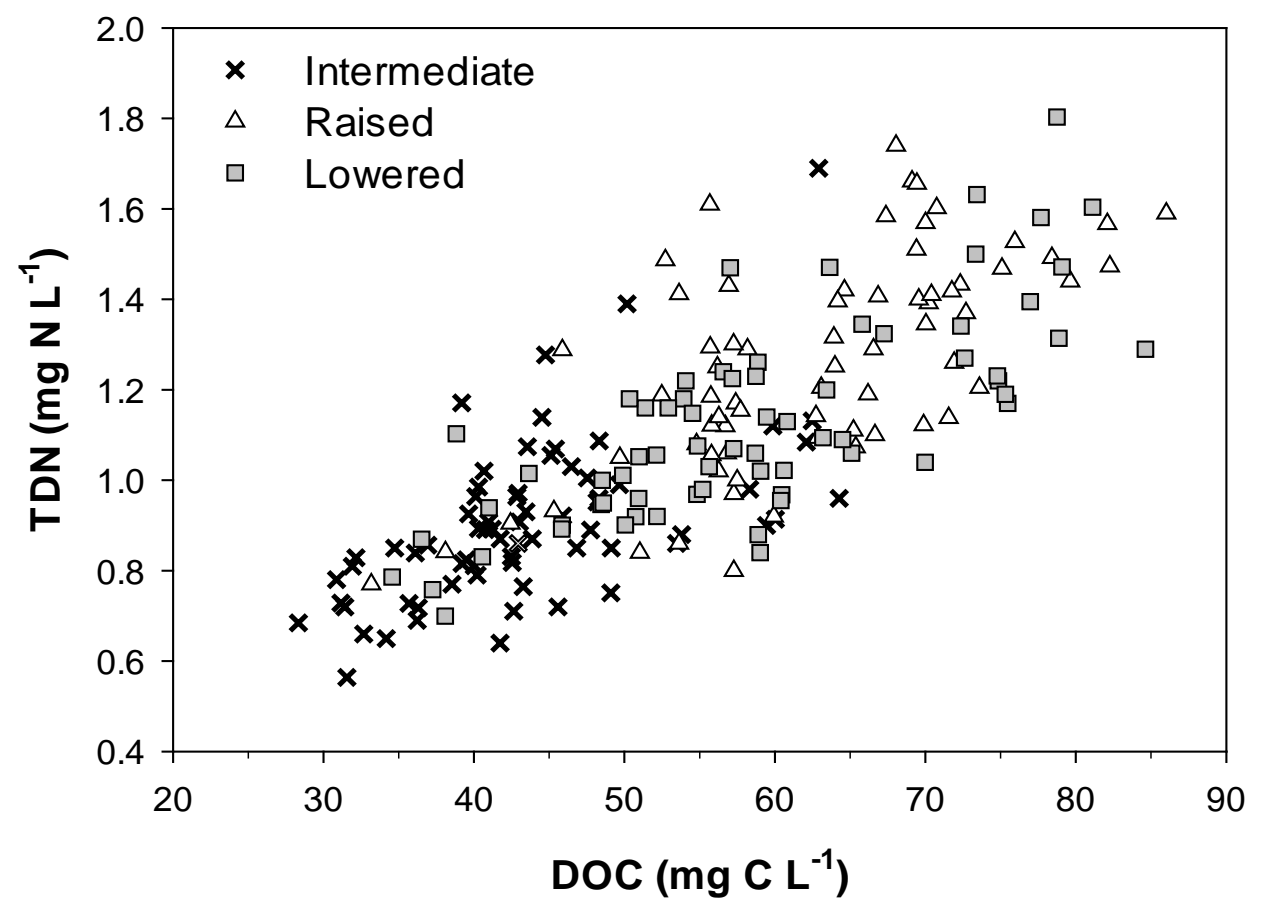

Figure 3.8 Relationship between TDN and DOC for the WT treatments (intermediate, raised, and lowered) including all piezometer sample depths (25, 50, and $75 \mathrm{~cm})$. There was no significant difference of TDN versus DOC as a function of WT treatments (ANCOVA; $\mathrm{F}=0.38, \mathrm{p}=0.68$ ). 

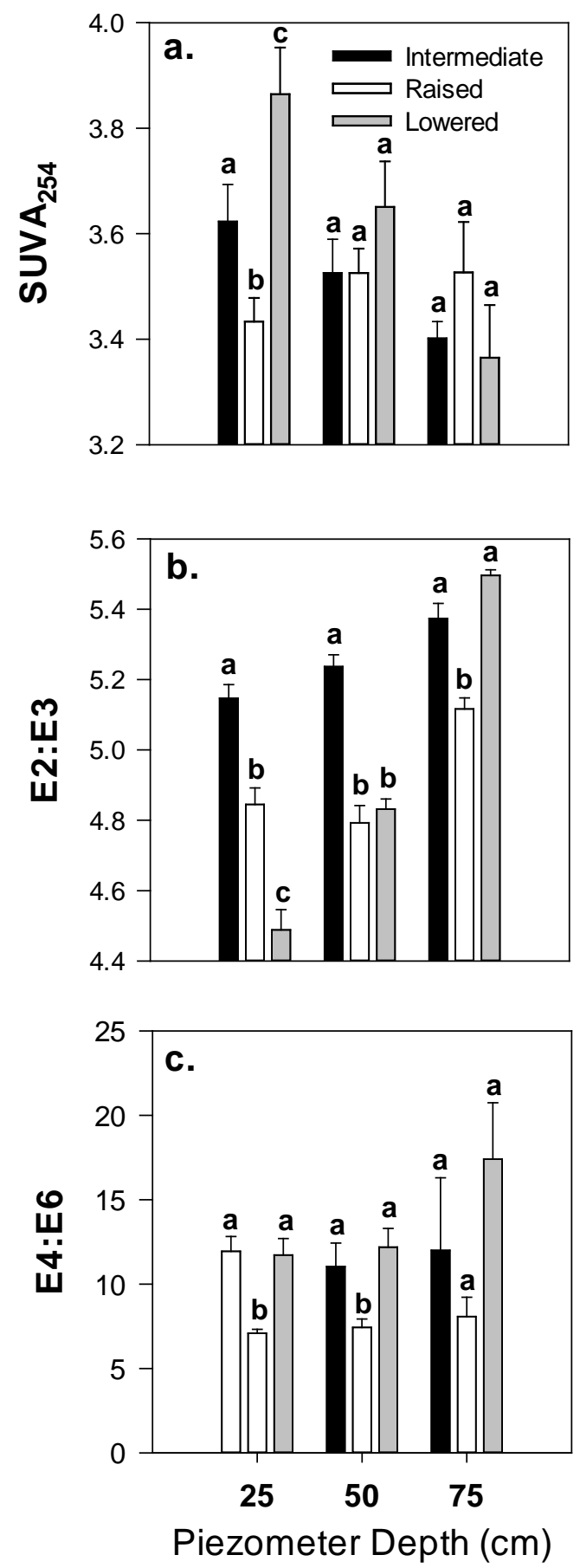

Figure 3.9 Pore water DOC spectral indices (mean + one SE) across the WT treatments (intermediate, raised, and lowered) and three depths (25, 50, and $75 \mathrm{~cm}$ ) from 2011 sampling season for (a). SUVA 254 (b). E2:E3 ratio (c). E4:E6 ratio. Different letters above bars represent significant differences across WT treatments for each depth (Tukey's $\mathrm{p}<0.05$ ). 


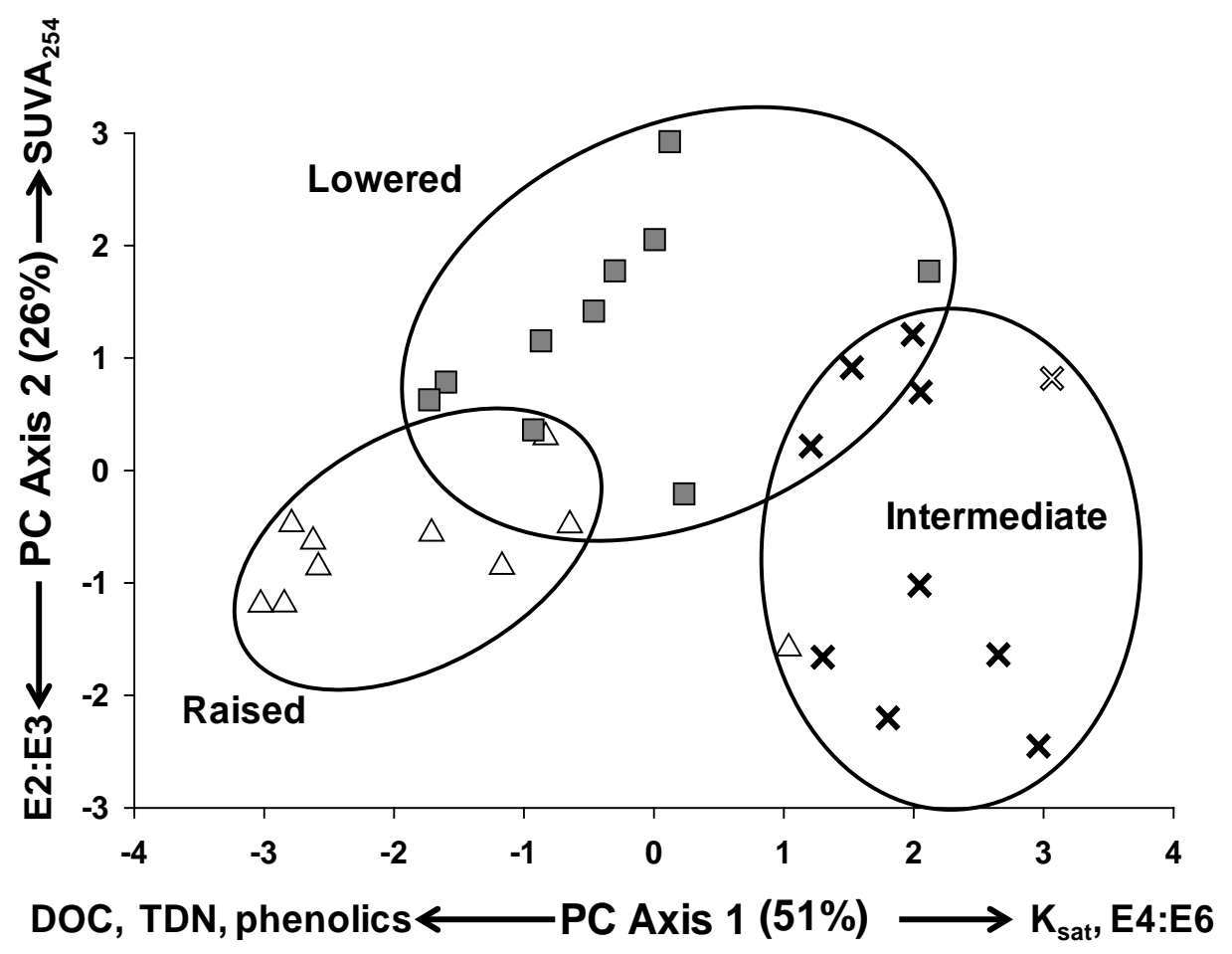

Figure 3.10 Principle component analysis (PCA) of pore water DOC quality indices from the $25 \mathrm{~cm}$ piezometers. Each point represents an individual water sample collected throughout the 2011 field season. The first and second axis explains 51\% and $26 \%$ respectively of the variation in the ordination. Ovals drawn around the individual water table treatments (intermediate, raised, and lowered) are for illustrative purposes and do not represent statistical significance. 


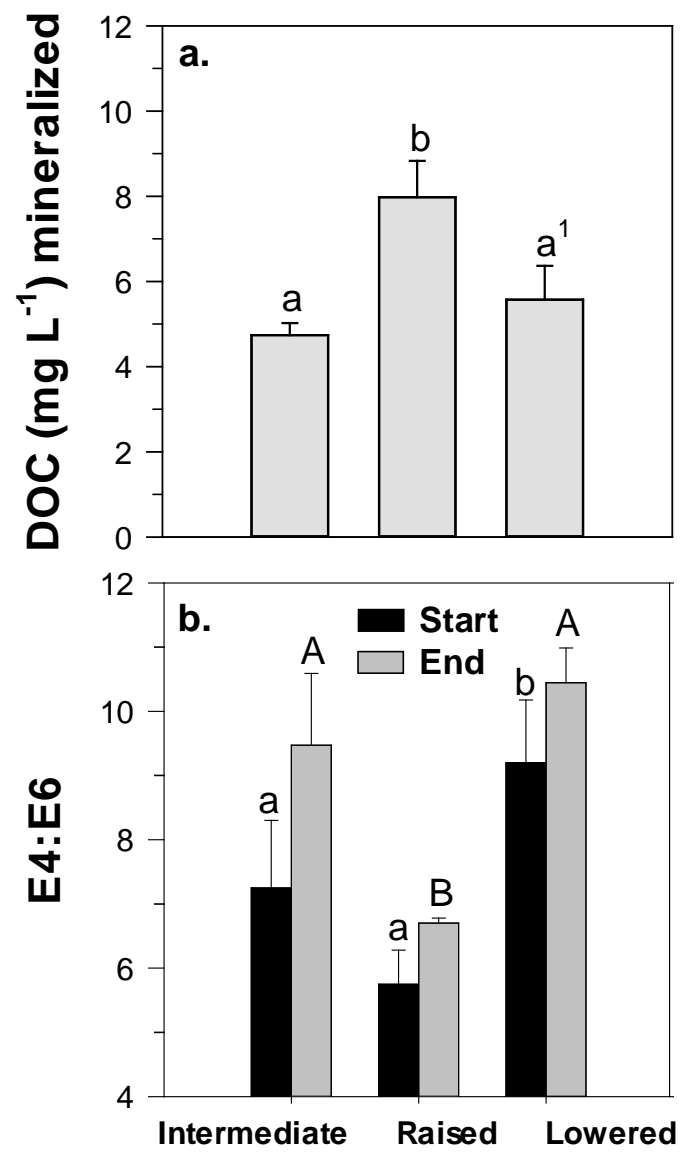

Figure 3.11 Incubation experiment conducted for 28 days with pore water collected at 25 $\mathrm{cm}$ below peat lawns at the three water table treatments (intermediate, raised, and lowered). (a). DOC mineralized for the entire 28 day incubation. (b). E4:E6 ratios at the beginning (time 0) and end (time 28) of incubation. Different letters above bars (mean + one SE) represent significant differences across WT treatments (Tukey's $p<0.05,{ }^{1} \mathrm{p}<$ $0.10)$. 


\section{Chapter 4. The Effect of Long-term Hydrology Changes on Peat Substrate Quality in a Northern Peatland ${ }^{1}$}

\subsection{Abstract}

Northern peatlands are large reservoirs of soil organic carbon and current climate change predictions estimate that increasing high latitude temperatures will alter the hydrology in northern peatlands. Therefore, it is uncertain how long-term changes in water table (WT) position will influence peat substrate quality with subsequent effects on carbon (C) and nitrogen (N) cycling. We investigated peat substrate quality and lability along a gradient of long-term water table (WT) alterations (intermediate, raised, and lowered) in a poor fen peatland in northern Michigan with Fourier transformed infrared (FTIR) spectroscopy, aerobic and anaerobic incubations, and $\mathrm{C}$ and $\mathrm{N}$ analysis. Canonical analysis of principle coordinates (CAP) ordination revealed differences in peat chemical constituent concentrations across the WT treatments. Additionally, hummock and lawn peat was chemically distinct in the lowered and intermediate WT treatments, but the raised WT treatment microforms had similar peat chemical characteristics. Lawn microform peat $\mathrm{N}$ concentrations in the raised and lowered WT treatments are greater than the intermediate WT treatment lawn peat and are displaying different down-core $\mathrm{N}$ stabilization rates. Potential anaerobic and aerobic peat $\mathrm{C}$ mineralization rates displayed differences between WT treatments and were related to peat quality. These results predict peatlands will experience significantly altered peat $\mathrm{C}$ and $\mathrm{N}$ cycling dynamics associated with long-term WT changes that may result from climate change.

\subsection{Introduction}

Northern peatlands are important long-term terrestrial carbon sinks (Vitt et al. 2000). The large reserves of organic matter (peat) stored in peatlands are created when anoxic waterlogged conditions favor net primary production over decomposition (Rydin

\footnotetext{
${ }^{1}$ The material contained in this chapter is planned for submission in the near future to the journal Biogeochemistry by Hribljan, J.A., Kane E.S., Pypker, T.G. and Chimner R.A. 
and Jeglum 2006). It is estimated high-latitude regions in the northern hemisphere contain more than $90 \%$ of the world's peatlands (Turetsky 2011) and store up to $25 \%$ of the global soil carbon (C) stocks (Roulet et al. 2007). Global weather pattern changes caused by increasing greenhouse gas concentrations in the upper atmosphere (ICPP 2007) has the potential to affect peatland $\mathrm{C}$ stocks by altering decomposition and primary productivity dynamics. Northern peatlands are anticipated to experience a $4-7^{\circ} \mathrm{C}$ rise in surface temperatures during the next century with subsequent alterations in hydrological conditions (Tarnocai 2006). Accelerated melting of permafrost is reported in boreal regions (Payette et al. 2004) and a greater variability of precipitation patterns in the northern hemisphere was measured for the twentieth century (Burkett and Kusler 2000; Tarnocai 2006). Since peatlands can influence atmospheric concentrations of greenhouse gases from fluxes of carbon dioxide $\left(\mathrm{CO}_{2}\right)$ and methane $\left(\mathrm{CH}_{4}\right)$ (Laine et al. 1996), it is important to understand how changes in hydrology will influence carbon cycling and contribute to potential climate change feedbacks.

Peatlands are sensitive to hydrological alterations (Aerta and Ludwig 1997; Blodau et al. 2004; Moore et al. in review) and subtle shifts in water table (WT) position can destabilize their C sequestering capacity (Bubier et al. 2003). However, there is uncertainty in the $C$ cycling trajectory of peatlands (McGuire et al. 2009) because climate induced hydrological changes can be multidimensional (Belyea and Malmer 2004; Whittington and Price 2006; Ise et al. 2008; Moore et al. in review). Northern peatlands experiencing an elevated WT have shown a decrease in $\mathrm{CO}_{2}$ production and increased $\mathrm{CH}_{4}$ emissions (Moore and Dalva 1993). In contrast, peatlands experiencing drier and warmer conditions are susceptible to WT draw-down that supports enhanced oxidative decomposition and increasing $\mathrm{CO}_{2}$ fluxes, but lower $\mathrm{CH}_{4}$ production due to aerobic conditions and enhanced methane oxidation (Strack et al. 2004).

Furthermore, the variability of peatland C fluxes observed from changes in WT position is tightly controlled by reduction and oxidation (redox) reactions within the peat column (Bladau 2002). Oxygen, the most energetically favorable terminal electron acceptor for microbial activity, is typically limited to the upper horizon of the peatland because of a low oxygen diffusion rate through saturated soil (Limpens et al. 2008). 
When the peatland WT is lowered, oxygen diffuses deeper into the peat and decomposition is accelerated. Additionally, aerobic conditions created by WT drawdown will reoxidize reduced alternative electron acceptor species in the peat that are utilized by microbes if anaerobic conditions are reestablished (Knorr and Bladau 2009). Therefore, WT position is critically important in establishing and controlling peatland thermodynamics that drive microbial decomposition of peat.

When redox conditions are favorable for decomposition, peatland $\mathrm{C}$ cycling is influenced by the substrate quality of the peat defined as the lability of $\mathrm{C}$ compounds and bioavailability of nutrients required for microbial metabolism (DeBusk and Reddy 1998). Substrate quality is primarily regulated by the chemical composition of peatland vegetation inputs (Moore et al. 2007). Peat is predominantly a heterogeneous mixture of partially decomposed plant material ranging from simple organic and inorganic compounds to highly complex large molecular weight organic C structures (Davidson and Janssens 2006) including, but not limited to carbohydrates, nitrogenous compounds, polyphenolics, nucleic acids, organic acids, and lipids (Rydin and Jeglum 2006). Because of the complex chemical composition of peat, it is difficult to efficiently and fully evaluate its substrate quality. Therefore, high throughput methods with fine resolution such as Fourier transformed infrared (FTIR) spectroscopy that simultaneously measures a large suite of chemical compounds are valuable techniques for peat characterization. FTIR has been successfully utilized to characterize and track changes in peat substrate quality (Chapman et al. 2001; Artz et al. 2008).

Additionally, peatland substrate quality is strongly regulated by nitrogen $(\mathrm{N})$, which is a primary constituent of peat organic matter (Rydin and Jeglum 2006). However, peatlands are likely $\mathrm{N}$ limited because predominately anoxic conditions limit microbial processing of organic matter that produces biologically available $\mathrm{N}$ for plant and microbial processes (Knicker 2004). In particular, ombrotrophic peatlands are principally dependant on internal $\mathrm{N}$ recycling because of low ground water nutrient inputs (Bridgham 1998). Moreover, organic matter stabilization during humification can affect $\mathrm{N}$ availability for biological processes by sequestering and storing $\mathrm{N}$ into deeper peat horizons (Knicker 2004). Retention of N into highly recalcitrant compounds has 
been shown to increase in anaerobic systems by $\mathrm{N}$ incorporation into protein-phenolic complexes (Olk et al. 2006). Phenolic compounds in peatlands are tightly regulated by WT position because the enzyme (phenolic oxidase) responsible for phenolic degradation requires bimolecular oxygen for activation (Freeman et al. 2006). The mechanisms of $\mathrm{N}$ stabilization related to climate induced changes in peatland WT is largely unexplored.

Peatland studies investigating short-term WT manipulations on peat substrate quality in situ (Prévost et al. 1999; Strack et al. 2004) and with laboratory incubations (Moore and Dalva 1993; Keller et al. 2004; Updegraff et al. 1995) have suggested that small changes in WT position can significantly influence substrate quality. However, it is unknown whether peat substrate quality changes will display similar trajectories between long-term and short-term WT alterations. Furthermore, most long-term WT investigations are from peatlands drained for forestry by ditching that typically display a dramatic drawdown of the WT (Wells and Williams 1996; Sundström et al. 2000; Laiho et al. 2008) that is not comparable to the predicted $14 \mathrm{~cm} \mathrm{WT}$ drawdown for northern peatlands under a 2 x CO 2 future climate change scenario (Roulet et al. 1992).

Lastly, peatlands are typically composed of a heterogeneous surface topography of microforms (hummocks and lawns) that react very differently to changes in WT position (Weltzin et al. 2001; Strack and Waddington 2008). Microforms contain site specific plant composition (Rydin and Jeglum 2006), decomposition rates (Strack and Waddington 2007), hydrological properties (Strack and Price 2009), and chemical and physical peat characteristics (Bubier et al.1993). Peat $\mathrm{N}$ pools and C mineralization rates are known to vary across peatland microtopographical formations (Biasi et al. 2005). Furthermore, peat physical and chemical differences are often masked when characterizing the peatland as one homogeneous surface and uncertainty exists in how these different microenvironments will respond to climate change (Belyea and Malmer 2004).

We examined a northern poor fen peatland to explore if subtle long-term alterations ( $\sim 70$ years) in WT position $( \pm \sim 10 \mathrm{~cm}$ ) have created changes in peat substrate quality. We utilized FTIR spectroscopy, nutrient extractions of peat, and laboratory incubations to tease apart the long-term effects of altered hydrology on peat substrate 
quality. We explored the hypothesis that: Long-term WT manipulations in a peatland will change peat substrate quality that will control peat $C$ mineralization. Therefore we predict that: a. Long-term WT drawdown will create a more recalcitrant peat with a lower potential C mineralization from historic aerobic conditions increasing heterotrophic peat mineralization. b. Long-term impoundment will suppress historic peat decomposition from saturated soil conditions creating peat that will have a greater substrate quality and increased peat C mineralization potential. Additionally, we hypothesized that: peatland $N$ pools and availability will display changes after long-term WT manipulations. In particular, peat $N$ stabilization will increase with long-term WT drawdown because of increased humification from long-term mineralization sequestering $N$ into recalcitrant compounds. However, long-term impoundment will increase $N$ availability by protecting peat substrates from mineralization because of anaerobic conditions.

\subsection{Methods}

\subsubsection{Study sites}

Our research sites are in the Seney National Wildlife Refuge (SNWR) located in the central portion of the Upper Peninsula of Michigan, USA. The greater landscape comprising SNWR is composed of a large sand plain (Heinselman 1954) consisting of well sorted sands, 0-60 m thick, deposited during the retreat of the Lake Michigan lobe of the Laurentide ice sheet (Krist and Lusch 2007). The sand plain covers a parent material of Ordovician sandstone, limestone, and dolomite (Wilcox et al. 2006). Two-thirds of the refuge is composed of a mosaic of marshes and peatlands (Nagel et al. 2008) interspersed with eskers formed from the underlining glacial sand. The sand plain has a gradual southeast slope of $1.89 \mathrm{~m} / \mathrm{km}$ (USFWS 2009). The climate of the refuge is greatly influenced by Lakes Michigan to the south and Lake Superior to the north. The average annual precipitation is $81 \mathrm{~cm}$ with an average annual snowfall of $312 \mathrm{~cm}$ (USFWS 2009). Annual average temperature is $5.1^{\circ} \mathrm{C}$ (Wilcox et al. 2006).

Six sites were established east of the Marsh Creek flooding $\left(46^{\circ} 11^{\prime} \mathrm{W}, 86^{\circ} 01^{\prime} \mathrm{N}\right)$ on a Sphagnum dominated poor fen peatland complex. The original hydrology was 
altered in the 1930's when the U.S. Fish and Wildlife Service constructed a series of earthen levees utilizing the existing eskers to create open water impoundments for migratory waterfowl habitat (Kowalski and Wilcox 2003) resulting in both the inundation and drying of peatlands. Our sites were positioned to take advantage of the hydrological alterations resulting from the levees intercepting southeastern sheetflow traveling across the refuge. Our sites are split equally between three different WT regimes; an intermediate (A and B), raised (C and D), and lowered ( $E$ and F). The levee has restricted surface flow to sites $\mathrm{E}$ and $\mathrm{F}$, hydrologically separating the area from sites $\mathrm{C}$ and D, which are currently inundated. Sites A and B were relatively unaffected by levee construction (Figure 4.1a).

\subsubsection{Hydrological monitoring}

Depth to WT at each site was monitored with a non-vented pressure transducers (Levellogger Junior Model 3001; Solinst, Canada) set at a recording interval of one hour placed in well pipes slotted the entire length inserted to the mineral soil. A barologger (Baralogger Gold Model 3001; Solinst, Canada) provided barometric compensation for

all pressure transducers. Water table elevations are in relation to the mean topography of each site. Microtopography was measured at $0.5 \mathrm{~m}$ increments along a $50 \mathrm{~m}$ transect centered at the monitoring well with a transit level. Well elevations across the WT treatments were surveyed relative to each other and referenced to a common datum.

\subsubsection{Peat physical and chemical analysis}

To conduct peat physical and chemical analysis of the upper peat horizon, six 10 cm diameter x $50 \mathrm{~cm}$ deep soil cores were extracted at each site split between hummock and lawn microforms in a regular systematic sampling design (McCune and Grace 2002) for a total of 48 cores across the three WT treatments. PVC pipes were carefully inserted into the peat by cutting around the perimeter of the pipe with a knife as the pipe was inserted into the peat. After extracting the peat core, the bottom and top of the PVC pipe were immediately capped to eliminate water loss. Cores were transported upright to Michigan Technological University's Wetland Laboratory, frozen, and then sectioned 
into $10 \mathrm{~cm}$ horizons with a bandsaw. Bulk density, gravimetric water content, percent carbon and nitrogen, and $\mathrm{C} / \mathrm{N}$ ratios were determined for each peat core horizon.

\subsubsection{Mineralization experiment}

Laboratory mineralization experiments provided a framework to examine substrate lability across the long-term WT treatments by constraining peat temperature, moisture conditions, and oxygen status (Bridgham et al. 1998). Twelve plots were established at each site in a regular systematic sampling design (McCune and Grace 2002) split between hummocks and lawns. Transects were positioned adjacent to the sampling locations for the $50 \mathrm{~cm}$ cores used in peat physical and chemical characterization. A $7 \mathrm{~cm}$ diameter x $20 \mathrm{~cm}$ deep core was extracted and the top $10 \mathrm{~cm}$ of the core that contained living plant material was discarded. An additional companion core was removed immediately adjacent to the mineralization core for FTIR analysis and determination of moisture content and bulk density. A total of 144 cores were collected, placed in individual zip lock bags, all head space air was pushed out, transported on ice in a cooler to Michigan Technological University’s Wetland Laboratory and placed in a refrigerator at $4^{\circ} \mathrm{C}$.

The mineralization experiment was started within 48 hours of peat collection and consisted of three treatments; aerobic hummock, aerobic lawn, and anaerobic lawn. Each treatment utilized 36 opaque incubation jars $(500 \mathrm{ml})$ fitted with septum lids. Peat was carefully hand sorted to remove large roots and twigs (> $2 \mathrm{~mm}$ ) without excessive disturbance to original peat bulk density and approximately $30 \mathrm{~g}$ wet mass was measured and then placed in each jar. The aerobic lawn treatment peat incubated at field moisture content did not significantly differ in water filled pore space (WFPS) between the intermediate, raised, and lowered WT treatments (mean \pm SE WFPS of 77.4 \pm 2.7, $81.3 \pm$ 2.3 , and $77.9 \pm 3.3$ respectively; $\mathrm{F}=0.58, \mathrm{p}=0.57$ ). Peat used in the aerobic hummock treatments were adjusted to $2500 \%$ gravimetric moisture content with reverse osmosis (RO) water to establish optimal moisture status for microbial activity in peat composed predominantly of Sphagnum mosses (Hogg 1993). Anaerobic lawn treatment peat was mixed into a 1:1 ratio with RO water (Keller et al. 2004). All jars were allowed to 
equilibrate for several days allowing for the sudden flush of carbon that can sometimes occur with sample disturbance and large root removal.

At the beginning of the experiment all jars were weighed. Aerobic treatments were loosely capped to allow air exchange and minimize moisture loss. Anaerobic treatment jars were flushed with a constant stream of nitrogen gas $\left(\mathrm{N}_{2}\right)$ for approximately 10 minutes while gently shaking jars to ensure any gas entrapped by the peat was removed and then jars were sealed (Bridgham and Richardson 1992). All of the jars were placed under a black sheet to eliminate light and incubated at $20^{\circ} \mathrm{C}$. Aerobic jars were weighed weekly and adjusted with RO water for any changes in moisture status for the duration of the experiment. During the $24 \mathrm{~h}$ sampling period aerobic jars were vented to the atmosphere and then lids were sealed. Headspace gas was sampled with a syringe (10 $\mathrm{ml}$ ) at time zero and $24 \mathrm{~h}$ (Hobbie et al. 2002) and analyzed for carbon dioxide $\left(\mathrm{CO}_{2}\right)$ on a GC chromatograph (Agilent, model 6890) with check standards run after every 12 samples. Respiration rate was calculated from the change in the $\mathrm{CO}_{2}$ concentration over the $24 \mathrm{~h}$ incubation period. Data was checked for nonnormal respiration rates that can be caused by leaking jars. After sampling head space gas, jars were vented to the atmosphere and then loosely capped to start the next incubation period. Anaerobic jars were analyzed for $\mathrm{CH}_{4}$ and $\mathrm{CO}_{2}$ on days 14, 28, and 60 on a GC chromatograph (Varian, model CP3800) and reported as head space gas produced during the proceeding incubation period (Keller et al. 2004). Concentrations of $\mathrm{CO}_{2}$ and $\mathrm{CH}_{4}$ from the aerobic and anaerobic incubations were corrected for head space volume based on the ideal gas law using atmospheric pressure and temperature. Carbon fluxes were adjusted for bulk density of each core and reported as $\mu \mathrm{g} \mathrm{CO}_{2}-\mathrm{C}$ and ng $\mathrm{CH}_{4}-\mathrm{C} \mathrm{cm}^{-3}$ oven dried peat day 1 .

Peat inorganic $\mathrm{N}$ extractions (ammonium $\left(\mathrm{NH}_{4}{ }^{+}\right)$and nitrate $\left(\mathrm{NO}_{3}{ }^{-}\right)$) were performed on peat from the aerobic and anaerobic hummock and lawn treatments at the beginning and conclusion of the experiment. Approximately $10 \mathrm{~g}$ wet mass of peat was extracted with $1 \mathrm{M} \mathrm{KCl}$, vacuum filtered, and immediately frozen until analysis. Concentrations of $\mathrm{NH}_{4}{ }^{+}$and $\mathrm{NO}_{3}{ }^{-}$were determined with salicylate and vanadium assays method respectively. Constituent concentrations $\mathrm{NH}_{4}{ }^{+}$and $\mathrm{NO}_{3}{ }^{-}$were corrected for bulk 
density and reported as ng $\mathrm{NH}_{4}{ }^{+}-\mathrm{N}$ and $\mathrm{NO}_{3}{ }^{-}-\mathrm{N} \mathrm{cm}^{-3}$ oven dried peat.

\subsubsection{IR spectroscopy}

Peat FTIR analysis was conducted on the companion cores harvested for the mineralization experiment. The entire core was oven dried at $65^{\circ} \mathrm{C}$, ground through a \#8 screen on a Wiley mill, and reduced to a fine powder with a ball mill grinder (SPEX CertiPrep 8000-series). The twelve cores collected at each site represented six lawn and six hummock samples that were bulked into two composite samples for each microform containing three cores. Therefore, each WT treatment was represented by four bulked samples for each microform. Samples were oven dried at $65^{\circ} \mathrm{C}$ to a constant mass to remove any moisture absorbed by the peat during grinding and sealed in glass vials prior to FTIR analysis. FTIR spectra of uniformly prepared mixtures of peat material and potassium bromide (KBr; ratio 1:6) were recorded using a Varian 800 Scimitar series FTIR (Varian, Inc, Palo Alto, CA, USA) equipped with a diffuse reflectance accessory (Pike Technologies, Madison, WI, USA). The FTIR spectrographs were normalized to a common baseline using four point rubber banding at 860, 1875, 2250, and $3825 \mathrm{~cm}^{-1}$ (OriginPro software, Northampton, MA, USA). Constituent relative absorbance peak heights were determined from the established baseline and used for peat qualitative indices. The ratios of 1060/1620 (polysaccharides/lignin) (Basiliko et al 2007), 1725/1620 (aromatics/lignin) (Kalbitz et al 1999), and 2920/1060 (lipids/polysaccharides) (McLaughton, personal communication) were used to calculate substrate quality indices. Peak height calculations are strongly correlated to peak areas $\left(r^{2}>0.99\right)$ providing reliable semiquantitative interpretation of constituent concentrations (Fraser et al. 2011).

\subsubsection{Statistical analysis}

Multivariate analysis was used to investigate the influence of WT position on FTIR spectroscopy peat characterization. All spectra were analyzed simultaneously using canonical analysis of principle coordinates (CAP) ordination (Anderson 2002). Spectra variables were initially reduced to a smaller subset of composite variables with 
unconstrained principal components analysis (PCA). Resulting PCA scores were then processed with constrained canonical discriminant analysis (CDA) based on chi-square distances using WT and topography as grouping factors since our goal was to determine whether there were differences in the spectra across the WT treatments (Anderson and Robinson 2003; Anderson and Willis 2003). Relationships between FTIR spectra and environmental data were examined with partial least squares (PLS) analysis. A PLS1 model was developed for each parameter utilizing leave one out cross validation. The final number of factors (latent variables) used in the predictive model were determined from the minimal root mean square error of cross validation (RMSECV), which prevents over-fitting of the model (ZhiChao et al. 2009). Evaluation of spectra peak height ratios across WT treatments was performed with two-way ANOVA's with microtopography and WT treatment as main effects (Minitab 2011).

We used a general linear model (PROC MIXED with repeated measures) generated using SAS software (SAS Institute Inc., Cary, NC, USA, version 8) with WT treatment (intermediate, raised, and lowered), microtopography (hummocks and lawns), $\mathrm{N}, \mathrm{C}$, mineral $\mathrm{N}$, bulk density, and date as predictor terms, WT x topography and WT x date as interactions, and date as repeated measure to interpret $\mathrm{CO}_{2}$ and $\mathrm{CH}_{4}$ incubation flux rates. The model used complex symmetry covariance structure for repeated measures analysis as determined by looking at the fit statistic and the Kenward and Roger's correction for degrees of freedom (Little et al. 2006). One-way ANOVA's were used to investigate peat physical and chemical traits of $\mathrm{C}, \mathrm{N}, \mathrm{C} / \mathrm{N}$ ratios, phenolics, gravimetric water content, bulk density, and $\mathrm{NH}_{4}{ }^{+}$and $\mathrm{NO}_{3}{ }^{-}$concentrations across the WT treatments. Peat down-core N concentrations were analyzed with correlation analysis and WT treatment effects explored with ANCOVA (Minitab 2011). Descriptive statistics were determined with Sigmastat software and comparisons between all treatments were conducted using Tukey's post hoc test with differences at $\mathrm{p}<0.05$ considered significant. 


\subsection{Results}

\subsubsection{Hydrology and surface topography}

Direction of water flow across the sites determined from hydraulic well head elevations matches the general northwest to southeast surface water flow path across the greater Seney landscape (Figure 4.1a). The expected differences in WT levels across the treatments were confirmed for 2010 and 2011 relative to mean microtopography of each site. The lowered WT sites south of the impoundment experienced the greatest WT draw-down with two year seasonal mean (April - October) WT of $36.6 \pm 5.7 \mathrm{~cm}$ (mean \pm 1 SD below mean topography). The raised WT treatment had the highest WT (14.4 \pm $6.9 \mathrm{~cm})$ while the intermediate treatment $(26.2 \pm 7.1 \mathrm{~cm})$ was staged between the raised and lowered WT treatments (Figure 4.1b).

\subsubsection{Soil core physical and chemical parameters}

Significant differences in bulk density, \%N, \%C, C:N ratio, and gravimetric water content across the three WT treatments were shown through combining the upper $50 \mathrm{~cm}$ soil core data from each microtopographical formation in each WT treatment. These results were similar to the trends measured for each soil horizon. Peat bulk density was similar for hummocks across the WT treatments $(\mathrm{F}=0.94, \mathrm{p}=0.394)$; however, the lawns displayed a higher bulk density in the lowered WT treatment compared to the intermediate treatment (Tukey's $\mathrm{p}=0.010$ ). Peat $\mathrm{N}$ concentrations were shown to be statistically similar across the WT treatment hummock formations $(F=2.89, p=0.060)$; however, the raised treatment hummocks did have slightly greater $\mathrm{N}$ concentrations than the intermediate treatment (Tukey’s $\mathrm{p}=0.055)$. In the lawns $\mathrm{N}$ was higher in the raised and lowered WT treatments than the intermediate treatment (Tukey’s p $=0.003$ and $\mathrm{p}=$ 0.017 respectively). The mean $\mathrm{C}: \mathrm{N}$ ratios were lower in the raised and lowered $\mathrm{WT}$ treatments for hummocks and lawns; however, only the raised treatment lawns displayed a significant result when compared to the intermediate treatment lawns (Tukey's $p=$ 0.018). Examining microtopography within each WT treatment showed that hummocks had significantly lower bulk density, $\mathrm{N}$, and C:N ratios for all three WT treatments (paired t-test $\mathrm{p}<0.001$ ) (Table 4.1). 
Nitrogen stabilization was explored by comparing down-core $\mathrm{N}$ concentrations across the WT treatments. The hummock microforms from all three WT treatments had a similar intercept indicating that surface peat in the $0-5 \mathrm{~cm}$ horizon was not significantly different $(\mathrm{F}=0.17, \mathrm{p}=0.85$ ), and differences in $\mathrm{N}$ accumulation were not detected as indicated by the similar line slopes $(F=0.61, p=0.55)$ between the treatments. Lawn microforms across the WT treatments also had similar intercepts $(F=0.59, \mathrm{p}=0.56)$; however, the raised and lowered WT treatments had significantly greater $\mathrm{N}$ accumulation down-core $(\mathrm{F}=0.23 .85, \mathrm{p}<0.001)$ (Figure 4.2).

\subsubsection{Nitrogen extractions}

Peat extractions before the mineralization experiment revealed high concentrations of $\mathrm{NH}_{4}{ }^{+}$in the lowered WT treatment lawns compared to raised and intermediate treatment lawns (Tukey’s $\mathrm{p}<0.001$ and $\mathrm{p}<0.001$ respectively). In addition, lawns in the lowered treatment contained higher concentrations of $\mathrm{NH}_{4}{ }^{+}$than the hummocks (Tukey's $\mathrm{p}=0.017$ ). Changes in $\mathrm{NH}_{4}{ }^{+}$concentrations were observed during the incubation experiment; however, because of the great variability within each treatment there were no significant effects during the incubation. Nonetheless, mean $\mathrm{NH}_{4}{ }^{+}$concentrations exhibited an increase in the lawns of the intermediate (18.9\%) and raised $(29.0 \%)$ WT treatments and a decrease in the lowered (6.5\%) WT treatment. Hummock peat $\mathrm{NH}_{4}{ }^{+}$concentrations increased in the intermediate, raised, and lowered WT treatments (18.1\%, 24.2\%, and 37.2\% respectively) during the incubation (Table 4.2).

Peat $\mathrm{NO}_{3}{ }^{-}$was significantly lower than $\mathrm{NH}_{4}{ }^{+}$concentrations across the three WT

treatments. Additionally, $\mathrm{NO}_{3}{ }^{-}$concentrations present at the beginning of the anaerobic incubation were not detected at the completion of the experiment confirming that anaerobic conditions were maintained in the incubation jars (Table 4.2).

\subsubsection{IR spectroscopy}

Infrared spectroscopy analysis of peat displayed very similar absorbance profiles across the entire wavelength profile; however, relative absorbance intensities were 
elevated in the raised and lowered WT treatments compared to the intermediateWT treatment (Figure 4.3). The lowered WT treatment displayed the largest relative absorbances for the lawn formations whereas the raised WT treatment had the highest absorbance values for the hummocks (Figure 4.4a). Pronounced absorbance peaks were present in all spectra that corresponded to published values for organic matter (Niemeyer et al. 1992; Haberhauer et al. 2000; Kačuráková and Wilson 2001; Artz et al. 2008): (1) a pronounced peak at $1060 \mathrm{~cm}^{-1}$ due to C-O stretching of polysaccharides; (2) a small peak at $1160 \mathrm{~cm}^{-1}$ from C-OH stretching indicative of polysaccharides; (3) distinctive peaks at 1265, 1371, and $1515 \mathrm{~cm}^{-1}$ caused by C-O stretching, C-H deformations, and aromatic $\mathrm{C}=\mathrm{C}$ stretching respectively attributed to lignin compounds; (4) a peak at $1426 \mathrm{~cm}^{-1}$ characteristic of humic acids (5) proteins were ascribed to a peak at $1550 \mathrm{~cm}^{-1}$ (6) a broad region between $1600-1650 \mathrm{~cm}^{-1}$ that is ascribed to $\mathrm{C}=\mathrm{C}$ aromatic stretching and asymmetric C-O stretch of lignin and/or aromatic or aliphatic carboxylates; (7) a sharp peak at $1720 \mathrm{~cm}^{-1}$ from $\mathrm{C}=\mathrm{O}$ stretching of carbonyl functions; (8) twin peaks at 2850 and $2930 \mathrm{~cm}^{-1}$ ascribed to the $\mathrm{CH}_{2}$ group of fats, lipids, and wax; and (9) broad band at 3400 $\mathrm{cm}^{-1}$ produced by O-H stretching in cellulose compounds (Figure 4.3). Comparing peatland microtopography within each WT treatment revealed hummocks in the raised WT treatment had a higher absorbance than lawns across the majority of the spectrum except for a broad region indicative of lignin $\left(1515 \mathrm{~cm}^{-1}\right)$ and $\mathrm{N}-\mathrm{H}$ compounds $\left(1550 \mathrm{~cm}^{-}\right.$ ${ }^{1}$ ). This trend was reversed for the intermediate and lowered WT treatments that generally had higher constituent concentration in the lawns excluding the region that represents polysaccharides (1030-1080 $\mathrm{cm}^{-1}$ ) (Figure 4.4b).

The CAP analysis of all 24 FT-IR peat samples resulted in a separation of the three WT treatments and the corresponding microtopography. The first four PCA axes $(\mathrm{m}=4)$ explaining $83.92 \%$ of the variance in original distance matrix were used in the CDA analysis. The final CAP analysis achieved a minimum misclassification error of 8.33\% and the first two squared canonical correlations were 0.976 and 0.856 . The multiresponse permutation (MRP) test statistics of trace statistic and first canonical correlation testing the a priori grouping of no significance between groups were both highly significant $(p=0.0001)$. The WT treatments were most strongly separated in the 
direction of axis one that explained the most variation in multivariate space. Axis two contributed strongly in the separation of microtography across the WT treatments (Figure 4.5). Correlation scores of predominant soil chemical groups agreed with constituent concentrations apparent in the spectra graphs. Most pronounced associations were elevated polysaccharides in hummocks and elevated lignin, phenolics, and proteins in the lawns. Cellulose was most strongly correlated with hummocks in the raised WT treatment. Fats, lipids, and waxes were most abundant in the lawns of the lowered WT treatment and in high concentrations in the intermediate lawns. Long carbon chain alkanes strongly correlated with hummocks across the WT treatments and were most pronounced in the raised WT treatments (Table 4.3).

Loading plots obtained from PLS regression analysis modeling describes the influence of each FTIR spectra wavelength and corresponding chemical group on the variability in the measured parameters of $\mathrm{TN}$ (total nitrogen), $\mathrm{C} / \mathrm{N}, \mathrm{N}_{\text {mineral }}$, and $\mathrm{CO}_{2}$ mineralized (Figure 4.6). The residual predictive deviation (RPD) and $r^{2}$ values from PLS regression provide a matrix to estimate reliability of the model for prediction with a model $\mathrm{r}^{2}>80 \%$ and RPD $>2.00$ shown to have strong predictive value for soils (Chang et al 2001). The peaks at 1550 and $1653 \mathrm{~cm}^{-1}$ (proteins) and 2850 and $2920 \mathrm{~cm}^{-1}$ (fats, wax, and lipids) were positively correlated with $\mathrm{TN}, \mathrm{N}_{\text {mineral }}$, and $\mathrm{CO}_{2}$ mineralized. The proteinaceous peaks displayed the highest relative absorbance and were most pronounced for the parameter $\mathrm{CO}_{2}$ mineralized with a model $\mathrm{r}^{2}=76 \%$ and RPD of 1.79 . The model predictive parameters $\mathrm{r}^{2}$ and RPD results were highest for TN and C/N (90.3\%, 2.40 and 89.2\%, 2.59 respectively). Polysaccharides displayed a negative correlation for TN, $\mathrm{N}_{\text {mineral, }}$ and $\mathrm{CO}_{2}$ mineralized. The $\mathrm{C} / \mathrm{N}$ ratio displayed similar trends; however, in the opposite direction of the previously listed parameters. The RMSECV values represent the goodness of fit for validation samples in relation to the regression line and were lower than the standard deviations for all parameters except $\mathrm{N}_{\text {mineral }}$ (Table 4.4).

Paired t-tests detected significant differences between topography (hummocks and lawns) within all three WT treatments for FTIR spectral ratios 2920/1060, 1725/1620, and 1060/1620. One-way ANOVA's detected a significant result between the raised and intermediate WT treatment hummocks for the three spectral ratios 2920/1060, 1725/1620, 
and 1060/1620 (Figure 4.7).

\subsubsection{Mineralization experiment}

Our general linear model showed that potential aerobic $\mathrm{CO}_{2}$ mineralization rates varied across and within each WT treatment. Microtopography was a highly significant variable explaining $\mathrm{CO}_{2}$ flux. Lawn aerobic $\mathrm{CO}_{2}$ mineralization rates were significantly greater than hummocks (intermediate $47.5 \%$, raised $29.4 \%$, and lowered $57.4 \%$ ) across the WT treatments $(\mathrm{F}=6.34, \mathrm{p}<0.001)$ (Figure 4.8a and $\mathrm{b}$ ). The general linear model variables bulk density, $\mathrm{N}_{\text {mineral, }}$ and $\mathrm{TN}$ were significant in explaining model variability ( $\mathrm{F}$ $=12.58, \mathrm{p}=0.001 ; \mathrm{F}=6.89, \mathrm{p}=0.009 ;$ and $\mathrm{F}=12.10, \mathrm{p}=0.001$ respectively). Total carbon was not a significant parameter in modeling $\mathrm{CO}_{2}$ production rates in the aerobic incubation $(\mathrm{F}=0.02 \mathrm{p}=0.891)$. Trends in aerobic $\mathrm{CO}_{2}$ production were consistent across the WT treatments and sample dates for lawns and hummocks (WT $\mathrm{x}$ topography $\mathrm{F}=$ 2.38, $\mathrm{p}=0.096$ and WT $\mathrm{x}$ date $\mathrm{F}=0.52, \mathrm{p}=0.724)($ Table 4.5).

Anaerobic incubation experiments produced significantly higher production rates of $\mathrm{CH}_{4}$ in the raised treatment compared to the intermediate (Tukey's $\mathrm{p}=0.02$ ) and lowered WT treatments (Tukey's $\mathrm{p}<0.001$ ) (Figure 4.6c). Bulk density, $\mathrm{N}_{\text {mineral, }} \mathrm{C}$, and $\mathrm{TN}$ did not have a significant effect explaining $\mathrm{CH}_{4}$ production (Table 4.6). A significant interaction between WT and time was detected because of the large increase in $\mathrm{CH}_{4}$ production in the raised treatment on day 28 of the incubation. Anaerobic $\mathrm{CO}_{2}$ was measured only on sample days 14 and 28 with no significant differences for the means of the two days $(\mathrm{F}=0.43, \mathrm{p}=0.650)$ across the intermediate, raised, and lowered WT treatments (5.96 $\pm 0.63,6.30 \pm 0.53$, and $5.57 \pm 0.49 \mathrm{nmol} \mathrm{C} \mathrm{g}^{-1}$ day $^{-1}$ respectively). The mean ratio of anaerobic $\mathrm{CO}_{2}: \mathrm{CH}_{4}$ for the first two incubation sample dates was different between the raised $(1199 \pm 132)$ and lowered $(1976 \pm 180)$ WT treatments (Tukey’s p < 0.001); however, no pairwise difference was detected for the intermediate treatment (1692 \pm 135). Examination of the ratio between aerobic and anaerobic $\mathrm{CO}_{2}$ production rates revealed no significant differences between the intermediate (2.2:1), raised (2.1:1), and lowered WT treatments $(3.1: 1)(\mathrm{F}=0.93, \mathrm{p}=0.40)$. 


\subsection{Discussion}

The objective of our study was to investigate peat substrate quality affects on C and $\mathrm{N}$ cycling dynamics due to the influence of long-term alterations in the seasonal mean WT $(\sim \pm 10 \mathrm{~cm})$ of a peatland. The gradient of WT's across our sites were established in the 1930's from levee construction, and this provided a unique opportunity to examine an in situ representation of potential climate induced changes to the WT of a northern peatland. We detected differences in peat substrate quality, potential C mineralization, and $\mathrm{N}$ accumulation rates. Our results suggest that peat biogeochemistry has not recovered from levee construction that altered the original hydrology across the peatland, and furthermore, the three WT treatments are currently displaying different $\mathrm{C}$ and $\mathrm{N}$ cycling trajectories.

\subsubsection{Long-term water table manipulation effects on peat quality}

\section{Peat physical characteristics}

Peat bulk density indirectly influences substrate quality through control of water status and air filled porosity that regulates microbial activity (Strong et al. 1998). Changes in peat bulk density are commonly observed with shifts in WT position (Whittington and Price 2006). Across our WT treatments, hummock bulk density was not different throughout the upper $50 \mathrm{~cm}$ peat profile. However, the lowered WT treatment lawn microforms have significantly denser peat than the intermediate WT treatment in the upper $50 \mathrm{~cm}$ peat horizon and this can be attributed to peat subsidence creating primary peat compression (Price 2003) and elevated decomposition reducing bulk density from the lower WT (Jukaine et al. 1995; Leifeld et al. 2011). We also detected an increased bulk density for the 30 - $50 \mathrm{~cm}$ peat horizon of the raised WT treatment lawns compared to the intermediate treatment. The increased bulk density was unexpected since an elevated WT is reported to create buoyancy in the peat column thereby decreasing effective stress and compression of the peat (Whittington and Price 2006); it should be noted that an elevated WT has the potential to cause collapse within the peat column (Schlotzhauer and Price 1999). Additionally, high WT's could 
accelerate leaching of surface peat and when followed by seasonal induced WT drawdown events could promote rapid decomposition and a subsequent reduction in bulk density (Blodau and Moore 2003). Furthermore, WT fluctuations can cause dissolved carbon from surface peat to percolate into deeper peat profiles contributing to higher bulk densities (Domisch et al. 1998).

Our results indicate that bulk density was a significant predictor of potential $\mathrm{CO}_{2}$ production in the aerobic incubations between the hummock and lawn microforms. The greater mineralization in the lawns is contributed to increased nutrient availability from a larger substrate nutrient pool (Bridgham et al. 1998), in particular the significantly greater $\mathrm{N}$ concentrations in the lawn microforms (Table 4.1). Since WT manipulations were only $\pm 10 \mathrm{~cm}$, the shifts in bulk density were not pronounced and did not contribute significantly to the changes in peat quality measured across the WT treatments.

\section{FTIR spectra of peat chemical composition}

The multivariate analysis of FTIR peat spectra (10-20 cm peat horizon) showed a significant separation of the three WT treatments and microforms displaying distinct groupings based on relative concentrations of organic compounds (Figure 4.5). We interpret differences in peat substrate quality across the WT treatments are primarily created by the long-term WT manipulations altering decomposition dynamics through changes in redox potential (Aerts and Ludwig 1997; Blodau et al. 2004). However, substrate quality differences between the microtopographic features (hummocks and lawns) within each WT treatment are potentially driven by a combination of vegetation inputs and moisture status. Chapman et al. (2006) also detected differences in peat quality related to vegetation structure and peat moisture status with FTIR analysis. C/N dynamics

The scope of the present research did not include organic compound analysis of moss and vascular plant litter contribution to peat chemistry. Litter chemistry can be changed by the influence of moisture stress on plant chemistry and nutrient use efficiency (Horner et al. 1988). We examined the $\mathrm{C} / \mathrm{N}$ ratio from the $0-5 \mathrm{~cm}$ peat horizon containing moss and recently deposited vascular plant litter to represent a general index of plant quality entering the peatland acrotelm to determine whether surface vegetation 
might be a dominate controller on the differences in peat substrate quality detected across the WT treatments by the FTIR analysis. The $\mathrm{C} / \mathrm{N}$ ratio is a primary index for substrate quality and strongly controls decomposition rates in organic soils (Hobbie 1992; Prescott 2008). Surface peat $\mathrm{C} / \mathrm{N}$ ratios were similar for hummocks and lawns when examining the microforms separately across the WT treatments (Table 4.1).

The lawn microforms at site $\mathrm{C}$ in the raised WT treatment deviates from this trend with a significantly lower $\mathrm{C} / \mathrm{N}$ ratio $(26.2 \pm 2.6)$ in comparison to the intermediate and lowered WT treatment lawns (Kruskal-Wallis $\mathrm{H}=24.5, \mathrm{p}<0.001$ ). The lower $\mathrm{C} / \mathrm{N}$ ratio is attributed to increased algal productivity. Algae have a low $\mathrm{C} / \mathrm{N}$ ratio (Wehr and Sheath 2003) and are abundant in peatland lawns and hollows, particularly during periods with standing water (Rydin and Jeglum 2006). Furthermore, pore water DOC in the raised WT treatment has the lowest specific ultraviolet absorbance $\left(\mathrm{SUVA}_{254}\right)$ (Hribljan et al. in preparation), which suggests inputs of algal photosynthate (Wyatt et al. 2011). Algal contribution to peat substrate quality influenced by long-term changes in WT is largely unexplored and warrants further research.

Hummock and lawn comparisons within each WT treatment showed significantly different $\mathrm{C} / \mathrm{N}$ ratios in the surface peat. Vegetation structure (Hribljan and Chimner, in preparation) and moisture conditions are suggested as the primary controllers creating the differences in peat quality characteristics between the microforms.

\subsubsection{Water table effects on potential aerobic CO2 production}

Differences in potential aerobic $\mathrm{CO}_{2}$ flux rates across the WT treatments for the lawn microforms were not detected. However, hummock peat from the raised WT treatment displayed increased potential $\mathrm{CO}_{2}$ production compared to the lowered treatment that is attributed to in situ oxygen restraints on microbial metabolism alleviated in the incubations (Blodau et al. 2004) in combination with measured differences in substrate quality. FTIR spectra peaks for fructose $\left(1063 \mathrm{~cm}^{-1}\right)$ showed a slight increase ( $\mathrm{F}=3.37, \mathrm{p}=0.081$ ) in the raised WT treatment hummocks in relation to the intermediate and lowered treatment hummocks. Fructose is a simple sugar that is easily degraded by microbial mineralization (Turetsky et al. 2006). Moreover, CAP analysis 
displayed a strong correlation of hummock peat in the raised treatment for polysaccharides while the lowered treatment had the weakest polysaccharide correlation (Table 4.3). An accumulation of labile carbohydrates is potentially priming $\mathrm{C}$ mineralization in the raised WT treatment hummocks (Updegraff et al. 1995).

The FTIR peat quality indices showed conflicting results when applied to the mineralization trends of the hummock microforms. The peat quality absorbance ratios for the intermediate treatment hummock peat displayed a nonsignificant trend of higher 1060/1620 (polysaccharide/aromatics) and lower 2920/1060 (lipids/polysaccharides) ratios than the raised and lowered treatments that is suggestive of a more labile substrate. Additionally, the lower 1725/1620 (carboxyl/aromatics) ratio in the raised WT treatment implies greater peat humification and a lower substrate quality from increased accumulation of aromatic compounds compared to organic acids (Figure 4.7). The peat quality ratios support the results of low potential $\mathrm{CO}_{2}$ production measured in the lowered WT treatment hummocks and are an indication of peat collected from a highly oxygenated environment with enhanced aerobic respiration producing a more recalcitrant substrate. However, the elevated potential $\mathrm{CO}_{2}$ mineralization rate from the raised WT treatment hummock peat seems to contradict the indication of lower substrate quality displayed by the FTIR peat quality indices.

Interestingly, specific carbohydrate classes in Sphagnum mosses have been shown to control substrate quality and microbial mineralization with structural carbohydrates more decay resistance than metabolic carbohydrates (Turetsky et al. 2008). The inhibitory nature of Sphagnum structural carbohydrates has been attributed to hemicelluloses in cell walls that may interact with microbial extracellular enzymes preventing $C$ and $N$ mineralization (Hajek et al 2011). The intermediate WT treatment hummocks are the most strongly correlated to hemicelluloses $\left(1050 \mathrm{~cm}^{-1}\right)$ (Kačuráková et al. 2000) that could contribute to a general lower $C$ mineralization rate. Moreover, the seasonally elevated WT in the raised treatment is potentially priming decomposition with highly labile polysaccharides from algae exudates that are readily available to microbial mineralization (Wyatt et al.2011). 
Combined hummock and lawn peat incubation results displayed similar $\mathrm{CO}_{2}$ respiration trends as eddy covariance $\mathrm{CO}_{2}$ flux data for the three WT treatments (Pypker, unpublished data) (Figure 4.9). Our incubations and substrate quality characterization are potentially demonstrating how small changes in WT can influence peat quality and ecosystem level carbon cycling.

\subsubsection{Water table effects on anaerobic carbon mineralization}

The raised WT treatment showed a 50\% and 63\% higher potential anaerobic $\mathrm{CH}_{4}$ production than the intermediate and lowered treatments respectively. The incubation results supported in situ measurements of elevated $\mathrm{CH}_{4}$ fluxes from the raised WT treatment (Ballantyne et al., in preparation). Our repeated measures ANOVA model revealed WT treatments were the primary factor controlling $\mathrm{CH}_{4}$ dynamics in the anaerobic incubations. Correlation scores from the CAP analysis (Table 4.3) indicated a greater relationship of accumulated organic acid concentrations in the intermediate lawn peat. Organic acid accumulation can signify reduced methanogen activity and eventually inhibit methanogenesis (White et al. 2008). In particular, acetate inhibition is common in especially at the low pH measured in our peatland (Horn et al. 2003; White et al. 2008). Compared to the raised WT treatment the lowered WT treatment lawn peat is associated with reduced substrate quality limiting methanogenesis because of a stronger correlation with lignin and fats and negative correlation with polysaccharides (Vasander and Kettunen 2006) (Table 4.3).

Additionally, the elevated potential $\mathrm{CH}_{4}$ fluxes from the raised WT treatment lawns are attributed to the unique chemical and biological parameters of the peat. First, the raised WT treatment has a significant decrease in Sphagnum mosses and an increase in sedges in the lawn microforms (Hribljan and Chimner, in preparation). Increased sedge cover can promote high $\mathrm{CH}_{4}$ production from labile root exudates rich in acetate that is readily utilized by methanogens using the acetoclastic pathway (Keller and Bridgham 2007) that was determined to predominate across our peatland (Ballantyne unpublished data). As previously noted, acetate can inhibit methanogenesis if allowed to accumulate; however, the raised sites displayed a trend of increased acetate consumption 
rate reflected in lower acetate concentrations throughout the upper $75 \mathrm{~cm}$ of the peatland (seasonal mean, $\mathrm{n}=45 ; 0.48 \pm 0.14 \mathrm{mg} \mathrm{L}^{-1}$ ) than the lowered (0.98 \pm 0.26$)$ and intermediate $(0.97 \pm 0.31)$ treatments (Hribljan et al., in preparation). Additionally, methanogenesis is potentially primed in the raised WT treatment from increased algae production indicated by the low peat $\mathrm{C} / \mathrm{N}$ ratios and the decreased $\mathrm{SUVA}_{254}$ value (Hribljan et al. in preparation) in the raised WT treatment lawns. Algal excreted DOC is a highly labile carbon source readily mineralized by methanogens (West et al. 2012).

Potential anaerobic $\mathrm{CO}_{2}$ production in the lawn microforms did not display a difference across the WT treatments. The ratio between aerobic and anaerobic $\mathrm{CO}_{2}$ potential production rates for the lawn peat from the intermediate (2.2:1), raised (2.1:1), and lowered WT treatments (3.1:1) were comparable to the lower range of reported values in peatlands (Glatzel et al. 2004). The significantly higher potential aerobic versus anaerobic $\mathrm{CO}_{2}$ production rates reinforce the dramatic increase in carbon mineralization associated with WT draw-down (Moore and Knowles 1989). The mean ratio of $\mathrm{CO}_{2 \text { (anaerobic) }}: \mathrm{CH}_{4}$ was greatest in the raised WT treatment because of the significantly greater concentration of $\mathrm{CH}_{4}$ produced as previously mentioned.

\subsubsection{Microtopography peat quality and lability}

Water table effects on microform substrate quality

FTIR spectroscopy analysis of peat revealed that differences in chemical constituent composition between microforms varied across the WT treatments (Figure 4.4b). The most distinct difference in chemical composition was between the hummocks and lawns within the lowered WT treatment as indicated by the greatest separation in ordination space. In contrast, the raised WT treatment microforms appear to be converging toward each other in ordination space (Figure 4.5) indicating they are the most alike in substrate quality as additionally indicated by the similar FTIR ratios for peat quality (Figure 4.7).

Moreover, potential aerobic $\mathrm{CO}_{2}$ fluxes between microforms within each WT treatment reflect the differences in substrate quality detected by CAP ordination of FTIR spectroscopy analysis. The greatest difference in $\mathrm{CO}_{2}$ fluxes between microforms 
occurred in the lowered WT treatment with lawns displaying a 535\% greater flux than the hummocks. The lawns in the raised WT treatment produced only 310\% more $\mathrm{CO}_{2}$ then the hummocks and the intermediate treatment lawn $\mathrm{CO}_{2}$ production was $344 \%$ greater than the hummocks. Significantly lower $\mathrm{CO}_{2}$ production from hummock compared to lawn peat has been previously reported (Belyea 1996), however the large variation of $\mathrm{CO}_{2}$ flux between the microforms across our WT treatments strongly demonstrates the different $\mathrm{C}$ cycling trajectories possible with subtle changes in WT position.

The microforms in the raised WT treatment have similar peat chemistry because the higher WT is inundating the hummocks creating moisture conditions that are closer to the lawns than is found in the intermediate and lowered treatments (Table 4.1). In addition, the long-term ( $\sim 80$ years) elevation of the raised WT treatment is a dominant driver in creating a more homogeneous plant community between the hummocks and lawns than the intermediate and lowered WT treatments (Hribljan and Chimner; in preparation).

\section{Peat chemistry effects on microform substrate quality}

The higher resistance of hummock peat to decomposition than lawn peat is ascribed to the chemical constituent content of Sphagnum species residing in the microforms (Rydin et al. 2006). As previously noted, hemicelluloses can exert a strong influence on C and N mineralization rates. Artz et al. (2008) reported on the high predictive power of FTIR analysis to quantify specific carbohydrates in peat.

Furthermore, Kačuráková et al. (2000) reported hemicelluloses from plant material can display a strong absorbance within the polysaccharide absorbance band $\left(1023-1080 \mathrm{~cm}^{-}\right.$ ${ }^{1}$ ) including but not limited to absorbance peaks at $1024 \mathrm{~cm}^{-1}$ and $1050 \mathrm{~cm}^{-1}$.

Spectra subtraction indicates that hummocks contain higher relative absorbance across the entire polysaccharide absorbance band indicating possible hemicellulose enrichment in hummocks protecting labile nonstructural polysaccharides from microbial mineralization. CAP ordination also strongly correlates polysaccharides $\left(1060 \mathrm{~cm}^{-1}\right)$ and hemicelluloses $\left(1050 \mathrm{~cm}^{-1}\right)$ to hummock microforms (Table 4.3). 
Moreover, the PLS loading diagram of aerobic $\mathrm{CO}_{2}$ production relative to FTIR spectra absorbances displayed a sharp negative correlation to polysaccharides (Figure 4.6). The negative polysaccharides peak on the loading plot is counter intuitive since polysaccharides are considered a highly labile fraction of peat organic matter (Gregorich et al. 1994). However, the polysaccharide loading peak at $\sim 1024 \mathrm{~cm}^{-1}$ (hemicellulose) indicates an inverse relationship between $\mathrm{CO}_{2}$ flux and structural carbohydrates supporting the findings of Turetsky et al (2008).

Previous studies have utilized FTIR absorbance ratios for peat quality by incorporating the $1050 \mathrm{~cm}^{-1}$ absorbance peak for microbial available polysaccharides (Basiliko et al. 2007). However, Kačuráková et al. (2000) reported a strong absorbance for the $\mathrm{OH}$ group on the hemicellulose xylose at $1050 \mathrm{~cm}^{-1}$, thus this absorbance peak might not be indicative of the labile nature of peat. Therefore, care needs to be taken when using FTIR spectra absorbance ratios containing polysaccharides as an indication of peat lability, especially in Sphagnum dominated peatlands.

In addition to elevated hemicellulose concentrations, the hummock microforms have a strong correlation to alkane (paraffins) compounds (Table 4.3). Alkanes are found primarily in leaf tissue of vascular plants and Sphagnum mosses and are highly resistant to decay, potentially increasing the recalcitrant nature of hummock peat (Nichols et al. 2006). Peat alkane concentrations could be influenced by differences in vegetation communities between the hummocks and lawns (Hribljan and Chimner; in preparation) and plant water stress (Horner et al. 1988). Future studies should investigate long-term WT manipulations on vegetation alkane chemistry contributions to peat quality.

Furthermore, lawn peat on a volumetric content contains over $250 \%$ greater TN stocks $/ \mathrm{m}^{3}$ than the hummocks in all three WT treatments. As indicated by the loading plots (Figure 4.6) and GLM regression model (Table 4.5), TN is strongly correlated with potential aerobic $\mathrm{CO}_{2}$ production. The elevated $\mathrm{N}$ concentrations in the lawn microforms is potentially elevating lawn $\mathrm{CO}_{2}$ fluxes compared to the hummocks, since increased $\mathrm{N}$ pools will improve soil substrate quality (Prescott 2010). Additionally, the lawn microforms have a higher in situ $\mathrm{N}$ mineralization and nitrification rate measured in the peat extractions at the start of the mineralization experiments (Table 4.2). Ammonium 
will accumulate in environments with higher $\mathrm{N}$ stocks and an increased rate of mineralization. Elevated $\mathrm{NH}_{4}{ }^{+}$concentrations can also contribute to increased nitrate production since nitrification is supported by chemoautotrophic bacteria that use ammonium as an energy source (Reddy and DuLaune 2006).

The differences detected between hummock and lawn peat substrate quality and lability reinforces previous research stressing the importance of treating peatland microforms separately in modeling and predictions of peatland carbon cycling (Ohlson and Oxland 1998; Belyea and Clymo 2001; Moore et al. 2002; Strack and Waddington 2007). Interpreting the peatland as a homogenous surface could potentially conceal processes unique to specific microforms. Lastly, our results indicate peatland microform exposure to long-term changes in WT position similar to estimated predictions for future climate change scenarios can display significantly different trajectories of substrate quality and potential microbial mineralization.

\subsubsection{Nitrogen stabilization}

Interestingly, despite the similar TN concentrations in the surface peat $(0-5 \mathrm{~cm})$ across the WT treatments, we detected significantly different trajectories of TN retention down-core, in the lawn microforms (Figure 4.2). Nitrogen is a dominant limiting growth factor and increased stabilization into humic soil fractions results in $\mathrm{N}$ that is not readily available to biological processes (Knicker 2004). Abiotic reaction of N-containing compounds with phenolic structures is one mechanism proposed for $\mathrm{N}$ stabilization (Lorenz et al. 2000; Schmidt-Rohl et al. 2004; Olk et al. 2006). We measured elevated pore water and peat phenolic concentrations in the raised and lowered WT treatments (Figure 4.10), but were unable to determine if these were directly contributing to increased $\mathrm{N}$ stabilization. Phenolic compounds are highly influenced by the redox conditions of a peatland because oxygen activates the enzyme (phenolic oxidase) responsible for their degradation (Freeman et al. 2006). Interestingly, the elevated phenolic compounds measured in the lowered WT treatment are in contradiction to the greater aerobic conditions. However, increased decomposition in the near surface peat 
could be rapidly releasing phenolic compounds from plant litter that is flushed down-core into anaerobic zones before being degraded by phenolic oxidases.

As previously mentioned the potential for algae affecting peat chemistry is strongly displayed in the pore water chemistry of the raised WT treatment. Microalgae found in peatlands are characterized by highly refractory algaenans (cell wall components) that covalently bond and encapsulate $\mathrm{N}$ containing amides and could be an additional mechanism in the raised WT treatment incorporating $\mathrm{N}$ into recalcitrant complexes inaccessible to plants and microbes (Bourdon et al. 2000; Knicker 2004). Therefore, changes in WT position could potentially be a potent and multidimensional controller on peatland $\mathrm{N}$ stabilization and deserves further investigation especially concerning phenolic-nitrogen dynamics.

\subsection{Conclusion}

We examined the potential influence of long-term changes in peatland WT position on peat substrate quality and C and N cycling. Our WT manipulations represent a small change in WT position ( $\pm \sim 10 \mathrm{~cm}$ ) that is commensurate to climate change predictions for northern peatlands. Peat substrate quality exhibited differences in chemical composition and lability across the WT treatments. Aerobic incubations of hummock peat demonstrated that potential C mineralization could be inhibited by structural carbohydrates and primed by labile simple sugars. In particular, WT induced changes to plant hemicellulose content is potentially influencing decomposition. Aerobic and anaerobic potential C mineralization in the raised WT treatment is potentially fueled by elevated algae production of highly labile carbohydrates. We also found WT position is altering the relationship of peat chemistry and lability between microforms across the WT treatments. Furthermore, the WT treatments are displaying different $\mathrm{N}$ stabilization rates potentially linked to phenolic compounds that create highly recalcitrant phenolicprotein complexes. Changes in plant communities and shifts in redox conditions are suggested as the primary influences on substrate quality and lability. These results suggest that subtle long-term WT changes can significantly alter peatland biogeochemistry and set the peatland on different $\mathrm{C}$ and $\mathrm{N}$ cycling trajectories. Future 
modeling of peatland carbon cycling needs to consider the multidimensional influence of WT alterations on peat substrate quality.

\subsection{Acknowledgements}

The authors gratefully acknowledge Tamara Baker, Arielle Garrett, Chris Johnson, and Laura Kangus for help with field and lab work. Peat FTIR spectroscopy analysis was graciously provided by James W. McLaughlin of the Ontario Ministry of Natural Resources. This research was supported by the U.S. Department of Energy's Office of Science (BER) through the Midwestern Regional Center of the National Institute for Climatic Change Research at Michigan Technological University. Additional support was provided by the Ecosystem Science Center at Michigan Technological University. The project would not have been possible without the cooperation of the SNWR providing access to the site.

\subsection{Literature cited}

Aerts, R. and F. Ludwig. 1997. Water-table changes and nutritional status affect trace gas emissions from laboratory columns of peatland soils. Soil Biology and Biochemistry 29:1691-1698.

Anderson, M. J. 2002. CAP: a FORTRAN computer program for canonical analysis of principal coordinates. Department of Statistics, University of Auckland.

Anderson, M. J. and J. Robinson. 2003. Generalized discriminant analysis based on distances. Australian \& New Zealand Journal of Statistics 45:301-318.

Anderson, M. J. and T. J. Willis. 2003. Canonical analysis of principal coordinates: a useful method of constrained ordination for ecology. Ecology 84:511-525.

Anshari, G., M. Afifudin, M. Nuriman, E. Gusmayanti, L. Arianie, R. Susana, R. Nusantara, J. Sugardjito, and A. Rafiastanto. 2010. Drainage and land use impacts on changes in selected peat properties and peat degradation in West Kalimantan Province, Indonesia. Biogeosciences 7:3403-3419.

Artz, R. R. E., S. J. Chapman, A. Jean Robertson, J. M. Potts, F. Laggoun-Défarge, S. Gogo, L. Comont, J. R. Disnar, and A. J. Francez. 2008. FTIR spectroscopy can 
be used as a screening tool for organic matter quality in regenerating cutover peatlands. Soil Biology and Biochemistry 40:515-527.

Basiliko, N., C. Blodau, C. Roehm, P. Bengtson, and T. R. Moore. 2007. Regulation of decomposition and methane dynamics across natural, commercially mined, and restored northern peatlands. Ecosystems 10:1148-1165.

Belyea, L. R. 1996. Separating the effects of litter quality and microenvironment on decomposition rates in a patterned peatland. Oikos:529-539.

Belyea, L. R. and N. Malmer. 2004. Carbon sequestration in peatland: patterns and mechanisms of response to climate change. Global Change Biology 10:10431052.

Blodau, C. 2002. Carbon cycling in peatlands-A review of processes and controls. Environmental Reviews 10:111-134.

Blodau, C., N. Basiliko, and T. R. Moore. 2004. Carbon turnover in peatland mesocosms exposed to different water table levels. Biogeochemistry 67:331-351.

Boelter, D. H. 1964. Water storage characteristics of several peats in situ. Soil Science Society of America Journal 28:433-435.

Bridgham, S. D. and C. J. Richardson. 1992. Mechanisms controlling soil respiration (CO2 and $\mathrm{CH} 4$ ) in southern peatlands. Soil Biology and Biochemistry 24:10891099.

Bridgham, S. D., K. Updegraff, and J. Pastor. 1998. Carbon, nitrogen, and phosphorus mineralization in northern wetlands. Ecology 79:1545-1561.

Bubier, J., A. Costello, T. Moore, N. Roulet, and K. Savage. 1993. Microtopography and methane flux in boreal peatlands, northern Ontario, Canada. Canadian Journal of Botany 71:1056-1056.

Bubier, J., P. Crill, A. Mosedale, S. Frolking, and E. Linder. 2003. Peatland responses to varying interannual moisture conditions as measured by automatic $\mathrm{CO} 2$ chambers. Global Biogeochemical Cycles 17:1066.

Burkett, V. and J. Kusler. 2000. Climate change: Potential impacts and interactions in wetlands of the United States1. Journal of the American Water Resources Association 36:313-320.

Chapman, S., C. Campbell, A. Fraser, and G. Puri. 2001. FTIR spectroscopy of peat in and bordering Scots pine woodland: relationship with chemical and biological properties. Soil Biology and Biochemistry 33:1193-1200. 
Davidson, E. A. and I. A. Janssens. 2006. Temperature sensitivity of soil carbon decomposition and feedbacks to climate change. Nature 440:165-173.

Domisch, T., L. Finér, M. Karsisto, R. Laiho, and J. Laine. 1998. Relocation of carbon from decaying litter in drained peat soils. Soil Biology and Biochemistry 30:15291536.

Fraser, W. T., M. A. Sephton, J. S. Watson, S. Self, B. H. Lomax, D. I. James, C. H. Wellman, T. V. Callaghan, and D. J. Beerling. 2011. UV-B absorbing pigments in spores: biochemical responses to shade in a high-latitude birch forest and implications for sporopollenin-based proxies of past environmental change. Polar Research 30.

Glatzel, S., N. Basiliko, and T. Moore. 2004. Carbon dioxide and methane production potentials of peats from natural, harvested and restored sites, Eastern Québec, Canada. Wetlands 24:261-267.

Gorham, E. 1957. The development of peat lands. The Quarterly Review of Biology 32:145-166.

Gregorich, E., C. Monreal, M. Carter, D. Angers, and B. H. Ellert. 1994. Towards a minimum data set to assess soil organic matter quality in agricultural soils. Canadian Journal of Soil Science 74:367-385.

Haberhauer, G., B. Feigl, M. Gerzabek, and C. Cerri. 2000. FT-IR spectroscopy of organic matter in tropical soils: changes induced through deforestation. Applied Spectroscopy 54:221-224.

Hájek, T., S. Ballance, J. Limpens, M. Zijlstra, and J. T. A. Verhoeven. 2011. Cell-wall polysaccharides play an important role in decay resistance of Sphagnum and actively depressed decomposition in vitro. Biogeochemistry 103:45-57.

Heinselman, M. 1965. String bogs and other patterned organic terrain near Seney, Upper Michigan. Ecology:185-188.

Hogg, E. H. 1993. Decay potential of hummock and hollow Sphagnum peats at different depths in a Swedish raised bog. Oikos:269-278.

Horn, M. A., C. Matthies, K. Küsel, A. Schramm, and H. L. Drake. 2003.

Hydrogenotrophic methanogenesis by moderately acid-tolerant methanogens of a methane-emitting acidic peat. Applied and Environmental Microbiology 69:7483.

Horner, J. D. 1990. Nonlinear effects of water deficits on foliar tannin concentration. Biochemical Systematics and Ecology 18:211-213.

IPCC, C. C. 2007. Synthesis report. IPCC, Geneva, Switzerland 104. 
Ise, T., A. L. Dunn, S. C. Wofsy, and P. R. Moorcroft. 2008. High sensitivity of peat decomposition to climate change through water-table feedback. Nature Geoscience 1:763-766.

Jukaine, J. Laine, H. Vasander, and R. Laiho. 1995. Long-term effects of water level drawdown on the vegetation of drained pine mires in southern Finland. Journal of Applied Ecology:785-802.

Kacurakova, M., P. Capek, V. Sasinkova, N. Wellner, and A. Ebringerova. 2000. FT-IR study of plant cell wall model compounds: pectic polysaccharides and hemicelluloses. Carbohydrate Polymers 43:195-203.

Kalbitz, K., W. Geyer, and S. Geyer. 1999. Spectroscopic properties of dissolved humic substances - a reflection of land use history in a fen area. Biogeochemistry 47:219-238.

Keller, J. K. and S. D. Bridgham. 2007. Pathways of anaerobic carbon cycling across an ombrotrophic-minerotrophic peatland gradient. Limnology and Oceanography:96107.

Keller, J. K., J. R. White, S. D. Bridgham, and J. Pastor. 2004. Climate change effects on carbon and nitrogen mineralization in peatlands through changes in soil quality. Global Change Biology 10:1053-1064.

Knicker, H. 2004. Stabilization of N-compounds in soil and organic-matter-rich sediments—what is the difference? Marine Chemistry 92:167-195.

Knorr, K. H. and C. Blodau. 2009. Impact of experimental drought and rewetting on redox transformations and methanogenesis in mesocosms of a northern fen soil. Soil Biology and Biochemistry 41:1187-1198.

Kowalski, K. P. and D. A. Wilcox. 2003. Differences in sedge fen vegetation upstream and downstream from a managed impoundment. The American Midland Naturalist 150:199-220.

Krist, F. J. and D. P. Lusch. 2004. Glacial history of Michigan, USA: A regional perspective. Developments in Quaternary Sciences 2:111-117.

Laiho, R. 2006. Decomposition in peatlands: reconciling seemingly contrasting results on the impacts of lowered water levels. Soil Biology and Biochemistry 38:20112024.

Laine, J., J. Silvola, K. Tolonen, J. Alm, H. Nykänen, H. Vasander, T. Sallantaus, I. Savolainen, J. Sinisalo, and P. J. Martikainen. 1996. Effect of water-level drawdown on global climatic warming: Northern peatlands. Ambio:179-184. 
Leifeld, J., M. Müller, and J. Fuhrer. 2011. Peatland subsidence and carbon loss from drained temperate fens. Soil Use and Management.

Letts, M. G., N. T. Roulet, N. T. Comer, M. R. Skarupa, and D. L. Verseghy. 2000. Parametrization of peatland hydraulic properties for the Canadian Land Surface Scheme. Atmosphere-Ocean 38:141-160.

Limpens, J., F. Berendse, C. Blodau, J. Canadell, C. Freeman, J. Holden, N. Roulet, H. Rydin, and G. Schaepman-Strub. 2008. Peatlands and the carbon cycle: from local processes to global implications? a synthesis. Biogeosciences Discussions 5:13791419.

Littell, R. C. 2006. SAS for mixed models. SAS Publishing.

Liu, Z., W. Cai, and X. Shao. 2009. A weighted multiscale regression for multivariate calibration of near infrared spectra. Analyst 134:261-266.

McGuire, A. D., L. G. Anderson, T. R. Christensen, S. Dallimore, L. Guo, D. J. Hayes, M. Heimann, T. D. Lorenson, R. W. Macdonald, and N. Roulet. 2009. Sensitivity of the carbon cycle in the Arctic to climate change. Ecological Monographs 79:523-555.

McLauchlan, K. K. and S. E. Hobbie. 2004. Comparison of labile soil organic matter fractionation techniques. Soil Science Society of America Journal 68:1616-1625.

Moore, T. and M. Dalva. 1993. The influence of temperature and water table position on carbon dioxide and methane emissions from laboratory columns of peatland soils. Journal of Soil Science 44:651-664.

Moore, T. and R. Knowles. 1989. The influence of water table levels on methane and carbon dioxide emissions from peatland soils. Canadian Journal of Soil Science 69:33-38.

Moore, T. R., J. L. Bubier, and L. Bledzki. 2007. Litter decomposition in temperate peatland ecosystems: the effect of substrate and site. Ecosystems 10:949-963.

Nagel, L. M., R. G. Corace III, and A. J. Storer. 2008. An Experimental Approach to Testing the Efficacy of Management Treatments for Glossy Buckthorn at Seney National Wildlife Refuge, Upper Michigan. Ecological Restoration 26:136-142.

Nichols, J. E., R. K. Booth, S. T. Jackson, E. G. Pendall, and Y. Huang. 2006. Paleohydrologic reconstruction based on n-alkane distributions in ombrotrophic peat. Organic Geochemistry 37:1505-1513. 
Niemeyer, J., J. M. Bollag, and Y. Chen. 1992. Characterization of humic acids, composts, and peat by diffuse reflectance Fourier-transform infrared spectroscopy. Soil Science Society of America Journal 56:135-140.

Ohlson, M. and R. Halvorsen Økland. 1998. Spatial variation in rates of carbon and nitrogen accumulation in a boreal bog. Ecology 79:2745-2758.

Olk, D., K. G. Cassman, K. Schmidt-Rohr, M. Anders, J. D. Mao, and J. Deenik. 2006. Chemical stabilization of soil organic nitrogen by phenolic lignin residues in anaerobic agroecosystems. Soil Biology and Biochemistry 38:3303-3312.

Payette, S., A. Delwaide, M. Caccianiga, and M. Beauchemin. 2004. Accelerated thawing of subarctic peatland permafrost over the last 50 years. Geophysical Research Letters 31:L18208.

Prescott, C. E. 2010. Litter decomposition: what controls it and how can we alter it to sequester more carbon in forest soils? Biogeochemistry 101:133-149.

Prévost, M., A. P. Plamondon, and P. Belleau. 1999. Effects of drainage of a forested peatland on water quality and quantity. Journal of Hydrology 214:130-143.

Price, J. S. 2003. Role and character of seasonal peat soil deformation on the hydrology of undisturbed and cutover peatlands. Water Resources Research 39:1241.

Price, J. S. and S. M. Schlotzhauer. 1999. Importance of shrinkage and compression in determining water storage changes in peat: the case of a mined peatland. Hydrological Processes 13:2591-2601.

Reddy, K. and W. DeBusk. 1998. Turnover of detrital organic carbon in a nutrientimpacted Everglades marsh. Soil Science Society of America Journal 62:14601468.

Roulet, N., T. Moore, J. Bubier, and P. Lafleur. 1992. Northern fens: methane flux and climatic change. Tellus B 44:100-105.

Roulet, N. T., P. M. Lafleur, P. J. H. Richard, T. R. Moore, E. R. Humphreys, and J. Bubier. 2007. Contemporary carbon balance and late Holocene carbon accumulation in a northern peatland. Global Change Biology 13:397-411.

Rydin, H., U. Gunnarsson, and S. Sundberg. 2006. The role of Sphagnum in peatland development and persistence. Boreal Peatland Ecosystems:47-65.

Rydin, H., J. K. Jeglum, and A. Hooijer. 2006. The biology of peatlands. Oxford University Press, USA.

Schäfer, C. M., L. Elsgaard, C. Hoffmann, and S. Petersen. 2012. Seasonal methane dynamics in three temperate grasslands on peat. Plant and Soil:1-15. 
Strack, M. and J. Price. 2009. Moisture controls on carbon dioxide dynamics of peat-Sphagnum monoliths. Ecohydrology 2:34-41.

Strack, M. and J. Waddington. 2007. Response of peatland carbon dioxide and methane fluxes to a water table drawdown experiment. Global Biogeochemical Cycles 21:GB1007.

Strack, M., J. Waddington, R. Bourbonniere, E. Buckton, K. Shaw, P. Whittington, and J. Price. 2008. Effect of water table drawdown on peatland dissolved organic carbon export and dynamics. Hydrological Processes 22:3373-3385.

Strack, M., J. Waddington, and E. Tuittila. 2004. Effect of water table drawdown on northern peatland methane dynamics: Implications for climate change. Global Biogeochemical Cycles 18:GB4003.

Summerfield, R. 1972. Biological Inertia--An Example. The Journal of Ecology:793-798.

Sundström, E., T. Magnusson, and B. Hånell. 2000. Nutrient conditions in drained peatlands along a north-south climatic gradient in Sweden. Forest Ecology and Management 126:149-161.

Tarnocai, C. 2006. The effect of climate change on carbon in Canadian peatlands. Global and Planetary Change 53:222-232.

Turetsky, M., W. Donahue, and B. Benscoter. 2011. Experimental drying intensifies burning and carbon losses in a northern peatland. Nature Communications 2:514.

Turetsky, M. R., S. E. Crow, R. J. Evans, D. H. Vitt, and R. K. Wieder. 2008. Trade-offs in resource allocation among moss species control decomposition in boreal peatlands. Journal of Ecology 96:1297-1305.

Updegraff, K., J. Pastor, S. D. Bridgham, and C. A. Johnston. 1995. Environmental and substrate controls over carbon and nitrogen mineralization in northern wetlands. Ecological Applications 5:151-163.

USFWS. 2009. Seney National Wildlife Refuge Comprehensive Conservation Plan. Vasander, H. and A. Kettunen. 2006. Carbon in boreal peatlands. Boreal peatland ecosystems:165-194.

Vitt, D. H., L. A. Halsey, and S. C. Zoltai. 2000. The changing landscape of Canada's western boreal forest: the current dynamics of permafrost. Canadian Journal of Forest Research 30:283-287.

Wehr, J. D. and R. G. Sheath. 2003. Freshwater algae of North America: ecology and classification. Academic Press. 
Wells, E. and B. Williams. 1996. Effects of drainage, tilling and PK-fertilization on bulk density, total N, P, K, Ca and Fe and net N-mineralization in two peatland forestry sites in Newfoundland, Canada. Forest Ecology and Management 84:97-108.

Weltzin, J. F., C. Harth, S. D. Bridgham, J. Pastor, and M. Vonderharr. 2001. Production and microtopography of bog bryophytes: response to warming and water-table manipulations. Oecologia 128:557-565.

West, W. E., J. J. Coloso, and S. E. Jones. 2012. Effects of algal and terrestrial carbon on methane production rates and methanogen community structure in a temperate lake sediment. Freshwater Biology.

White, J. R., R. D. Shannon, J. F. Weltzin, J. Pastor, and S. D. Bridgham. 2008. Effects of soil warming and drying on methane cycling in a northern peatland mesocosm study. Journal of Geophysical Research 113:G00A06.

Whittington, P. N. and J. S. Price. 2006. The effects of water table draw-down (as a surrogate for climate change) on the hydrology of a fen peatland, Canada. Hydrological Processes 20:3589-3600.

Wilcox, D. A., M. J. Sweat, M. L. Carlson, and K. P. Kowalski. 2006. A water-budget approach to restoring a sedge fen affected by diking and ditching. Journal of Hydrology 320:501-517.

Wyatt, K. H., M. R. Turetsky, A. R. Rober, D. Giroldo, E. S. Kane, and R. J. Stevenson. 2011. Contributions of algae to GPP and DOC production in an Alaskan fen: effects of historical water table manipulations on ecosystem responses to a natural flood. Oecologia:1-12. 


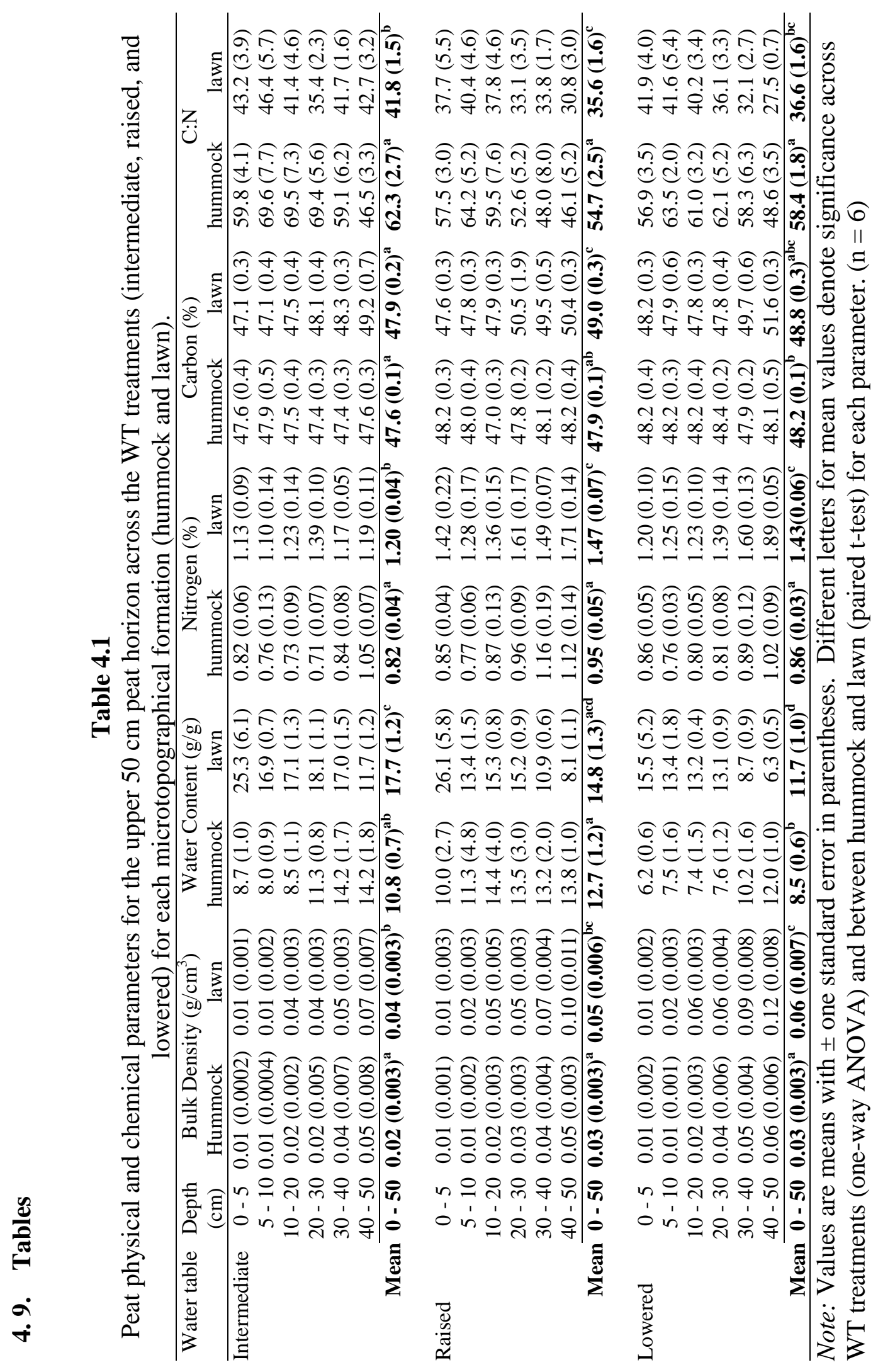


Table 4.2

Peat extractions (ng $\mathrm{N} \mathrm{cm}^{-3}$ dry peat) for $\mathrm{NH}_{4}{ }^{+}-\mathrm{N}$ and $\mathrm{NO}_{3}{ }^{-}-\mathrm{N}$ from the three WT treatments (intermediate, raised, and lowered) for each microtopographical formation (hummock and lawn). Extractions were conducted at the start and end of a 58 day mineralization experiment.

\begin{tabular}{llllcc}
\hline Nutrient & Topography & Time & Intermediate & Raised & Lowered \\
\hline $\mathrm{NH}_{4}{ }^{+}$ & lawn & start & $502.4(36.7)^{\mathrm{a}}$ & $596.2(47.3)^{\mathrm{a}}$ & $922.4(56.7)^{\mathrm{b}}$ \\
& & end & $563.1(43.5)^{\mathrm{a}}$ & $844.6(224.8)^{\mathrm{a}}$ & $906.9(224.6)^{\mathrm{a}}$ \\
& & end* & $703.6(112.8)^{\mathrm{a}}$ & $921.8(93.2)^{\mathrm{a}}$ & $1028.2(214.9)^{\mathrm{a}}$ \\
$\mathrm{NH}_{4}{ }^{+}$ & \multirow{2}{*}{ hummock } & start & $237.3(29.0)^{\mathrm{a}}$ & $221.3(24.6)^{\mathrm{a}}$ & $200.9(22.9)^{\mathrm{a}}$ \\
& & end & $312.0(40.4)^{\mathrm{a}}$ & $283.7(41.3)^{\mathrm{a}}$ & $318.9(36.0)^{\mathrm{a}}$ \\
$\mathrm{NO}_{3}{ }^{-}$ & \multirow{2}{*}{ lawn } & start & $26.9(6.7)^{\mathrm{a}}$ & $16.5(6.0)^{\mathrm{a}}$ & $9.5(6.2)^{\mathrm{a}}$ \\
$\mathrm{NO}_{3}{ }^{-}$ & \multirow{2}{*}{ hummock } & end & $5.7(4.2)^{\mathrm{a}}$ & $4.2(2.7)^{\mathrm{a}}$ & $5.5(3.3)^{\mathrm{a}}$ \\
& & start & $4.1(0.9)^{\mathrm{a}}$ & $2.8(0.8)^{\mathrm{a}}$ & $0.7(0.4)^{\mathrm{b}}$ \\
& & end & $0.7(0.7)$ & n.d & n.d \\
\hline
\end{tabular}

Note: Values are means with \pm one standard error in parentheses. Different letters denote significance between WT treatments for each time period. Asterisk denotes anaerobic incubation. $(\mathrm{n}=12)$ 
Table 4.3

Correlation scores of predominant peat chemical groups from canonical analysis of principle coordinates (CAP) ordination analysis of peat analyzed with FTIR spectroscopy from across the WT treatments (intermediate, raised, and lowered).

\begin{tabular}{ccrl}
\hline wavelength $\left(\mathrm{cm}^{-1}\right)$ & axis 1 & axis 2 & chemical group \\
\hline 720 & 0.3005 & -0.8245 & alkanes \\
1050 & 0.7289 & -0.3792 & hemicelluloses \\
1060 & 0.7090 & -0.3327 & polysaccharides \\
1160 & 0.0199 & 0.4119 & cellulose \\
1265 & 0.2684 & -0.0982 & lignin \\
1426 & 0.1568 & -0.1311 & humic acids \\
1450 & -0.3203 & 0.2488 & phenolic \\
1515 & -0.4130 & 0.5100 & lignin \\
1550 & -0.3976 & 0.3737 & proteins \\
1620 & -0.3871 & 0.0394 & lignin \\
1725 & 0.4636 & -0.2493 & aromatics \\
1710 & 0.1016 & 0.1694 & organic acids \\
2850 & -0.2971 & 0.7451 & fats, wax, lipids \\
2930 & -0.1559 & 0.7635 & fats, wax, lipids \\
3400 & 0.5041 & -0.5972 & cellulose \\
\hline
\end{tabular}




\section{Table 4.4}

Partial least squares (PLS) regression analysis of FTIR spectra of peat harvested across the WT treatments (intermediate, raised, and lowered) for the chemical parameters (TN, C/N, $\mathrm{N}_{\text {mineral }}$, and $\mathrm{CO}_{2}$ ).

\begin{tabular}{lcccrc}
\hline Variable & RMSECV $^{\mathrm{a}}$ & Factors & $\mathrm{r}^{2}(\%)$ & SD $^{\mathrm{b}}$ & RPD $^{\mathrm{C}}$ \\
\hline $\mathrm{TN}$ & 0.12 & 3 & 90.3 & 0.3 & 2.40 \\
$\mathrm{C} / \mathrm{N}$ & 5.18 & 3 & 89.2 & 13.4 & 2.59 \\
$\mathrm{~N}_{\text {mineral }}$ & 43.45 & 2 & 22.2 & 41.3 & 0.95 \\
$\mathrm{CO}_{2}$ & 88.70 & 2 & 75.9 & 158.4 & 1.79 \\
\hline
\end{tabular}

${ }^{\mathrm{a}} \mathrm{RMSECV}=$ root mean standard error of cross validation.

${ }^{\mathrm{b}} \mathrm{SD}$ is standard deviation of parameter before PLS analysis and units for each value are listed in text. ${ }^{\mathrm{C}} \mathrm{RPD}=$ residual prediction deviation. $(\mathrm{n}=24)$ 


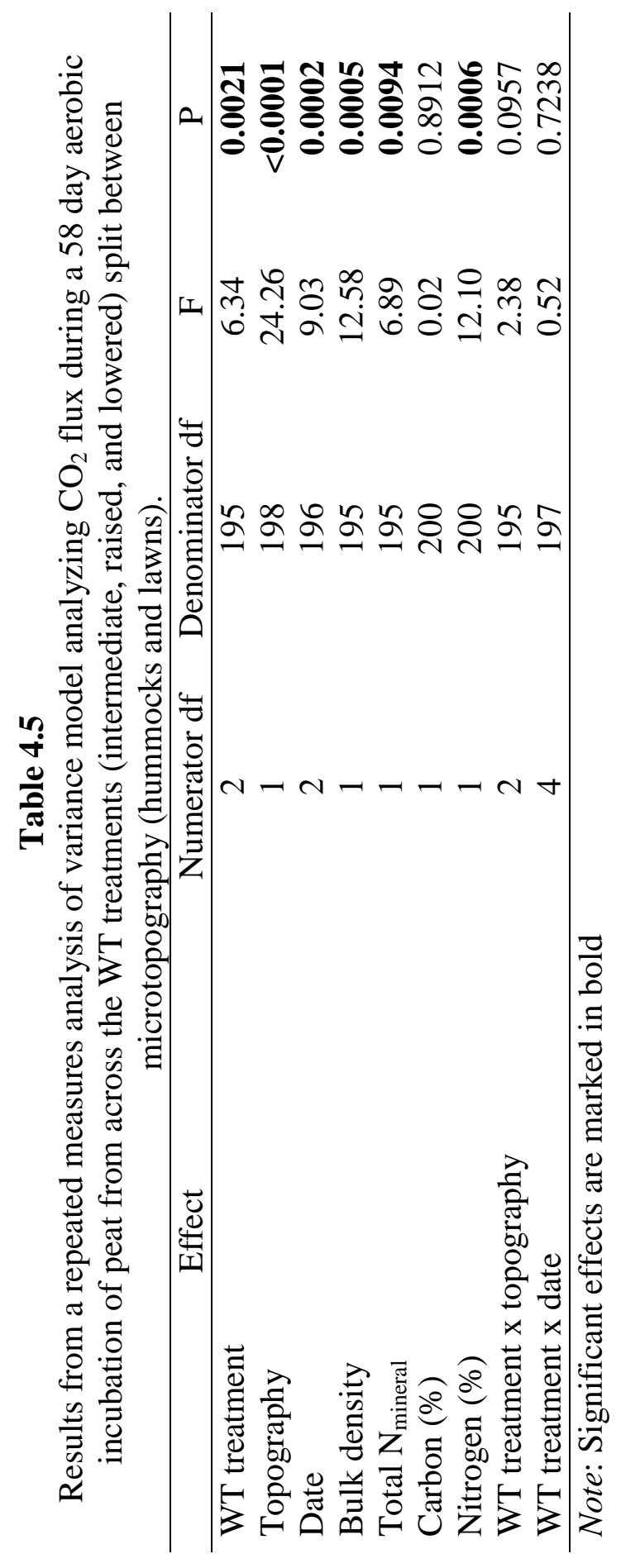




\section{Table 4.6}

Results from a repeated measures analysis of variance model analyzing $\mathrm{CH}_{4}$ flux during a 58 day anaerobic incubation of lawn peat from across the WT treatments (intermediate, raised, and lowered).

\begin{tabular}{lcccr}
\hline \multicolumn{1}{c}{ Effect } & Numerator df & Denominator df & F & \multicolumn{1}{c}{ P } \\
\hline WT treatment & 2 & 90.3 & 9.45 & $\mathbf{0 . 0 0 0 2}$ \\
Date & 2 & 89.8 & 25.56 & $<\mathbf{0 . 0 0 0 1}$ \\
Bulk density & 1 & 95.0 & 0.00 & 0.9605 \\
Total N & 1 & 95.0 & 2.60 & 0.1099 \\
Carbon (\%) & 1 & 90.1 & 0.43 & 0.5115 \\
Nitrogen (\%) & 1 & 90.1 & 0.23 & 0.6309 \\
WT treatment x date & 4 & 89.8 & 5.00 & $\mathbf{0 . 0 0 1 1}$ \\
\hline
\end{tabular}

Note: Significant effects are marked in bold 


\subsection{Figures}

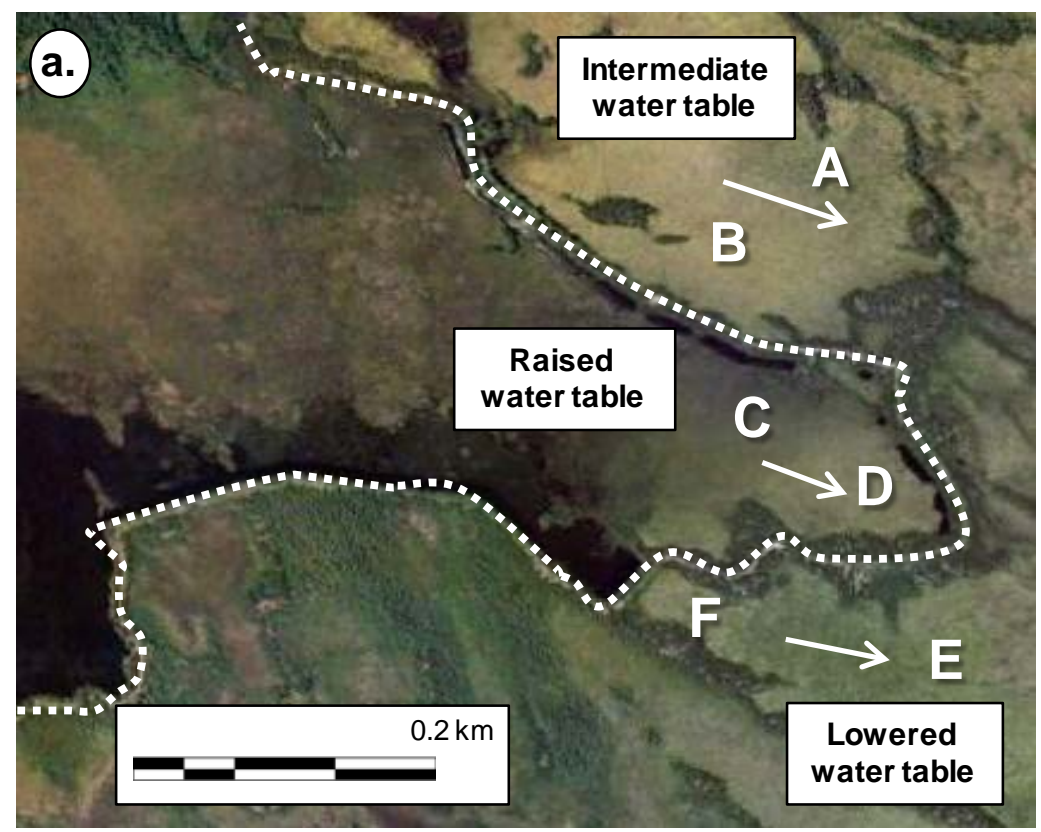

b.

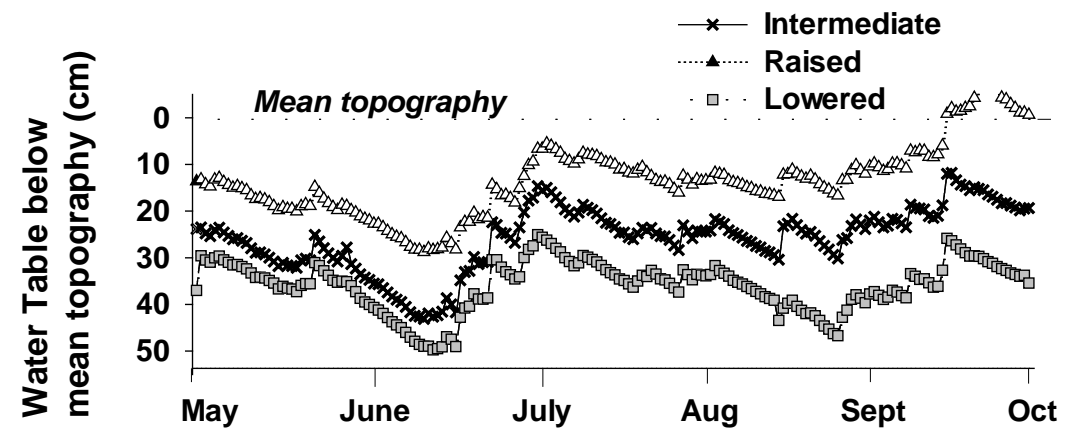

Figure 4.1 (a) Site placement across the WT treatments (intermediate, raised, and lowered) in relation to an earthen levee (dotted line) with arrows depicting surface flow across the peatland complex. Sites A and B were relatively unaffected by the levee. Sites $\mathrm{C}$ and D have a raised WT and sites E and F are experiencing a lowered WT. (b) Seasonal WT levels for years 2010 and 2011 across the three WT treatments. Image in panel (a): Google Earth 2012. Seney, Michigan, 46²11'15.22" N 8600'54.93" W, elevation 683ft., Accessed 8 October 2012. 

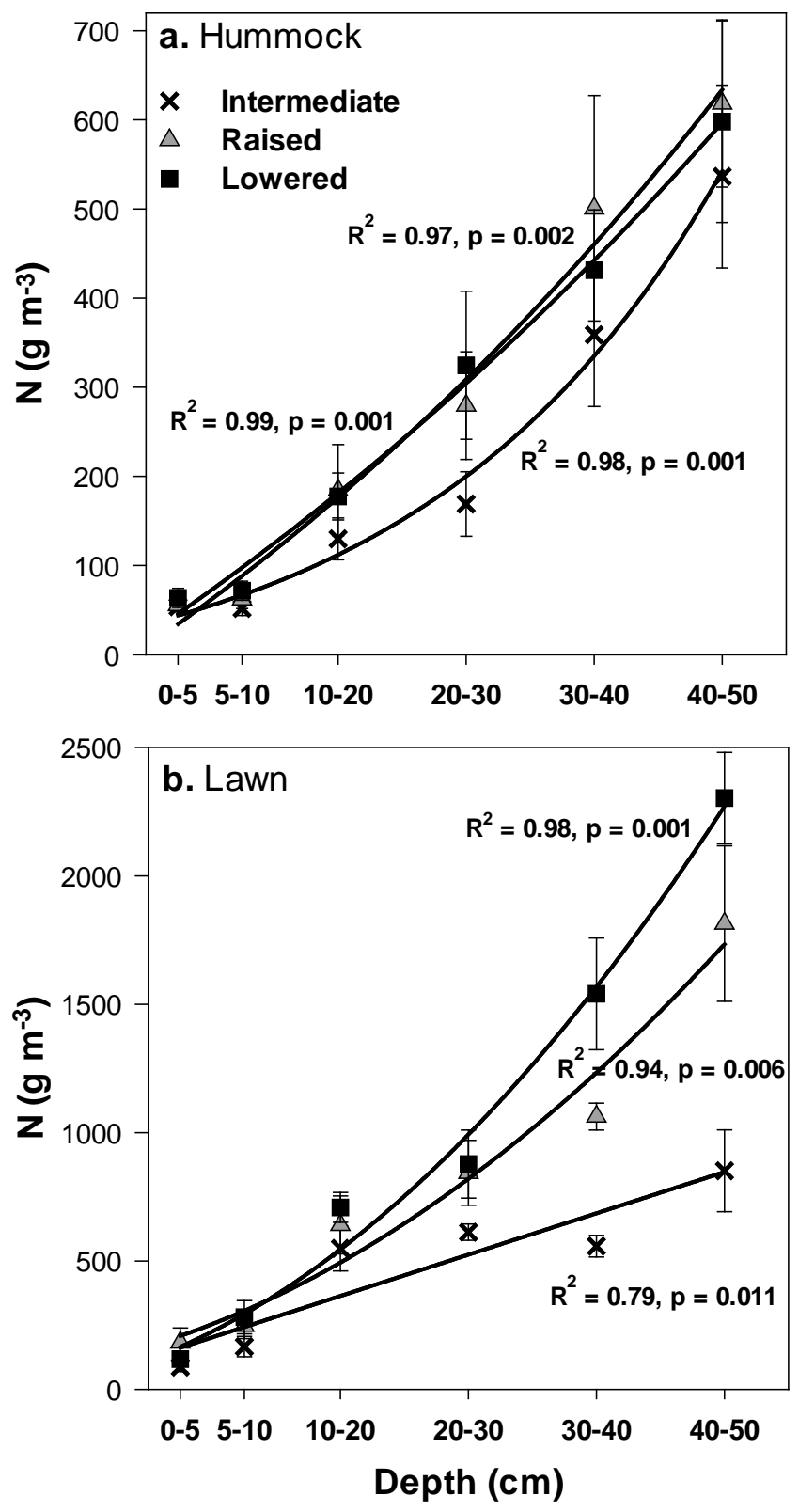

Figure 4.2 Relationship of N concentrations corrected for bulk density (mean \pm one SE) and sample depth across the WT treatments (intermediate, raised, and lowered) from the upper $50 \mathrm{~cm}$ peat horizon for the microforms. (a) In the hummock microforms, there was no significant difference of $\mathrm{N}$ versus depth as a function of WT treatments (ANCOVA; $\mathrm{F}$ $=0.10, \mathrm{p}=0.90$ ). (b) In the lawn microforms, $\mathrm{N}$ by depth interaction was significant as a function of WT treatment (ANCOVA; $F=13.92, \mathrm{p}<0.001) .(\mathrm{n}=6)$ 


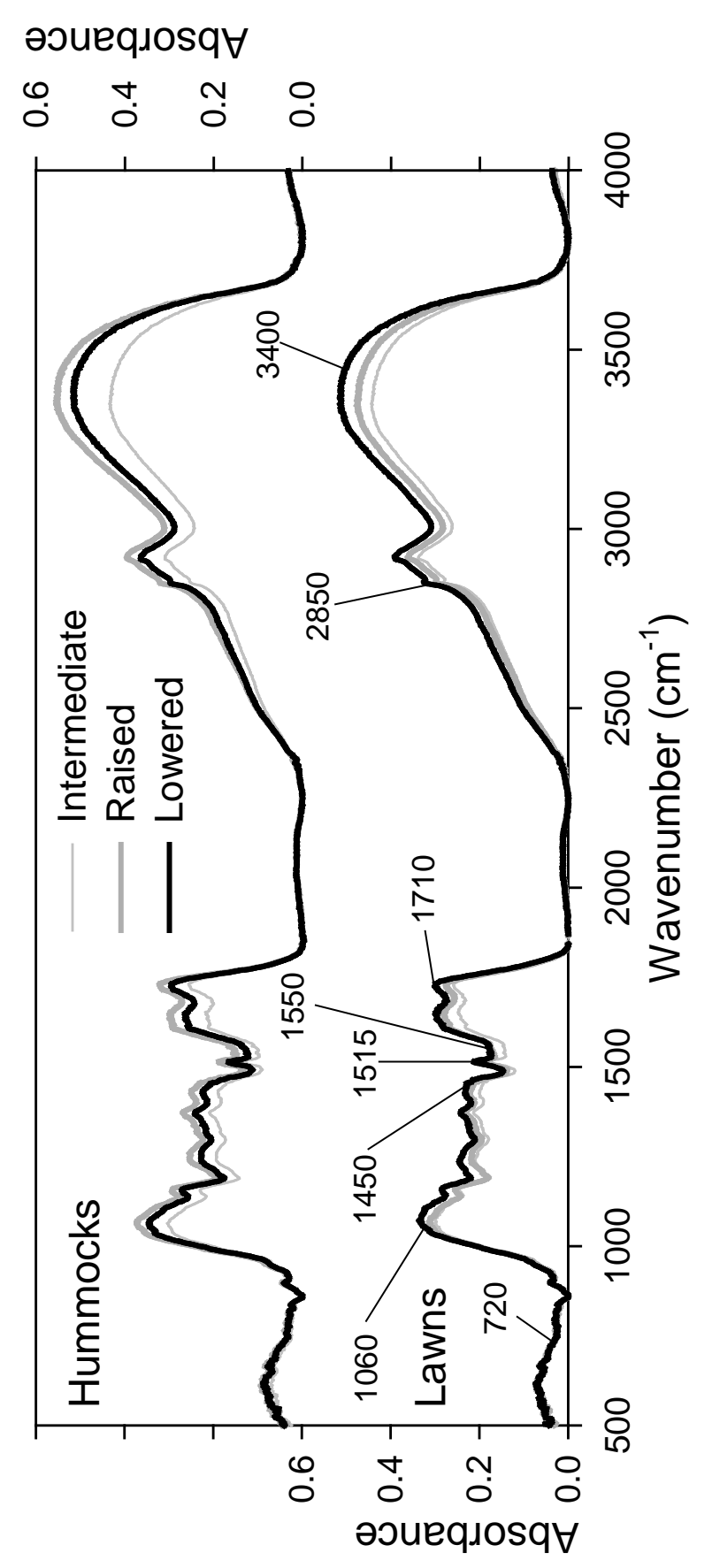

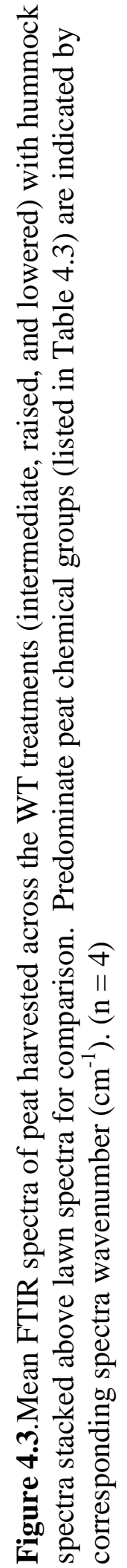




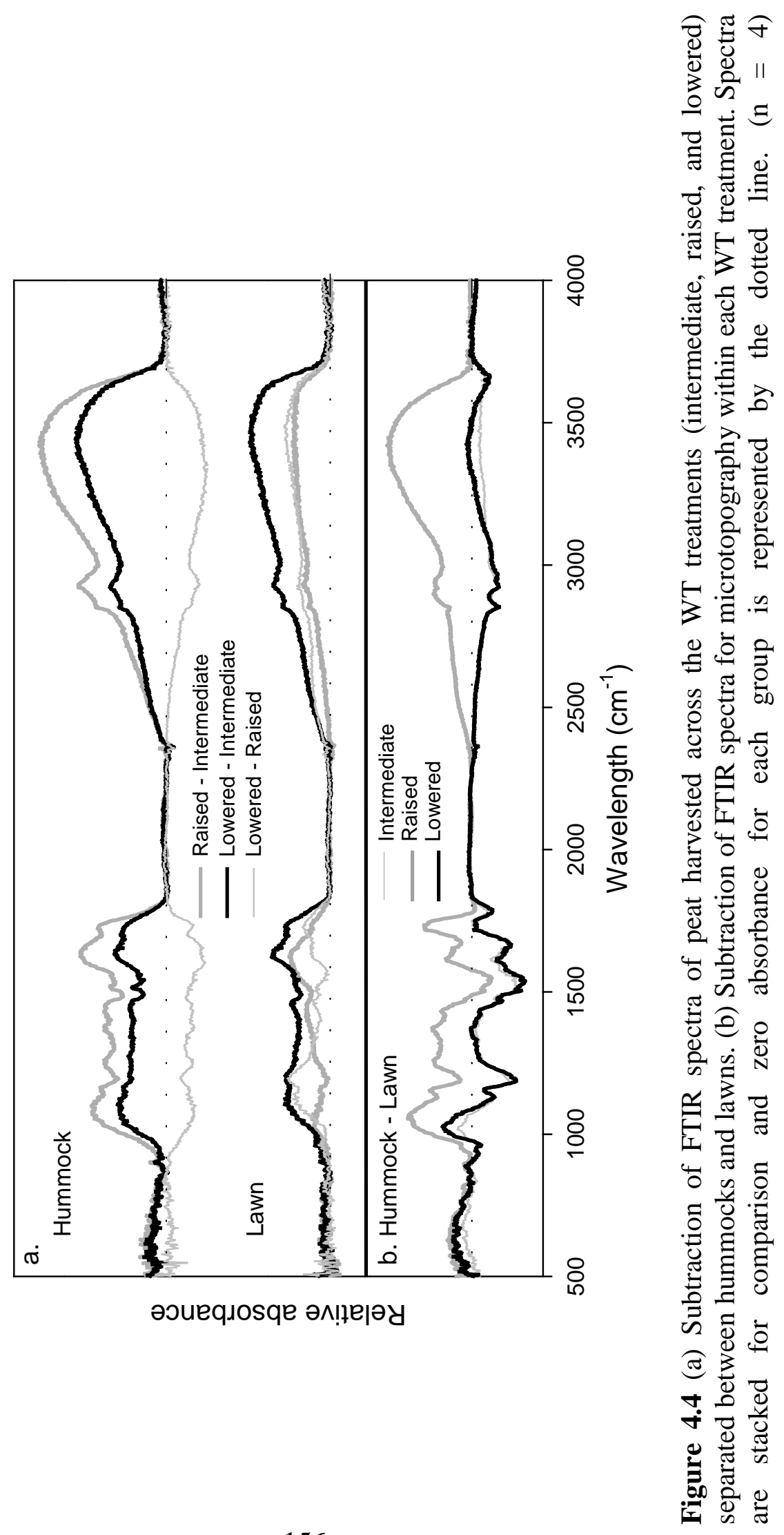




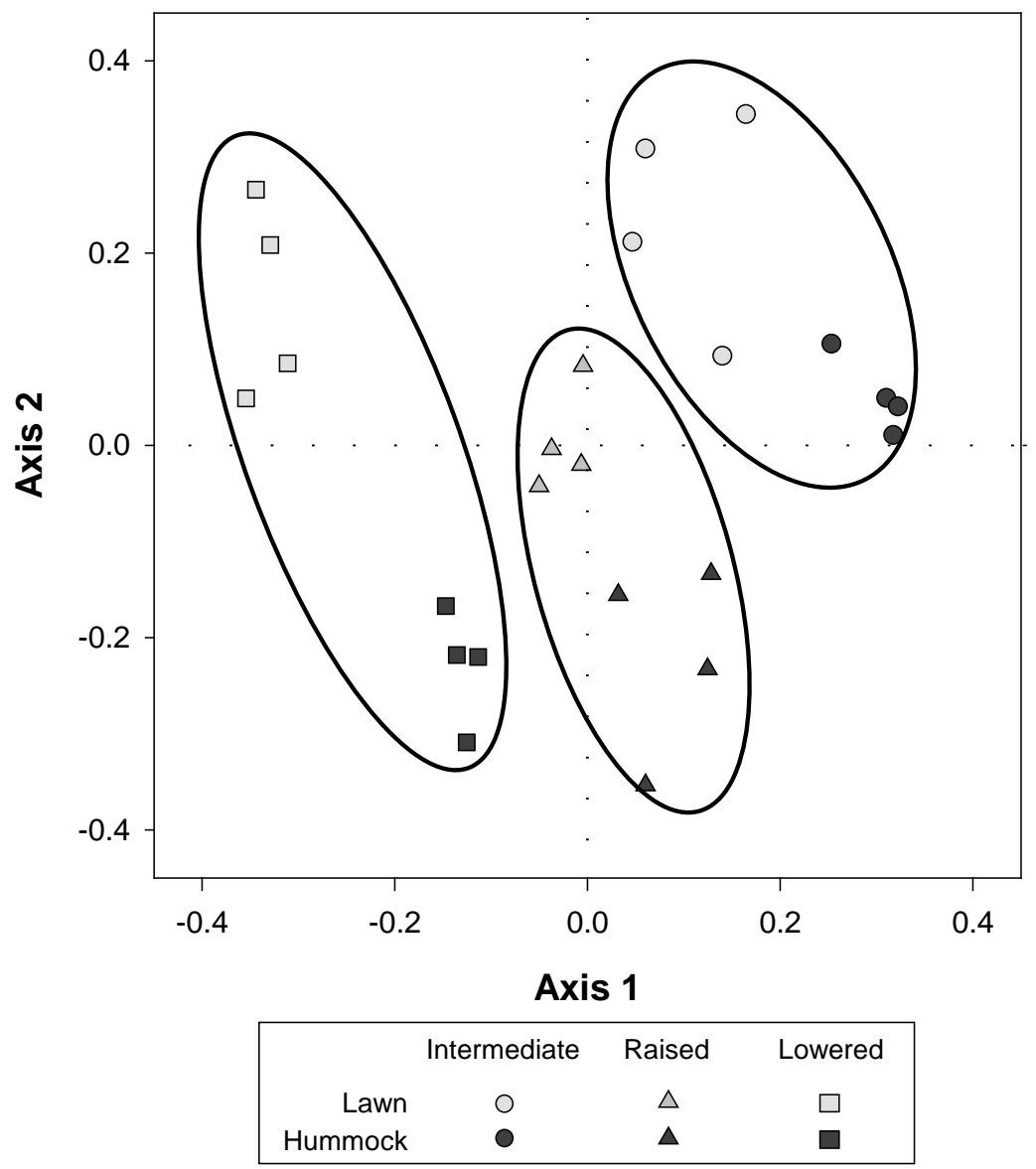

Figure 4.5 Canonical analysis of principle coordinates (CAP) ordination of peat FTIR spectra analysis from the WT treatments (intermediate, raised, and lowered) split by microtography (lawns and hummocks). A significant separation of the three WT treatments and microforms is displaying distinct groupings based on relative concentrations of organic compounds. 


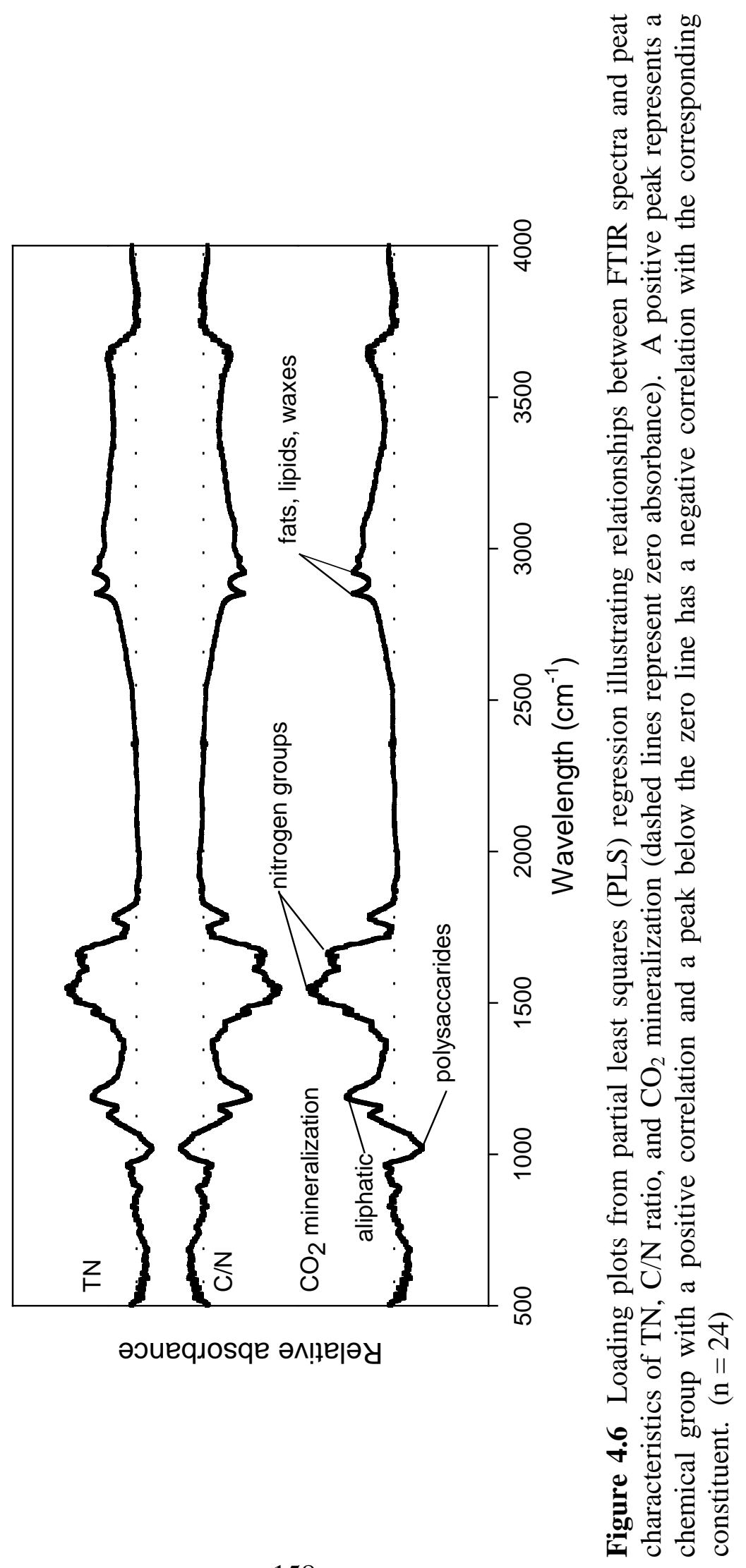



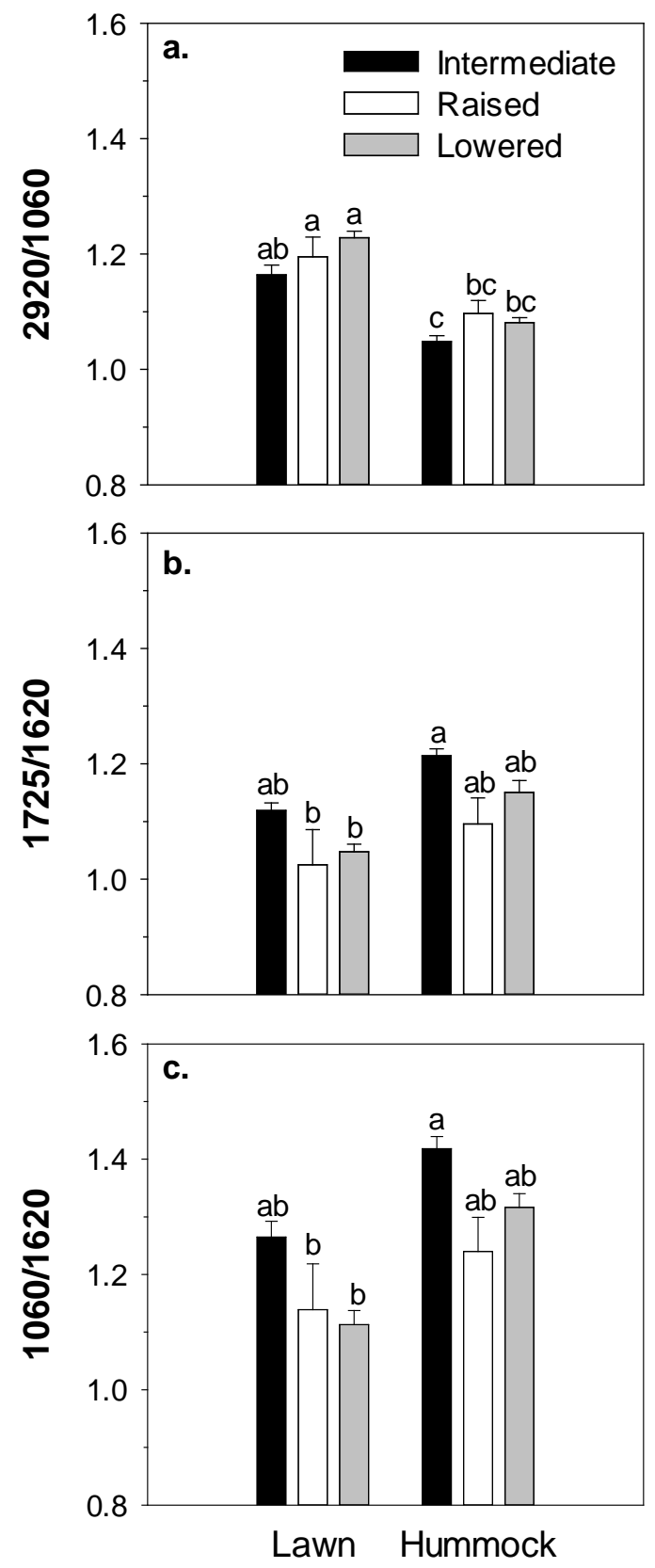

Figure 4.7 Ratios of FTIR peak heights (mean + one SE) across the WT treatments (intermediate, raised, and lowered) for (a) 2920/1060 (fats/polysaccharides), (b) 1725/1620 (aromatics/ lignin), and (c) 1060/1620 (polysaccharides/lignin). Different letters above bars represent significant differences (Two-way ANOVA; Tukey’s p < $0.05) .(n=4)$ 

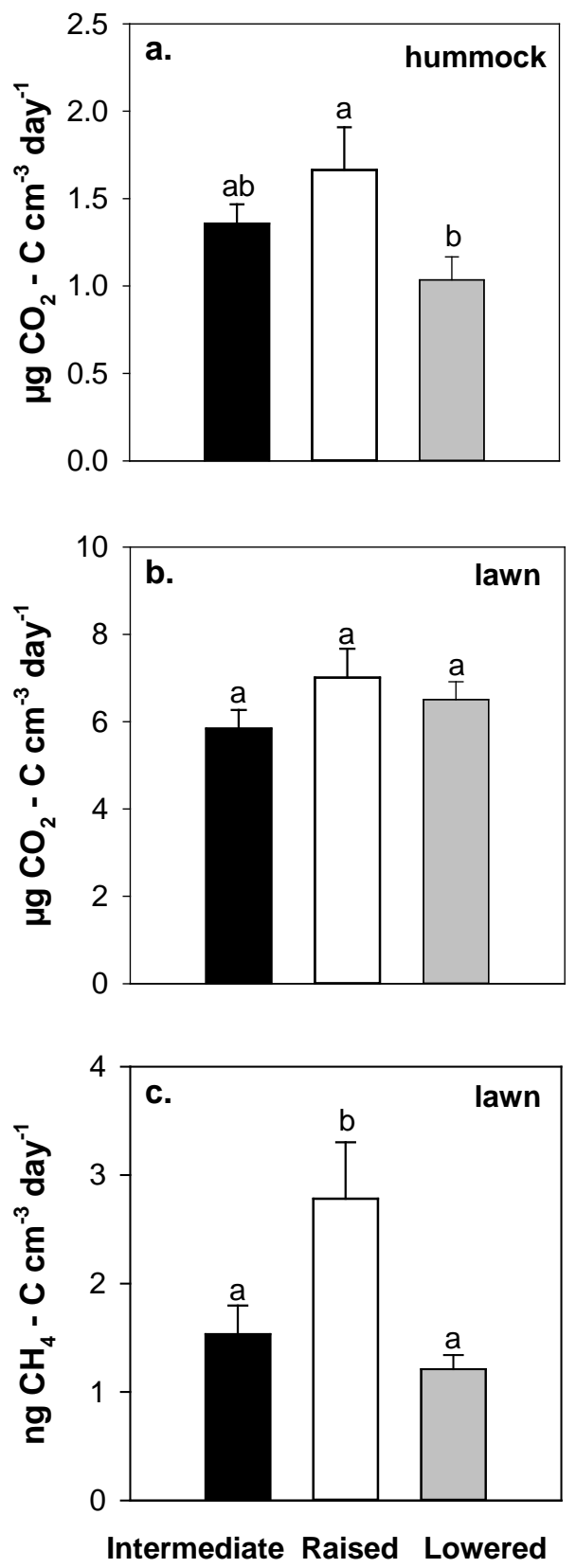

Figure 4.8 Peat $\mathrm{C}$ mineralization (10 - $20 \mathrm{~cm}$ horizon) across the WT treatments (intermediate, raised, and lowered) for aerobic $\mathrm{CO}_{2}$ incubations of (a) hummocks, (b) lawns, and (c) anaerobic $\mathrm{CH}_{4}$ incubation for lawns (mean + one SE). Different letters above bars represent significant differences across WT treatments (One-way ANOVA; Tukey's $\mathrm{p}<0.05)$. $(\mathrm{n}=12)$ 

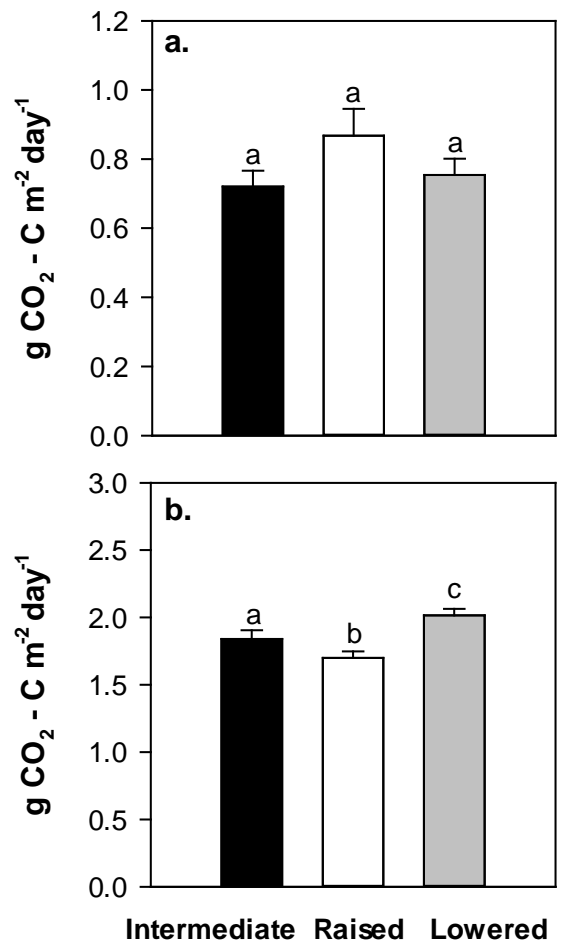

Figure 4.9 (a) Peat aerobic $\mathrm{C}$ mineralization incubation (10 - $20 \mathrm{~cm}$ horizon) across the WT treatments (intermediate, raised, and lowered) combining hummocks and lawns. (b) Eddy covariance nighttime respiration across the WT treatments (mean + one SE). Different letters above bars represent significant differences across treatments (One-way ANOVA; Tukey's $\mathrm{p}<0.05$ ). 

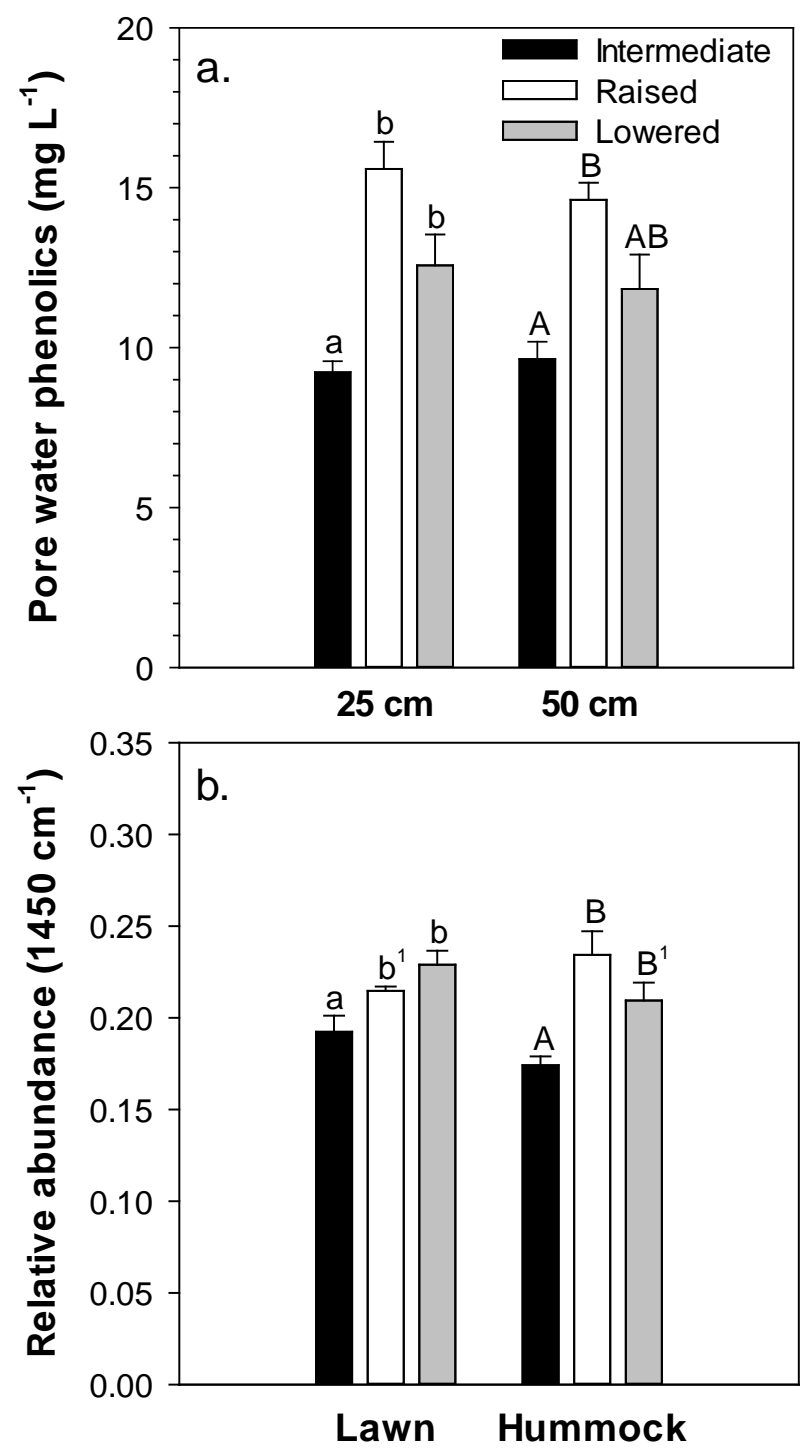

Figure 4.10 Phenolic concentrations across the WT treatments (intermediate, raised, and lowered) (a) from piezometer pore water sampled at 25 and $50 \mathrm{~cm}$ below the peat lawns (2011 seasonal mean + one SE, $\mathrm{n}=4$ ) and (b) measured as relative abundance (mean + one SE) $(1450 \mathrm{~cm}-1)$ from the $10-20 \mathrm{~cm}$ peat horizon by FTIR spectroscopy $(\mathrm{n}=4)$. Different letters above bars represent significant differences across WT treatments (Oneway ANOVA; Tukey's $\mathrm{p}<0.05 ;{ }^{1} \mathrm{p}<0.10$ ). 